\title{
Initial Findings: The Integration of Water Loop Heat Pump and Building Structural Thermal Storage Systems
}
T. J. Marseille
S. A. Chiu
B. K. Johnson
D. B. Crawley
R. P. Wallin

January 1989

Prepared for the U.S. Department of Energy under Contract DE-AC06-76RLO 1830

Pacific Northwest Laboratory

Operated for the U.S. Department of Energy by Battelle Memorial Institute 


\title{
DISCLAIMER
}

This report was prepared as an account of work sponsored by an agency of the United States Government. Neither the United States Government nor any agency thereof, nor Battelle Memorial Institute, nor any or their employees, makes any warranty, expressed or implied, or assumes any legal liability or responsibility for the accuracy, completeness, or usefulness of any information, apparatus, product, or process disclosed, or represents that its use would not infringe privately owned rights. Reference herein to any specific commercial product, process, or service by trade name, trademark, manufacturer, or otherwise does not necessarily constitute or imply its endorsement, recommendation, or favoring by the United States Government or any agency thereof, or Battelle Memorial institute. The views and opinions of authors expressed herein do not necessarily state or reflect those of the United States Government or any agency thereof.

\author{
PACIFIC NORTHWEST LABORATORY \\ operated by \\ BATTELLE MEMORIAL. INSTITUTE \\ for the \\ UNITED STATES DEPARTMENT OF ENERGY \\ under Contract DE-AC06-76RLO 1830
}

\begin{tabular}{|c|c|}
\hline \multicolumn{2}{|c|}{ Printed in the United States of America } \\
\hline \multicolumn{2}{|c|}{ Available from } \\
\hline \multicolumn{2}{|c|}{ National Technical Information Service } \\
\hline \multicolumn{2}{|c|}{ United States Department of Commerce } \\
\hline \multicolumn{2}{|c|}{5285 Port Royal Road } \\
\hline \multicolumn{2}{|c|}{ Springfield, Virginia 22161} \\
\hline \multicolumn{2}{|c|}{ NTIS Price Codes } \\
\hline \multicolumn{2}{|c|}{ Microfiche $\mathrm{A} 01$} \\
\hline \multicolumn{2}{|c|}{ Printed Copy } \\
\hline & Price \\
\hline Pages & Codes \\
\hline $001-025$ & $\mathrm{~A} 02$ \\
\hline 026-050 & A03 \\
\hline 051.075 & A04 \\
\hline $076-100$ & A05 \\
\hline $101-125$ & $A 06$ \\
\hline $126-150$ & A07 \\
\hline 151.175 & A08 \\
\hline $176-200$ & A09 \\
\hline $201-225$ & A10 \\
\hline $226-250$ & A11 \\
\hline $251-275$ & A12 \\
\hline $276-300$ & A13 \\
\hline
\end{tabular}


INITIAL FINDINGS: THE INTEGRATION OF WATER LOOP HEAT PUMP AND BUILDING STRUCTURAL

THERMAL STORAGE SYSTEMS

T. J. Marseille

B. K. Johnson

R. P. Wallin

S. A. Chiu

D. B. Crawley

January 1989

Prepared for

the U.S. Department of Energy

under Contract DE-AC06-76RLO 1830

Pacific Northwest Laboratory

Richland, Washington 99352 


\section{FOREWORD}

This report is one in a series of reports describing research activities in support of the U.S. Department of Energy (DOE) Commercial Building System Integration Research Program. The goal of the program is to develop the scientific and technical basis for improving integrated decisionmaking during design and construction. Improved decision-making could significantly reduce buildings' energy use by the year 2010 .

The objectives of the Commercial Building System Integration Research Program are:

- to identify and quantify the most significant energy-related interactions among building subsystems [for example, walls; roofs; windows; heating, ventilation, and air conditioning (HVAC) subsystems and equipment; lighting: power]

- to develop the scientific and technical basis for improving energy-related interactions in building subsystems

- to provide guidance to designers, owners, and builders for improving the integration of building subsystems for energy efficiency.

The lead laboratory for this program is the Pacific Northwest Laboratory. A wide variety of expertise and resources from industry, academia, other government entities, and other DOE laboratories are used in planning, reviewing and conducting research activities. Cooperative and complementary research, development, and technology transfer activities with other interested organizations are actively pursued.

In this report, the interactions of a water loop heat pump system and building structural mass and their effect on whole-building energy performance is analyzed. Comments about the work described in this report will be appreciated by the authors or program managers. The research reports prepared for the program are in a bibliographic list at the back of this report.

Drury B. Crawley

Program Manager

Building Systems Integration

Applied Physics Center

Pacific Northwest Laboratory
Jean J. Boulin

Group Leader

Architectural and Engineering Systems

Building Systems Division

U.S. Department of Energy 



\section{SUMMARY}

An earlier study of small office buildings indicated that many commercial buildings need heat in one part of a building while cooling another part. Even more common is the need for heating during one part of the day and cooling during another in the same spaces. If that energy could be economically shifted or stored for later use, significant energy might be saved. It was also hypothesized that if a building's heating and cooling subsystems could be integrated with the building's structural mass and be effectively used to collect, store, and deliver energy, the cost effectiveness of such an approach might be enhanced.

In response to the above problem and hypothesis, researchers at the Pacific Northwest Laboratory (PNL) examined the thermal interactions in a commercial building between the heating, ventilating, and air conditioning (HVAC) system and the building structure. Computer models were developed to simulate this interaction in an existing base building located in Seattle, Washington, in order to find how these building subsystems could be integrated to improve energy efficiency.

The HVAC subsystems in the existing building were modeled. These subsystems consist of decentralized water-source heat pumps in a closed water loop, interconnected to cooling towers for heat rejection during cooling mode and auxiliary boilers for heating. An initial computer model of the base building "as built" was developed. Metered data available for the building was used to calibrate this model to ensure the analys is would provide information closely related to the operation of a real building.

The strategy of HVAC and building structure integration focused on using the concrete floor slabs as thermal storage media. For example, the slabs may be actively charged during off-peak periods with the chilled water in the loop, and either actively or passively discharged into the conditioned space during peak periods. In the computer model this concept was implemented by manifolding an additional water loop to the main HVAC hydronic loop. Tubing in this loop was embedded in the concrete floor slabs of the building. Water was routed to this loop by a controller to charge or discharge thermal energy 
to and from the slabs. This integration strategy is referred to as the Building Structural Thermal Storage (BSTS) system.

The building model with the BSTS system was simulated and the results compared to the results of the base case building. Simulations were aiso performed, for both the base case building model and the building model with the BSTS system, using weather data for five other locations in the United States. The measure of performance was annual HVAC energy consumption of the total building.

The simulations predicted that the annual energy savings using the BSTS system vary significantly with climate, ranging from approximately 3 to $30 \%$. In general, the BSTS system was found to be beneficial where hot and dry summer outdoor air conditions exist. The benefits in predominantly cold climate regions appear to be limited. Future studies are needed to develop generalized design guidelines, control strategies, and costs applicable to building design. 


\section{CONTENTS}

FOREWORD ......................

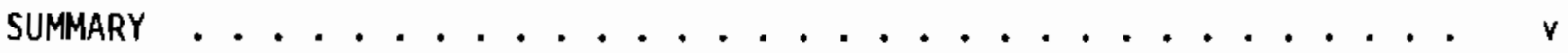

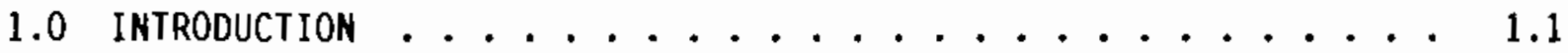

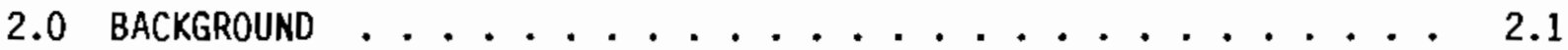

2.1 SUBSYSTEM INTERACTION RESEARCH ............. 2.1

2.2 INTEgRATION OF THE hVAC AND MASS SUBSYSTEMS $\ldots \ldots . . . .2 .1$

2.3 TEST BUILDING . . . . . . . . . . . . . . . 2.5

2.4 COMPUTER SIMULATION $\ldots \ldots \ldots \ldots$

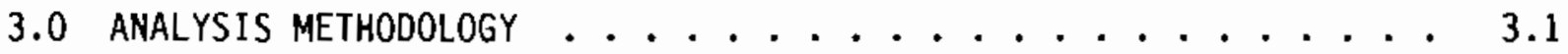

3.1 METERED DATA ANALYSIS . . . . . . . . . . . 3.1

3.2 TRANSIENT SYSTEM SimULATION PROGRAM (TRNSYS) . . . . . . 3.2

3.3 BASE CASE BUILding MODEL DEVELOPMENT . . . . . . . . 3.4

3.3.1 TRNSYS Building Systern Mode1 . . . . . . . 3.4

3.3.2 Component Modules . . . . . . . . . . 3.8

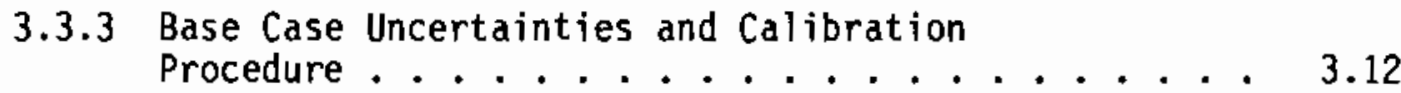

3.4 BUILDING STRUCTURAL THERMAL STORAGE (BSTS) SYSTEM MODEL DEVELOPMENT ............................. 3.16

3.4.1 Thermal Energy Storage in Slab ........ 3.17

3.4.2 BSTS System Model and Basic Control Strategy . . . 3.19

3.4.3 Parametric Studies ............ . . 3.22

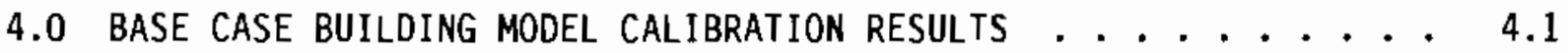

5.0 EVALUATION OF BUILDING STRUCTURAL THERMAL STORAGE SYSTEM

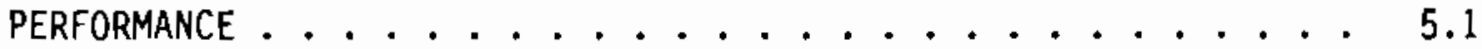

5.1 SIMULATION RESULTS . . . . . . . . . . . 5.1 
5.2 DIURNAL RESPONSE ............................... 5.4

5.3 LiMITATIONS . . . . . . . . . . . . . . 5.12

6.0 EFFECTS OF CLIMATE ON BUILDING STRUCTURAL THERMAL STORAGE SYSTEM

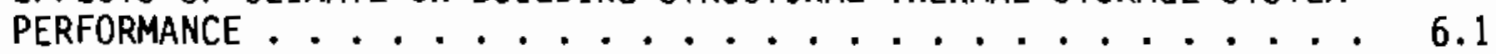

7.0 CONCLUSIONS AND RECOMMENDATIONS . . . . . . . . . 7.1

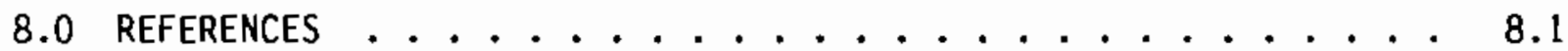

9.0 BIBLIOGRAPHIC LIST OF BUILDING SYSTEMS INTEGRATION RESEARCH

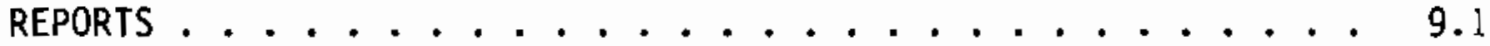
APPENDIX A - MONTHLY ENERGY CONSUMPTION FOR HVAC COMPONENTS . . . A A.I APPENDIX B - ANNUAL ENERGY CONSUMPTION FOR THE HVAC COMPONENTS . . . B.1 APPENDIX $c$ - COMPUTER CODES .............. c.1 


\section{FIGURES}

2.1 Typical Water-Source Heat Pump Subsystem . . . . . . . 2.3

2.2 Integrated BSTS and Heat Pump Subsystems . . . . . . . 2.4

3.1 Plan and Elevation Views of the Single Floor (One-Sixth Building) Zone Arrangements Used in the Building Mode1 . . . . . 3.6

3.2 Building System Model Block Diagram .......... 3.7

3.3 STab with Water Loop Circuit . . . . . . . . . 3.18

3.4 Block Diagram of BSTS System Control Scheme ........ 3.21

4.1 Comparison of Metered Simulated Monthly Total HVAC Energy Consumption .................. 4.3

4.2 Comparison of National 0ceanic Atmospheric Administration and Typical Meteorological Year Average Monthly Temperatures . . . .

4.3 Metered Versus Simulated Monthly Heat Pump Energy Consumption .................... 4.4

4.4 Metered Versus Simulated Monthly Boiler Energy Consumption . . . 4.4

4.5 Metered Versus Simulated Monthly Cooling Tower Energy

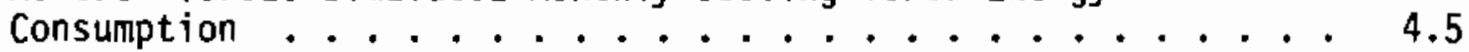

4.6 Simulated Monthly Energy Consumption of HVAC Components . . . 4.5

4.7 Simulated Annual Energy Consumption of HVAC Components . . . . 4.6

5.1 Total HVAC Monthly Energy Consumption for Simulated BSTS

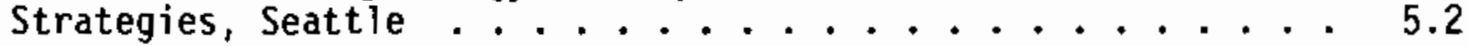

5.2 Heat Pump Monthly Energy Consumption for Simulated BSTS Strategies, Seattle ............... 5.2

5.3 Boiler Monthly Energy Consumption for Simulated BSTS Strategies, Seattle ...................

5.4 Cooling Tower Monthly Energy Consumption for Simulated BSTS Strategies, Seattle .............. 5.3

5.5 January 5th Heat Transfer Rate History for the Core Zone of the Simulated Building with the BSTS System ......... 
5.6 January 5th Temperature History for the Core Zone of the Simulated Building with the BSTS System ......... 5.5

5.7 January 5th Heat Transfer Rate History for the Core Zone of the Simulated Base Case Building .............

5.8 January 5th Temperature History for the Core Zone of the

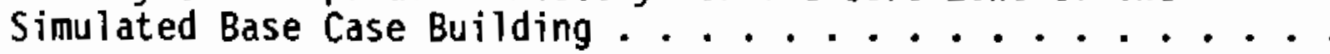

5.9 January 5 th Heat Transfer Rate History for the South Zone of the Simulated Building with the BSTS System ..........

5.10 January 5 th Temperature History for the South Zone of the Simulated Building with the BSTS System ......... 5.8

5.11 January 5th Heat Transfer Rate History for the South Zone of the Simulated Base Case Building ..............

5.12 January 5th Temperature History for the South Zone of the Simulated Base Case Building ..............

5.13 April 3rd Heat Transfer Rate History for the Core Zone of the Simulated Building with the BSTS System ...........

5.14 April 3rd Temperature History for the Core Zone of the Simulated Building with the BSTS System .............

5.15 July 5th Heat Transfer Rate History for the Core Zone of the Simulated Building with the BSTS System ........ 5.13

5.16 July 5th Temperature History for the Core Zone of the Simulated

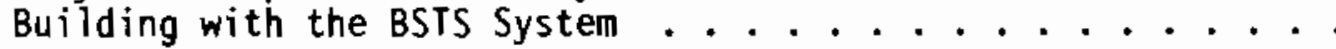

5.17 July 5th Heat Transfer Rate History for the South Zone of the Simulated Building with the BSTS System .........

5.18 July 5th Temperature History for the South Zone of the Simulated Building with the BSTS System ......... 5.14

6.1 Total HVAC Monthly Energy Consumption for Simulated BSTS System Strategies, Los Angeles ............ 6.2

6.2 Total HVAC Monthly Energy Consumption for Simulated BSTS System Strategies, El Paso ............... 6.2

6.3 Total HVAC Monthly Energy Consumption for Simulated BSTS System Strategies, Houston ..............

6.4 Total HVAC Monthly Energy Consumption for Simulated BSTS System Strategies, Washington, OC 
6.5 Total HVAC Monthly Energy Consumption for Simulated BSTS System Strategies, Milwaukee ............. 6.4

6.6 Total HVAC Annual Energy Consumption for Simulated BSTS System Strategies ................ . 6.4

A.1 Heat Pump Monthly Energy Consumption for Simulated BSTS System Strategies, Los Angeles............. A.1

A.2 Heat Pump Monthly Energy Consumption for Simulated BSTS System Strategies, El Paso ...............

A.3 Heat Pump Monthly Energy Consumption for Simulated BSTS

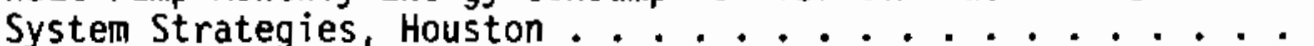

A.4 Heat Pump Monthly Energy Consumption for Simulated BSTS System Strategies, Washington, D.C.

A.5 Heat Pump Monthly Energy Consumption for Simulated BSTS System Strategies, Milwaukee .............. A.3

A.6 Boiler Monthly Energy Consumption for Simulated BSTS System Strategies, El Paso ................. A.4

A.7 Boiler Monthly Energy Consumption for Simulated BSTS System

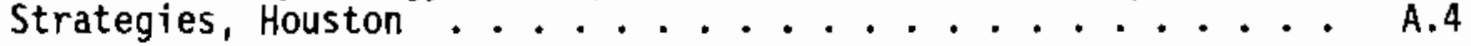

A.8 Boiler Monthly Energy Consumption for Simulated BSTS System Strategies, Washington, $\mathrm{DC} \ldots \ldots \ldots$

A.9 Boiler Monthly Energy Consumption for Simulated BSTS System Strategies, Milwaukee .................... A.

A.10 Cooling Tower Monthly Energy Consumption for Simulated BSTS System Strategies, Los Angeles . . . . . . . . . A.6

A.11 Cooling Tower Monthly Energy Consumption for Simulated BSTS System Strategies, El Paso . . . . . . . . A.6 A

A.12 Cooling Tower Monthly Energy Consumption for Simulated BSTS System Strategies, Houston ............

A.13 Cooling Tower Monthly Energy Consumption for Simulated BSTS System Strategies, Washington, DC

A.14 Cooling Tower Monthly Energy Consumption for Simulated BSTS System Strategies, Milwaukee ............ A.8

B.1 Heat Pump Annual Energy Consumption for Simulated BSTS Systern Strategies .................. 
B.2 Boiler Annua] Energy Consumption for Simulated BSTS System

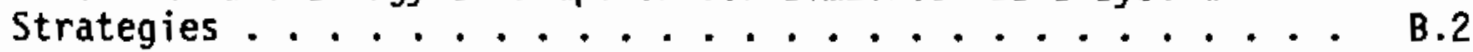

B.3 Cooling Tower Annual Energy Consumption for Simulated BSTS

System Strategies ................ B.2

TABLES

3.1 Seattle City Light Metered Data Analysis . . . . . . . . 3.2 


\section{INITIAL FINDINGS: THE INTEGRATION OF WATER LOOP HEAT PUMP AND BUILDING STRUCTURAL THERMAL STORAGE SYSTEMS}

\subsection{INTRODUCTION}

Previous research on building energy consumption has focused primarily on improving the performance of building subsystems operating independently rather than interactively. From this perspective, many of the potential energy-conserving improvements in individual subsystems have been identified. Understanding how these independent building subsystems are integrated is a key step to further energy conservation, because of the complex and dynamic nature of the energy delivery process in commercial buildings.

An earlier study of small office buildings indicated that many commercial buildings need heat in one part of a building while cooling another part. Even more common is the need for heating during one part of the day and cooling during another in the same spaces. If that energy could be economically shifted or stored for later use, significant energy might be saved. It was also hypothesized that if a building's heating and cooling subsystems could be integrated with the building's structural mass and be effectively used to collect, store, and deliver energy, the cost effectiveness of such an approach might be enhanced.

To test this hypothesis, researchers at the Pacific Northwest Laboratory (PNL) (a) analyzed the integration of heating, ventilation, and air conditioning (HVAC) systems with the mass of a building. This analysis, performed for the U.S. Department of Energy (DOE) Conmercial Building System Integration Research Program, included development of a numerical simulation mode1--the Building Structural Thermal Storage (BSTS) System--and selection of a specific existing building with which to test the integration.

(a) Operated by Battelle Memorial Institute for the U.S. Department of Energy under Contract DE-ACO6-76RLO 1830. 
This report provides a detailed description of PNL's analys is. Background information critical to this analysis appears in Section 2.0. In Section 3.0, the analysis methodology is fully described. Results obtained for the simulated base case building are presented in Section 4.0. The effect that integrating the building mass with the HVAC system has on building performance are discussed in Section 5.0. Information in Section 6.0 describes the effects of climate on $\mathrm{HVAC} /$ mass integration. The conclusions and recommendations are presented in Section 7.0. Supporting detailed information is provided in Appendices $A$ and $B$. Computer code developed for use in this analysis is documented in Appendix C. 


\subsection{BACKGROUND}

This section provides background information that is critical in understanding the analysis that follows later in this report. Section 2.1 describes the nature and purpose of building subsystems interaction research, of which the work reported here is a part. A general discussion of thermal structural storage in buildings, water-source neat pump (WSHP) systems, and the way these two building subsystems can be integrated is given in Section 2.2. Background on the actual test building modeled in this study is given next in Section 2.3. Finally, a discussion of the appropriateness of using a computer simulation code as the primary analytical tool for this study is given in Section 2.4 .

\subsection{SUBSYSTEM INTERACTION RESEARCH}

This investigation is a part of subsystems interaction research, which is one element of the commercial portion of the Building System Integration (BSI) program, a multiyear research endeavor. Subsystems interaction research will develop an understanding of how various materials, components, equipment, and subsystems interact or can be made to interact, and how these interactions affect energy consumption. Examples of subsystems in conmercial buildings are the building structure and envelope, the HVAC energy conversion equipment, the HVAC distribution subsystems, and the lighting subsystems. Collectively, they provide enclosure and division of space, temperature and humidity control, ventilation, internal load control, and illumination.

\subsection{INTEGRATION OF THE HVAC AND MASS SUBSYSTEMS}

Energy storage in building structures occurs passively in all buildings to some extent, and has been shown to have nontrivial energy impacts. When HVAC equipment is shut off or set back during unoccupied periods, the affect of the building mass often results in long temperature recovery time periods. To reduce morning recovery peak in the heating season, some building owners leave the lighting on overnight to maintain the space temperature in a moderate range. For the cooling mode, recent work by researchers at Lawrence Berkeley 
Laboratory (Eto 1985) indicates that Monday morning recovery from the passive heat addition to the building mass over a summer weekend negates part of the savings gained by the system shutdown. A Monday morning purging strategy with cool outdoor air is shown to improve performance. However, the efficiency of such a strategy is low compared to active cold storage technologies such as a chilled water storage tank (Eto 1985). As demonstration of this, thermal storage in centralized chiller systems has gained wide acceptance in recent years.

Active thermal storage in building structures, on the other hand, is a relatively new concept. A case study of a Swedish commercial building by Lawrence Berkeley Laboratory (Andersson et at. 1979) discussed the use of a massive floor structure for storage of heat, via an air distribution subsystem, using hollow-core concrete slabs. However, using a water distribution subsystem to charge and discharge the energy stored in the structure appears to have the potential for better control in most applications, because water has a higher heat capacitance than air and thus allows a more thorough purging of stored heat.

The HVAC subsystems used in this study consist of decentralized watersource heat pumps in a closed water loop. This is not a new technology, and it has been recently gaining popularity among designers because of occupant satisfaction (due to excellent zone temperature control) and because of its flexibility in both new design and retrofit applications. A typical watersource heat pump (WSHP) system design is shown in Figure 2.1(a).

Water-source heat pump subsystems with thermal storage have been studied only sporadically. A 1980 Canadian study (Rogers 1980) indicates that adding storage to a water loop heat pump subsystem can substantially improve subsystem performance. In practice, thermal storage can be added by increasing the heat capacitance of the water loop through increasing the amount of water or, in principle, by coupling the loop to the building thermal mass. The structural thermal mass is usable for storage in a water loop heat pump subsystem because

(a) Note that this system corresponds to the base building simulation model described in Section 3.0. 


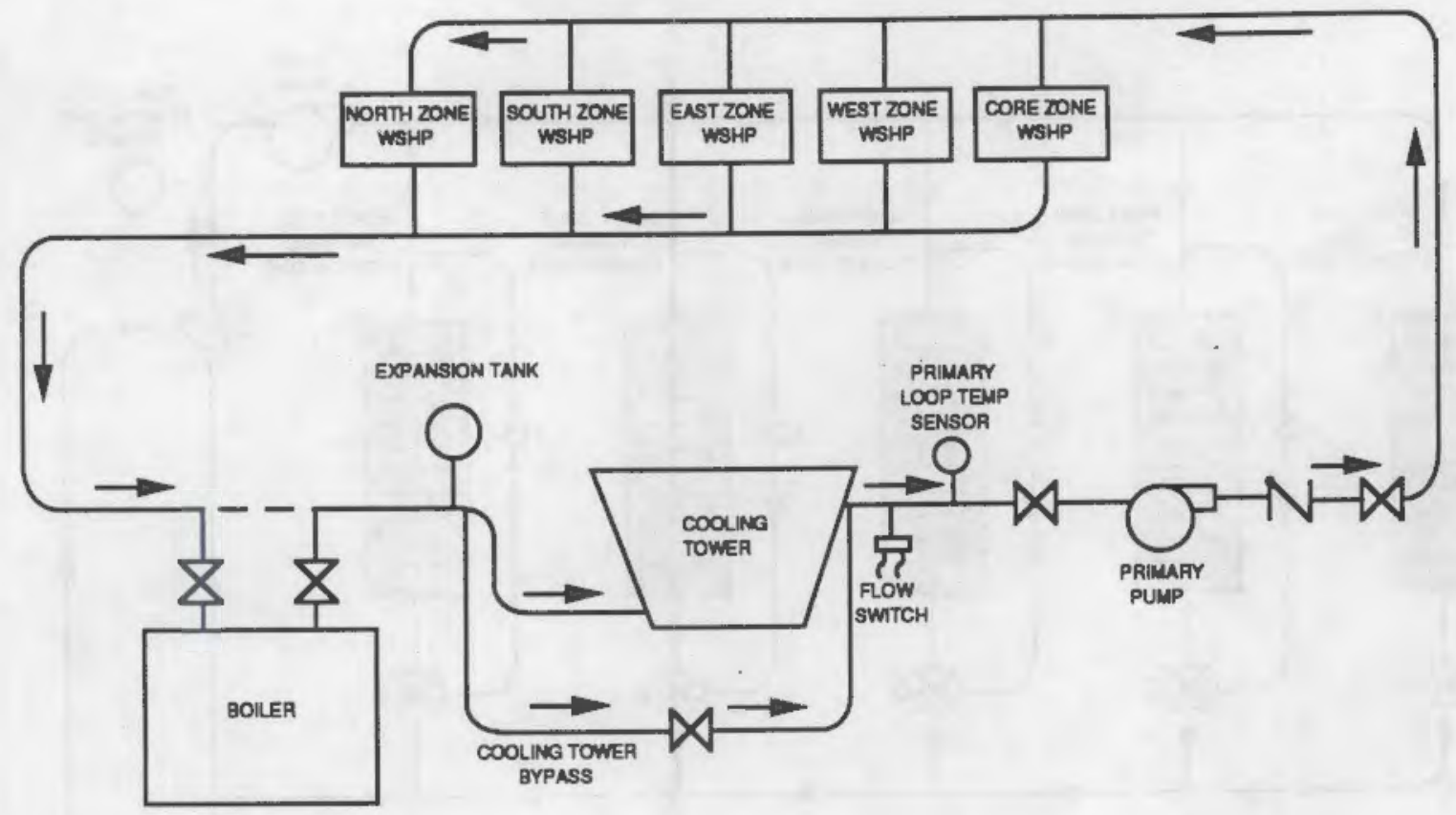

FIGURE 2.1. Typical Water-Source Heat Pump Subsystem

of the inherent dynamics of the system configuration. Thermal mass is known to create time lags in heat transfer, which can be beneficial if properly applied. Because heat pumps can either extract heat from the water loop or reject heat to it, all of the heat capacitance of the distribution piping and fluid, as well as any storage tank or structure coupling, is available for storage.

The drawing in Figure 2.2 shows the water loop for the actual BSTS and water-source heat pump subsystems used in this study(a). A secondary water loop connects the conventional WSHP water loop to pipes embedded within concrete floor slabs. These pipes are used to transfer heat to and from the structure and the water loop. Practical considerations associated with using the floor slab as the storage medium involve material compatibilities, component connections, and configuration of the piping in the water loop. However, embedding

(a) Figure 2.2 is presented here to illustrate conceptually the integrated design. More detailed descriptions in Section 3.0 will also refer to this figure, because it portrays the actual building subsystems that were simulated. 


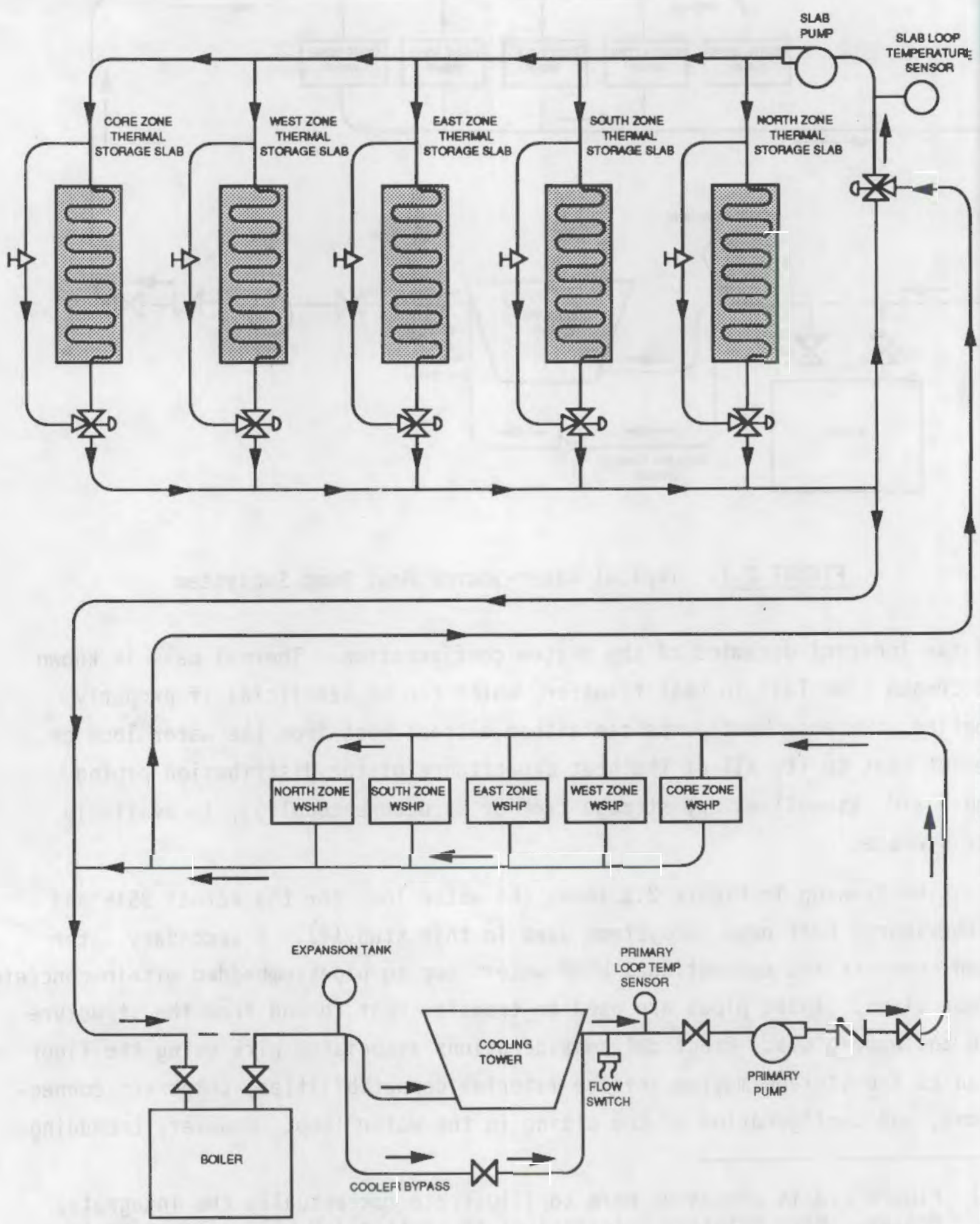

FIGURE 2.2. Integrated BSTS and Heat Pump Subsystems 
water pipes within concrete is a proven concept; thus, many of these considerations have already been addressed in past research. Practical experience has been gained in solar-charged as well as conventional radiant slab heating applications (Solar Heating and Cooling 1979).

The cost of these applications are reasonable in comparison to other HVAC subsystems. Established design criteria for the application include: pipes embedded in floors must be leakproof; long continuous lengths and good flexibility for bending are necessary to minimize the use of any connections and elbows; the pipe must be inert to corrosion, scaling, and electrolysis; and excellent long-term pressure rating and easy installation are needed.

Another important practical consideration for the design and operation of the BSTS system is the effect of structure thermal storage on occupant comfort, which, in turn, affects control strategies in two ways. First, comfort requirements will set limits on the allowable temperature at the surface of the concrete structural elements and, ultimately, on the allowable temperature swings in the water loop, a key determinant of the amount of thermal energy stored and the heat pump efficiency. Second, for the example of cool storage in the structure, the decreased mean radiant temperature of the conditioned space may allow the dry-bulb temperature to be increased and still maintain comfort. Increased space temperature will reduce cooling equipment operating time. Finally, slab temperatures should be moderated to avoid possible condensation on the slab during high wet-bulb temperature conditions.

\subsection{IEST BUILDING}

The simulation model is based on an existing six-story office building located in Seattle that was monitored by Seattle City Light (SCL) between 1983 and 1985 (Cleary and Crimmin 1986). It is typically occupied 50 hours a week, 8 a.m. to 6 p.m., Monday through Friday; the average occupancy level is 400 people. Built in 1976, the building consists of two rectangular sections, one four stories and the other six. The structure was built on a concrete slab with pre-cast concrete walls. Total floor area is approximately 89,550 $\mathrm{ft}^{2}$. Forty-seven percent of the gross wall area is glass. 
Heating and cooling are provided by 97 water-source heat pumps that are connected to a common water loop. Two electric boilers are the heat source for the water loop, and a cooling tower is used to reject excess heat during cooling. Ventilation air is provided by a constant-volume supply/exhaust system such that about $20 \%$ of the supply air to each zone is outside air. The ventilation system uses a runaround heat recovery system and a resistance duct heater to temper outside air, and operates for 15 hours on weekdays only. There is no economizer ( $100 \%$ outside air) mode in this system; this eliminates the need for larger ducts and fans and for fan capacity modulation. Lighting is predominantly fluorescent with some incandescent task lighting.

\subsection{COMPUTER SIMULATION}

For this study, PNL developed a computer model for analyzing the integrated system. For a building-level analysis, such as this project, a computer simulation is the most cost-effective and appropriate analysis tool. It can readily provide the researcher with much insight and understanding of the subject by allowing many variations to be examined with relative ease.

Although field monitoring can supply some actual building operation data that are unavailable in simulations, the costs in terms of time and effort involved generally preclude full-scale experiments. In addition, because of the strong influence of independent variables such as weather, consistent comparisons and assessments of alternative subsystems within the building is difficult, if not impossible. In contrast, parametric sensitivity analyses may be readily conducted wherein most variables are held constant while others are varied through a range of physically realistic values.

When using computer simulations as a research tool, care must be taken to appreciate the inherent limitations of mathematical modeling. A model of a complex system can never perform exactly as the real system does in every minute detail. Computer simulation should thus be used to ascertain the relative importance of particular variables to the overall effect under observation. 


\subsection{ANALYSIS METHODOLOGY}

This section describes the analysis methodology followed during the course of the research reported here. The metered data collected by SCL for the existing building are discussed in Section 3.1. The Transient System Simulation Program (TRNSYS), the primary modeling tool employed on this project, is discussed in Section 3.2. A discussion of the development of the base case building simulation model follows in Section 3.3, along with details of the TRNSYS subroutines used and/or developed specifically for modeling the building subsystem and components. Finally, the strategies and methodology employed in introducing and then optimizing the interaction between the HVAC subsystems and the BSTS system are detailed in Section 3.4.

\subsection{METERED DATA ANALYSIS}

The metered data for the actual base building consist of electricity consumption in amperes and kilowatt-hours for the boilers, cooling tower, heat pumps, supply and exhaust fans, lights, outlets, hot water, and elevators. Although the building's 97 unitary heat pumps operate independently, only the total heat pump electricity consumption measurement was available. In addition, no water temperatures or control signals were monitored. This data aggregation, plus the lack of any building temperature measurements, limited the analysis possibilities.

The 1985 data were analyzed, because the 1983 and 1984 data sets are incomplete. In the 1985 data there are occasional missing hours and a period of approximately 3 weeks of missing data in late November and early December. A total of 507 hours $(6 \%)$ are missing. Most of the analysis was performed by directly summing various quantities such as the monthly or yearly electricity consumed by a specific piece of equipment or the number of hours of operation.

The primary end-use loads of the actual base building are heating and cooling equipment ( $47.9 \%$ of the total energy consumption), lights (34.4\%) and miscellaneous (17.7\%). The building consumed the equivalent of 73,460 $\mathrm{Btu} / \mathrm{yr}-\mathrm{ft}^{2}$ in 1985 , or a total of $1,413,900 \mathrm{kWh}$ with an average monthly demand of $410 \mathrm{~kW}$ (Table 3.1 ). 
TABLE 3.1. Seattle City Light Metered Data Analysis

SCL Building Specifications

Gross floor area

$89,550 \mathrm{ft}^{2}$

Year built

1976

Shell materials

Concrete

Principal use

office

Billed Consumption - 1985

kWh

$\mathrm{kWh} / \mathrm{ft}^{2}$

$1,413,900$

15.8

Electric End-Uses (a)

HVAC

Lights

Misc equipment

TOTAL

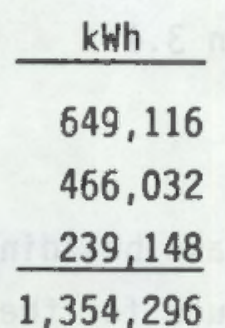

$1,354,296$

\begin{tabular}{c}
$\mathrm{kwh} / \mathrm{ft}^{2}$ \\
\hline 7.2 \\
5.2 \\
$\frac{2.7}{15.1}$
\end{tabular}

Percent

47.9

34.4

17.7

100.0

(a) Within the precision range of the monitoring equipment.

\subsection{TRANSIENT SYSTEM SIMULATION PROGRAM (TRNSYS)}

The Transient System Simulation (TRNSYS) Program was selected as the analysis tool for this study because it can perform a dynamic whole building system analysis and it can be readily modified and new building subsystem component models incorporated (University of Wisconsin 1983). TRNSYS was designed with a modular structure. A wide variety of component models are available in the standard TRNSYS library. For the system modeled in this project, assembling the component modules according to the TRNSYS format was a relatively straightforward procedure.

The modular nature of TRNSYS gave the program flexibility and facilitated the addition of user-formulated mathematical models (see Section 3.3.2). Unlike other programs without a modular structure (e.g., DOE-2), the main program of TRNSYS itself does not have to be modified as new models are added. 
Available in TRNSYS is a building load model that uses temperature level control, a dynamic modeling approach, as opposed to energy rate control used in programs such as DOE-2. Depending on the objective of the study, each approach offers different advantages.

In energy rate control, the model calculates the thermal loads based only upon the net thermal gains or losses from the space. The loads are considered to be independent of the HVAC equipment operation. The program determines the heat addition or extraction to maintain the space at specified heating and cooling temperatures (the thermal loads). An HVAC equipment model subsequently calculates the energy required to satisfy these loads. The advantage of the energy rate control is that once the building loads are determined, the researcher may reuse them for various equipment simulations without having to repeat the load calculations. However, in this type of simulation no energy balance is ensured, and much of the detailed dynamics of the equipment, the control, and the building itself are lost.

On the other hand, for temperature level control, the room condition is determined by not only the ambient conditions, but also the heating and cooling equipment inputs. The interactive feedback of the building subsystems is captured. This is a more realistic reflection of the actual thermal responses of the building. The temperature level control requires more complicated modeling schemes, including a controller to command the operation of the building system. In addition, as the building load is no longer assumed to be independent of the instantaneous inputs of its subsystems, it must be calculated for each simulation.

The system under study is complex; its performance is affected by the interactive feedback from the subsystems involved. For example, the energy performance of a water-source heat pump is strongly dependent on the room temperature and humidity, as well as on the water temperature and flow rate. This room condition, in turn, depends on the sensible and latent capacities of the heat pump and the ambient conditions, along with the thermal integrity of the building. The water loop temperature is a function of boiler and cooling tower operation and the coincident operation of other heat pumps that also take heat from or reject heat to the loop. In addition, the operation of 
Available in TRNSYS is a building load model that uses temperature level contral, a dynamic modeling approach, as opposed to energy rate control used in programs such as DOE-2. Depending on the objective of the study, each approach offers different advantages.

In energy rate control, the model calculates the thermal loads based only upon the net thermal gains or losses from the space. The loads are considered to be independent of the HVAC equipment operation. The program determines the heat addition or extraction to maintain the space at specified heating and cooling temperatures (the thermal loads). An HVAC equipment model subsequently calculates the energy required to satisfy these loads. The advantage of the energy rate control is that once the building loads are determined, the researcher may reuse them for various equipment simulations without having to repeat the load calculations. However, in this type of simulation no energy balance is ensured, and much of the detailed dynamics of the equipment, the control, and the building itself are lost.

On the other hand, for temperature level control, the room condition is determined by not only the ambient conditions, but also the heating and cooling equipment inputs. The interactive feedback of the building subsystems is captured. This is a more realistic reflection of the actual thermal responses of the building. The temperature level control requires more complicated modeling schemes, including a controller to command the operation of the building system. In addition, as the building load is no longer assumed to be independent of the instantaneous inputs of its subsystems, it must be calculated for each simulation.

The system under study is complex; its performance is affected by the interactive feedback from the subsystems involved. For example, the energy performance of a water-source heat pump is strongly dependent on the room temperature and humidity, as well as on the water temperature and flow rate. This room condition, in turn, depends on the sensible and latent capacities of the heat pump and the ambient conditions, along with the thermal integrity of the building. The water loop temperature is a function of boiler and cooling tower operation and the coincident operation of other heat pumps that also take heat from or reject heat to the loop. In addition, the operation of 
the duct heater used to temper the ventilation air also affects the operation of the space conditioning equipment. Finally, the use of the building structure for thermal storage and the use of the water loop as its heat source and sink further complicates these interactions by affecting the building load and the water loop temperature. Because the objective of this project was to study the dynamic interaction of the building subsystems, the temperature rate control modeling approach was required. TRNSYS offered such a modeling scheme.

\subsection{BASE CASE BUILDING MODEL DEVELOPMENT}

As a first stage in the development of the BSTS system model, TRNSYS was used to simulate the existing base case building. To verify that the actual building was being realistically modeled, the input was calibrated using the metered data results. Using the calibrated base case building model as a starting point, the BSTS system could then be implemented. The simulated results of the base case model with the BSTS system would then provide a realistic estimate of the impact of integrating the HVAC subsystems and the building structural mass.

The basic TRNSYS building system modeling approach is discussed in Section 3.3.1. Key component module subroutines used in the base case, some of which were developed specifically for this project, are detailed in Section 3.3.2. Finally, a discussion of modeling uncertainties and the methodology used to calibrate the base case model to achieve close agreement with metered data is covered in Section 3.3.3.

\subsubsection{TRNSYS Building System Model}

The TRNSYS model can mathematically represent building envelope thermal properties, HVAC subsystems performance, occupant heat and moisture generation, light and equipment convective and radiative heat gains, solar radiation, heat conduction to and from the environment, and other properties for an entire building. However, because of limits on computer speed and memory, it was not practical for this study to simulate the entire base case building. Hence, it was necessary to simplify the system model in several ways. 
The first such simplification was to model the entire multistory base case building as a single representative floor. This implies that the heating or cooling loads on all floors are equal, an assumption justified for commercial buildings where the space usage on each floor is roughly identical and the building envelope is homogeneous. When each floor has approximately the same load profile there is no net heat transfer between floors. Furthermore, in most commercial buildings, heat losses from the first-floor slab to the ground are small compared to other losses because the perimeter of a large slab is much smaller than the floor area. Unless the building has large conditioned spaces underground, the effects of ground coupling may be ignored. The roof area, on the other hand, does exchange heat with the environment, and was included in the model. Because the base building has six stories, one-sixth of the roof was modeled and the heat conductance was coupled to the single floor, which represents the entire building.

The next simplifying aggregation was to assume that the single floor can be modeled as a core zone, four perimeter zones, and a common ceiling plenum zone (see Figure 3.1). The core and perimeter zones are each conditioned by a single heat pump that represents the performance of a number of smaller units. In the actual building, each floor contains approximately 16 heat pumps, ranging in capacity from 1 to 3 tons of cooling. In the model, each floor is served by five units sized according to the amount of space served. However, this is only a capacity scaling; the efficiency of the aggregated heat pumps is the same as that of the actual smaller units. Boiler, cooling tower, and other component capacities were scaled by one-sixth as well to maintain the proper fluid temperatures and flow rates. The energy consumption of these components was multiplied by six to produce totals comparable to the actual six-floor building.

Figure 3.2 shows the information flows in the TRNSYS base case building model. Hourly values of temperature, solar radiation, humidity, and wind speed for a Typical Meteorological Year (TMY) imposed loads on the building zones. Internal heat gains from people, lights, and equipment were established by 24-hour weekend and weekday profiles sequenced into a repeating weekly profile. These energy flows plus the supply air temperature and mass flow 

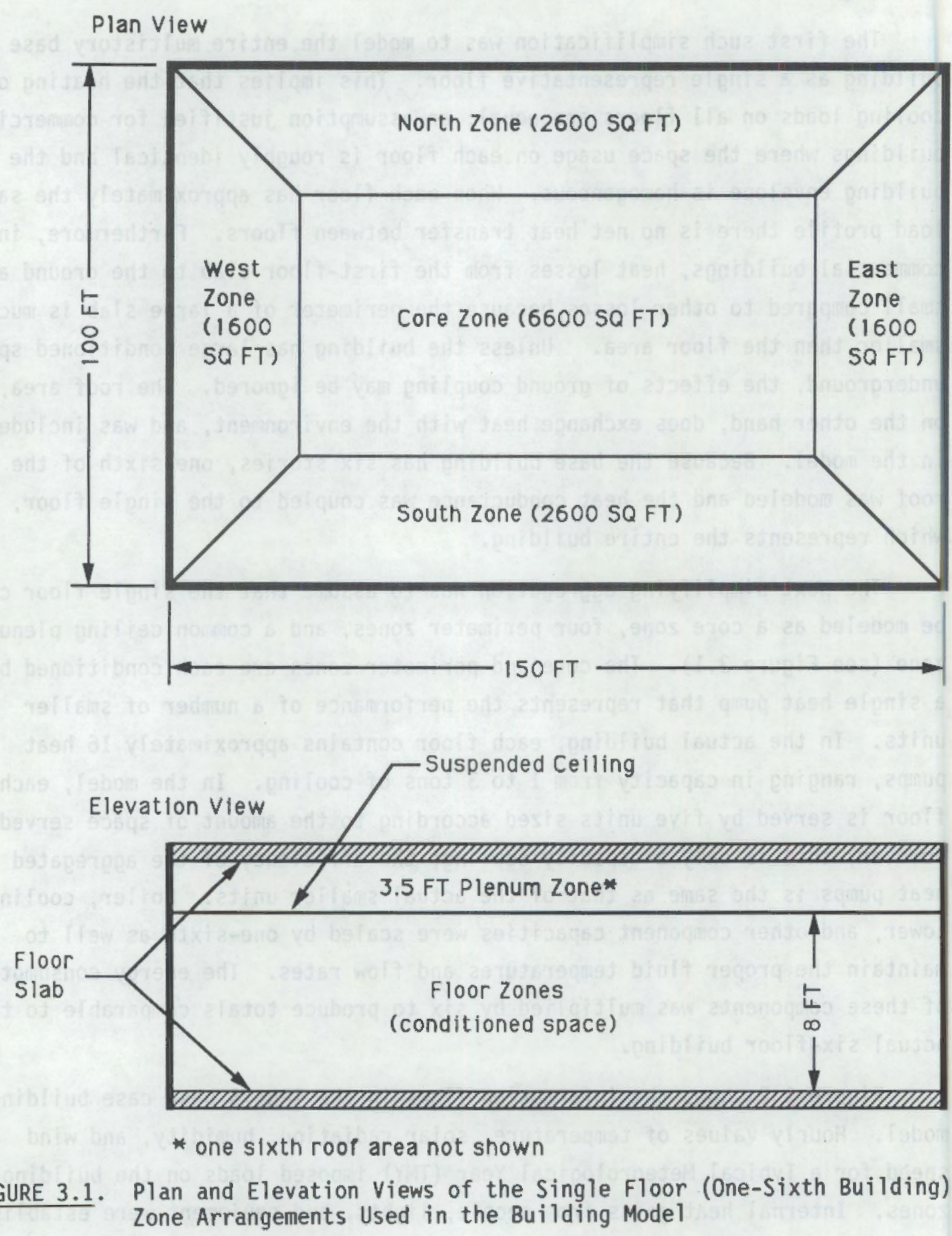


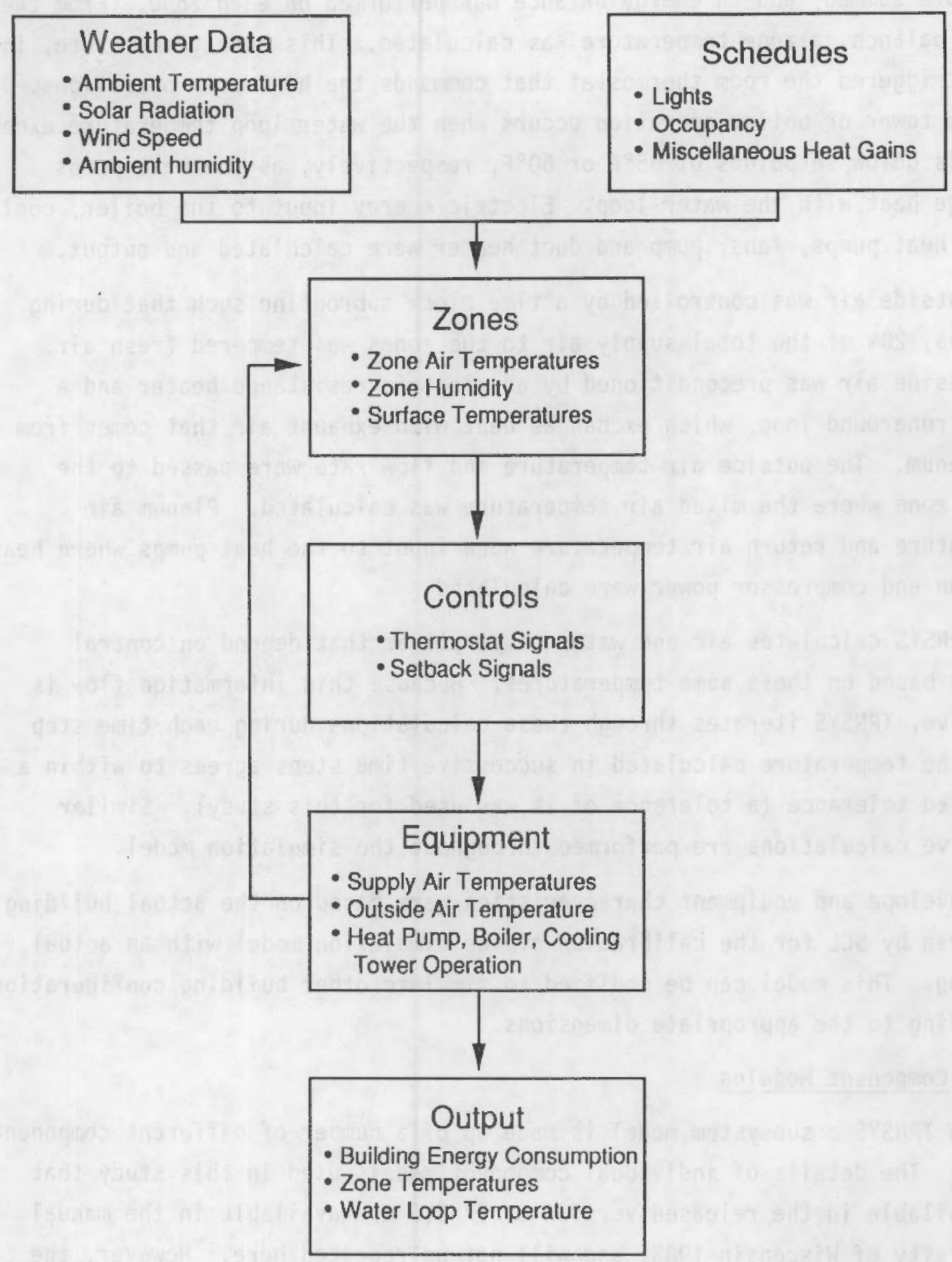

FIGURE 3.2. Building System Model Block Diagram 
rate were summed, and an energy balance was performed on each zone. From the energy balance, a zone temperature was calculated. This zone temperature, in turn, triggered the room thermostat that commands the heat pump operations. Cooling tower or boiler operation occurs when the water loop temperature exceeds or falls below setpoints of $85^{\circ} \mathrm{F}$ or $60^{\circ} \mathrm{F}$, respectively, as the heat pumps exchange heat with the water loop. Electric energy input to the boiler, cooling tower, heat pumps, fans, pump and duct heater were calculated and output.

Outside air was controlled by a time clock subroutine such that during weekdays, $20 \%$ of the total supply air to the zones was tempered fresh air. The outside air was preconditioned by an electric resistance heater and a glycol runaround 1oop, which exchanges heat with exhaust air that comes from the plenum. The outside air temperature and flow rate were passed to the plenum zone where the mixed air temperature was calculated. Plenum air temperature and return air temperature were input to the heat pumps where heat pump fan and compressor power were calculated.

TRNSYS calculates air and water temperatures that depend on control signals based on these same temperatures. Because this information flow is recursive, TRNSYS iterates through these calculations during each time step until the temperature calculated in successive time steps agrees to within a specified tolerance (a tolerance of $1 \%$ was used for this study). Similar iterative calculations are performed throughout the simulation model.

Envelope and equipment characteristics were based on the actual building monitored by SCL for the calibration of the simulation model with an actual building. This model can be modified to simulate other building configurations by scaling to the appropriate dimensions.

\subsubsection{Component Modules}

In TRNSYS a subsystem model is made up of a number of different component models. The details of individual component models used in this study that are available in the released version of TRNSYS are available in the manual (University of Wisconsin 1983) and will not be repeated here. However, the existing TRNSYS building zone model will be summarized in terms of the approach it uses to model the inside heat exchanges. 
In addition, five new component models were developed by PNL researchers specifically for this study: the cooling tower, the heat pump, the water loop boiler, the water loop thermostat (used to control cooling tower and boiler operations), and the floor slab used in the BSTS system. Two of these components, the boiler and thermostat, are extended versions of existing TRNSYS modules. They were modified so that boiler heat output during the simulation would be linearly proportional to inlet water loop temperature over a user specified range above the heating setpoint. The thermostat module was also modified for use in the BSTS system control scheme to turn on the cooling tower to maintain water temperatures at or below $65^{\circ} \mathrm{F}$ from 4:00 to $6: 00$ am on summer working days (see Section 3.4.2). The heat pump, cooling tower and floor slab models are, on the other hand, entirely new, and their simulation approaches are described in Sections 3.3.2.2, 3.3.2.2, and 3.4.1, respectively. Appendix $C$ includes a code listing for all five of these component models.

\subsubsection{TRNSYS Building Zone Model}

The component model used to simulate the thermal behavior of the building was the TRNSYS Detailed Zone Model (TRNSYS Type 19). The zone model uses the temperature level control modeling approach discussed in Section 3.3.1. The zone temperature and humidity reflect the ambient conditions, the heating and cooling equipment inputs, and any other thermal inputs (for example, the passive thermal discharge of the thermal storage slab). This model individually simulates the zone subcomponents such as walls, windows, flat roof, doors, and floor. A multizone building such as the one analyzed for this report is simulated through multiple uses of this model.

An energy balance equation for each subcomponent within each zone is formulated to account for the conduction, convection, and radiation heat transfers. These equations are detailed in the TRNSYS manual. Specifically, it should be noted that conduction through walls is modeled using the American Society of Heating, Refrigeration, and Air Conditioning Engineers' transfer function approach (ASHRAE 1985). Convection heat exchange is determined using a constant value of convection heat transfer coefficients and the difference between the surface temperature and the room temperature. 
Solar radiation passing through windows is assumed to be isotropic, striking diffusely reflecting gray (i.e., having radiative properties that do not vary with wavelength) interior surfaces within the zone. TRNSYS computes overall exchange factors for solar radiation at the beginning of a simulation using surface reflectivities input by the user and geometric view factors. A simplified method for determining geometric view factors that was available in TRNSYS was used for the base building that computes these factors based on area ratios(a). In TRNSYS all surfaces are assumed to be black (i.e., perfect absorbers) to radiation from lights, people, and equipment, as well as longwave radiation from other surfaces. Radiative gains from people are assumed to be $70 \%$ of their total sensible energy output; the remaining $30 \%$ is assumed to be convected directly to the space. Radiation heat transfer from lights, people, and equipment is apportioned evenly over all zone interior surface areas. Long-wave radiation heat transfer is modeled using a linearized radiation heat transfer coefficient. Constant radiative coefficients are calculated for pairs of zone surfaces using average initial surface temperatures and the black body view factors.

An energy balance equation for each subcomponent and the room air is set up in matrix format. For the long-wave radiative and convective exchanges of each interior surface, an equivalent zone temperature is used. This equivalent zone temperature is analogous to the sol-air(b) temperature used for the exterior surfaces to account for both solar and convection heat transfers. The surface temperatures are calculated at each time step by solving the simultaneous equations using direct matrix-inversion (University of Wisconsin 1983).

(a) This simplified approach for computing geometric view factors was used because of uncertainties in the actual geometric configuration of the interior space in the base building. Sensitivity studies of the base case building model were performed, however, that compared results obtained using this approximation to those obtained when approximated user input view factors in the southern exposure zone were used. The differences were found to be insignificant.

(b) Sol-air temperature is the inside air temperature which in the absence of long-wave surface radiative exchange results in the same heat transfer as actually occurs. 


\subsubsection{Water-Source Heat Pump Model}

The heat pump component model developed for this study was not a detailed equipment model that simulates the individual energy conversion components, such as the compressor and the heat exchangers. Rather, it was an extension of an empirical fit to the manufacturer's rating data.

At given entering water and air conditions, the model calculates the steady-state sensible and latent capacities and power inputs of the heat pump. A time constant is applied to approximate transient performance. The amount of heat rejected or extracted from the water loop is determined by an energy balance on the refrigeration loop. Finally, the exit temperature and humidity of the air, and the exit temperature of the water are calculated based on the heat addition or extraction.

\subsubsection{Cooling Tower Model}

A cooling tower model is used to calculate the exiting water temperature at a given set of conditions. The most commonly used cooling tower model is the Merkel model (ASHRAE 1983). It involves a numerical integration of the heat transfer rate across the two flow streams through the tower. To predict the outlet states of the flow streams, an iterative process is required. In order to reduce the execution time of the model, a simpler approach developed by Whillier (Whillier 1976) was used that follows closely the algorithm used by Braun (Braun, Mitchell, and Kline 1987).

The whillier model was established based on the assertion that the performance of a cooling tower may be characterized by a single linear function that correlates its effectiveness, $E$, to its capacity factor, $R(a)$ :

$$
E=F /[F+(1-F) R]
$$

(a) Cooling tower effectiveness is defined as the ratio of the actual to the maximum possible heat transfer from the water to the air stream. THe capacity factor is the ratio of the minimum to maximum thermal capacities of the air and water streams. 
where $F$, a relative factor of merit for the cooling tower, is determined from experimental results or manufacturer's data, while $R$ is directly computed from given air and water inlet conditions. After using the above relation to determine $E$, the exit state of the water for any off-design conditions is easily determined.

The results calculated by the Whillier model have been compared with the Merkel model. It has been shown that the accuracy of the two models are essentially the same, and they both compare favorably against experimental data (Braun, Mitchell, and Kline 1987). Based on this data, Whillier suggests that for a typical commercial cooling tower an $F$ of 0.65 is reasonable. Because of a lack of specific data for the actual cooling tower in the existing building, this value of $F$ was chosen for the model.

\subsubsection{Base Case Uncertainties and Calibration Procedure}

In developing the overall building simulation model, physical parameters were required for each of the building components. Parameters are variables that are held constant during the simulation in contrast to inputs that may vary with time. Examples of parameters include the physical dimensions and configuration of the building spaces, zone temperature setpoints, operation schedules, material properties, equipment capacities, distribution of lighting and equipment, and rated efficiencies. Inputs include temperatures, flow rates, humidity, and control signals. Inputs are passed from one component subroutine to another and are calculated based on the outputs from other components, subroutine algorithms, and parameter values. Thus, changing a parameter changes the outputs from the component subroutine, which, in turn, changes the inputs to other components. This ultimately affects the results of the simulation, namely, the equipment energy consumption outputs.

Many parameters in the test building were not known or were not well understood. For those parameters, a sensitivity analysis was performed to establish the model's responsiveness to the parameter value within a physically realistic range. If the model was insensitive, then a high degree of uncertainty was considered permissible, and a reasonable value within the range was selected. 
If the model was sensitive to an unknown or uncertain parameter, a variety of methods was used to estimate an appropriate and/or typical value; reasonableness was checked by evaluating the simulation outputs such as zone or water loop temperature fluctuations and total energy consumption. In some cases, a parameter such as interzonal heat and mass transfer was related to a physical process in buildings about which little is known.

Finally, many parameters (such as the manual operation of outside air fans and re-insulation of the roof) were changed seasonally in the actual building, either intentionally or unintentionally,. These changes could have been modeled but were not because of the considerable difficulty in doing so.

Because the final analysis is concerned with the overall energy consumption difference--not individual parameter quantities--between the base building and the building with the BSTS system, these parameters were exploited (within reasonable bounds) during calibration of the base building input so as to obtain the best agreement with metered results. This process entailed an iterative series of parametric simulation runs in which "sensitive" parameters for which actual values were uncertain or unobtainable were varied. Final values of these parameters were established when simulated monthly HVAC energy consumption was found to be within $10 \%$ of metered data.

Model deficiencies resulting from uncertain building parameters were uncovered during the calibration that significantly affected the simulation results. These deficiencies, discussed in Section 3.3.3.1 through 3.3.3.3, include

- unknown or inconsistent control or occupant behavior

- uncertainties in equipment operation

- lack of basic data.

\subsubsection{Unknown/Inconsistent Control or Occupant Behavior}

Exact thermostat setpoints for the different zones were unknown. They appeared to be in the range of 70 to $80^{\circ} \mathrm{F}$, but were not uniform either with time or location. As there are thermostat controls located in the occupied areas of the actual building, it is likely that they were adjusted by the 
occupants. Constant setpoints of $78^{\circ} \mathrm{F}$ cooling and $71^{\circ} \mathrm{F}$ heating were chosen during the calibration of the base case.

Occupant use of operable window shading (venetian blinds) was unknown, resulting in uncertainties related to solar gains. The calibration of the test building suggested overall window shading factors were quite low.

Occupancy levels are not known and are subject to changes, resulting in variable internal loads. Sporadic occupancy on Saturdays was not modeled. Constant occupancy during normal building occupied hours was assumed.

The actual monthly lighting and equipment loads varied by a factor of two during 1985, as indicated by metered data. This is probably related to changes in building tenancy, because the metered data indicates electricity consumption jumps roughly $25 \%$ in July. Constant lighting and equipment loads were used, the value of which were determined through model calibration. Distribution of these loads in the model were also determined through calibration.

\subsubsection{Uncertainties in Equipment Operation}

Night and weekend thermostat setbacks are inconsistent. The heat pumps are supposed to be shut off each night by disconnecting power to the thermostats, but the January metered data, for example, reveals nighttime heat pump operation that is inconsistent with this strategy. For the model, 24-hour heating operation with a $5^{\circ} \mathrm{F}$ night setback during nights and weekends was used. The cooling operation mode was shut off nights and weekends.

Constant boiler and cooling tower setpoints of $60^{\circ} \mathrm{F}$ and $85^{\circ} \mathrm{F}$ were used in the model, respectively, but may deviate in the actual building due to alteration or drift.

It is not certain from the metered data whether heat pump fans are on all day or cycling with compressors. Because these subsystems are most commonly controlled so heat pump fans are operational whenever the outdoor ventilation fans operate, this operation schedule was used in the model.

The metered data show seasonal control strategy changes, most notably in the supply and exhaust fan operation of the ventilation system. Although 
this could have been simulated using individual monthly runs, it was overburdening for annual runs; therefore, these changes were not modeled.

An outside air fraction of $20 \%$ was used in the model, but it is not clear how the use of indirect ducting through plenum affects this in the actual building. (The flow rate through a fan is a function of the power input and the static pressure. Because a plenum has an uncertain static pressure, the outdoor air fraction is affected.)

\subsubsection{Lack of Basic Data}

The effective quantity of thermal mass in the zones was unknown. It depends on not only the quantity of heat storage material in the zone (such as furniture), but also its composition, color, and placement, as well as the rate of heat transfer to and from the zone air. This important parameter, which tempers the heating and cooling loads, was estimated using iterative calibration of the test building.

The rates of infiltration, exfiltration, and interzonal air exchange rates were not known. Constant rates of infiltration and exfiltration were assumed; the interzonal air exchange was not explicitly modeled.

The effective thermal mass in the water loop, which also includes the thermal mass of the piping, heat exchanger coils, and cooling tower sump water, was not certain. This parameter was estimated by calculating the total water volume in the loop and comparing it with metered water loop temperature responsiveness.

The effectiveness of the glycol loop outside air heat recovery heat exchanger was unknown because the entering and exiting air temperatures were not metered. The value used in the model is believed to be representative.

Thermal storage effects in glazings (if any) and light fixtures were not accounted for. There are no definitive data on this phenomenon nor on the apportioning of lighting heat gains between the conditioned zones and the plenum and of convective versus radiant heat transfer. The type of glass used in the windows was unknown; thus properties of the glass were considered parametric variables during the calibration of the base case. 
Because actual physical floor configurations were unavailable, modeling the heat gains and interzonal air exchange between the core and perimeter was estimated indirectly. The model simplified the interaction by assuming a continuous interior wall separated the core from the perimeter zones. The conductance and other properties of the wall were then established during the calibration of the base case. Because of uncertainties in the actual physical floor configuration and the (somewhat) arbitrary way in which the model was divided into zones, the modeling of radiation heat transfer between interior surfaces had to be simplified. For example, geometric view factors between interior surfaces were computed based on area ratios (see Section 3.3.2).

\subsubsection{Additional Discrepancies}

Replacement of building roof insulation during 1985 added significant thermal resistance to the roof. The thermal resistance of the original insulation was poor and its value unknown because it was partially water-saturated. In the simulation model, it was assumed that the overall resistance of the roof was constant throughout the year.

There was no accounting for holidays in the model. TRNSYS has this simulation capability but it is cumbersome to use. It is uncertain whether occupancy is actually negligible on holidays and likely that many occupants take additional vacation time near holidays.

The use of TMY data for Seattle-Tacoma Airport, rather than local data for 1985 (the latter was not available) resulted in somewhat erroneous instantaneous conductance and solar loads. As shown in Section 4.1, in the long run these errors tend to cancel out unless a seasonal or annual bias occurs, because of significant variations in local average temperatures during the metering period from the typical average.

\subsection{BUILDING STRUCTURAL THERMAL STORAGE (BSTS) SYSTEM MODEL DEVELOPMENT}

The fourth activity in the analysis was the development of the BSTS system model. The numerical model developed by PNL researchers to simulate the floor slabs used in the BSTS system is discussed in Section 3.4.1. A description of the BSTS system configuration and control strategy used in the building model 
is given in Section 3.4.2. Finally, a short description of the parametric simulating studies used to optimize the BSTS system is given in Section 3.4.3.

\subsubsection{Thermal Energy Storage in Slab}

A numerical heat transfer model was developed by PNL researchers to simulate the thermal charging and discharging of the hot or cold water flowing through 1-in.-diameter polybutylene pipes(a) embedded in the building floor slabs. The model solves for the two-dimensional unsteady conduction equation in a cartesian coordinate space:

$$
\frac{1}{a} \frac{\partial T}{\partial t}=\frac{\partial^{2} T}{\partial x^{2}}+\frac{\partial^{2} T}{\partial Y^{2}}
$$

where $T=$ temperature

$\mathrm{t}=\mathrm{time}$

$a=$ thermal diffusivity

Explicit formulas for the temperature field were derived from this relation using the central difference approximation. These formulas are applied in the model at each node in a user specified grid that includes portions of the slab, the pipe wall, and the water.

The model assumes uniform surface temperature at the top and bottom of the slab, consistent with the assumptions of the TRNSYS Zone Model. The temperature gradient along the direction of the water flow is not directly modeled. Instead, an iterative procedure is used to determine an average temperature (average of slab inlet and outlet temperature) of the water. It is then assumed that the water throughout the pipes is at this average temperature. This assumption is justified because these pipes are typically laid in multiple parallel circuits at high enough flow rates to ensure that water of about the same temperature is available at every point of the grid (Shell Chemical 1984). Hence, the entire pipe system is made up of sets of

(a) Reports on existing radiant slab heating applications using polybutylene confirm the practicality of this material (Shell Chemical 1984). 
identical circuits. Figure 3.3 shows a sample pipe pattern for a single circuit. Because of the symmetry of the pipe field, the simulation of only the smallest common element (half of the pipe and its associated slab) is required, simplifying the formulation of the model. Figure 3.3 also shows the portion of the slab being modeled.

At each simulation time step, the model uses the surface temperatures calculated from the Zone Model as inputs. It then calculates the amount of heat transferred from the fluid to the slab, and that transferred from the slab surfaces to the conditioned space (above) and plenum space (below). These heat transfer rates are a function of the fluid temperature and flow through the embedded pipes, as well as of the pipe diameter and spacing, the thickness of the slab, and the surface temperatures. In addition to the heat transfer rates, the cross sectional temperature distribution of the slab, hence the stored energy, is also calculated by the model. At the next time step, the heat transfers at the surfaces are input back to the Zone Model, and the simulation continues.

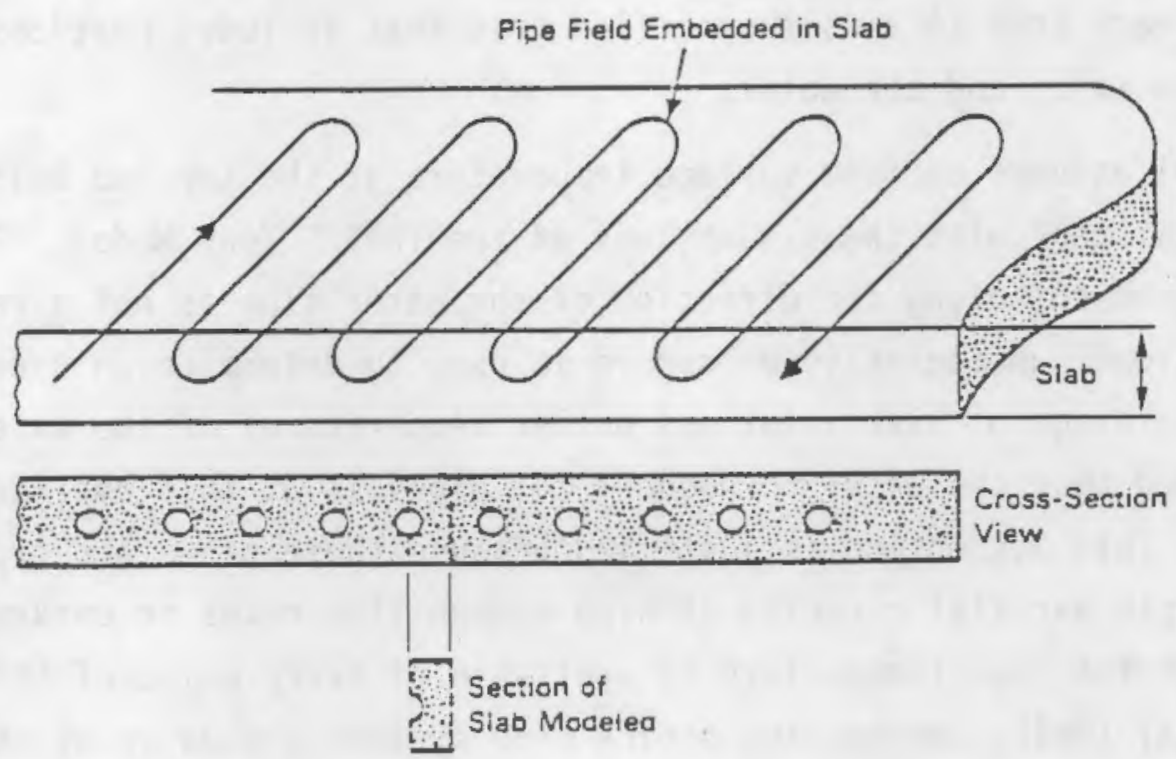

FIGURE 3.3. Slab with Water Loop Circuit 


\subsubsection{BSTS System Model and Basic Control Strategy}

In incorporating the BSTS system model into the building model, the existing base building subsystems and structure were modified as little as possible for three primary reasons:

- to maintain the integrity of the base building HVAC system design; this was a "design" decision, as it was felt a real building owner would want the capability of running the HVAC system alone

- simplicity in modeling

- interpretation of results; tracing the cause and effect of various system parameter modifications becomes more difficult, the more the basic model is changed.

Thus, the existing HVAC subsystems and controls were left essentially intact. The thermostats were identical to the base case for each of the controlled zones. The HVAC water loop flow rate was the same as in the base case, as were boiler, cooling tower, and heat pump capacities. The primary physical change to the HVAC water loop was the additional secondary piping loop used to route water through the concrete floor of the model (see Figure 2.2).

Included in the actual model are five separate slabs, one for each of the four perimeter zones, and one for the core. The slab water loop parallel circuits were arranged to maintain turbulent water flow (approximately $3 \mathrm{feet} / \mathrm{second}$ ) at a reasonable pressure drop. The total water flow available to each slab equaled the flow rate of the heat pump associated with the same zone as that slab(a). Inlet water temperature to the slabs was based on the overall mixed temperature of water leaving the five zone heat pumps.

A basic control scheme was used for the slab. Two slab water flow controllers were employed in the model: one sensed the core zone space temperature and the other sensed the volumetrically weighted average perimeter space

(a) Because heat pumps in all zones were nominally sized at $370 \mathrm{ft}^{2} / \mathrm{ton}, 3$ $\mathrm{gpm} / \mathrm{ton}$, this meant water flow to the slab was uniform over the entire floor area. 
temperature(a). These temperatures were compared to available water loop temperature to determine if water flow control valves to the slabs should be open or closed and if the slab water pump should be on or off. Night and weekend setback was identical to the base building model for winter heating conditions. During summer cooling, the cooling tower was turned on prior to morning startup to pre-cool the slab and space from 4:00 to 6:00 a.m. This was not used on weekend mornings, because the cooling was shut off.

The two slab water flow controllers, like the zone thermostats, had both heating and cooling setpoints. These setpoints were established so slab heating or cooling would be used (assuming water loop temperatures were appropriate) before the room thermostats signaled the heat pumps to start. For example, during occupied hours the slab water flow controller setpoint for heating was set at $72^{\circ} \mathrm{F}$, while zone thermostats (as established by the base case simulation) were set at $71^{\circ} \mathrm{F}$. If a zone temperature drops to $72^{\circ} \mathrm{F}$ during the day, the controller checks the loop temperature to see if water above $72^{\circ} \mathrm{F}$ is available to help heat the slab associated with the zone in question. If water is available for heating, the controller opens the flow control valve to that zone's slab and the pump is started. Figure 3.4 is a block diagram summarizing the BSTS system control scheme.

The establishment of appropriate slab flow valve controller setpoints is essential for the design. First, to work at all, they must be coupled to the zone thermostat setpoints. A slab water flow controller heating setpoint for a zone that is lower than that zone's heat pump thermostat heating setpoint would be counterproductive, because zone heat pump operation may lower loop water temperatures below a level at which this water can be used for heating in the slab.

Another concern with this control strategy comes about because of the thermal capacitance of the slab. The response time of the slab is slowed by its mass. Thus, although the controller directs warm water to the slab to

(a) Only two controllers were used because of TRNSYS size limitations. Ideally, individual controllers for each of the four perimeter zone slabs would have been used. 


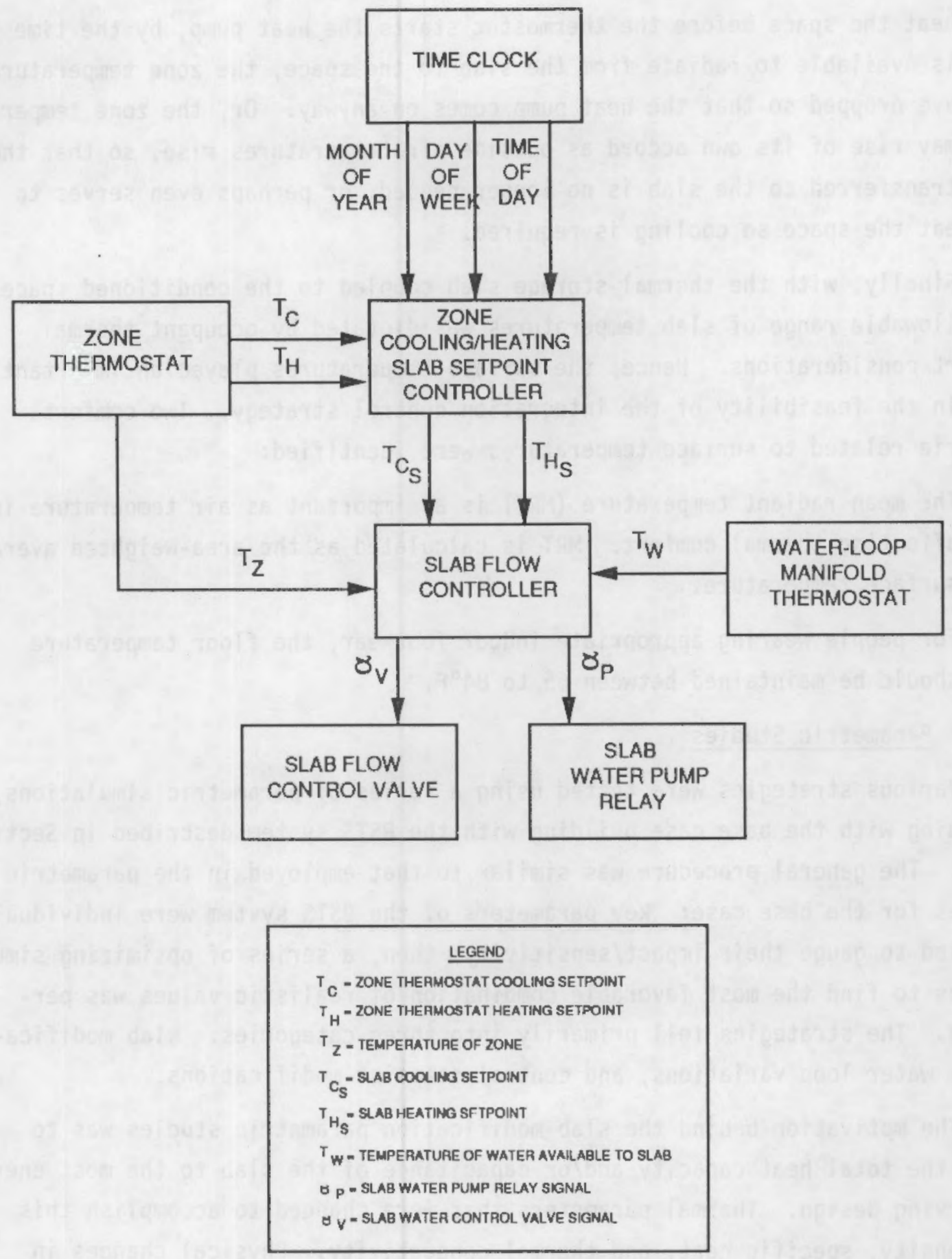

FIGURE 3.4. Block Diagram of BSTS System Control Scheme 
help heat the space before the thermostat starts the heat pump, by the time this heat is available to radiate from the slab to the space, the zone temperature may have dropped so that the heat pump comes on anyway. Or, the zone temperature may rise of its own accord as outside air temperatures rise, so that the heat transferred to the slab is no longer needed, or perhaps even serves to overheat the space so cooling is required.

Finally, with the thermal storage slab coupled to the conditioned space, the allowable range of slab temperatures was dictated by occupant thermal comfort considerations. Hence, the surface temperatures played an important role in the feasibility of the integration control strategy. Two comfort criteria related to surface temperatures were identified:

- The mean radiant temperature (MRT) is as important as air temperature in affecting thermal comfort. MRT is calculated as the area-weighted average surface temperature.

- For people wearing appropriate indoor footwear, the floor temperature should be maintained between 65 to $84^{\circ} \mathrm{F}$.

\subsubsection{Parametric Studies}

Various strategies were tested using a series of parametric simulations, beginning with the base case building with the BSTS system described in Section 3.4.2. The general procedure was similar to that employed in the parametric studies for the base case: key parameters of the BSTS system were individually modified to gauge their impact/sensitivity; then, a series of optimizing simulations to find the most favorable combination of realistic values was performed. The strategies fell primarily into three categories: slab modifications, water loop variations, and control setpoint modifications.

The motivation behind the slab modification parametric studies was to alter the total heat capacity and/or capacitance of the slab to the most energyconserving design. Thermal parameters that were changed to accomplish this are density, specific heat, and thermal conductivity. Physical changes in the slab that were examined included slab thickness. The conductance of the insulating materials such as carpeting, which cover the top and bottom of the slab, were also varied. 


\subsection{BASE CASE BUILDING MODEL CALIBRATION RESULTS}

An important step in this investigation was the calibration of the base case building model with metered data (see Section 3.3.3), because it helps verify that the actual building was realistically modeled. This, in turn, provides confidence that the simulated results of the building model with the BSTS system added (see Section 5.0 ) provides a reasonable estimate of the impact of integrating the HVAC system and the building structural mass.

The simulated monthly overall HVAC energy consumption results are compared with the available corresponding metered data in Figure 4.1. These comparisons are the most reasonable that could be obtained, given the limitations of the data and the computer model (see Section 3.3.3). Monthly simulated energy consumption is within $10 \%$ of metered performance except for February, March, April, and November. These larger discepancies, unresolved by the calibration, can primarily be attributed to the difference between the Typical Meteorological Year (TMY)(a) weather data used in the simulation and the actual weather at the building site during 1985. For example, as indicated in Figure 4.2, the TMY average monthly temperature was approximately $11^{\circ} \mathrm{F}$ higher in November than National Oceanic and Atmospheric Administration (NOAA) temperature data for 1985 (measured at Seattle-Tacoma airport). For February and April the differences were $3^{\circ} \mathrm{F}$. These differences correlate with the discrepancies between metered and simulated building energy consumption. No attempt was made to use NOAA weather data for 1985 because solar radiation data is not included, and the merging of TMY data with NOAA data would produce numerous hours when solar radiation and temperatures were inconsistent.

In Figures 4.3 through 4.5 , the simulated monthly energy consumption of the major HVAC components is compared to the metered data. Although differences are not within $10 \%$ for many of the months, the operational trends for each component compare well, as does the overall annual energy consumption.

(a) The TMY weather data represents "typical" values of temperatures, solar radiation, and wind speed in a year. 


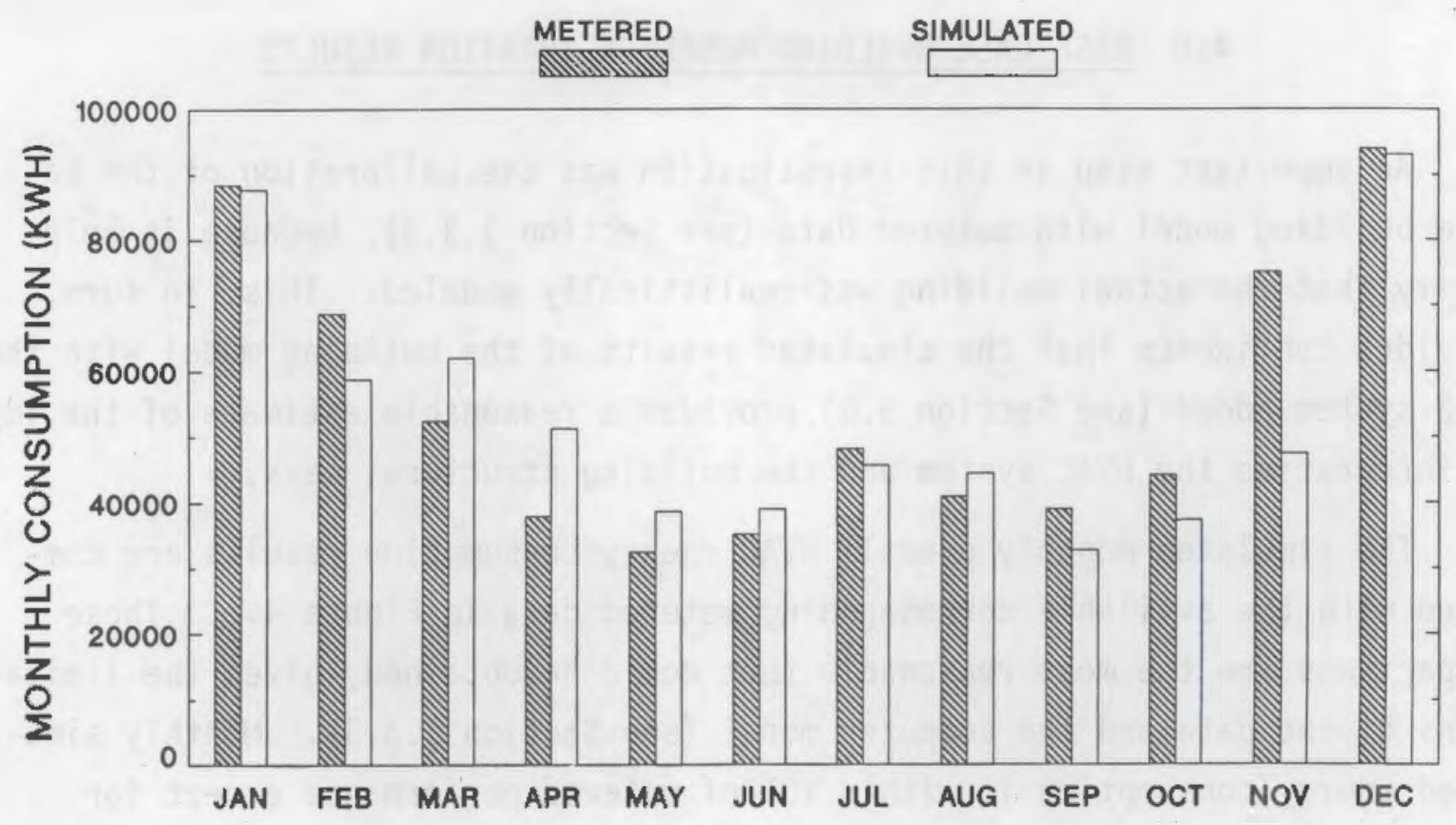

FIGURE 4.1. Comparison of Metered Simulated Monthly Total HVAC Energy Consumption

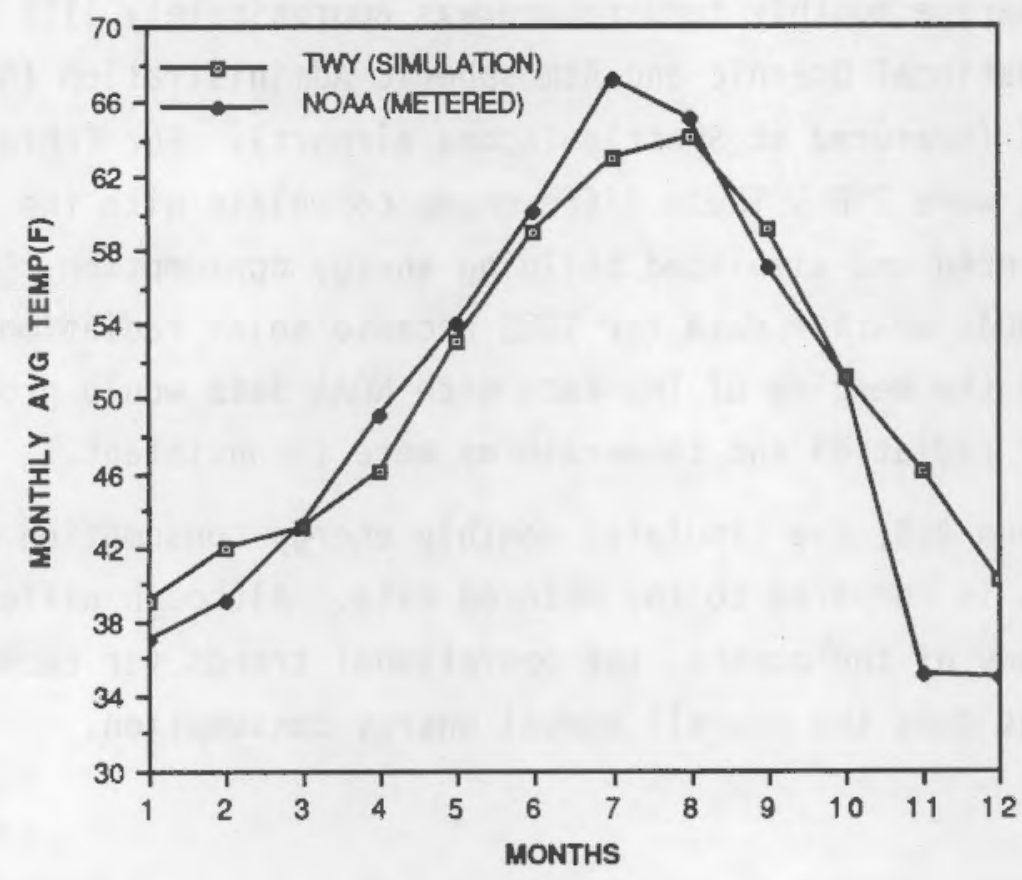

FIGURE 4.2. Comparison of National Oceanic Atmospheric Administration and Typical Meteorological Year Average Monthly Temperatures 


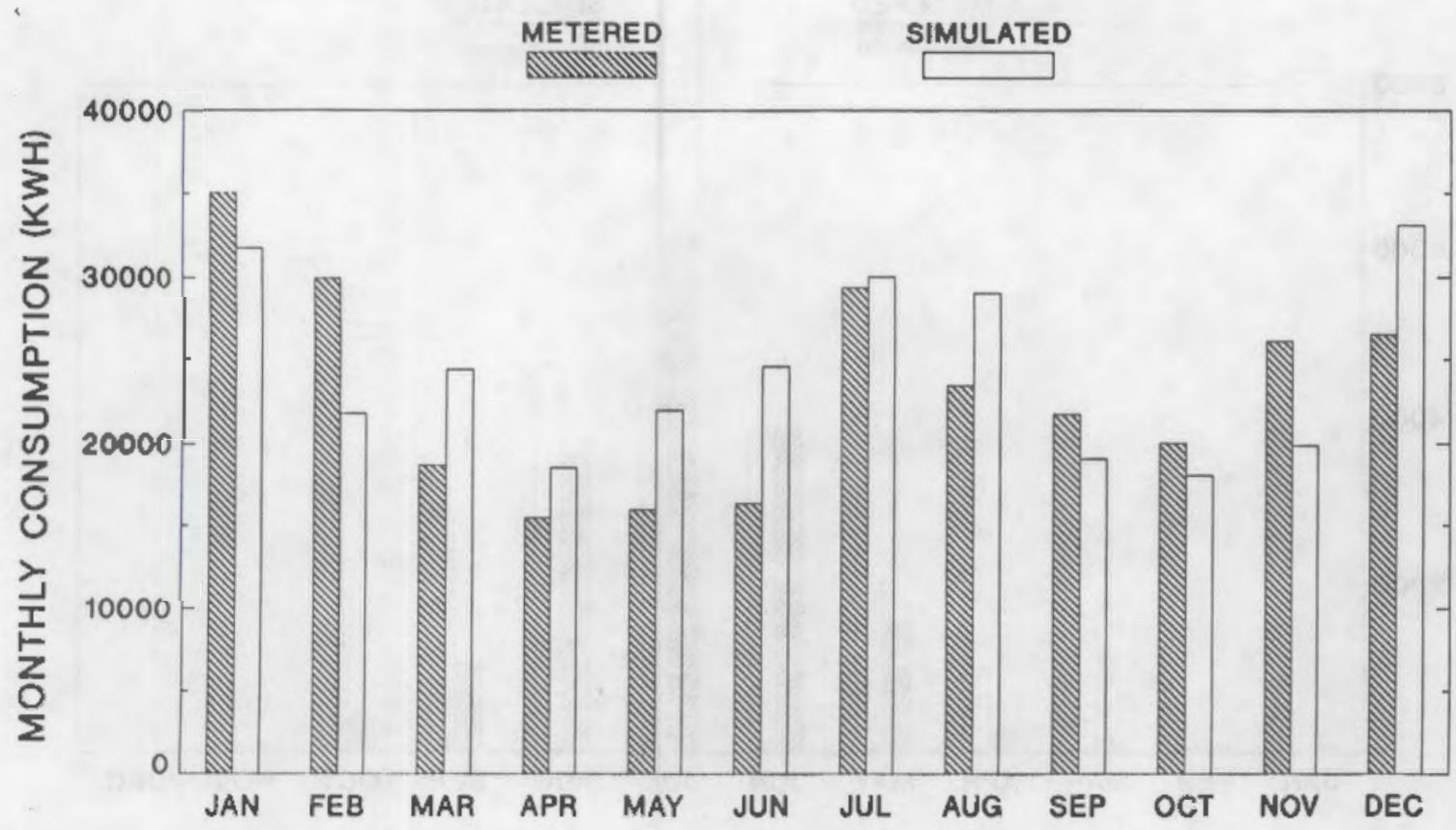

FIGURE 4.3. Metered Versus Simulated Monthly Heat Pump Energy Consumption

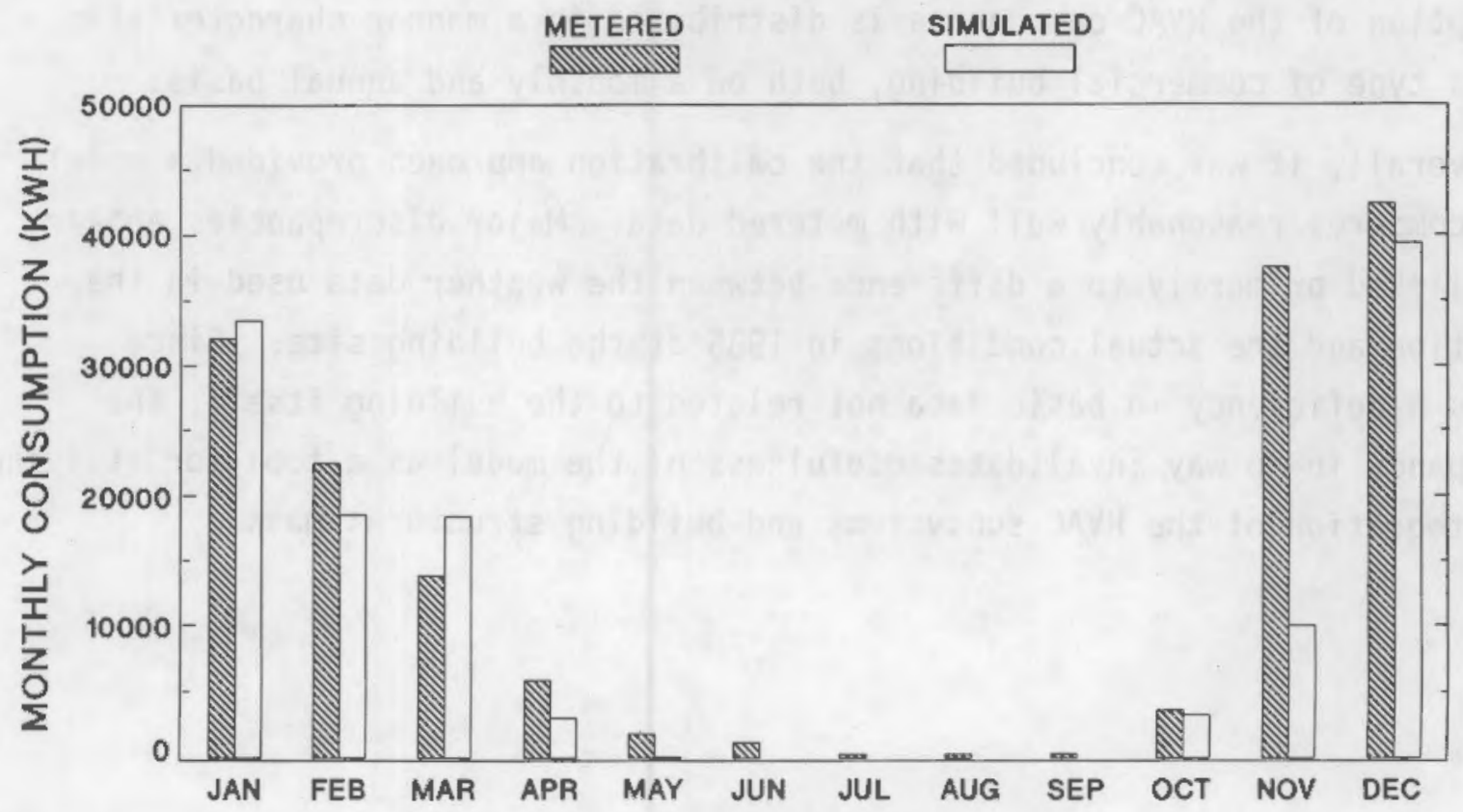

FIGURE 4.4. Metered Versus Simulated Monthly Boiler Energy Consumption 


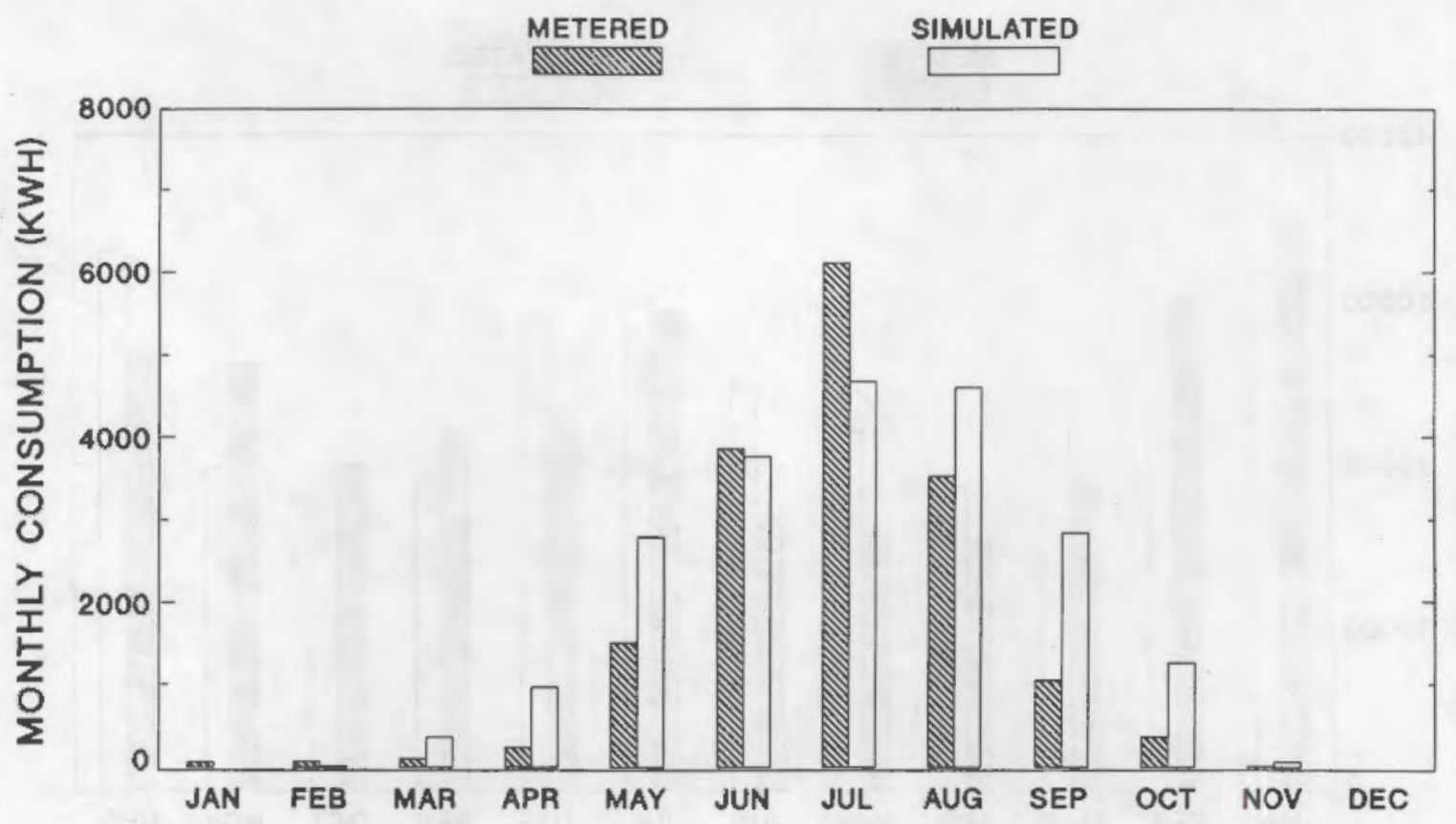

FIGURE 4.5. Metered Versus Simulated Monthly Cooling Tower Energy Consumption

Figures 4.6 and 4.7 sumnarize the simulated monthly and annual energy consumption of the HVAC components. These also indicate that the energy consumption of the HVAC components is distributed in a manner characteristic of this type of commercial building, both on a monthly and annual basis.

Overall, it was concluded that the calibration approach provided a model which compares reasonably well with metered data. Major discrepancies appear to be linked primarily to a difference between the weather data used in the simulation and the actual conditions in 1985 at the building site. Since this is a deficiency in basic data not related to the building itself, the discrepancy in no way invalidates usefulness of the model as a tool for studying the integration of the HVAC subsystems and building structural mass. 


$$
\begin{gathered}
B=\text { Boiler } D=\text { Duct Heaters } C=\text { Cooling Tower } \\
H=\text { Heat Pumps } P=\text { Pumps } F=\text { Fans }
\end{gathered}
$$

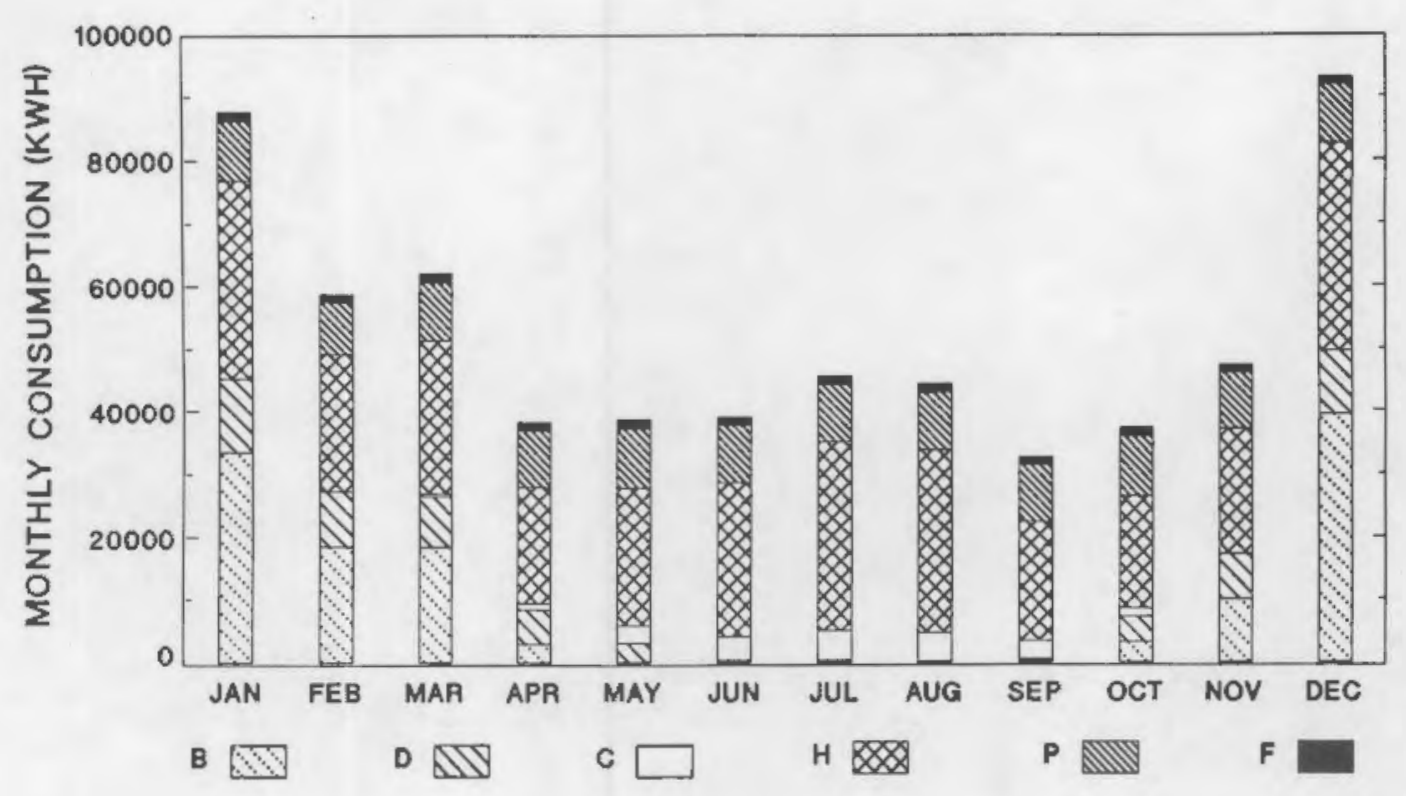

FIGURE 4.6. Simulated Monthly Energy Consumption of HVAC Components

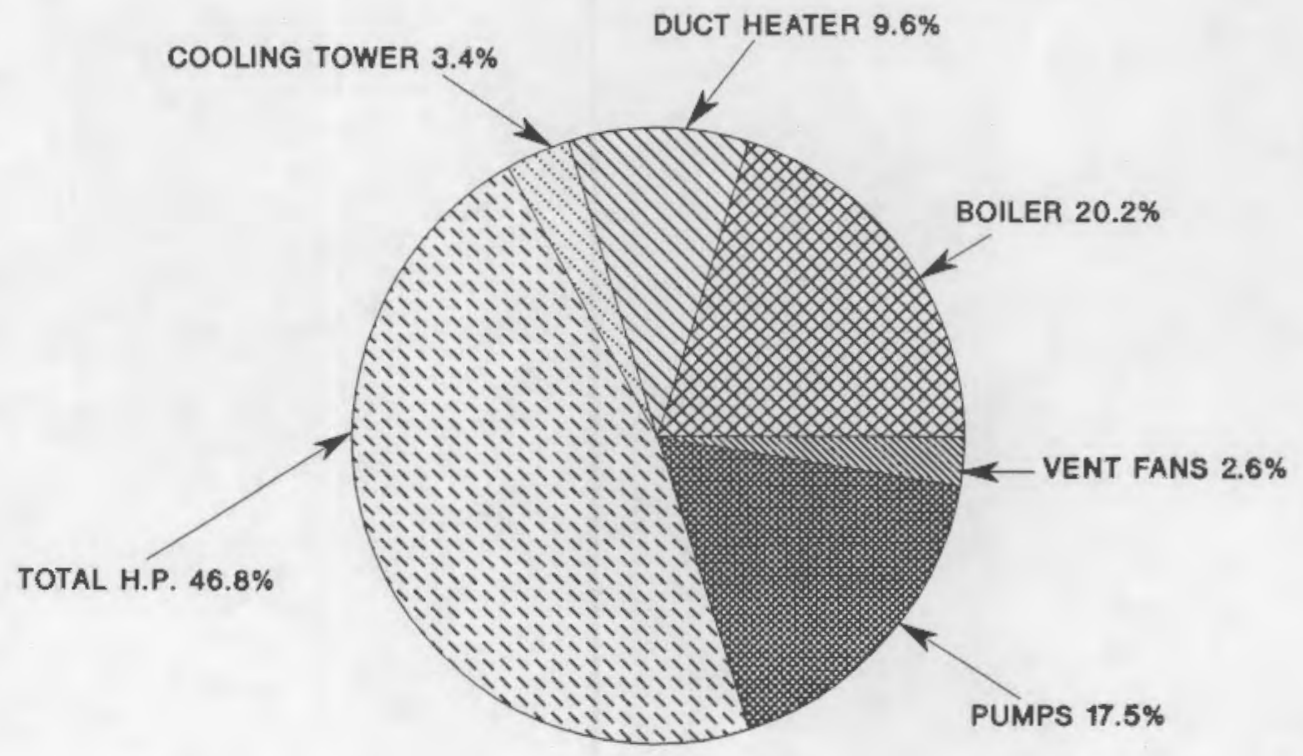

FIGURE 4.7. Simulated Annual Energy Consumption of HVAC Components 


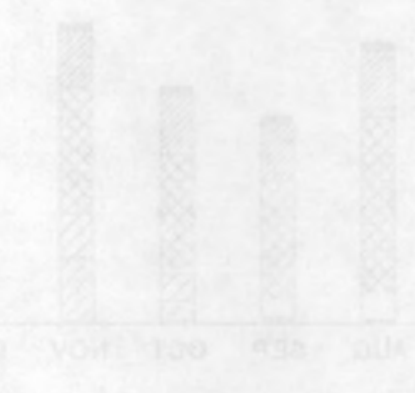

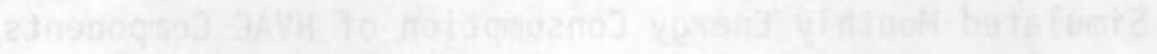




\subsection{EVALUATION OF BUILDING STRUCTURAL THERMAL STORAGE SYSTEM PERFORMANCE}

After the base case building model was established for the Seattle location, study of the interaction between the HVAC system and building mass began. Results of the BSTS system simulation are presented and interpreted in Sections 5.1 and 5.2. A discussion of the limitations noted in the system follow in Section 5.3 .

\subsection{SIMULATION RESULTS}

The BSTS system was simulated with the temperate Seattle weather data first to provide a basis for determining whether to continue simulations in other locations. Trends in energy consumption and sensitivities of the BSTS system operation were found at this stage of the testing, which included brief sensitivity analysis simulations and full annual simulations. The sensitivity simulations used portions of the January and July months, with which trends in peak heating and cooling operation were found. Slab thermal properties and water loop control parameters were altered in the sensitivity analyses, providing information on the best-performing BSTS system configuration.

Comparisons of simulated building base case and simulated building with the BSTS system results for Seattle are shown in Figures 5.1 through 5.4. Definite energy-conserving patterns were found for the Seattle location, suggesting further study of the BSTS system in other locations (see Section 6.0). The first measure of performance noted was the building total HVAC energy consumption for a year. The BSTS system energy consumption was $585,435 \mathrm{kWh}$, as compared to $637,748 \mathrm{kWh}$ for the base case. On a monthly bas is for total HVAC, shown in Figure 5.1, energy savings were found in every month for the period of April through November. Additional energy was consumed during December, January, February, and March; however, the net reduction in annual energy consumption shown in the above results was $8.2 \%$.

Heat pump energy consumption (see Figure 5.2) followed the same monthly pattern as the overall HVAC energy consumption described above. The boiler consumed virtually no energy from May through September; however, the boiler 


\section{SEATTLE}

TOTAL MONTHLY

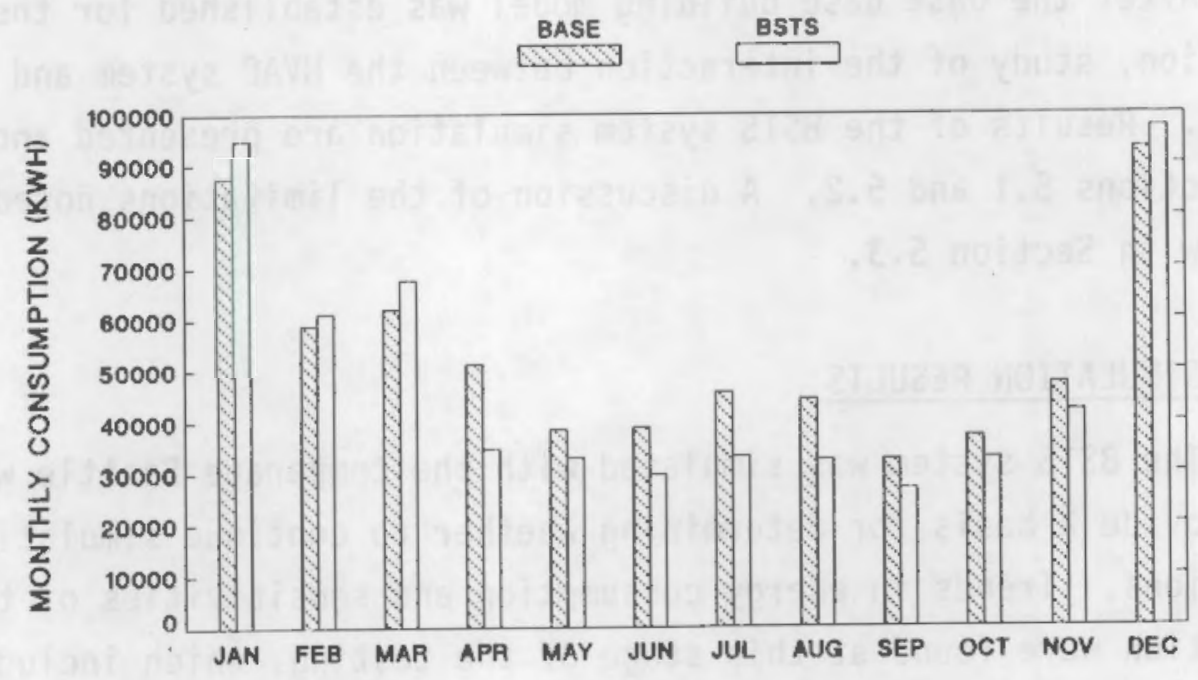

FIGURE 5.1. Total HVAC Monthly Energy Consumption for Simulated BSTS Strategies, Seattle

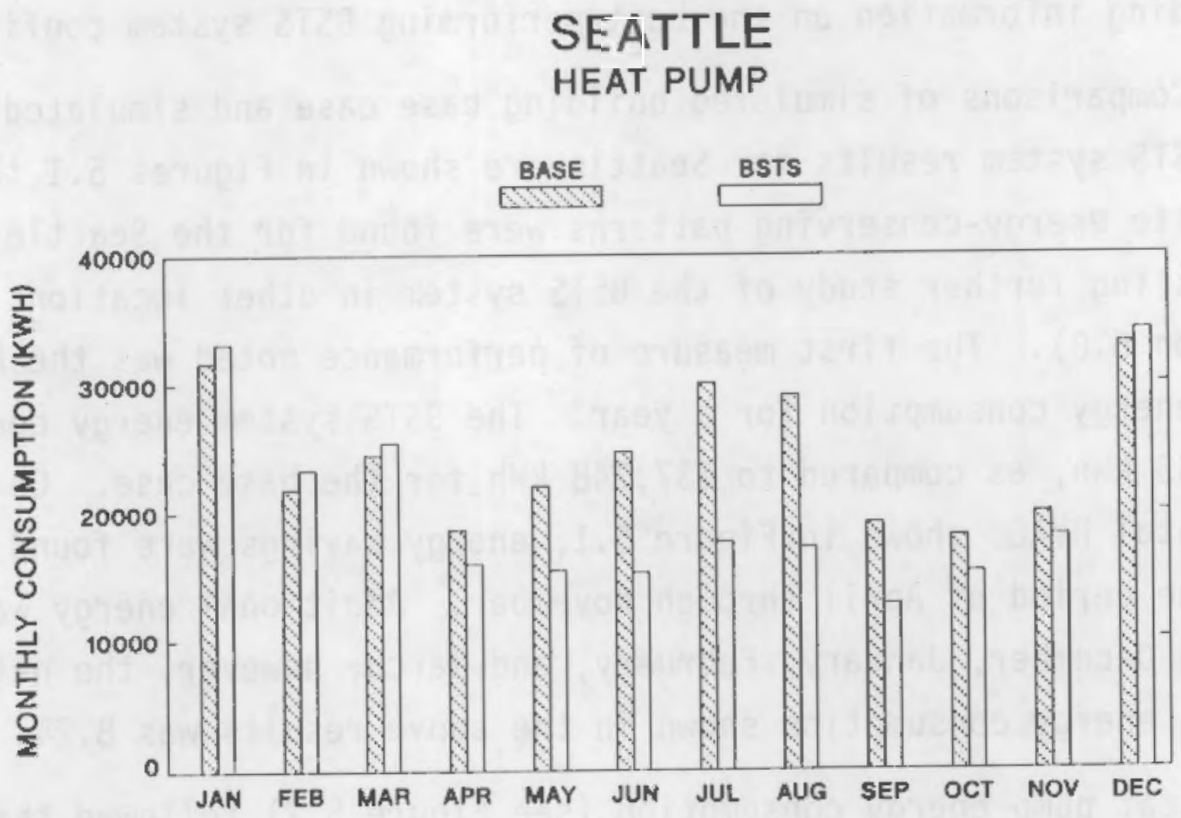

FIGURE 5.2. Heat Pump Monthly Energy Consumption for Simulated BSTS Strategies, Seattle 


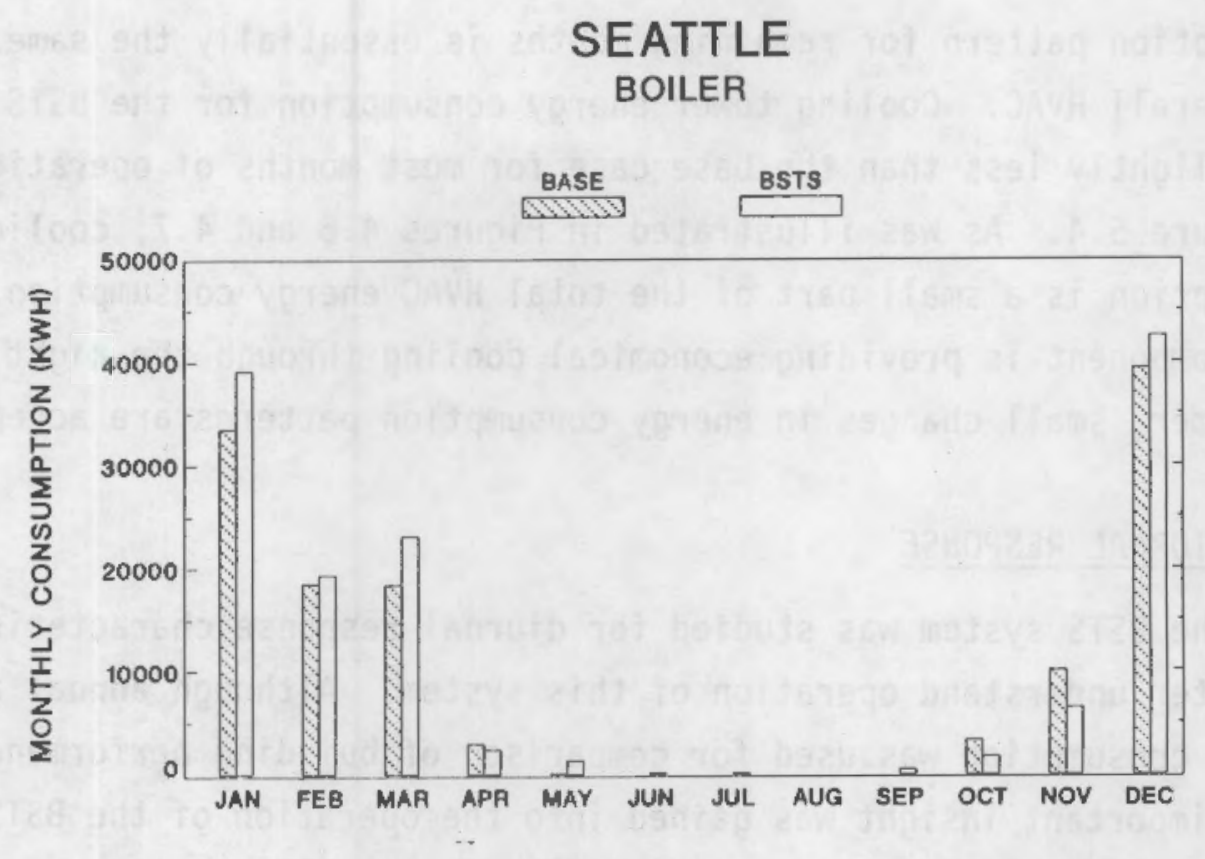

FIGURE 5.3. Boiler Monthly Energy Consumption for Simulated BSTS Strategies, Seattle

\section{SEATTLE COOLING TOWER}

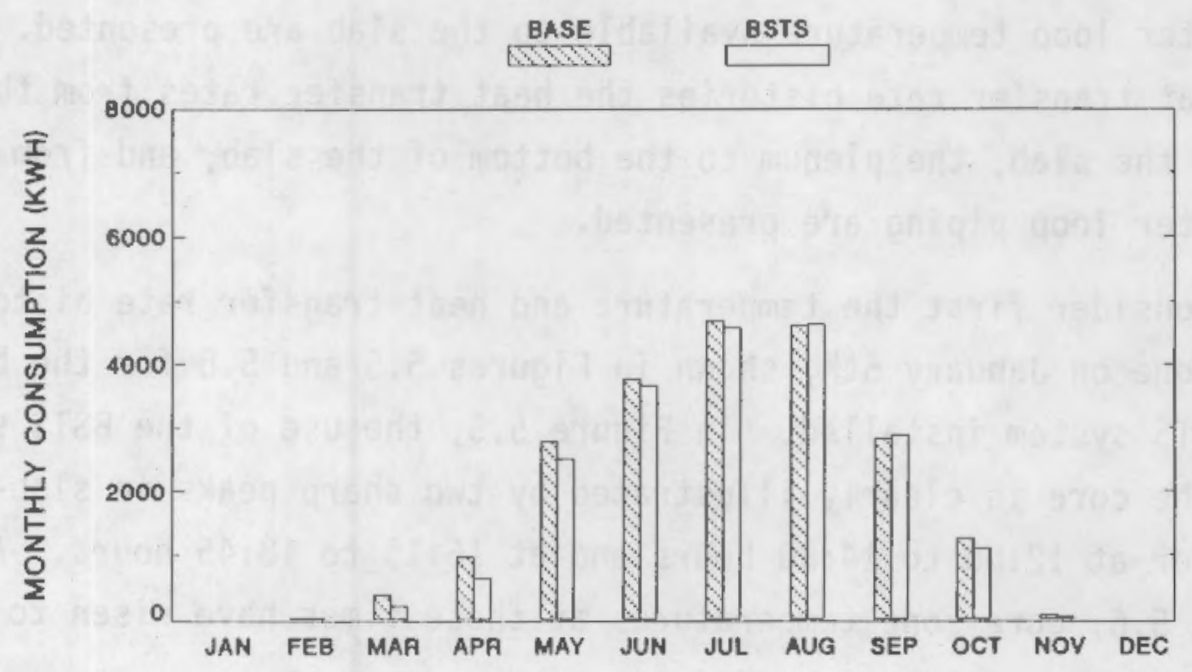

FIGURE 5.4. Cooling Tower Monthly Energy Consumption for Simulated BSTS Strategies, Seattle 
consumption pattern for remaining months is essentially the same as that for the overall HVAC. Cooling tower energy consumption for the BSTS system is only slightly less than the base case for most months of operation, as shown in Figure 5.4. As was illustrated in Figures 4.6 and 4.7, cooling tower energy consumption is a small part of the total HVAC energy consumption. Because this component is providing economical cooling through the night "purge" cycle in summer, small changes in energy consumption patterns are acceptable.

\subsection{DIURNAL RESPONSE}

The BSTS system was studied for diurnal response characteristics in order to better understand operation of this system. Although annual and monthly energy consumption was used for comparison of building performance in this work, important insight was gained into the operation of the BSTS system by studying daily temperature and heat transfer profiles. A series of zone temperature and heat transfer rate histories for different days of the year are presented in this section for the building, both with and without the BSTS system.

In each of the temperature history figures the applicable zone temperature, bulk temperature of the slab adjacent to the zone(a), outdoor air ambient, and water loop temperature available to the slab are presented. In each of the heat transfer rate histories the heat transfer rates from the zone to the top of the slab, the plenum to the bottom of the slab, and from the slab to the water loop piping are presented.

Consider first the temperature and heat transfer rate histories for the core zone on January 5 th, shown in Figures 5.5 and 5.6 for the building with the BSTS system installed. In Figure 5.5, the use of the BSTS system to help cool the core is clearly illustrated by two sharp peaks in slab-to-pipe heat transfer at 12:00 to 14:30 hours and at 16:15 to 18:45 hours. As shown in

Figure 5.6, core zone temperatures at these times have risen to $74^{\circ} \mathrm{F}$ (the slab

(a) The "bulk" slab temperature is computed in subroutine THESIS (see Appendix $C$ ) by taking the arithmetic average of each discretely defined numerical node. 


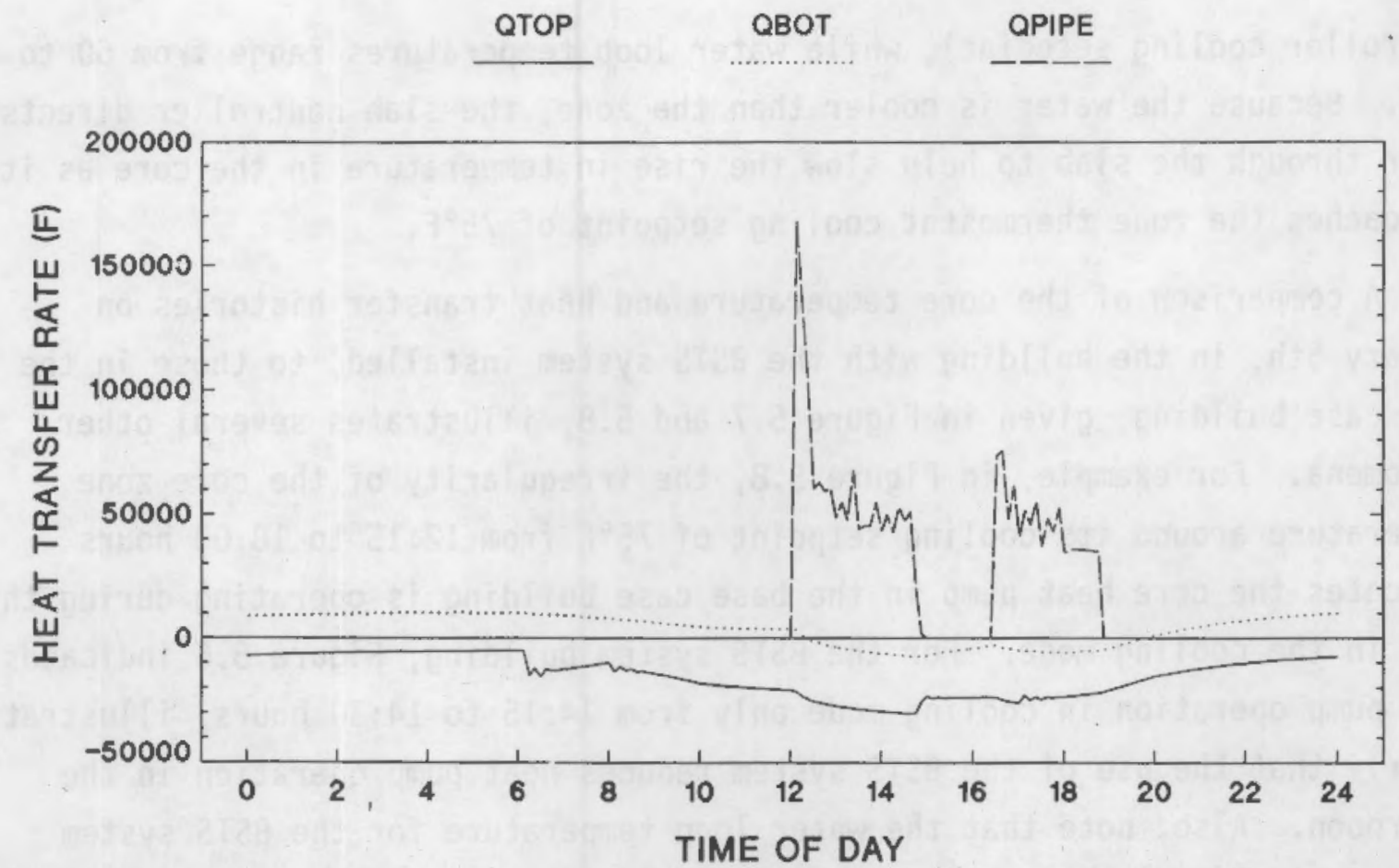

FIGURE 5.5. January 5th Heat Transfer Rate History for the Core Zone of the Simulated Building with the BSTS System

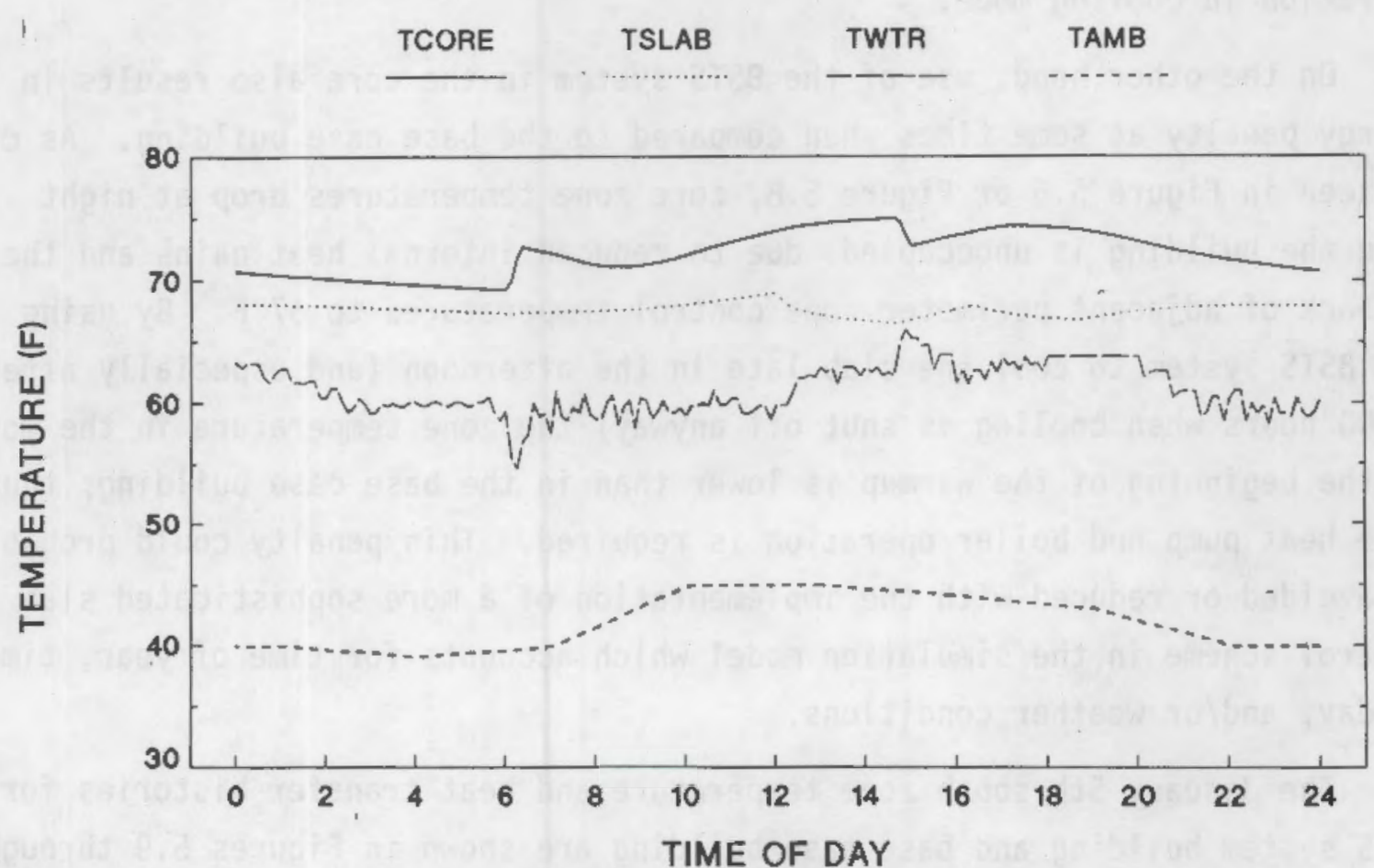

FIGURE 5.6. January 5th Temperature History for the Core Zone of the Simulated Building with the BSTS System 
controller cooling setpoint), while water loop temperatures range from 60 to $65^{\circ} \mathrm{F}$. Because the water is cooler than the zone, the slab controller directs water through the slab to help slow the rise in temperature in the core as it approaches the zone thermostat cooling setpoint of $75^{\circ} \mathrm{F}$.

A comparison of the core temperature and heat transfer histories on January 5th, in the building with the BSTS system installed, to those in the base case building, given in Figure 5.7 and 5.8, illustrates several other phenomena. For example, in Figure 5.8, the irregularity of the core zone temperature around its cooling setpoint of $75^{\circ} \mathrm{F}$ from 12:15 to 18:00 hours indicates the core heat pump in the base case building is operating during this time in the cooling mode. For the BSTS system building, Figure 5.6 indicates heat pump operation in cooling mode only from 14:15 to 14:30 hours, illustrating clearly that the use of the BSTS system reduces heat pump operation in the afternoon. Also, note that the water loop temperature for the BSTS system building is lower than in the base case building in the second half of the day, because less heat is rejected by the core heat pump due to less frequent operation in cooling mode.

On the other hand, use of the BSTS system in the core also results in an energy penalty at some times when compared to the base case building. As can be seen in Figure 5.6 or Figure 5.8, core zone temperatures drop at night when the building is unoccupied, due to reduced internal heat gains and the setback of adjacent perimeter zone control temperatures to $67^{\circ} \mathrm{F}$. By using the BSTS system to cool the slab late in the afternoon (and especially after 18:00 hours when cooling is shut off anyway) the zone temperature in the morning at the beginning of the warmup is lower than in the base case building; thus, more heat pump and boiler operation is required. This penalty could probably be avoided or reduced with the implementation of a more sophisticated slab control scheme in the simulation model which accounts for time of year, time of day, and/or weather conditions.

The January 5 th south zone temperature and heat transfer histories for the BSTS system building and base case building are shown in Figures 5.9 through 5.12. Zone temperatures are seen to be essentially the same throughout the day. No heat transfer from the water loop to the slab occurs in the BSTS system 


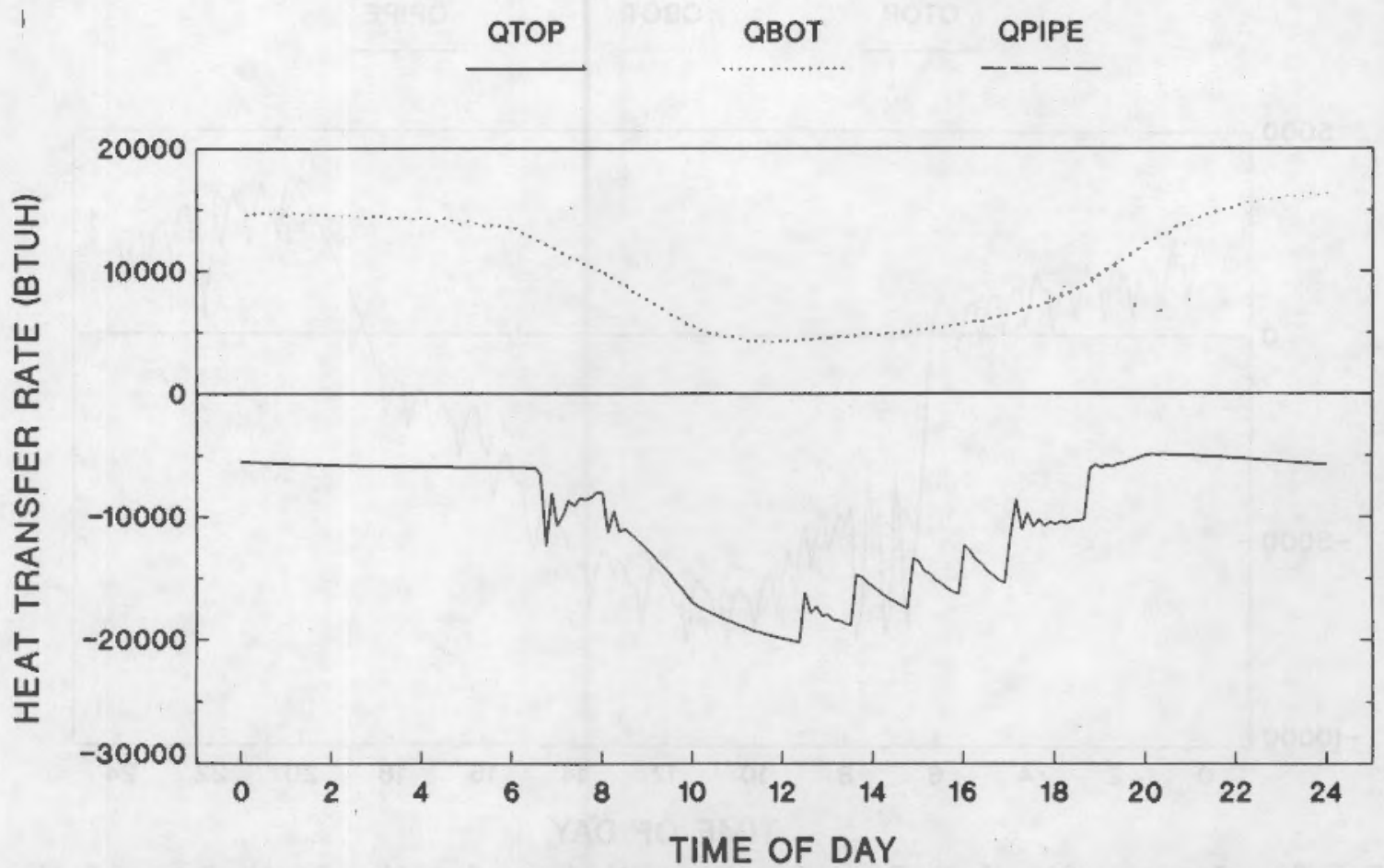

FIGURE 5.7. January 5th Heat Transfer Rate History for the Core Zone of the Simulated Base Case Building
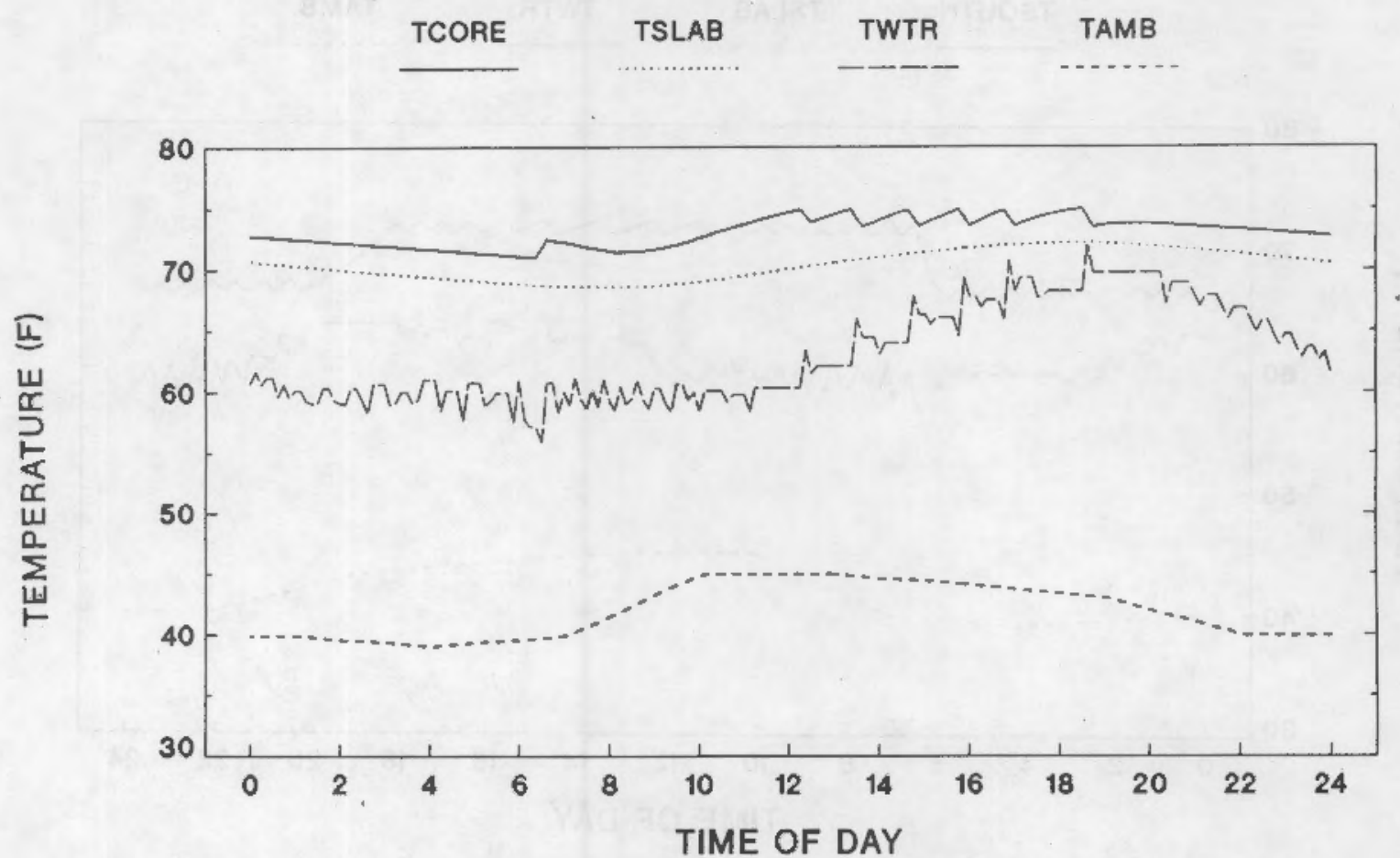

FIGURE 5.8. January 5th Temperature History for the Core Zone of the Simulated Base Case Building 


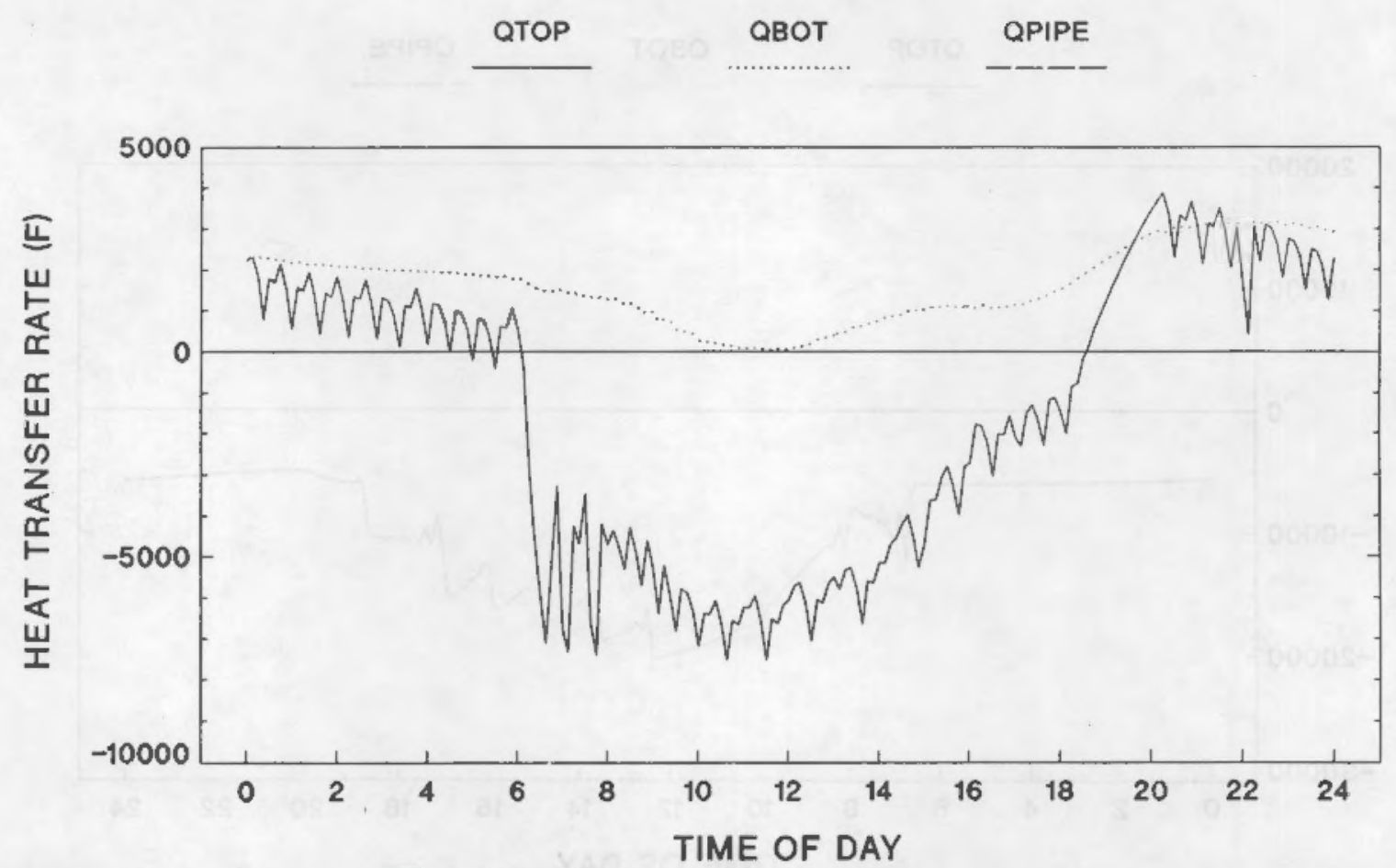

FIGURE 5.9. January 5th Heat Transfer Rate History for the South Zone of the Simulated Building with the BSTS System
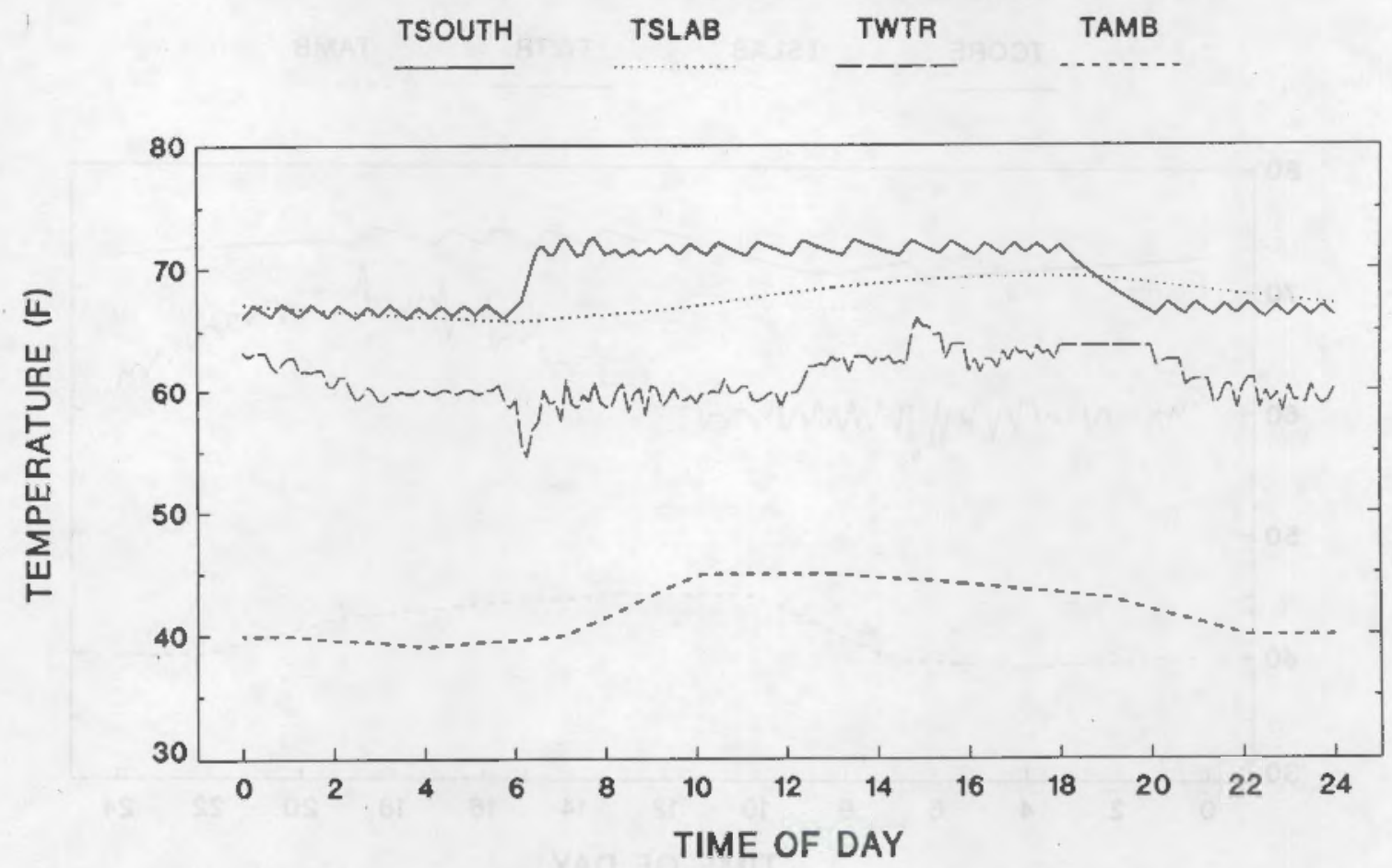

FIGURE 5.10. January 5th Temperature History for the South Zone of the Simulated Building with the BSTS System 


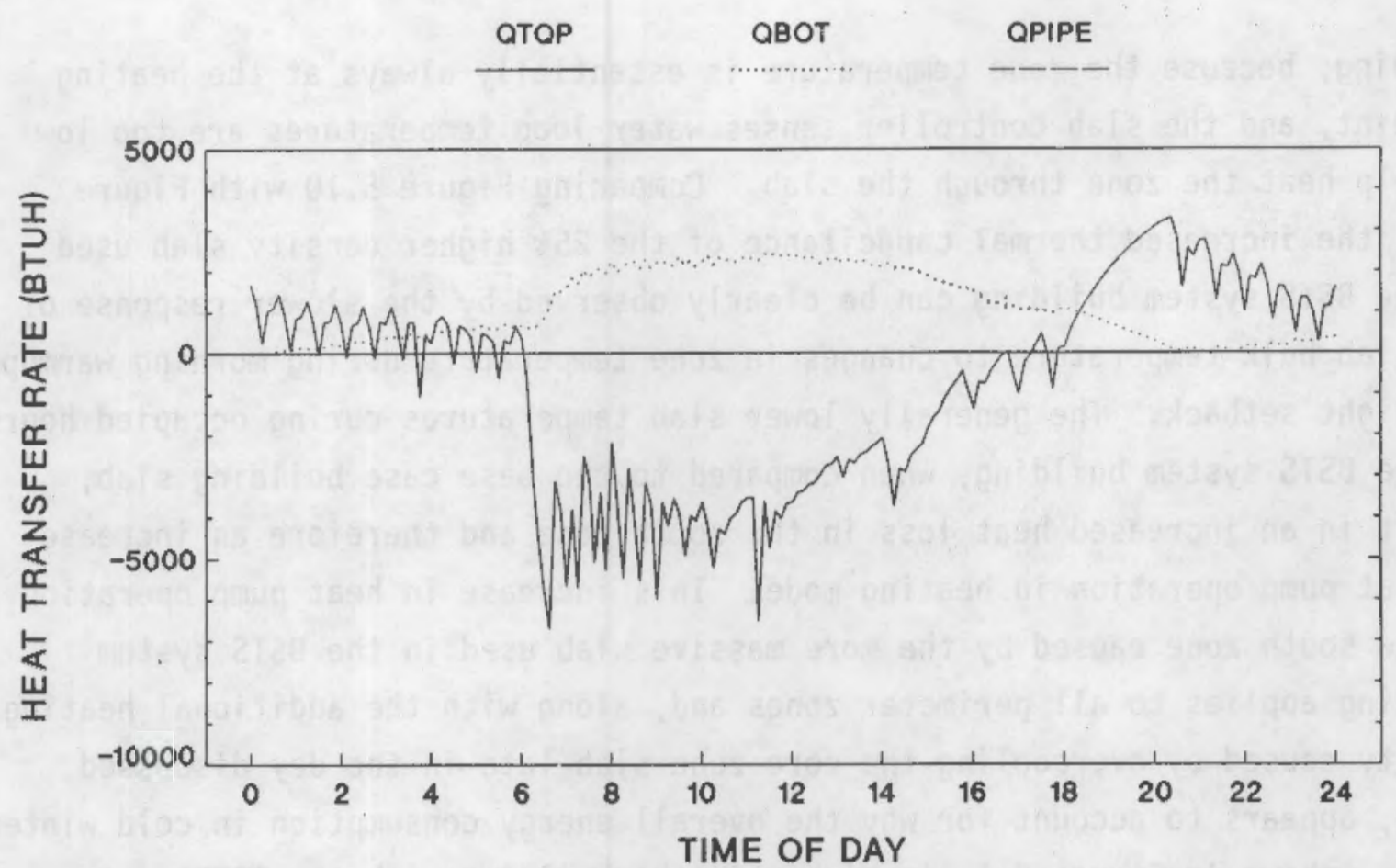

FIGURE 5.11. January 5th Heat Transfer Rate History for the South Zone of the Simulated Base Case Building

\begin{tabular}{lll} 
TSOUTH TSLAB TWTR TAMB \\
\hline
\end{tabular}

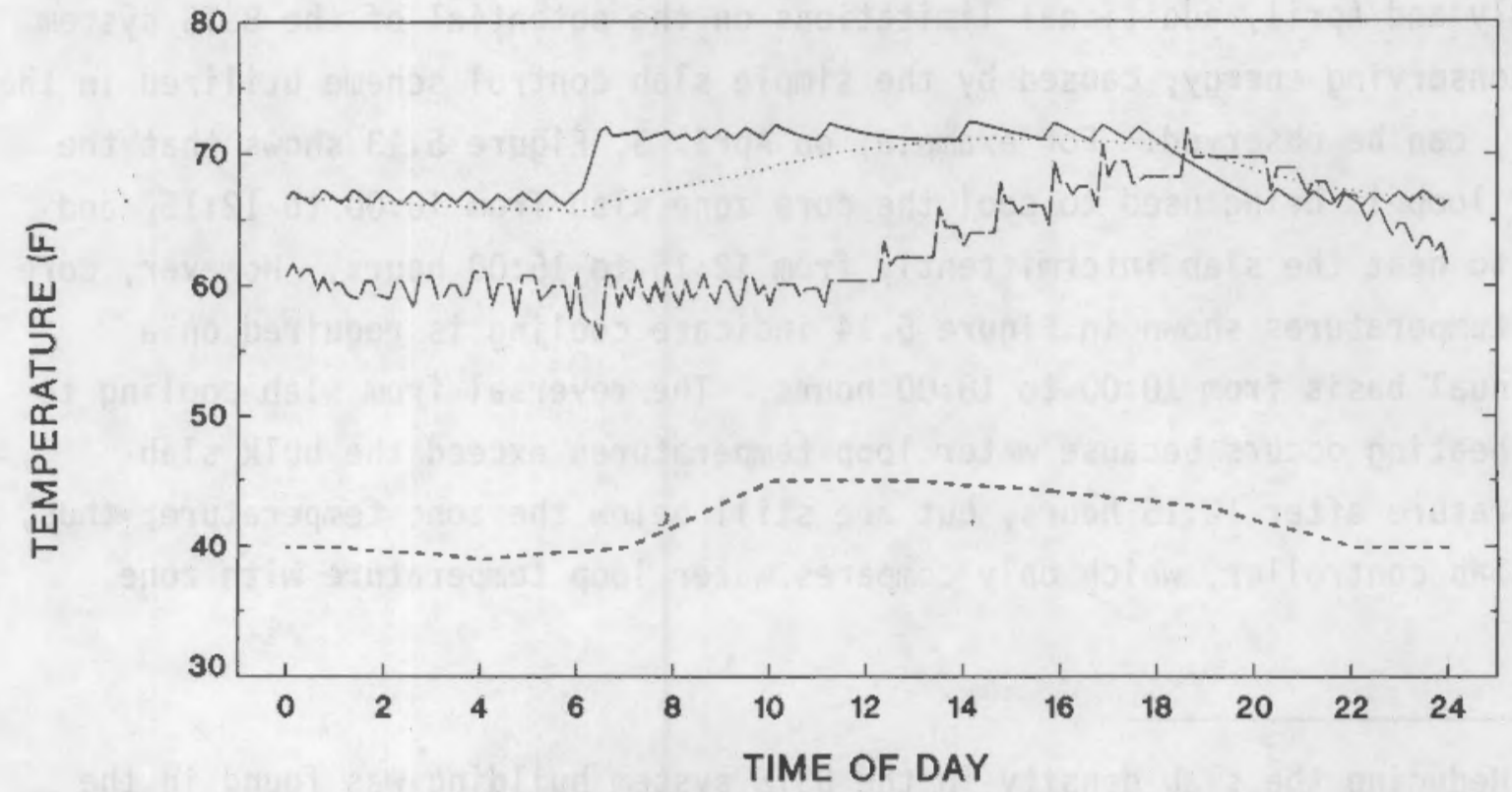

FIGURE 5.12. January 5th Temperature History for the South Zone of the Simulated Base Case Building 
building, because the zone temperature is essentially always at the heating setpoint, and the slab controller senses water loop temperatures are too low to help heat the zone through the slab. Comparing Figure 5.10 with Figure 5.12 , the increased thermal capacitance of the $25 \%$ higher density slab used in the BSTS system building can be clearly observed by the slower response of the slab bulk temperature to changes in zone temperature during morning warmup and night setback. The generally lower slab temperatures during occupied hours in the BSTS system building, when compared to the base case building slab, result in an increased heat loss in the south zone and therefore an increase in heat pump operation in heating mode. This increase in heat pump operation in the south zone caused by the more massive slab used in the BSTS system building applies to all perimeter zones and, along with the additional heating penalty caused by overcooling the core zone slab late in the day discussed above, appears to account for why the overall energy consumption in cold winter months, shown in Figure 5.1, is higher in the building with the BSTS system installed than in the base case simulated building. As was mentioned before, a more sophisticated slab control scheme should limit these energy penalties(a).

By inspecting temperature and heat transfer histories for typical days in July and April, additional limitations on the potential of the BSTS system for conserving energy, caused by the simple slab control scheme utilized in the model, can be observed. For example, on April 3, Figure 5.13 shows that the water loop is being used to cool the core zone slab from 10:00 to 12:15, and then to heat the slab intermittently from 12:15 to 15:00 hours. However, core zone temperatures shown in Figure 5.14 indicate cooling is required on a continual basis from 10:00 to 18:00 hours. The reversal from slab cooling to slab heating occurs because water loop temperatures exceed the bulk slab temperature after 12:15 hours, but are still below the zone temperature; thus, the slab controller, which only compares water loop temperature with zone

(a) Reducing the slab density in the BSTS system building was found in the sensitivity studies to degrade improvements in summer performance more than it helped in winter; therefore this option for the BSTS system building model was not used. 


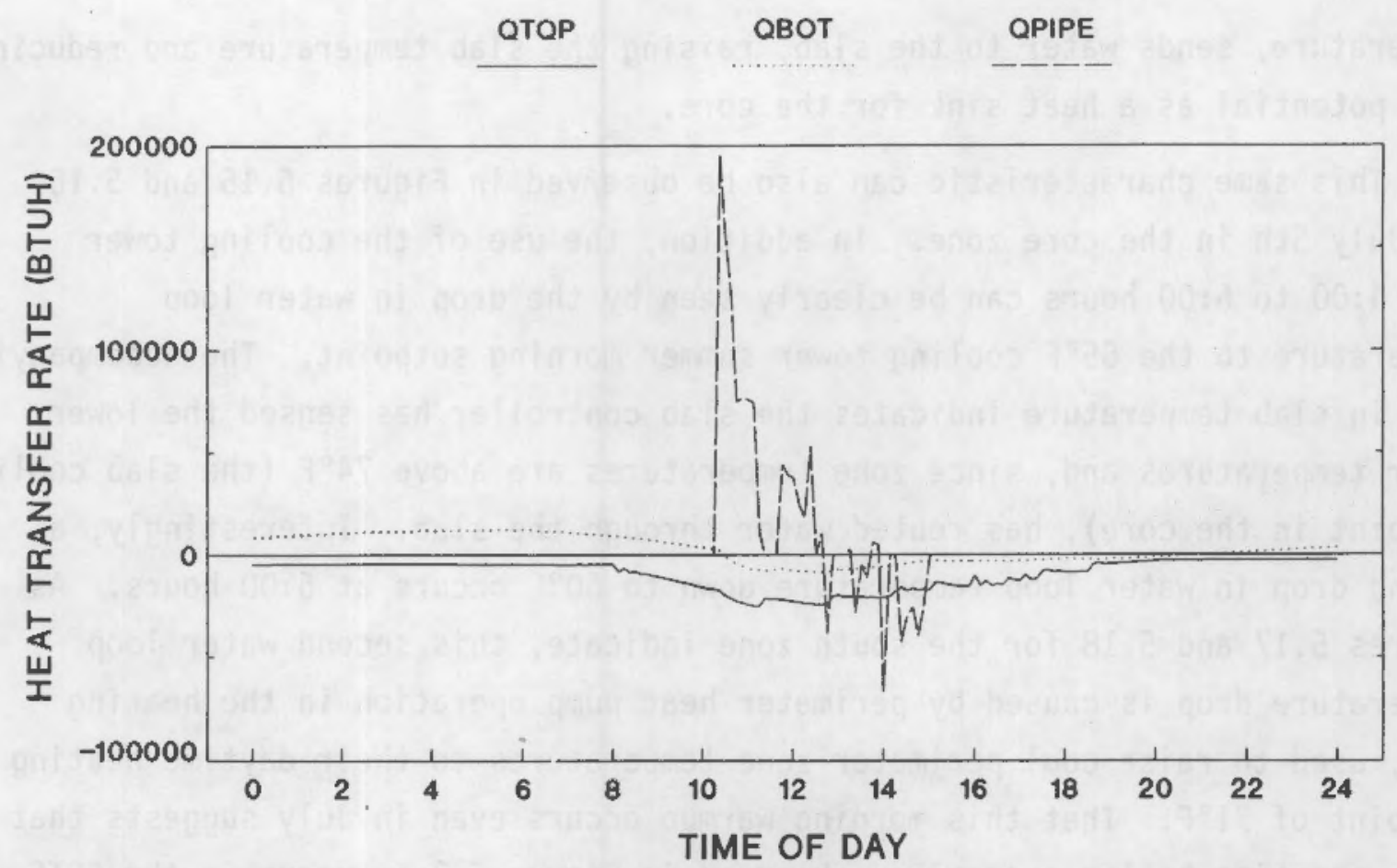

FIGURE 5.13. April 3rd Heat Transfer Rate History for the Core Zone of the Simulated Building with the BSTS System

TCORE

TSLAB

TWTR

TAMB

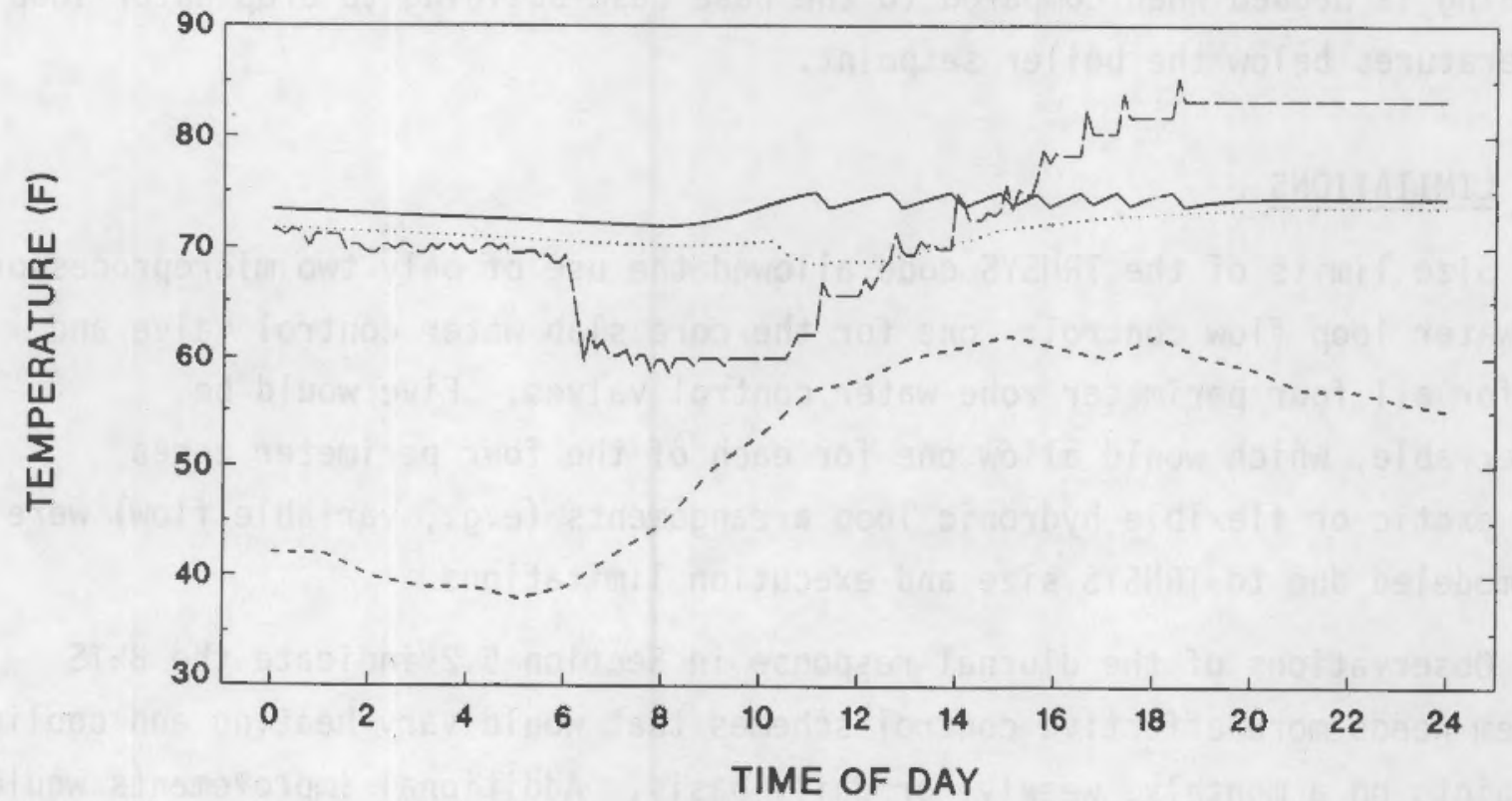

FIGURE 5.14. April 3rd Temperature History for the Core Zone of the Simulated Building with the BSTS System 
temperature, sends water to the slab, raising the slab temperature and reducing it's potential as a heat sink for the core.

This same characteristic can also be observed in Figures 5.15 and 5.16 for July 5th in the core zone. In addition, the use of the cooling tower from 4:00 to 6:00 hours can be clearly seen by the drop in water loop temperature to the $65^{\circ} \mathrm{F}$ cooling tower summer morning setpoint. The accompanying drop in slab temperature indicates the slab controller has sensed the lower water temperatures and, since zone temperatures are above $74^{\circ} \mathrm{F}$ (the slab cooling setpoint in the core), has routed water through the slab. Interestingly, a second drop in water loop temperature down to $60^{\circ} \mathrm{F}$ occurs at 6:00 hours. As Figures 5.17 and 5.18 for the south zone indicate, this second water loop temperature drop is caused by perimeter heat pump operation in the heating mode, used to raise cool perimeter zone temperatures to their daytime heating setpoint of $71^{\circ} \mathrm{F}$. That this morning warmup occurs even in July suggests that the summertime boiler operation, observed in Figure 5.3 to occur in the BSTS system building but not in the base case building, is caused because the cooling tower has lowered water loop temperatures to $65^{\circ} \mathrm{F}$ during the morning purge cycle; thus, less heat pump operation in heating mode in the BSTS system building is needed when compared to the base case building to drop water loop temperatures below the boiler setpoint.

\subsection{LIMITATIONS}

Size limits of the TRNSYS code allowed the use of only two microprocessors for water loop flow control: one for the core slab water control valve and one for all four perimeter zone water control valves. Five would be preferrable, which would allow one for each of the four perimeter zones. More exotic or flexible hydronic loop arrangements (e.g., variable flow) were not modeled due to TRNSYS size and execution limitations.

Observations of the diurnal response in Section 5.2 indicate the BSTS system needs more effective control schemes that would vary heating and cooling setpoints on a monthly, weekly, or daily basis. Additional improvements would be gained by using controls that dynamically respond to the needs of the zones. As modeled, water is supplied to the slab based on current zone temperature 


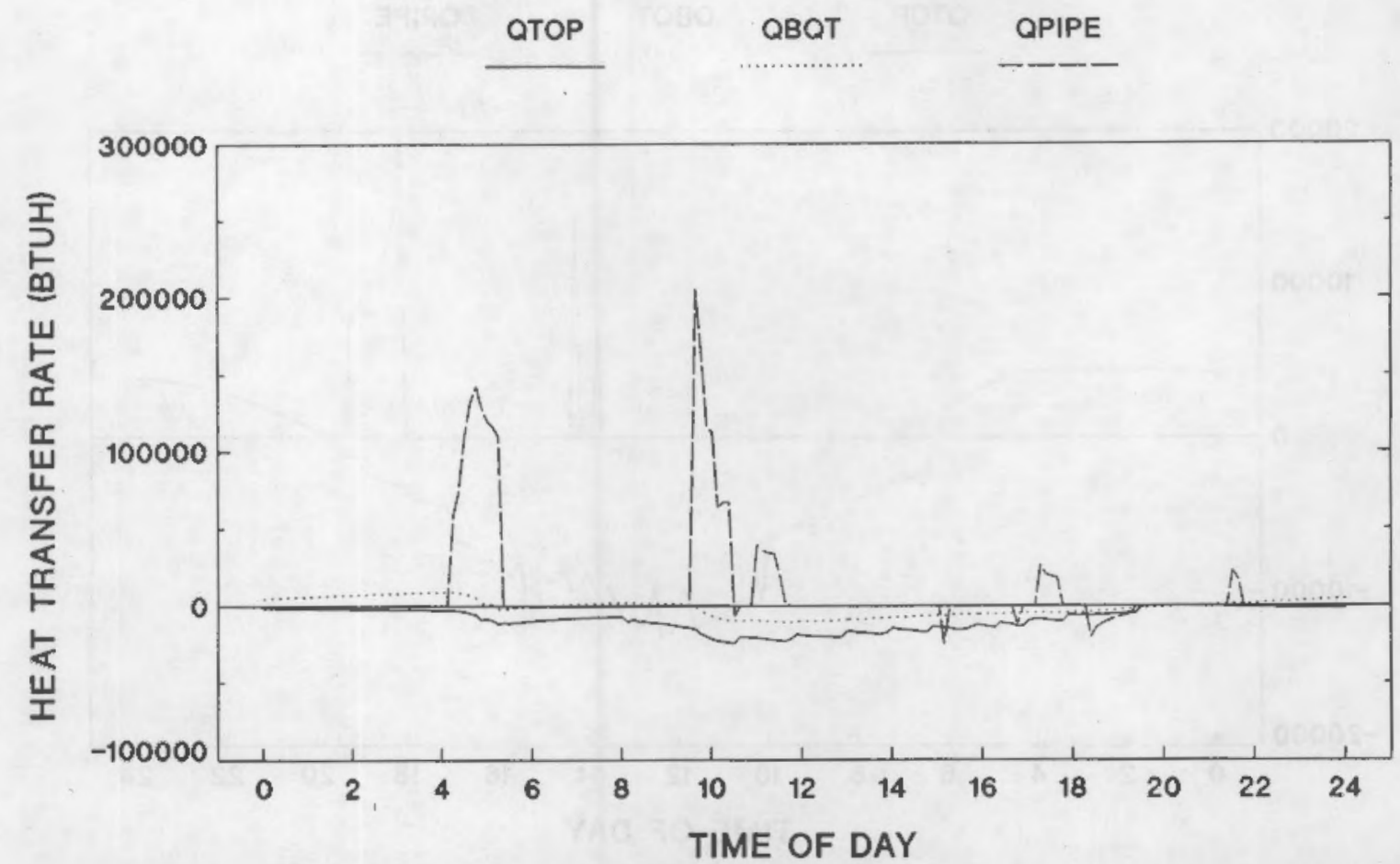

FIGURE 5.15. July 5th Heat Transfer Rate History for the Core Zone of the Simulated Building with the BSTS System
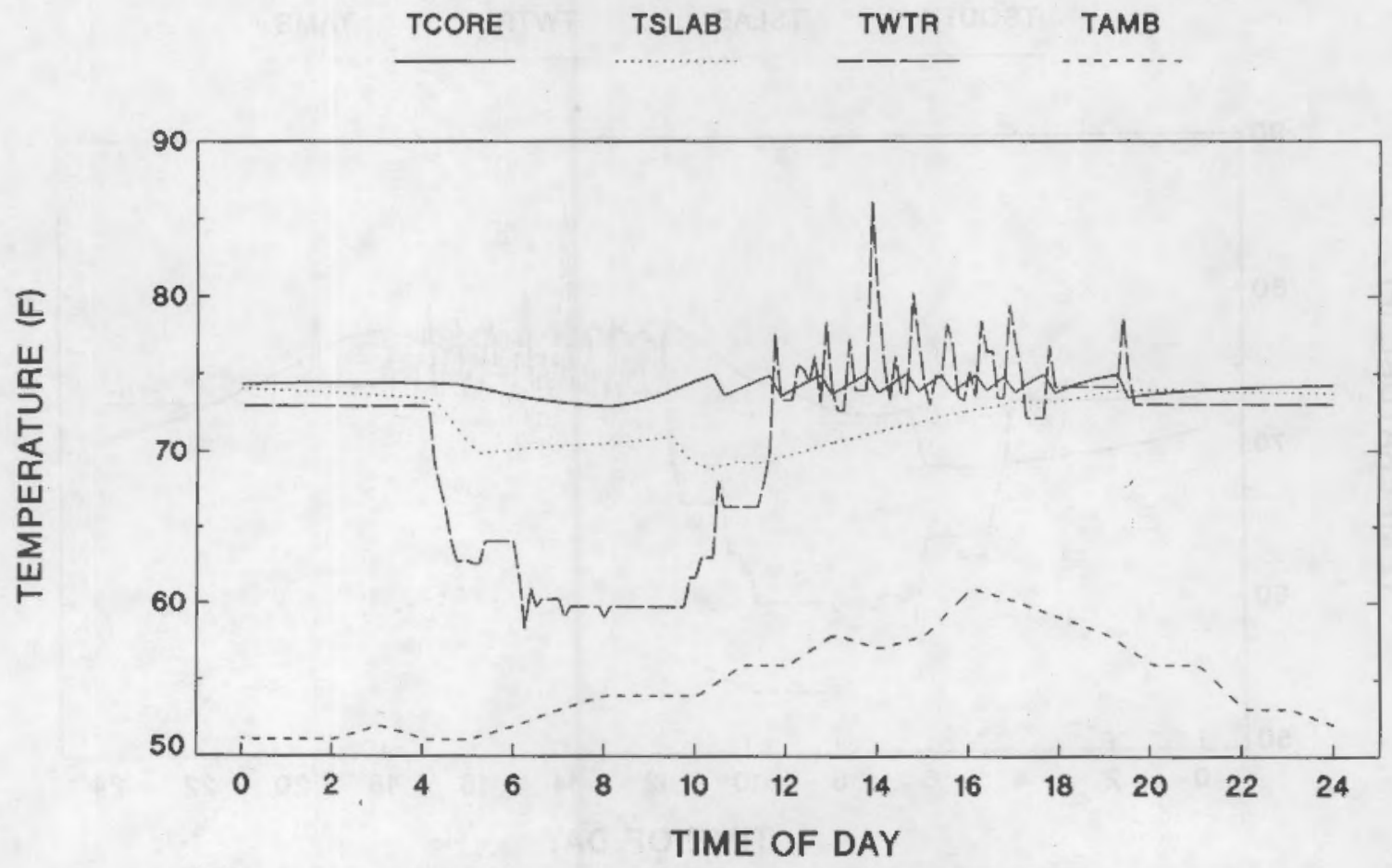

FIGURE 5.16. July 5th Temperature History for the Core Zone of the Simulated Building with the BSTS System 


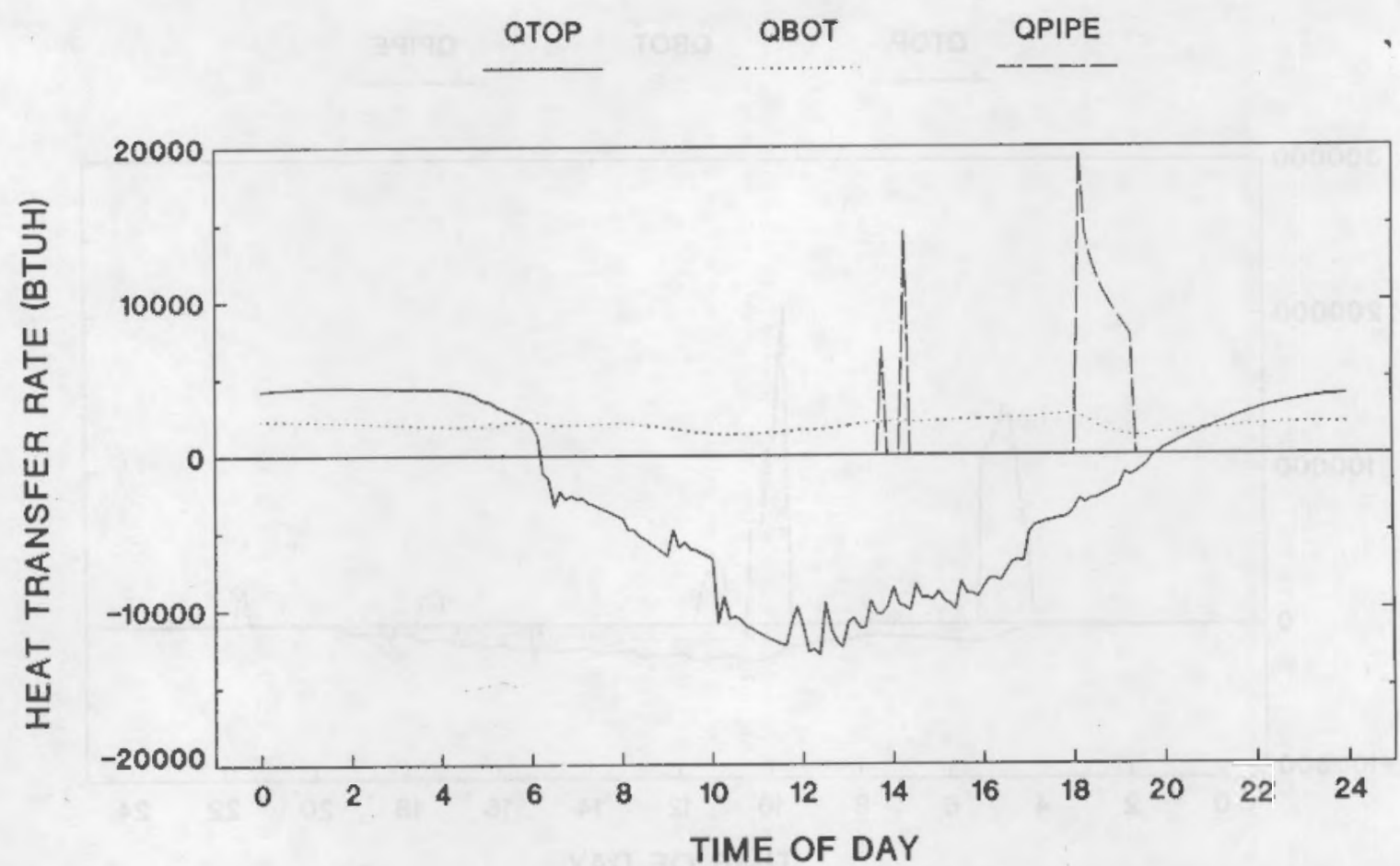

FIGURE 5.17. July 5th Heat Transfer Rate History for the South Zone of the Simulated Building with the BSTS System
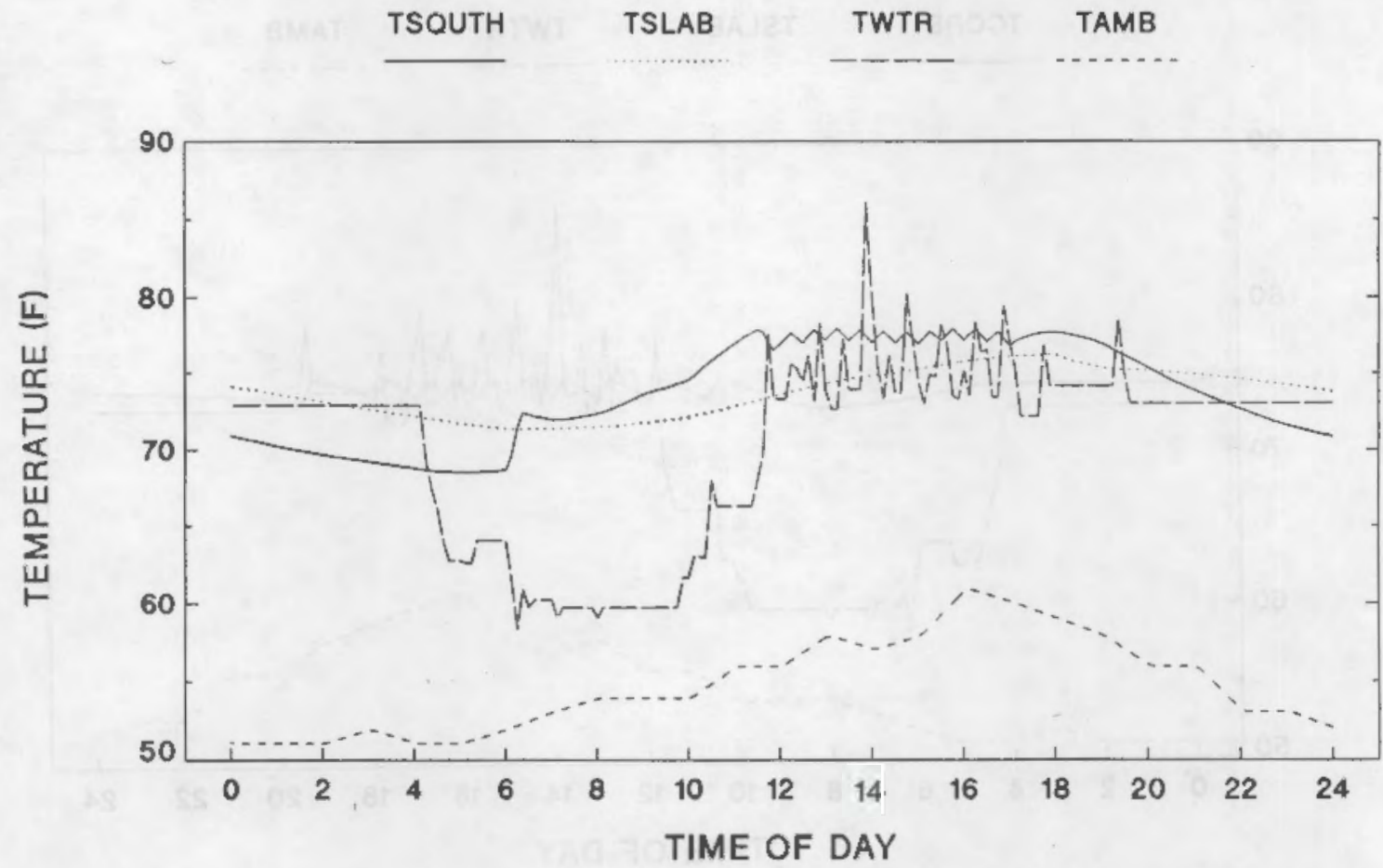

FIGURE 5.18. July 5th Temperature History for the South Zone of the Simulated Building with the BSTS System 
and current water loop temperature. The controls ignore the time-delayed response inherent in the heat capacitance of the slab when deciding whether routing available water to the slab would be beneficial. 


\subsection{EFFECTS OF CLIMATE ON BUILDING STRUCTURAL THERMAL STORAGE SYSTEM}

PERFORMANCE

Additional simulations modeling the same building were performed using TMY weather data from five additional cities; Los Angeles, Houston, El Paso, Washington, and Milwaukee. These cities were chosen because of their unique climatic conditions when compared to the temperate climate found in Seattle. Specifically, Milwaukee has a predominantly cold climate, El Paso and Los Angeles are hot and dry, Houston is hot and humid, while Washington is hot and humid in summer and cold in winter. Together, these cities typify fairly well the range of climatic conditions found across the U.S.; thus, performing the simulations in each of these locations provided quantitative insight as to where a BSTS system can be most effectively applied.

The approach used for assessing the effectiveness of the BSTS system in these different locations was as follows. First, the Seattle base case building model (reported on in Section 4.0) was simulated for an entire year in a new location with no other changes. The capacities for the boiler, cooling tower, and heat pumps were then adjusted if necessary so that zone temperature setpoints could be maintained during peak load conditions, and the simulation rerun. Next, the BSTS system used for the Seattle simulation (reported in Section 5.0) was incorporated into this adjusted base case model for the new location. Simulations were then performed in the new location for short winter and summer peak load periods to establish appropriate values for slab thermal properties and those water loop control parameters identified as being highly sensitive during the Seattle studies (see Section 5.0). Finally, an annual simulation of the building with this modified BSTS system was performed, and these results were compared to the base case building annual simulation results in the new location.

Figures 6.1 through 6.5 compare the total simulated HVAC monthly energy consumption for the base building in each of the five new locations to that of the same building with the BSTS system. In Figure 6.6, the total HVAC annual energy consumption is compared for all of the locations. Additional comparisons are shown in Appendix A and B for individual HVAC subsystem components. 


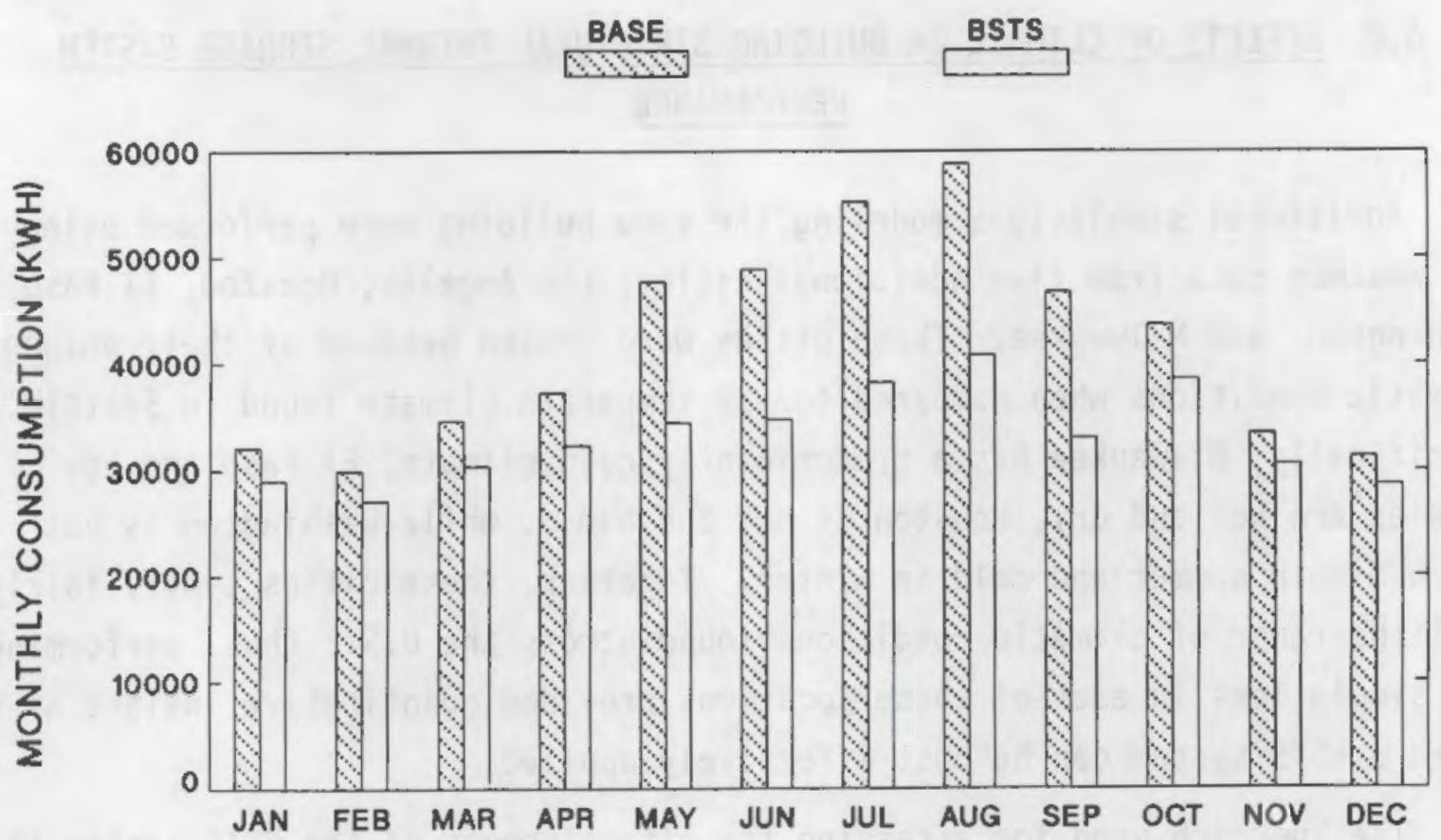

FIGURE 6.1. Total HVAC Monthly Energy Consumption for Simulated BSTS System Strategies, Los Angeles

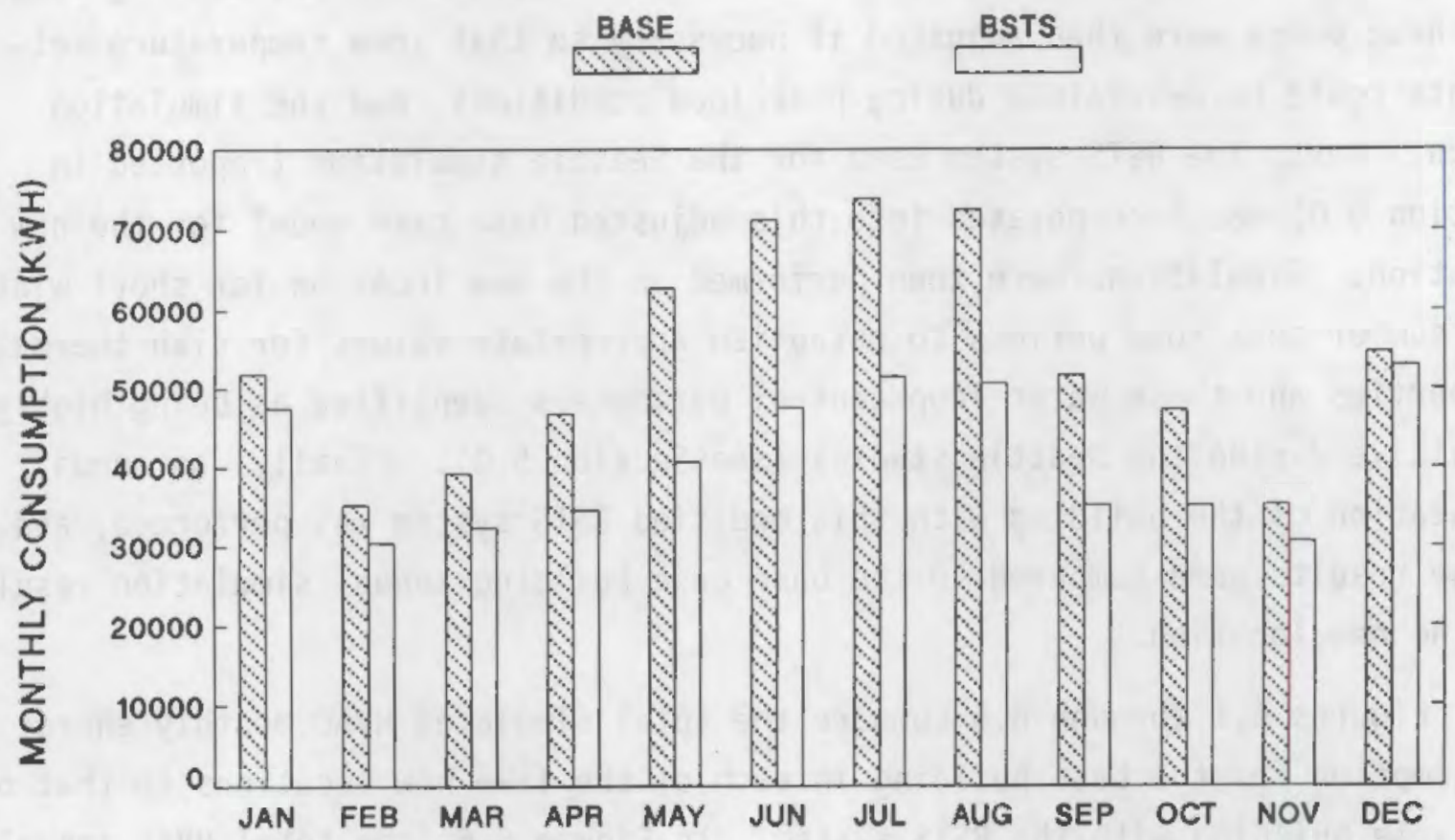

FIGURE 6.2. Total HVAC Monthly Energy Consumption for Simulated BSTS System Strategies, El Paso 

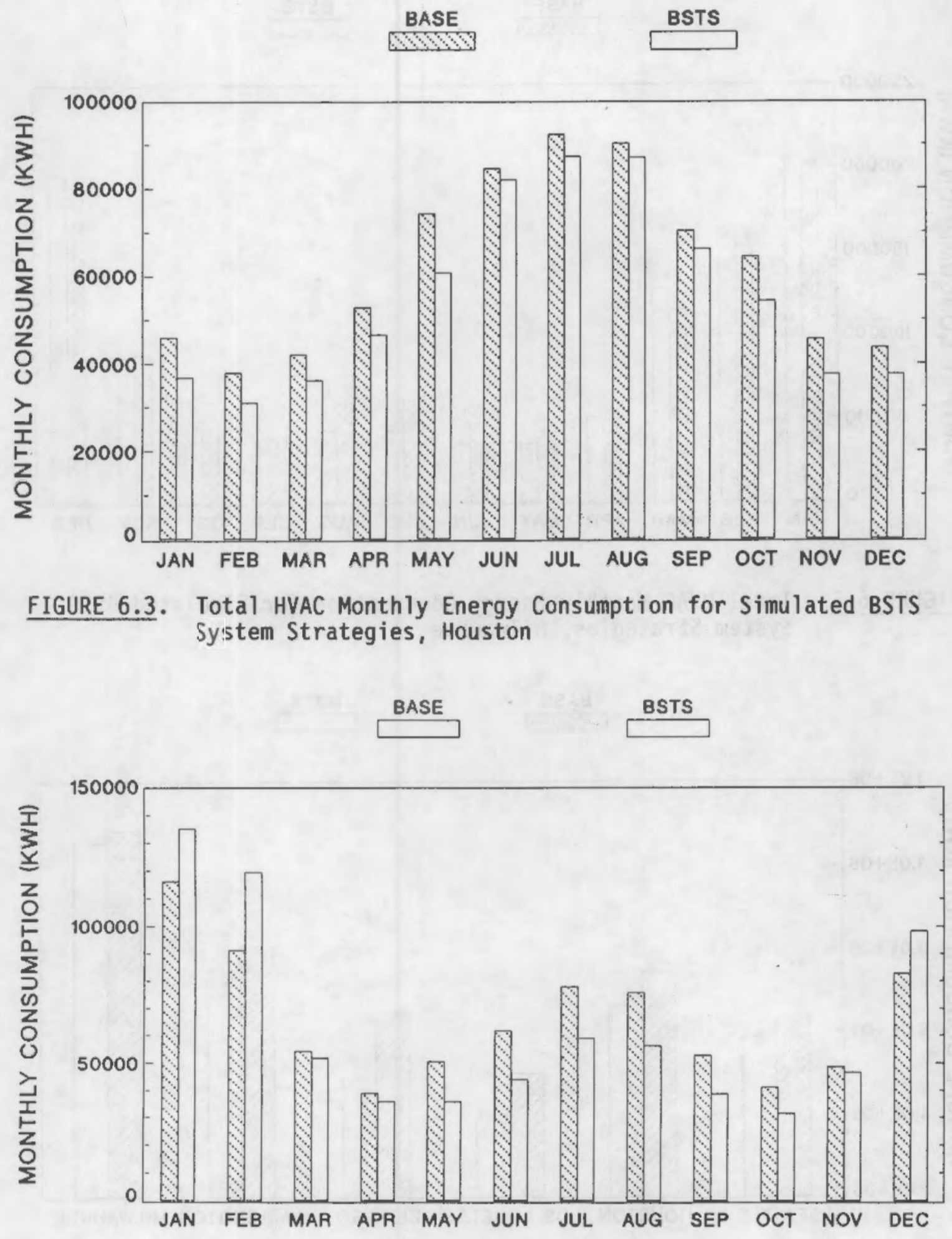

FIGURE 6.4. Total HVAC Monthly Energy Consumption for Simulated BSTS System Strategies, Washington, OC 


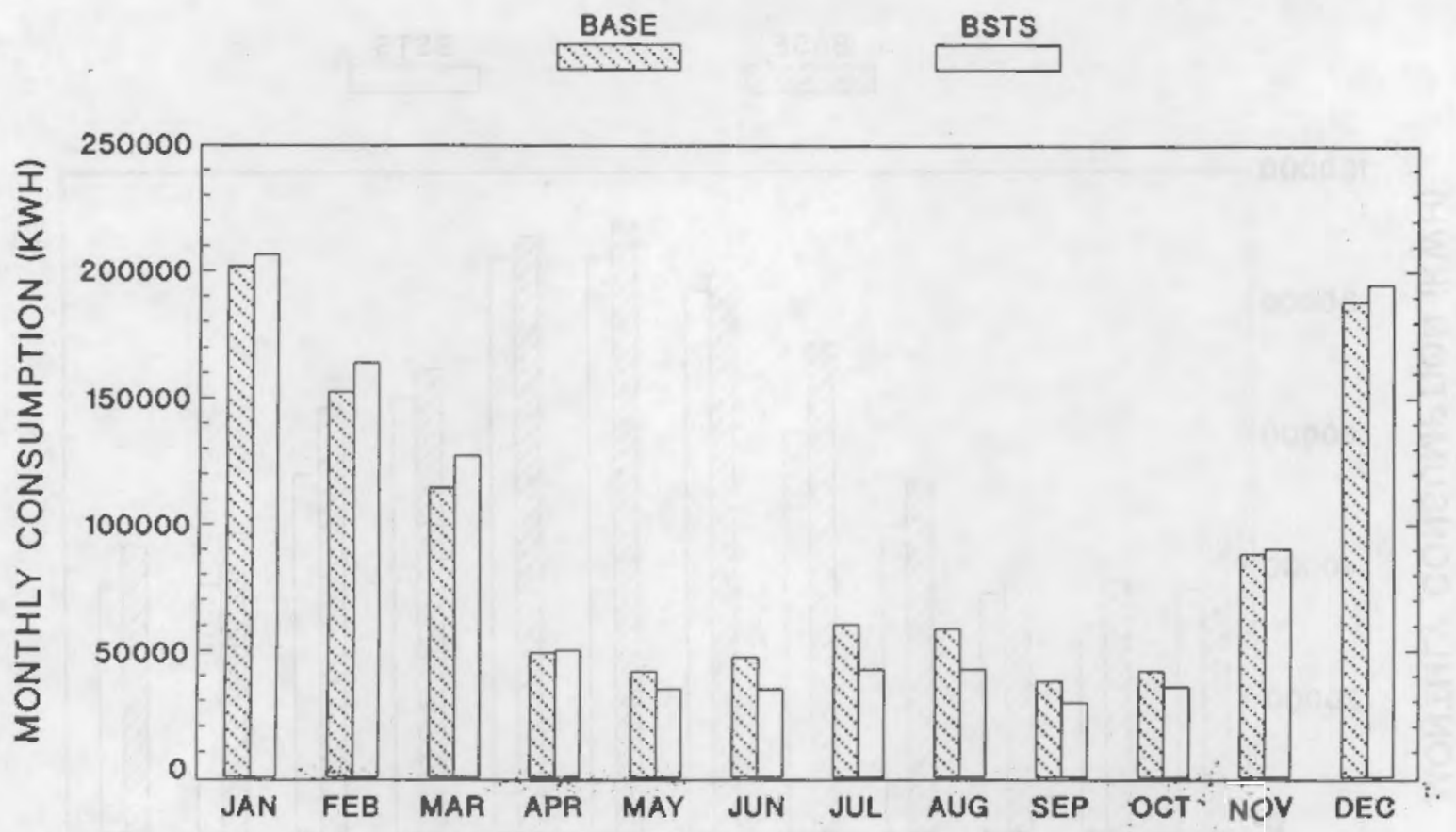

FIGURE 6.5. Total HVAC Monthly Energy Consumption for Simulated BSTS System Strategies, Milwaukee

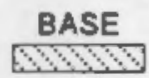

BSTS

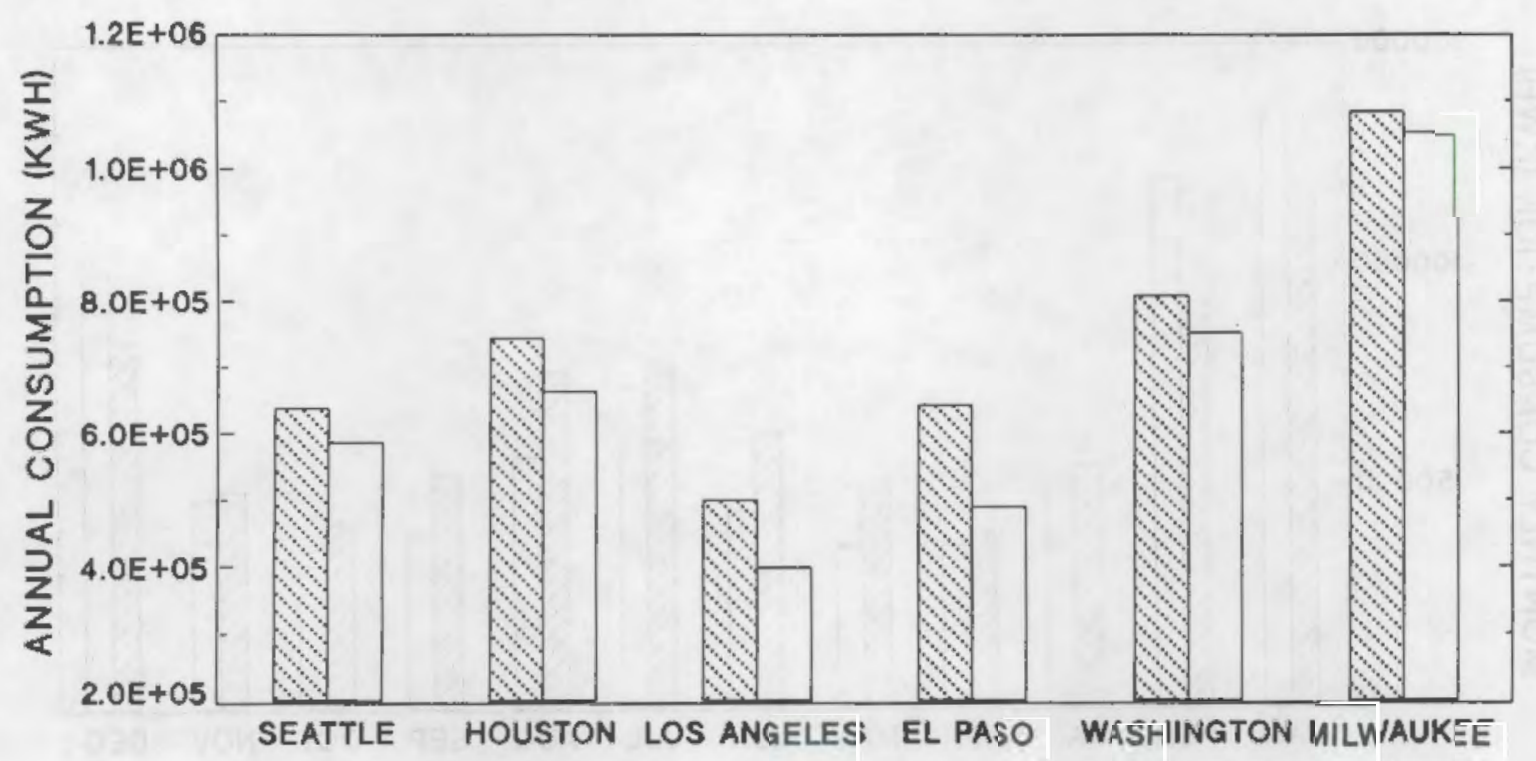

FIGURE 6.6. Total HVAC Annual Energy Consumption for Simulated BSTS System Strategies 
The energy-conserving effects of the BSTS system were found to be most pronounced in the hot, dry climates. El Paso and Los Angeles benefited greatly, with annual energy savings on the order of $30 \%$. A substantial fraction of these energy savings occurred during the May through September cooling period. Although also a hot climate, Houston did not fair as well because the higher wet-bulb temperatures found in Houston limited the ability of the cooling tower to reject heat; thus, water loop temperatures were higher, and the performance of the BSTS system was decreased. Energy savings in Washington D.C. were low due to cold winter conditions and high summer wet-bulb temperatures. The building with the BSTS system showed only minimal improvement in the cold climate of Milwaukee, achieving on the order of $3 \%$ annual energy savings. As was the case in Seattle, the BSTS system was found to actually increase energy consumption in winter months for Milwaukee and Washington, D.C.

This poor winter performance raised questions about winter operation of the BSTS system. It was observed through the simulations that though high slab mass improved summer performance, it hindered winter performance. This negative effect was in large part due to the fact that the higher slab mass meant additional heat was needed to warmup the space in the morning from the night setback point of $67^{\circ} \mathrm{F}$. In addition, a low cooling load was observed in the core zone in the coldest climates in winter. Because loop water temperatures were far below the BSTS system cooling setpoint, water would be routed through the slab to help cool the zone under these conditions. The time-lag caused by the thermal capacitance of the slab could often result in a significant overcooling of the slab, and thus the zone, to the point where heating would eventually be required by the heat pumps. This cycling between heating and cooling was due to limitations in the BSTS control scheme (see Section 5.3). To limit these winter penalties on performance, the BSTS system was shut off during cold winter months and the slab mass was chosen which provided the best tradeoff of summer and winter performance. 


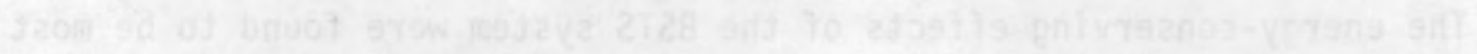

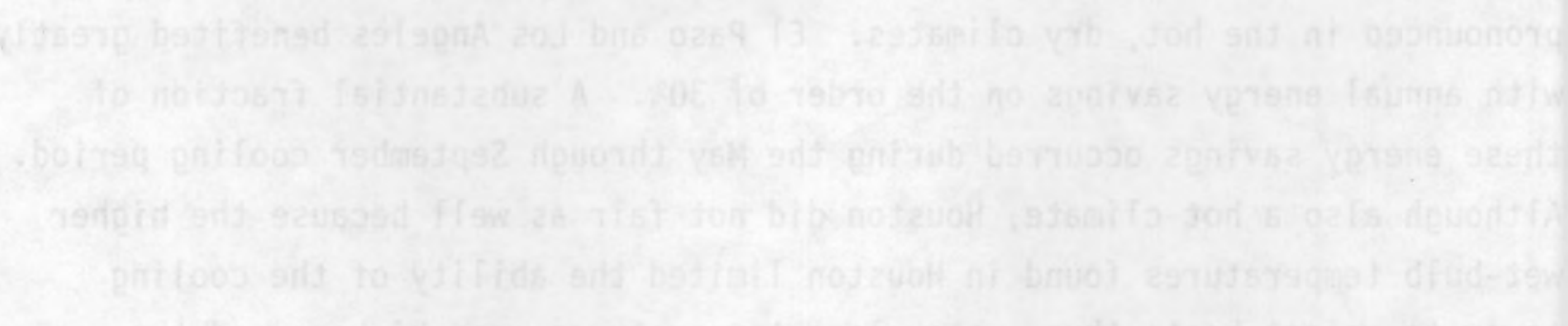

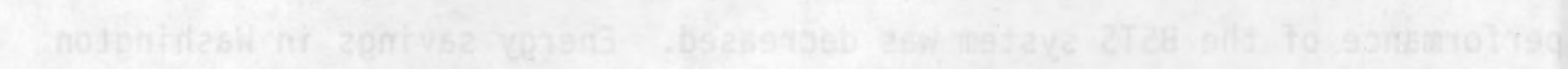

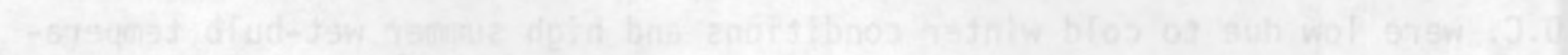

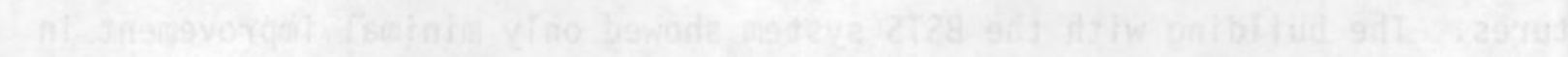

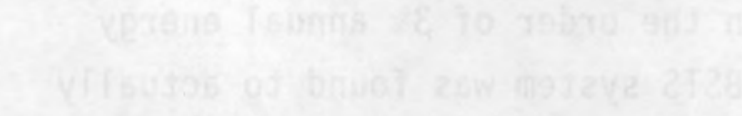

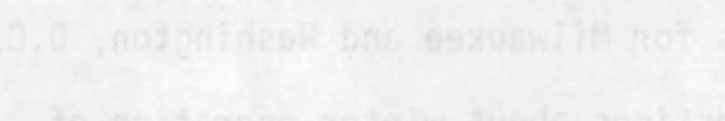

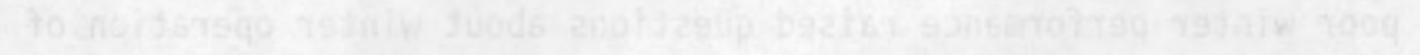

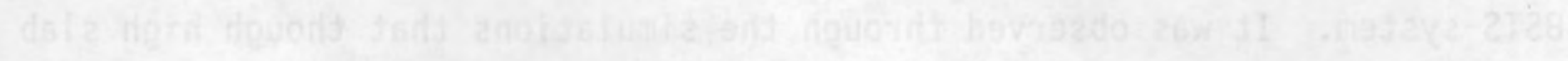




\subsection{CONCLUSIONS AND RECOMMENDATIONS}

The BSTS system was shown to be an energy-conserving system for the building modeled in this study when compared to identical buildings without the BSTS system. The HVAC annual energy savings predicted by the Transient System Simulation Program (TRNSYS) simulations for the building with the BSTS system used were found to vary significantly with climate, ranging from approximately $3 \%$ to $30 \%$. The BSTS system performed best in the hotter, drier climates of Los Angeles and El Paso, where summer cooling at lower ambient wet bulb temperatures dominate building energy use. More moderate benefits were achieved in Houston, Seattle, and Washington, D.C. Little gain in annual performance was found in the Milwaukee climate simulation. In general, the BSTS system is beneficial whenever hot and dry summer outdoor air conditions exist. The benefits in cold climate regions, on the other hand, appear to be limited.

Further energy savings may be possible if every facet of the BSTS system was optimized fully for every climate region tested. The optimization for each climate of all important BSTS system model parameters identified using sensitivity studies for the Seattle climate region was beyond the scope of this research. Thus, when a new climate was studied after the Seattle simulations, building models of both the reported base case building and the building with the BSTS system added were essentially those used in Seattle.

Indeed, a truly optimized BSTS system is still needed even for Seattle, because of the limitations inherent in the computer model used. Improved HVAC control schemes were desired, but could not be constructed from modules available in TRNSYS, primarily because of size limitations and excessive computer processing time. The interactions of the BSTS system occurring in the winter mode and cold climates were sensitive to the controls employed. Intelligent, adaptive/predictive controls for truly thermally efficient water loop flow control in core and perimeter zones would improve performance, but would entail significant new code development.

Mean radiant temperatures (MRT) were not analyzed. The space temperature set points used in the simulations do not take into account the MRT effect of 
the floor slab system. An analysis of this is recommended to determine if the effect of MRT would further reduce energy consumption.

Another issue not addressed by this study is the effect of the BSTS system on cooling/heating peak electrical demand, because actual building electrical billing rates are dependent on both demand and total overall consumption. Although thermal storage did occur, it was low temperature storage and it is uncertain if this could significantly shift energy consumption during peak hours to off-peak hours.

Finally, it should be reiterated that the BSTS system has been applied to only a single building with a single type of HVAC subsystem. Future studies must address the potential cost and energy effectiveness of the BSTS system in other building designs, so that designers and owners will be able to determine whether integrating the HVAC subsystems with the building mass makes sense for their needs. 


\subsection{REFERENCES}

American Society of Heating, Refrigeration and Air Conditioning Engineers (ASHRAE), Inc. 1988. ASHRAE Handbook of Equipment. ASHRAE, New York.

Andersson, L. 0., K. G. Bernander, E. Isfält and A. H. Rosenfeld. 1979. Storage of Heat and Coolth in Hollow-Core Concrete Slabs. Swedish Experience and Application to Large, American Style Buildings. Lawrence Berkeley Laboratory, Berkeley, California.

Braun, J. E., J. W. Mitchell, and S. A Klein. 1987. "Performance and Control Characteristics of a Large Cooling System." ASHRAE Transactions. 93(1).

Cleary, C., and B. Crimmin. 1986. Commercial Hourly End-Use Study Status Report 1982 - 1985. Seattle City Light.

Eto, J. H. 1985. "Cooling Strategies Based on Indicators of Thermal Storage in Commercial Building Mass." Presented at the Second Annual Symposium on Improving Building Energy Efficiency in Hot and Humid Climates, September, 1985, Texas A\&M University, College Station, Texas.

Rogers, T. W. 1980. "Thermal Storage and Water Source Heat Pumps in Canada." ASHRAE Transactions. 86(2):731-740.

Shell Chemical Company. 1984. Radiant Heating: The Ideal System for Comfortable, Cost-Efficient Buildings. Houston, Texas.

Solar Energy Laboratory, University of Wisconsin-Madison. 1983. A Transient System Simulation Program, Version 12.1.

Solar Heating and Cooling. 1979. "Builder Develops Heating-Cooling System." December.

Whillier, A. 1976. "A Fresh Look at the Calculation of Performance of Cooling Towers." ASHRAE Transactions. 82(1):269-282. 


\subsection{BIBLIOGRAPHIC LIST OF BUILDING SYSTEMS INTEGRATION RESEARCH REPORTS}

PNL-4358

PNL-4435

PNL-5123

PNL-5143 Vol. I

PNL-5143 Vol. 11

PNL -5143 Vol. III

PNL-5143 Vol. IV

PNL-4870-1

through 40

PNL-5027
Pacific Northwest Laboratory, Project Plan, Development of Recommendations to Upgrade ASHRAE/IES Standard 90A1980 "Energy Conservation in New Building Design, Pacific Northwest Laboratory, Richland, Washington. June 1982.

W. M. Bowen, S. Moreno, A. R. 0lsen, Climate Selection and Development of $\mathrm{Cl}$ imate Indicators, Pacific Northwest Laboratory, Richland, Washington. September 1982.

J. L. Stoops, J. J. Deringer, S. Moreno, H. P. Misuriello, Summary Report: The BEPS Redesign of 168 Commercial Buildings, Pacific Northwest Laboratory, Richland, Washington. May 1984.

A. R. 01sen, S. Moreno, J. J. Deringer, C. R. Watson, Weather Data for Simplified Energy Calculation, Volume I. Eastern United States: TRY Data, Pacific Northwest Laboratory, Richland, Washington. August 1984.

A. R. 01 sen, S. Moreno, J. J. Deringer, C. R. Watson, Weather Data for Simplified Energy Calculation, Volume II. Middle United States: TRY Data, Pacific Northwest Laboratory, Richland, Washington. August 1984.

A. R. 0lsen, S. Moreno, J. J. Deringer, C. R. Watson, Weather Data for Simplified Energy Calculation, Volume III. Western United States: TRY Data, Pacific Northwest Laboratory, Richland, Washington. August 1984.

A. R. 01sen, S. Moreno, J. J. Deringer, C. R. Watson, Weather Data for Simplified Energy Calculation, Volume IV. United States: WYEC Data, Pacific Northwest Laboratory, Richland, Washington. August 1984.

R. W. Reilly, Recommendations for Energy Conservations Standards and Guidelines for New Commercial Buildings, Pacific Northwest Laboratory, Richland, Washington. October 1984.

Burt Hill Kosar Rittelmann Associates, Small Office Building Handbook: Design for Reducing First Costs \& Utility Costs, Van Nostrand Reinhold, New York, New York. January 1985.

J. A. Heidell, R. P. Mazzucchi, R. W. Reilly, Commercial Building End-Use Energy Metering Inventory, Pacific Northwest Laboratory, Richland, Washington. April 1985. 
C. Claar, R. P. Mazzucchi, J. A. Heidell, Project on Restaurant Energy Performance End-Use Monitoring, Pacific Northwest Laboratory, Richland, Washington. June 1985.

PNL-5462

Appendices

PNL-5696

PNL-5709

$\star \star$

DOE/CE-0166 Vol.1

DOE/CE-0166 Vol.2

DOE/CE-0166 Vol.3

D0E/CE-0166 Vol.4

PNL-5854 Vol.1
C. Claar, R. P. Mazzucchi, J. A. Heide11, Project on Restaurant Energy Performance End-Use Monitoring, Pacific Northwest Laboratory, Richland, Washington. June 1985.

R. W. Reilly, Recommendations for a Multi-Year Plan for Building Systems Integration Research, Pacific Northwest Laboratory, Richland, Washington. January 1986.

J. A. Heidell, J. J. Deringer, Developing an Energy Design Tool -- Phase I Report, Pacific Northwest Laboratory, Richland, Washington. February 1987.

National Association of Home Builders, Cutting Costs in Mulitfamily Housing: Case Studies in Energy Savings, National Association of Home Builders, Washington, D.C. August 1986.

G. L. Wilfert, J. W. Callaway, Environmental Assessment: Proposed Interim Energy Conservation Standards for New Commercial and Multifamily High Rise Buildings. U.S. Department of Energy, Washington, D.C. November 1986.

J. M. Roop, Economic Analysis: Proposed Interim Energy Conservation Standards for New Commercial and Multifamily High Rise Buildings. U.S. Department of Energy, Washington, D.C. November 1986.

Volume 3 of 4. D. B. Crawley, P. D. Gilbride, Envelope System Performance Compliance Calculation Program Documentation - Version 1.0. U.S. Department of Energy, Washington, D.C. November 1986.

Volume 4 of 4 . D. B. Crawley, E. G. Stephan, Lighting Prescription and System Performance Compliance Calculation Program Documentation - Version 1.0. U.S. Department of Energy, Washington, D.C. November 1986.

D. B. Crawley, R. S. Briggs, J. W. Jones, W. W. Seaton, J. E. Kaufman, J. J. Deringer, E. W. Kennett, Development of Whole-Building Energy Design Targets for Commercial Buildings -- Phase 1 Planning, Volume 1: Final Report, Pacific Northwest Laboratory, Richland, Washington. April 1987. 
PNL-5854 Vol.2 D. B. Crawley, R. S. Briggs, J. W. Jones, W. W. Seaton, J. E. Kaufman, J. J. Deringer, E. W. Kennett, Development of Whole-Building Energy Design Targets for Commercial Buildings -- Phase 1 Planning, Volume 2: Technical Report, Pacific Northwest Laboratory, Richland, Washington. September 1987.

PNL -6255

M. R. Brambley, D. B. Crawley, D. D. Hostetler, R. C. Stratton, M. S. Addison, J. J. Deringer, J. D. Hall, S. E. Selkowitz, Advanced Design and Operation Technologies Research--Recommendations for a U.S. Department of Energy Multi-Year Program Plan Pacific Northwest Laboratory, Richland, Washington. December 1988.

PNL-6751

T. J. Marseille, B. K. Johnson, R. P. Wallin, S. A. Chiu, D. B. Crawley, Initial Findings: The Integration of Water Loop Heat Pump and Building Structural Mass Storage Systems, Pacific Northwest Laboraratory, Richland, Washington. January 1989.

* Available directly from the publisher:

Van Nostrand Reinhold, New York, New York.

** Available directly from the publisher: National Association of Home Builders, washington, D.C.

All Other Research Reports are Available from:

National Technical Information Service

U.S. Department of Commerce

5285 Port Royal Road

Springfield, VA 22161 


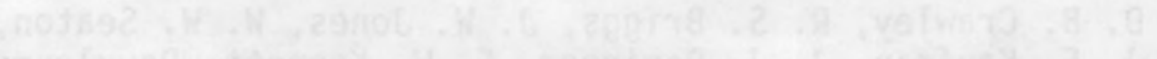

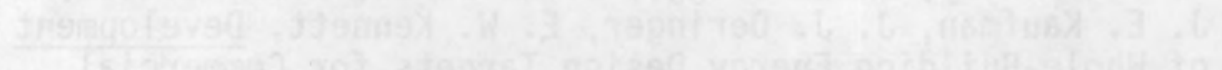

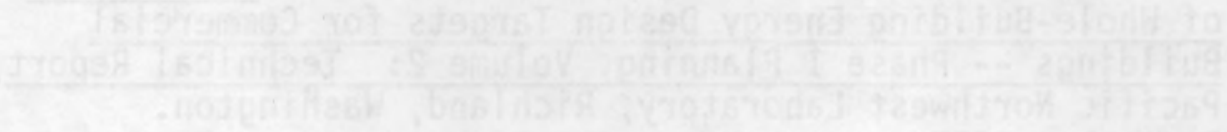

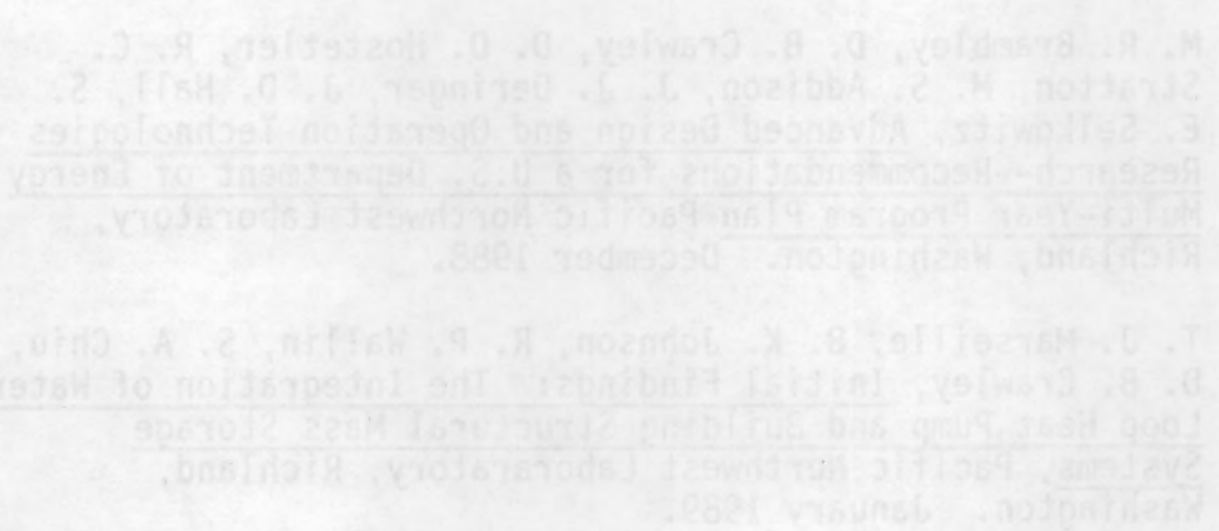

$2 a 5 d-515$

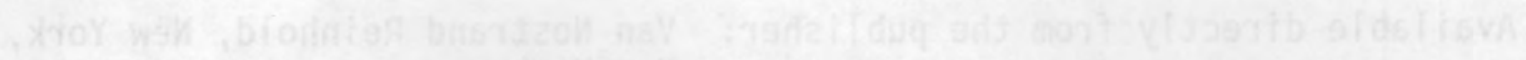

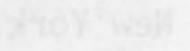


mONTHLY ENERGY CONSUMPTION FOR HVAC COMPONENTS 


\section{MONTHLY ENERGY CONSUMPTION FOR HVAC COMPONENTS}

The following bar graphs portray simulated monthly energy consumption results of HVAC system components for five U.S. cities in both the base case building model and the base case building model with the Building Structural Thermal Storage (BSTS) system added. This information is supplementary to Section 6.0 of the main report, in which total building energy consumption results are presented. The five cities are Los Angeles, El Paso, Houston, Washington, and Milwaukee.

In Figures A.1 through A.5, the total heat pump monthly energy consumption for each city is presented. Following these, Figures A.6 through A.9 are for the boiler (no boiler operation was required in Los Angeles), and Figures A.10 through A.14 are for the cooling tower.

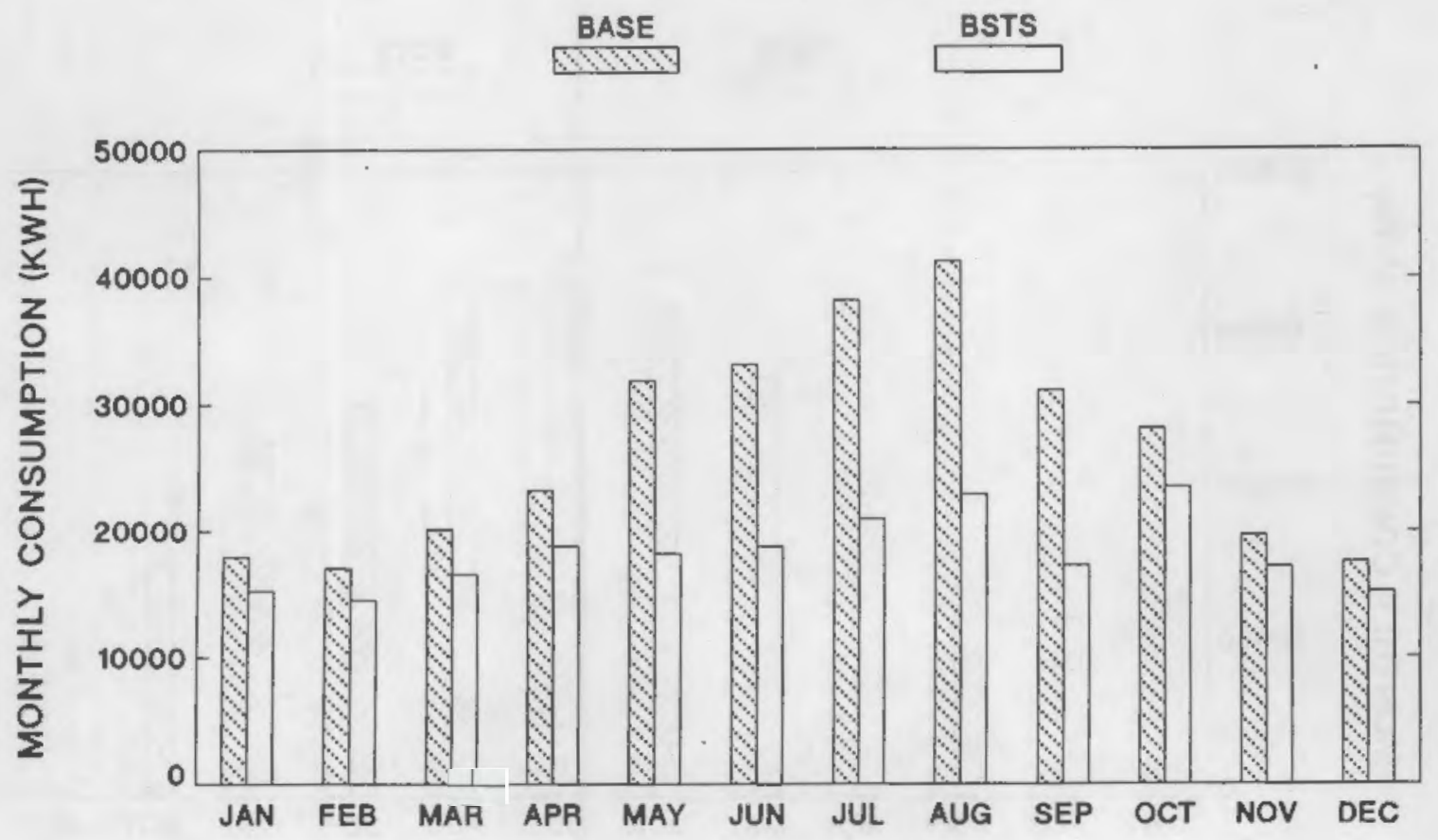

FIGURE A.1. Heat Pump Monthly Energy Consumption for Simulated BSTS System Strategies, Los Angeles 


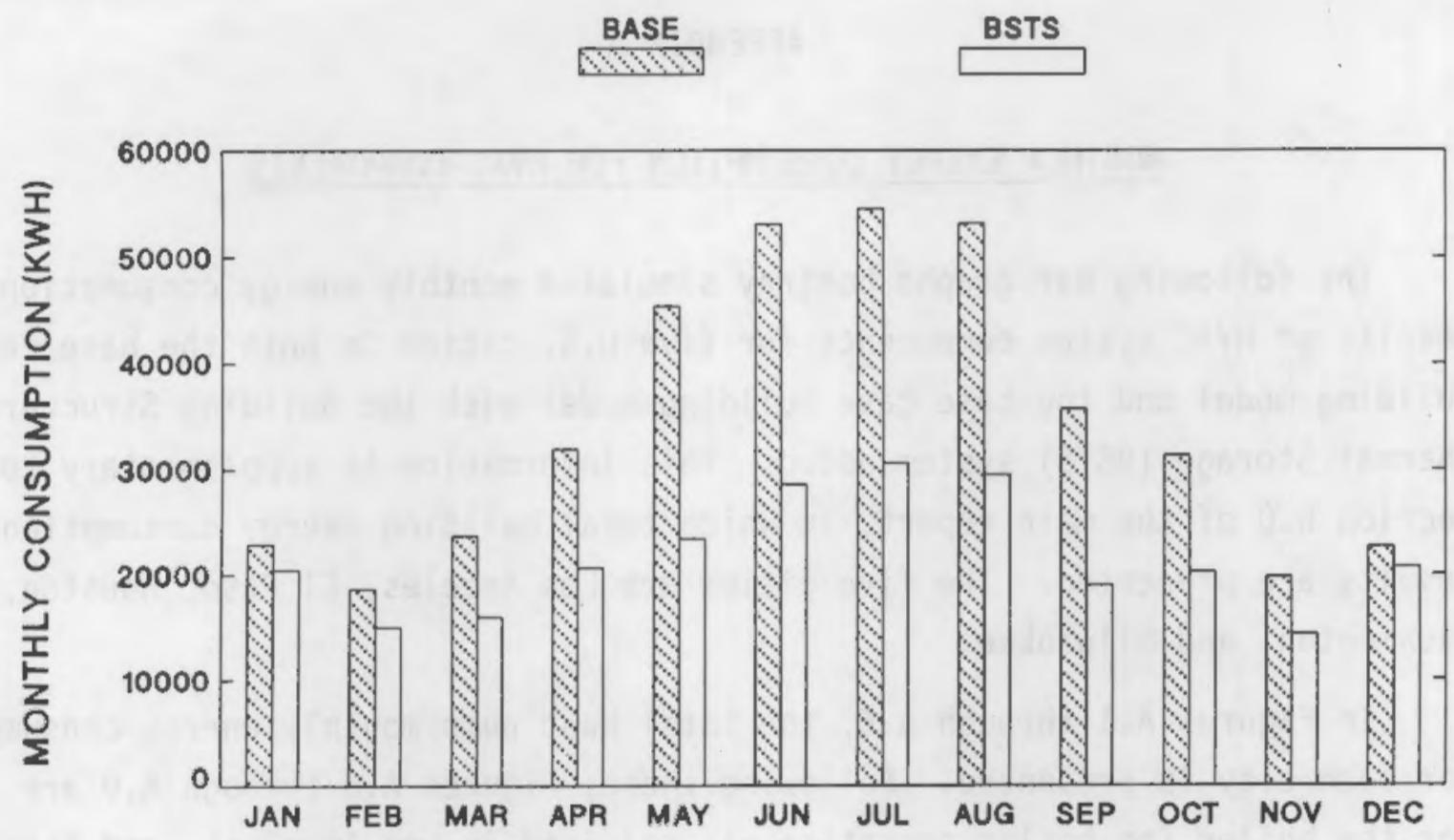

FIGURE A.2. Heat Pump Monthly Energy Consumption for Simulated BSTS System Strategies, El Paso
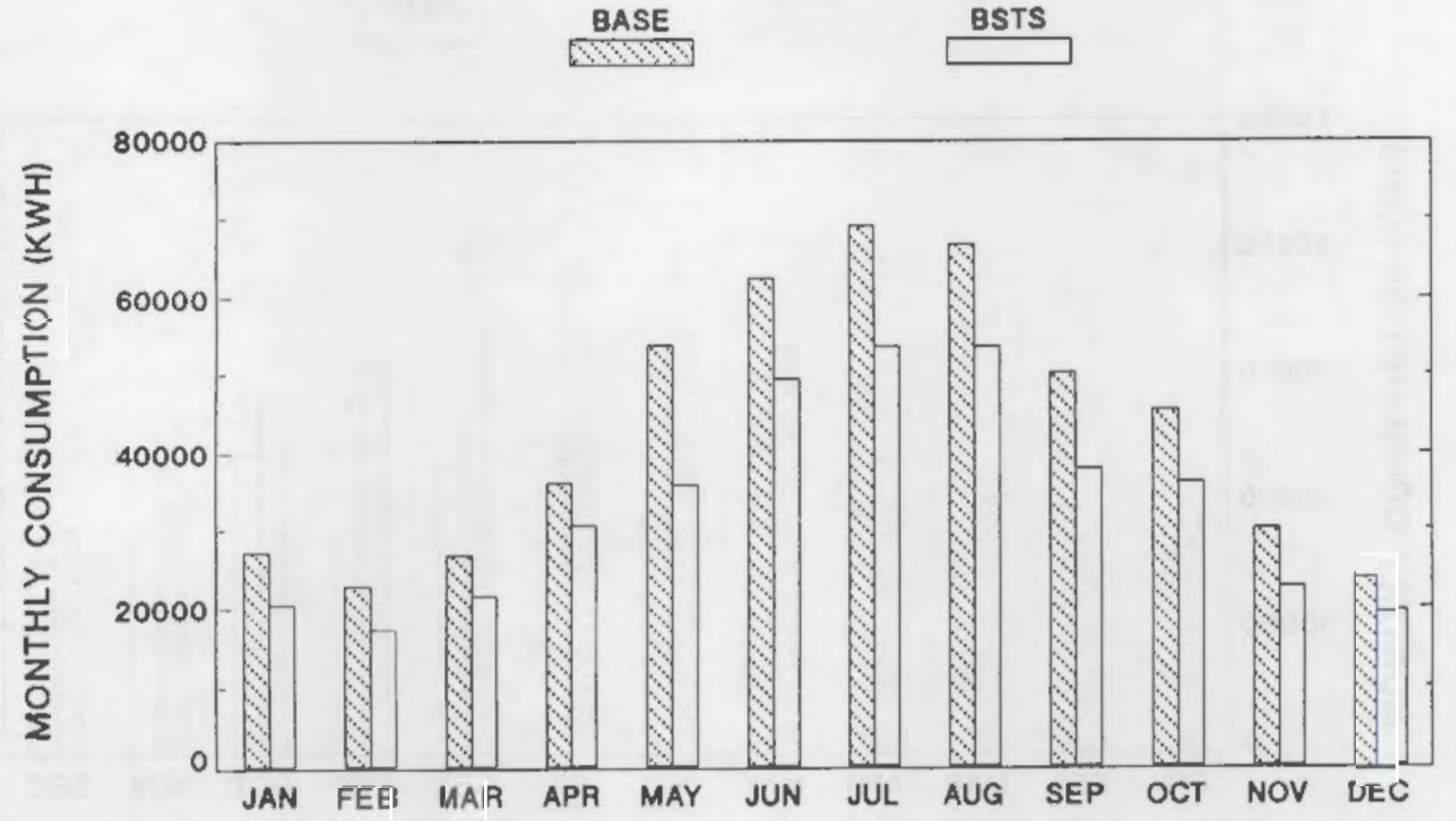

FIGURE A.3. Heat Pump Monthly Energy Consumption for Simulated BSTS System Strategies, Houston 


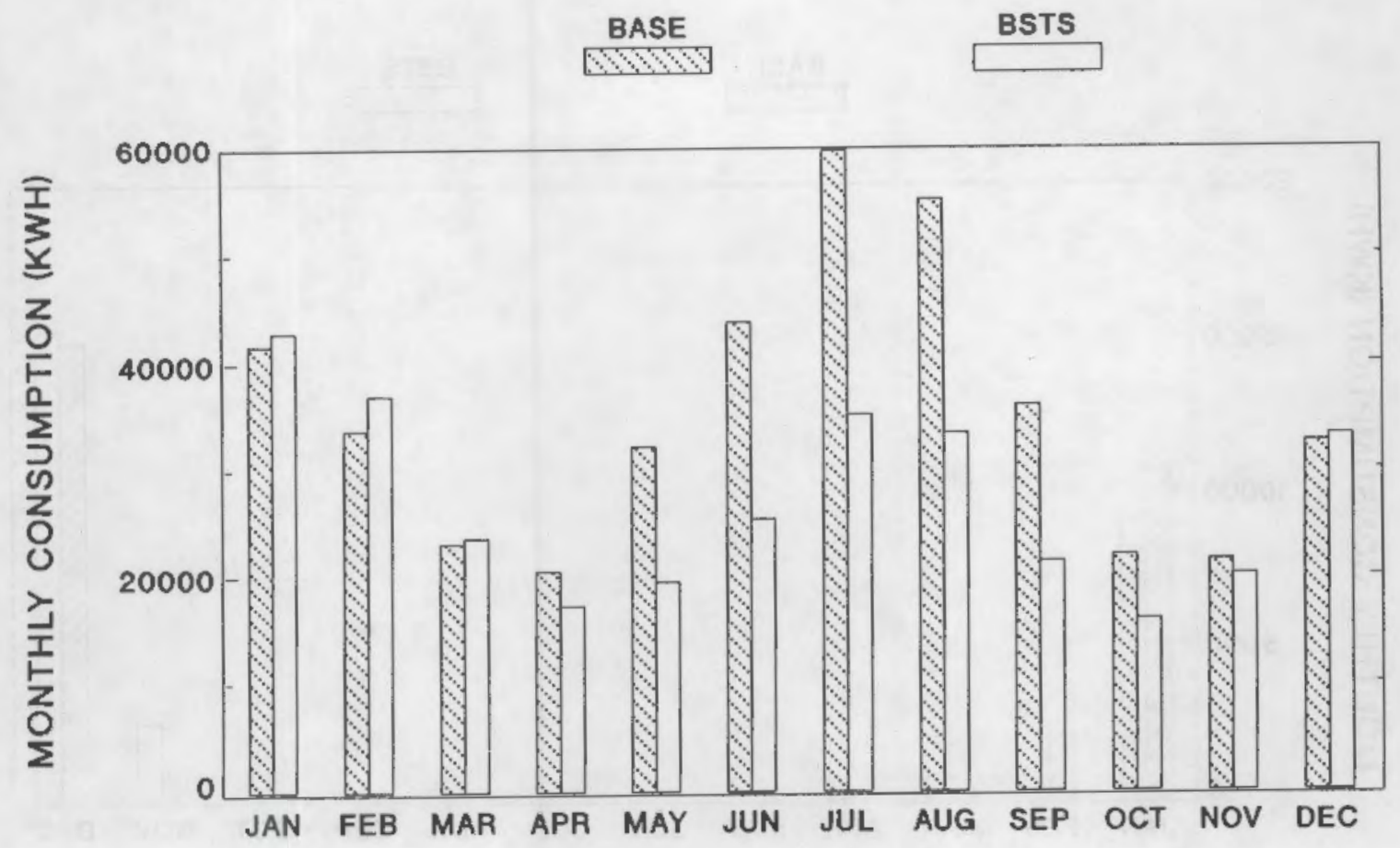

FIGURE A.4. Heat Pump Monthly Energy Consumption for Simulated BSTS System Strategies, Washington, D.C.

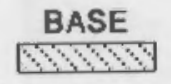

BSTS

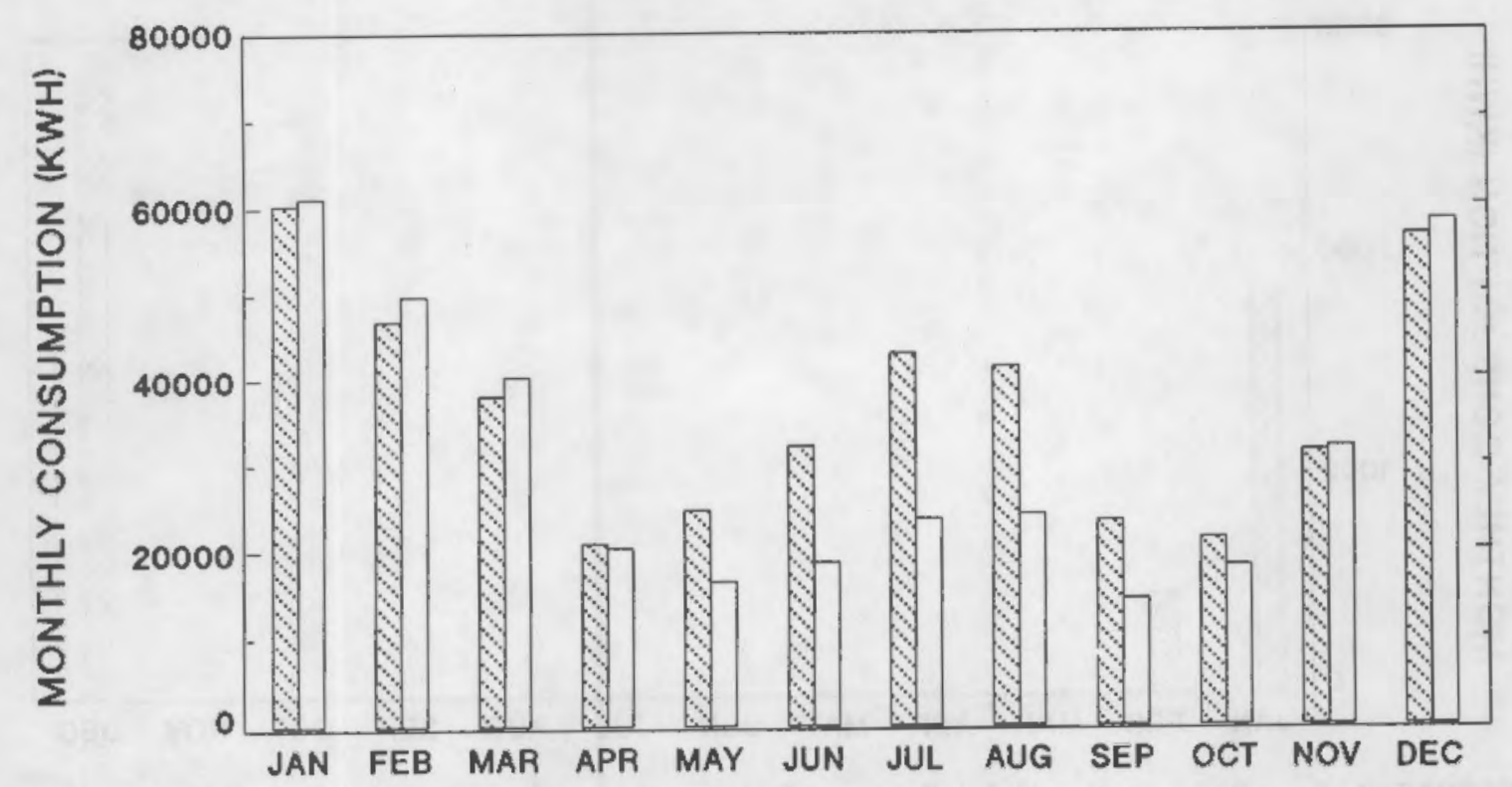

FIGURE A.5. Heat Pump Monthly Energy Consumption for Simulated BSTS System Strategies, Milwaukee 


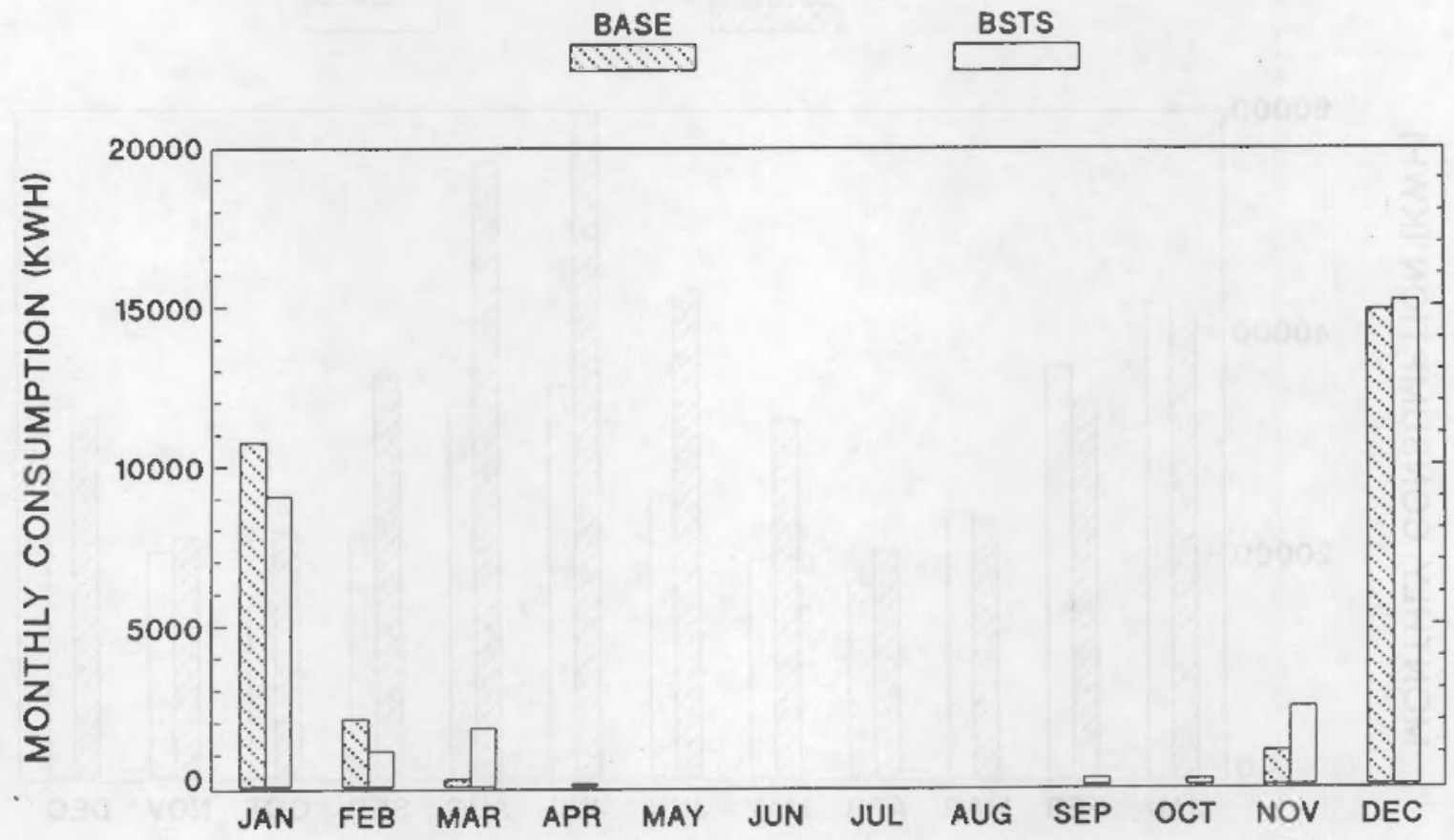

FIGURE A.6. Boiler Monthly Energy Consumption for Simulated BSTS System Strategies, El Paso

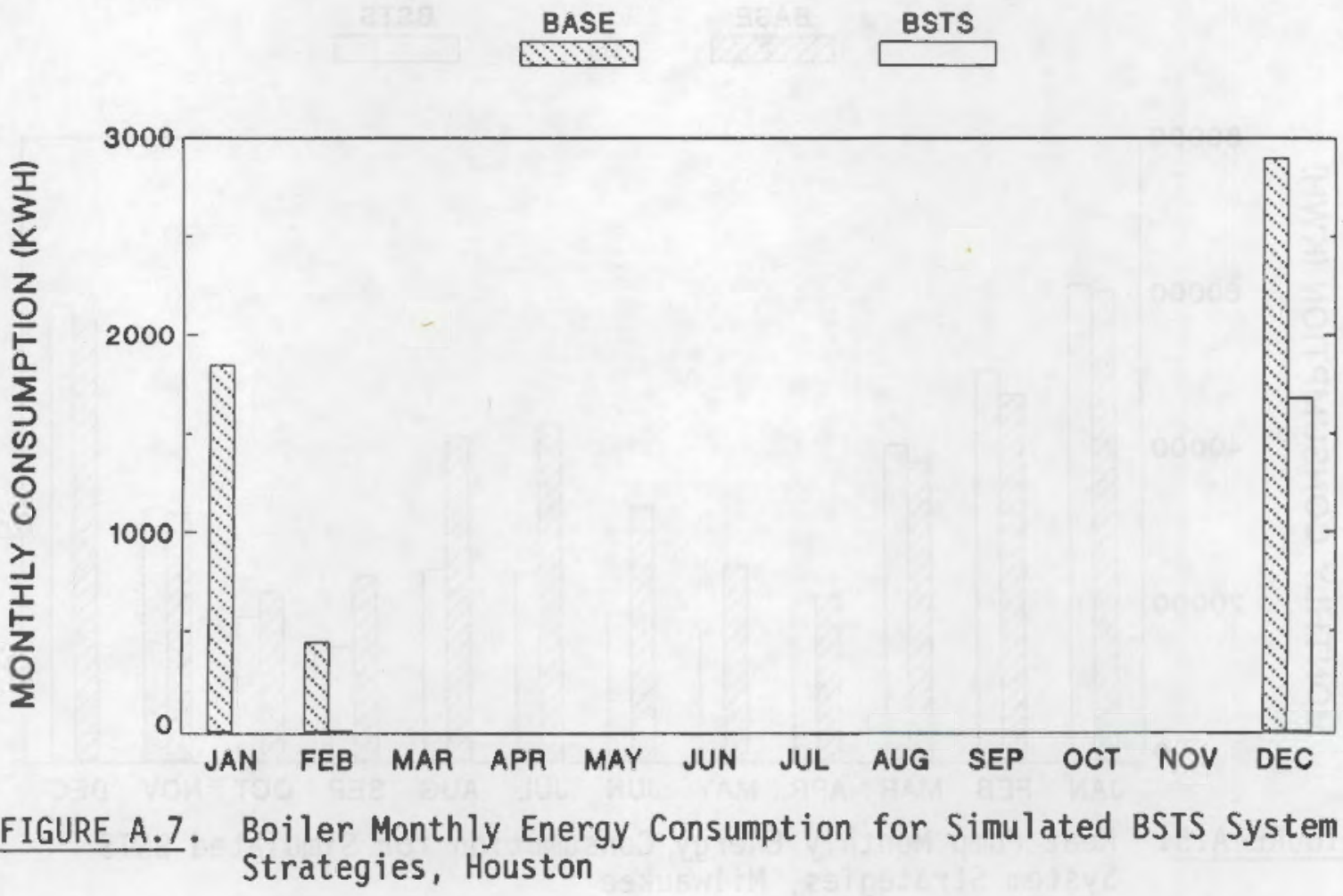




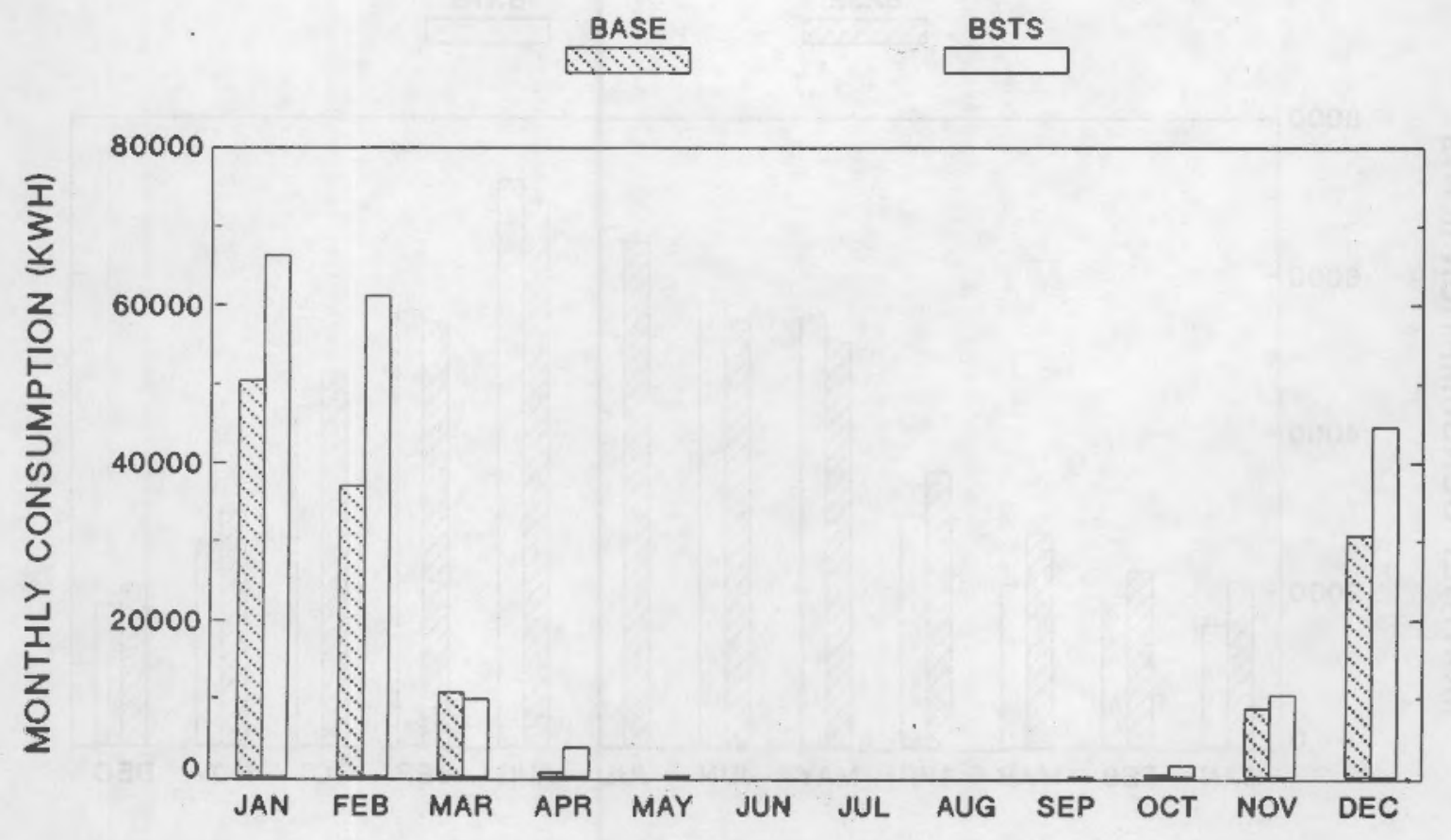

FIGURE A.8. Boiler Monthly Energy Consumption for Simulated BSTS System Strategies, Washington, $D C$

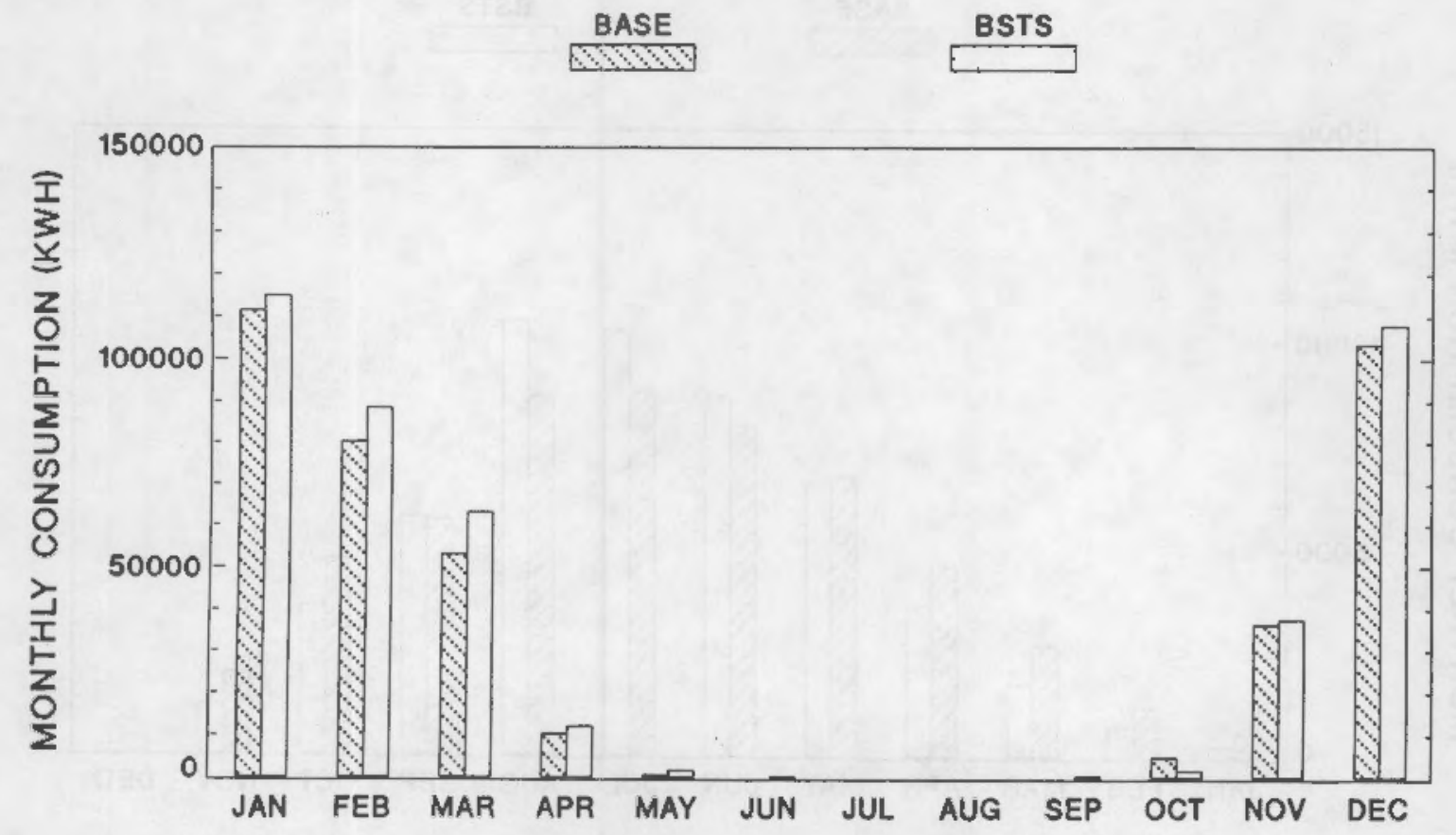

FIGURE A.9. Boiler Monthly Energy Consumption for Simulated BSTS System Strategies, Milwaukee 


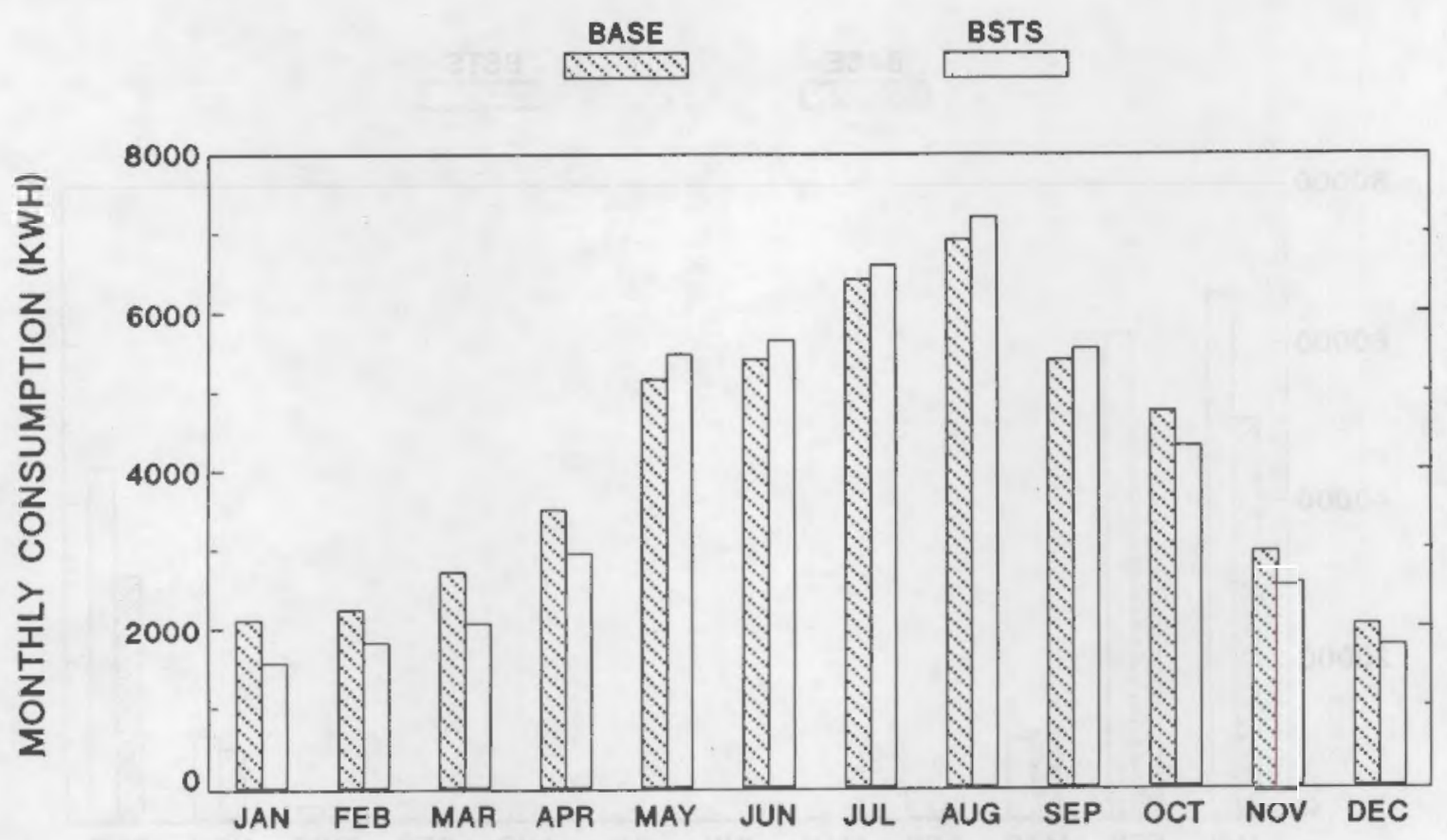

FIGURE A.10. Cooling Tower Monthly Energy Consumption for Simulated BSTS System Strategies, Los Angeles

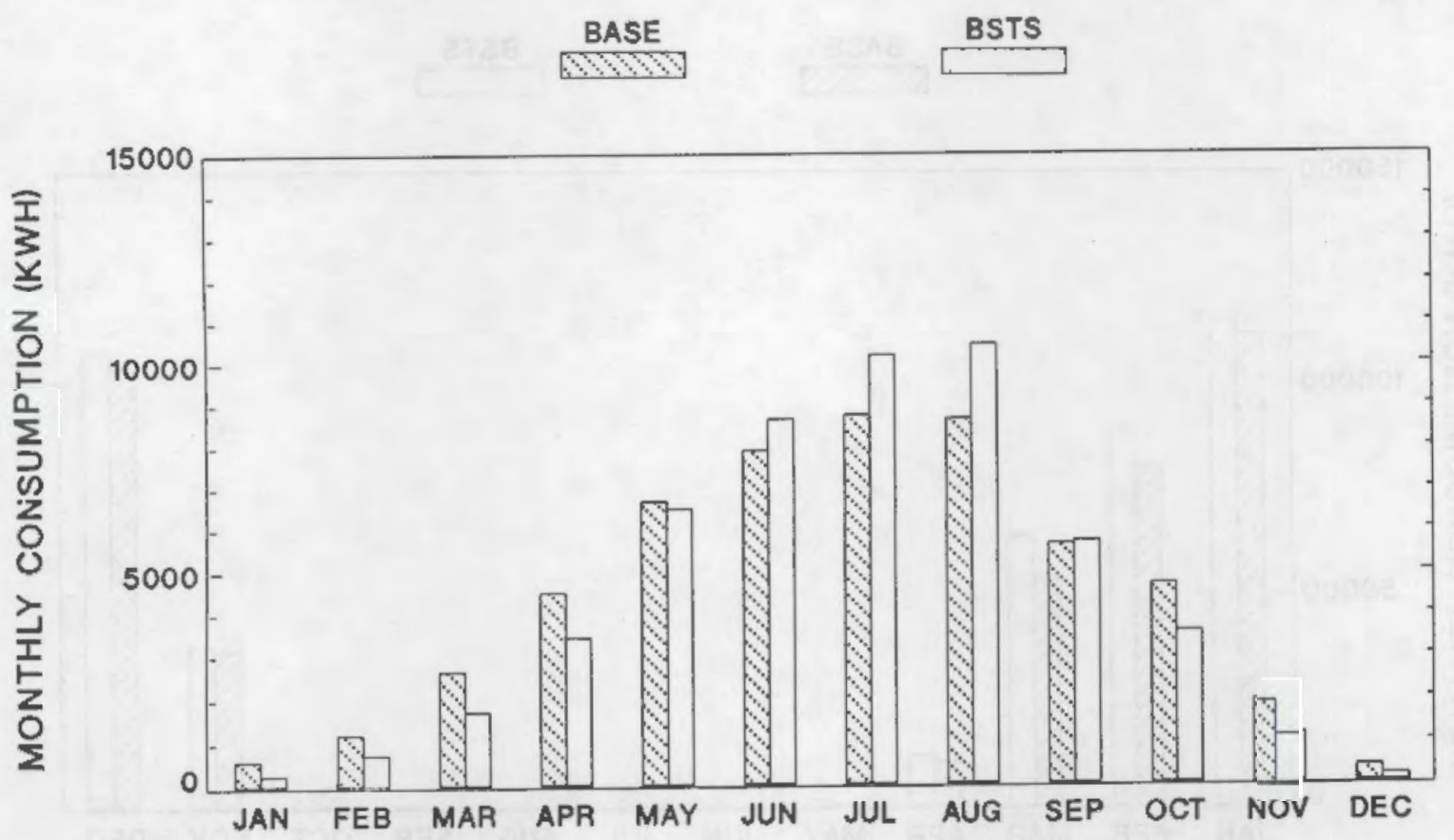

FIGURE A.11. Cooling Tower Monthly Energy Consumption for Simulated BSTS System Strategies, E1 Paso 


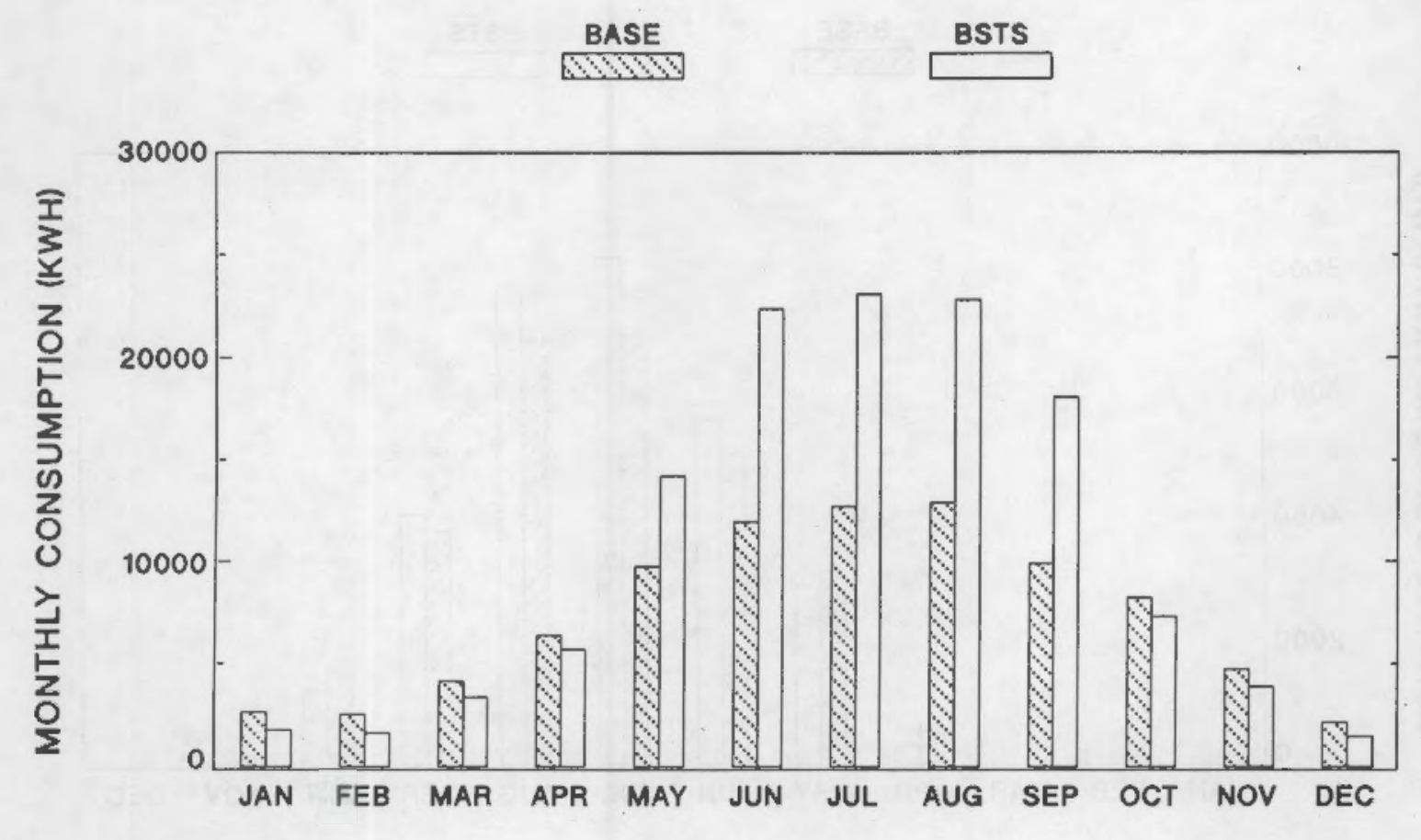

FIGURE A.12. Cooling Tower Monthly Energy Consumption for Simulated BSTS System Strategies, Houston

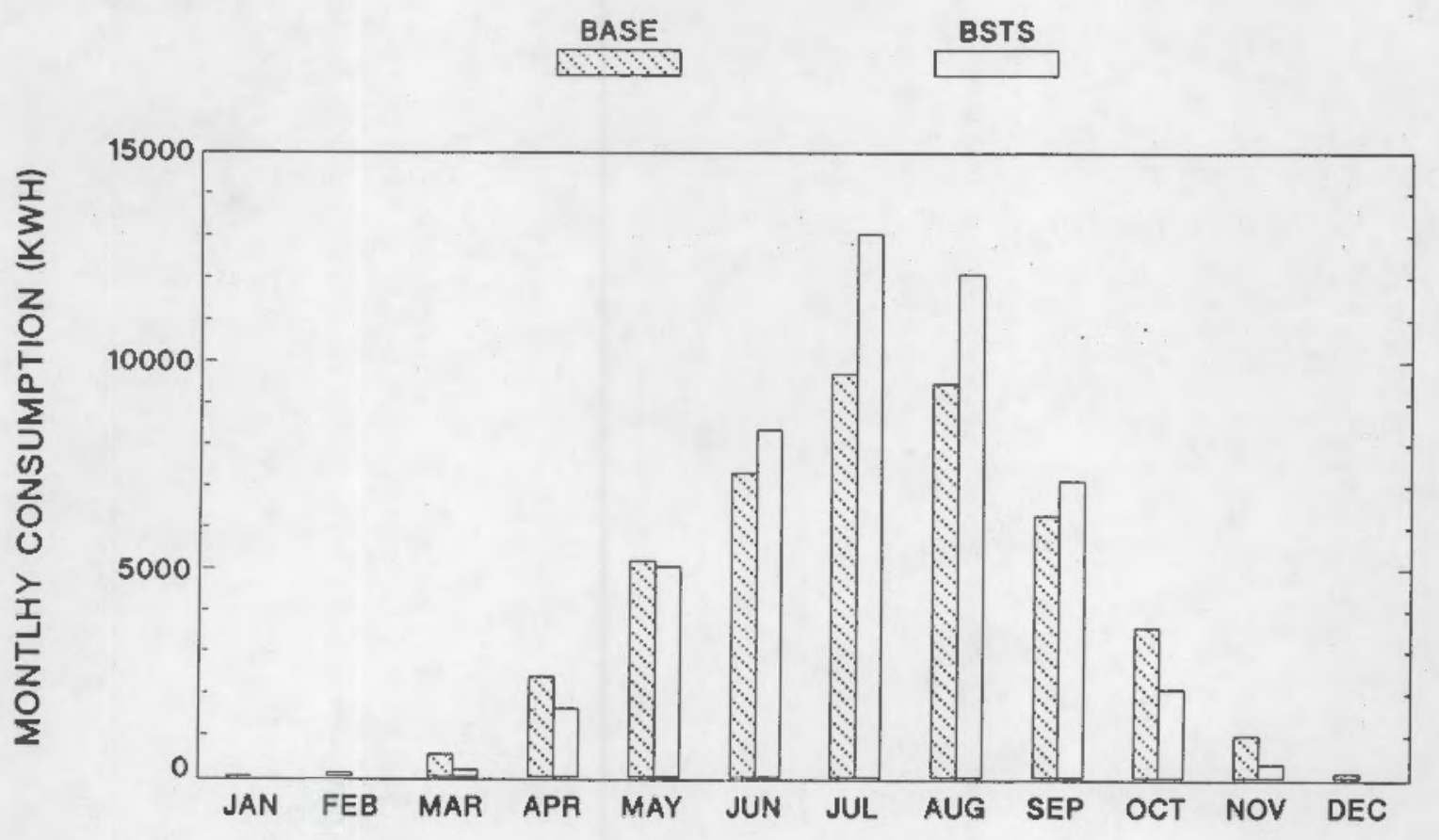

FIGURE A.13. Cooling Tower Monthly Energy Consumption for Simulated BSTS System Strategies, Washington, DC 


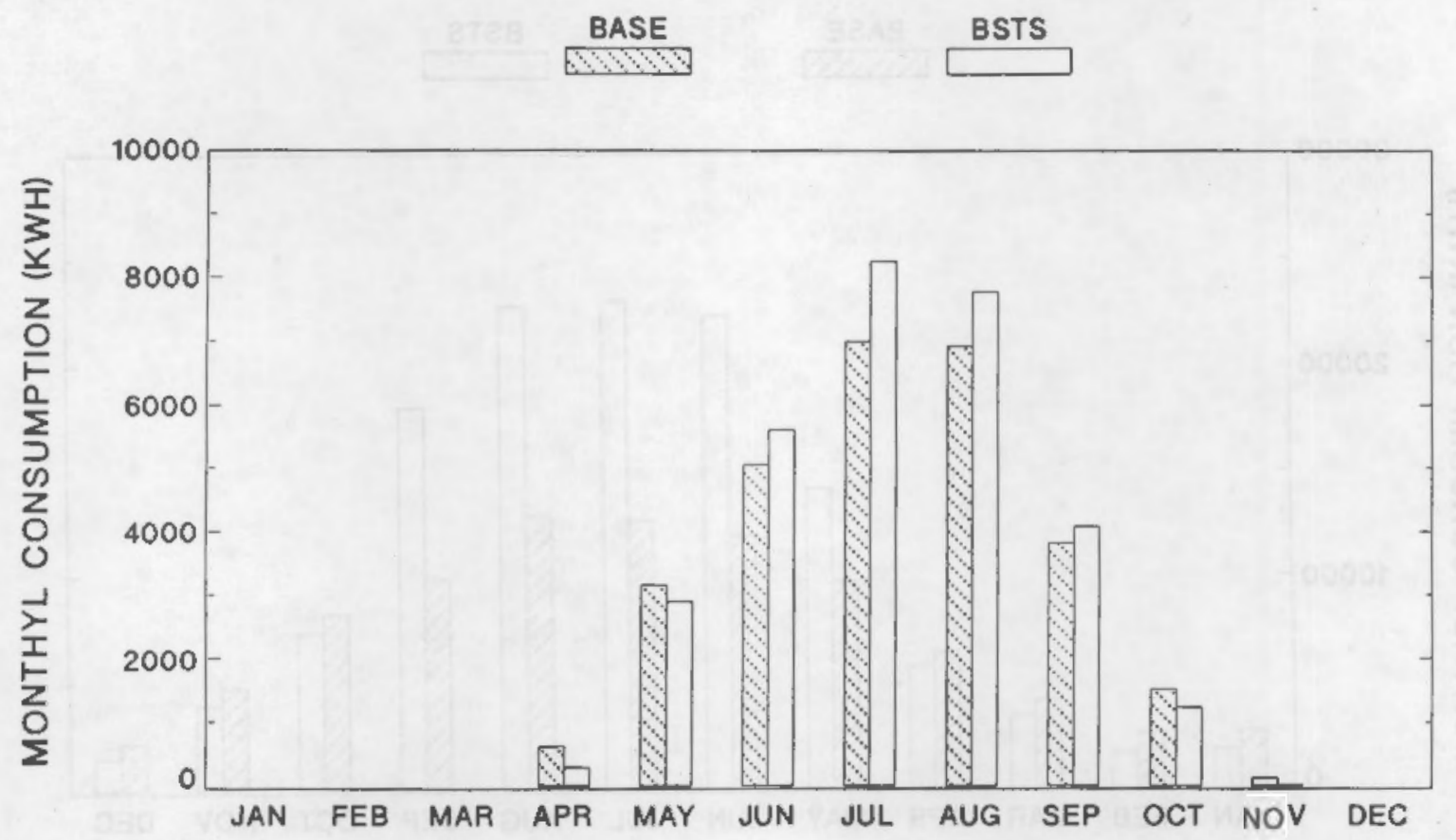

FIGURE A.14. Cooling Tower Monthly Energy Consumption for Simulated BSTS System Strategies, Milwaukee 
APPENDIX B

ANNUAL ENERGY CONSUMPTION FOR THE HVAC COMPONENTS 


\section{ANNUAL ENERGY CONSUMPTION FOR THE HVAC COMPONENTS}

The following bar graphs portray simulated annual energy consumption results of HVAC system components for six U.S. cities in both the base case building model and the base case building model with the Building Structural Thermal Storage (BSTS) system added. This information is supplementary to Section 6.0 of the main report, in which total building energy consumption results are presented. The six cities are Seattle, Los Angeles, El Paso, Houston, Washington, and Milwaukee.

In Figures B.1 the total heat pump annual energy consumption for each city is presented. Figure B.2 is for the boiler, and Figure B.3 is for the cooling tower.

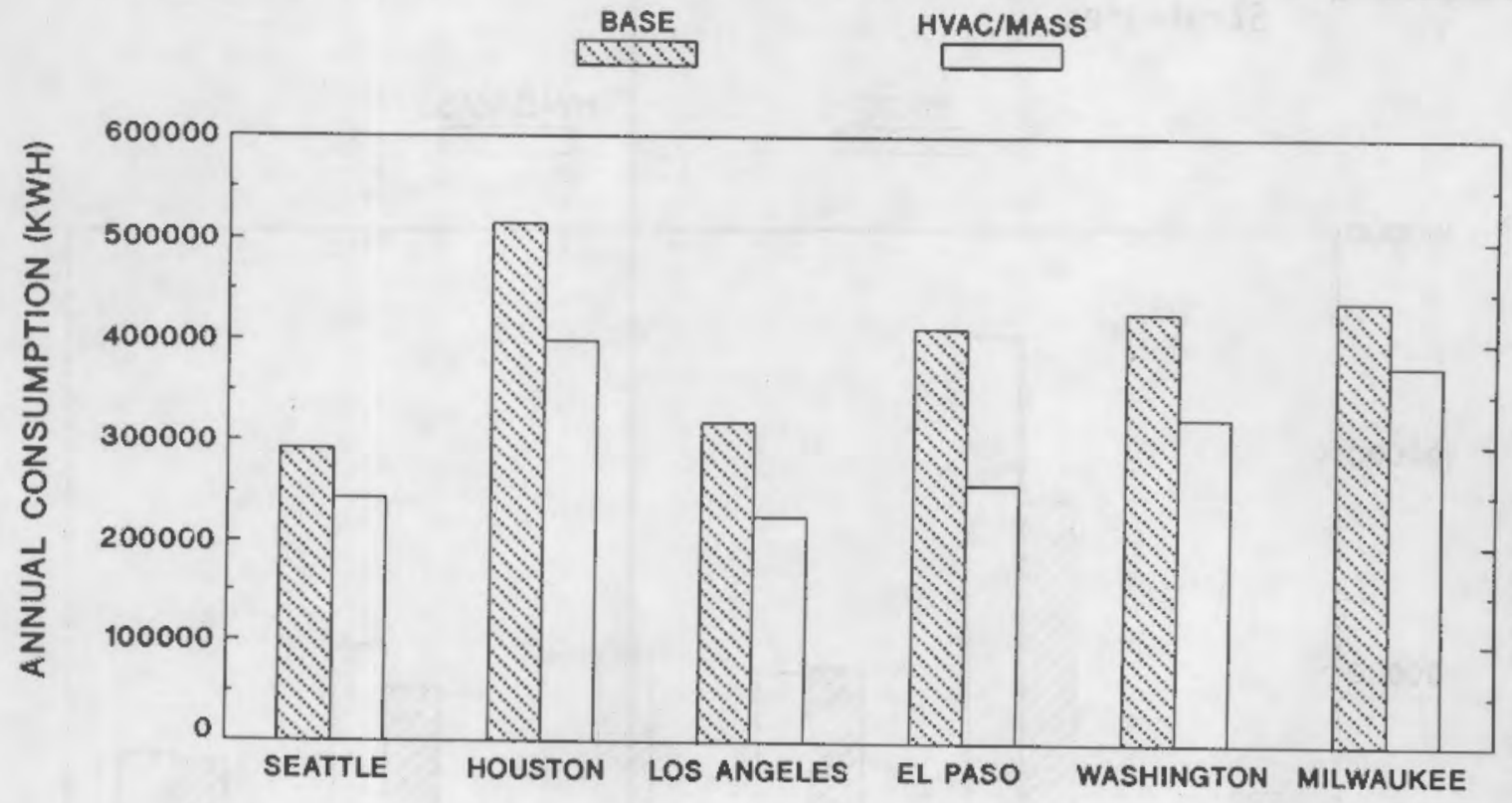

FIGURE B.1. Heat Pump Annual Energy Consumption for Simulated BSTS System Strategies 


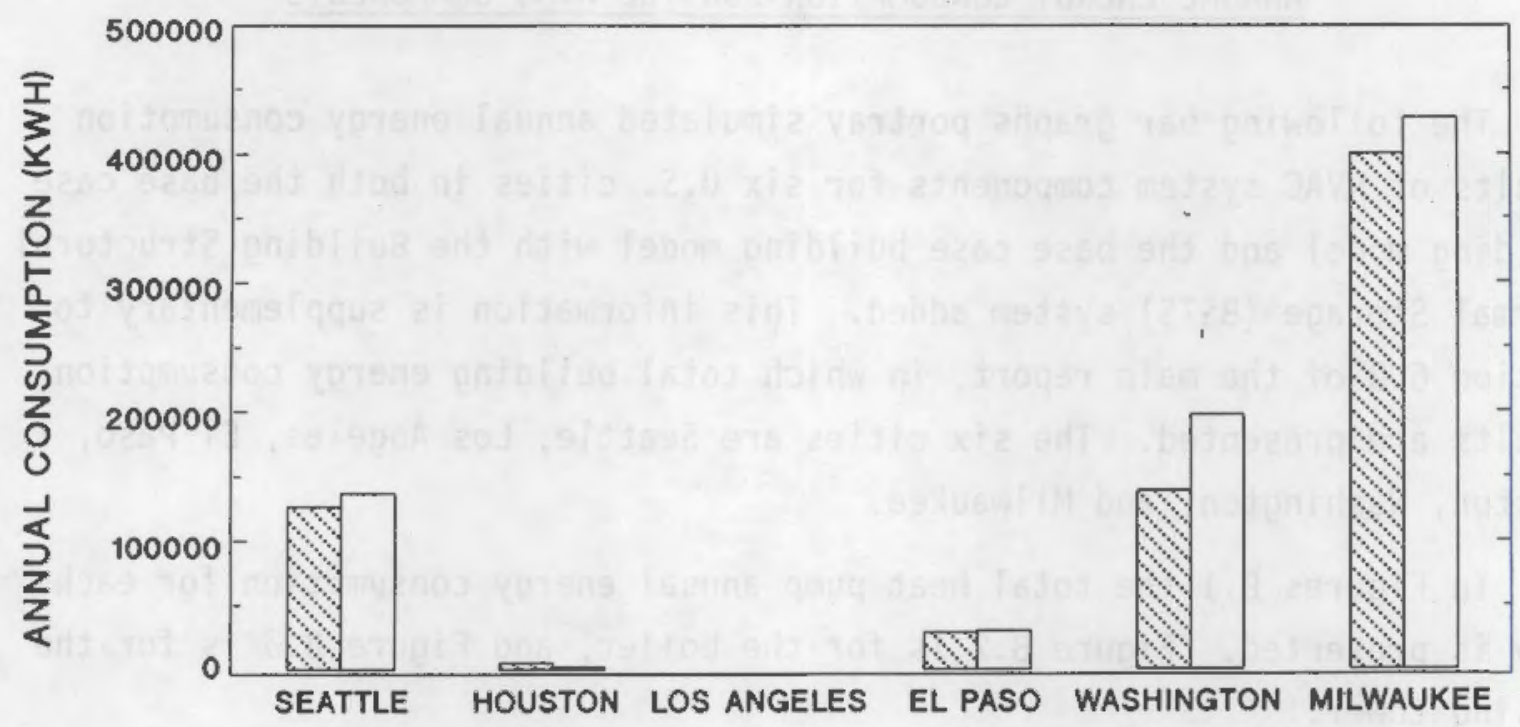

FIGURE B.2. Boiler Annual Energy Consumption for Simulated BSTS System Strategies

BASE

HVAC/MASS

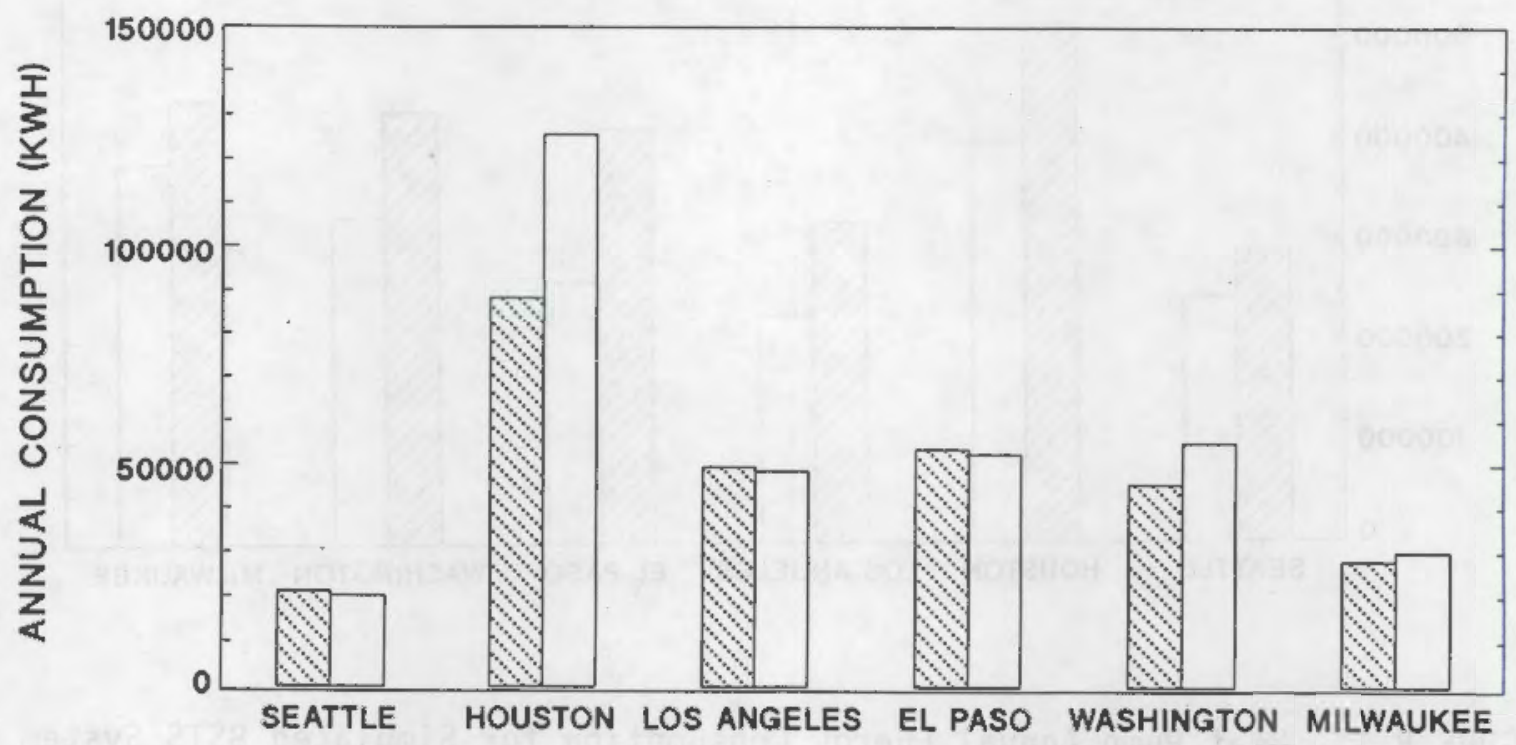

FIGURE B.3. Cooling Tower Annual Energy Consumption for Simulated BSTS System Strategies 
APPENDIX C

COMPUTER CODES 


\section{COMPUTER CODES}

This appendix contains code listings of the five component modules developed by Pacific Northwest Laboratory researchers specifically for this study: the cooling tower, the heat pump, the water loop boiler, the water loop thermostat (used to control cooling tower and boiler operation), and the floor slab used in the BSTS system.

Each module is written as a FORTRAN subroutine. These subroutines were linked after compilation with the main TRNSYS source code and those additional existing TRNSYS component modules also required for the model to create executables used for the simulations described in the main report.

BOILER

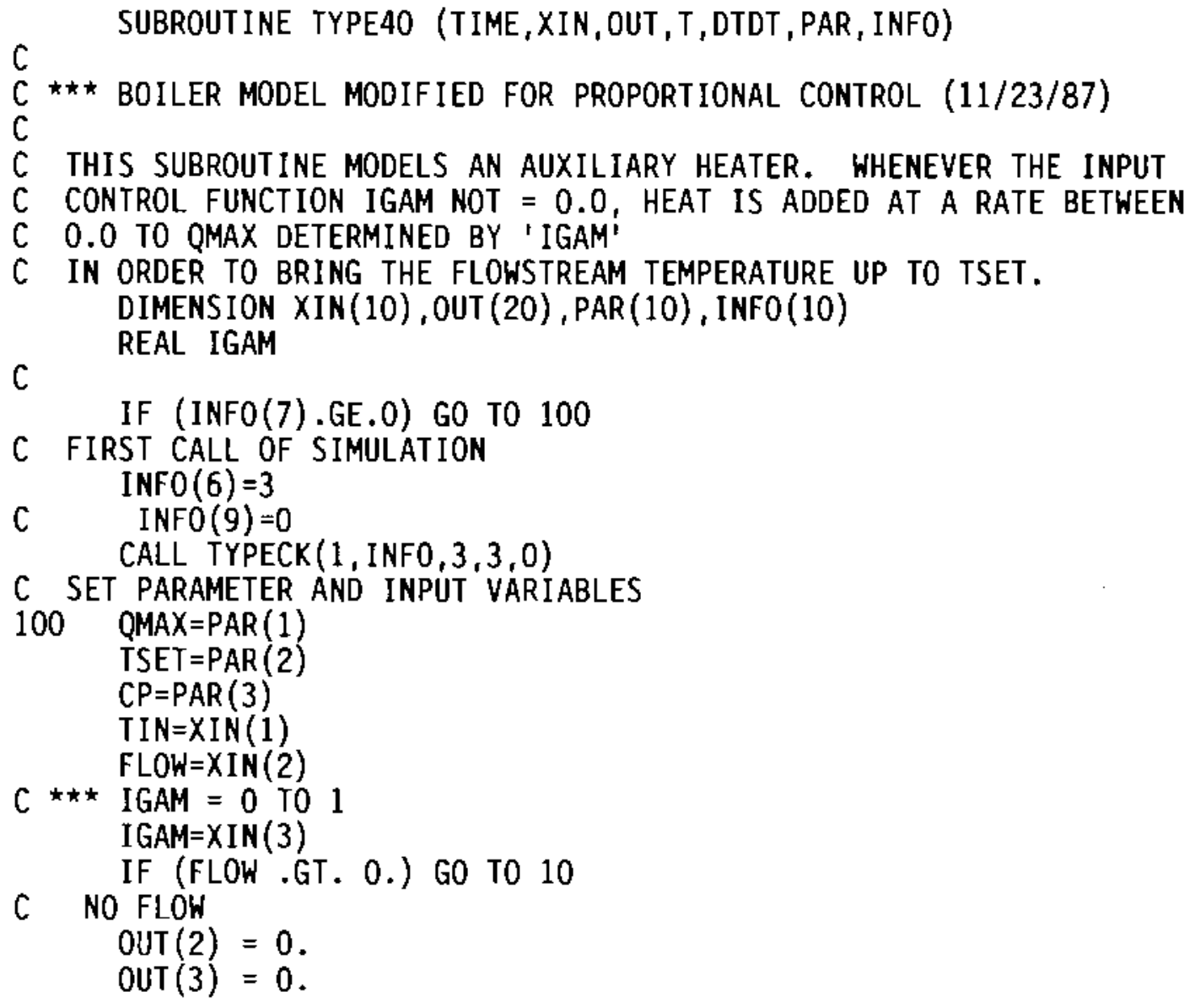




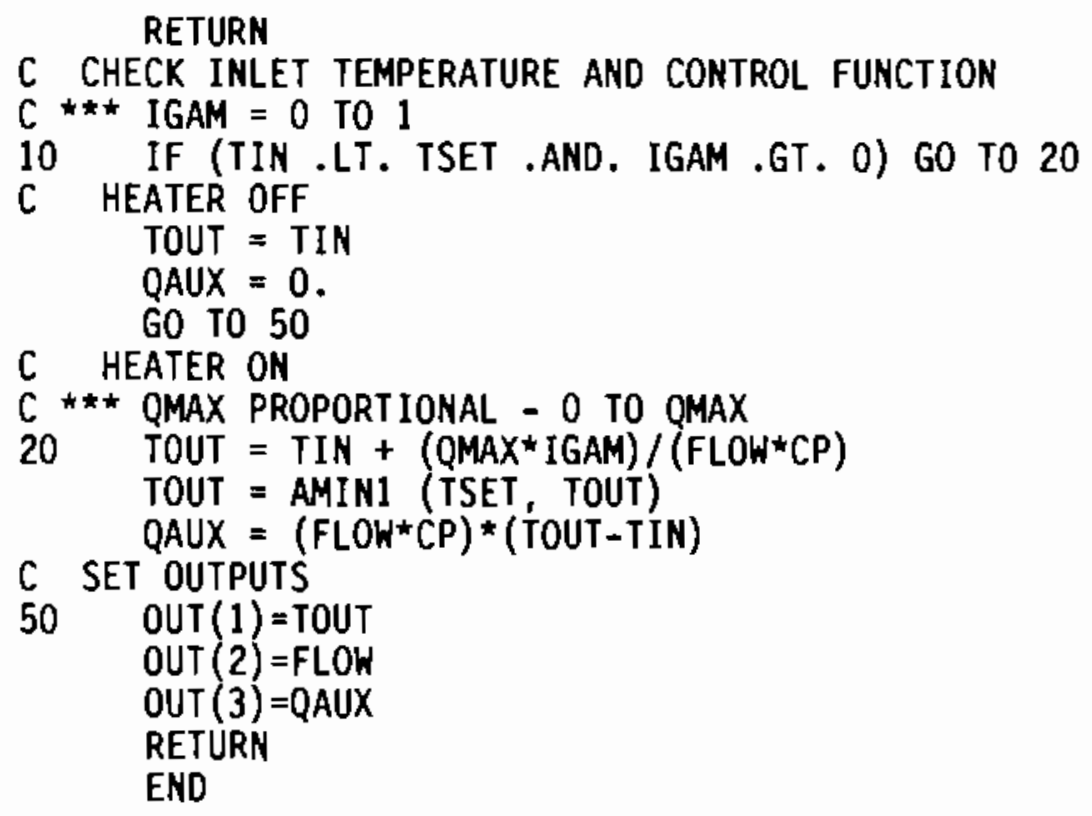


COOLING TOWER

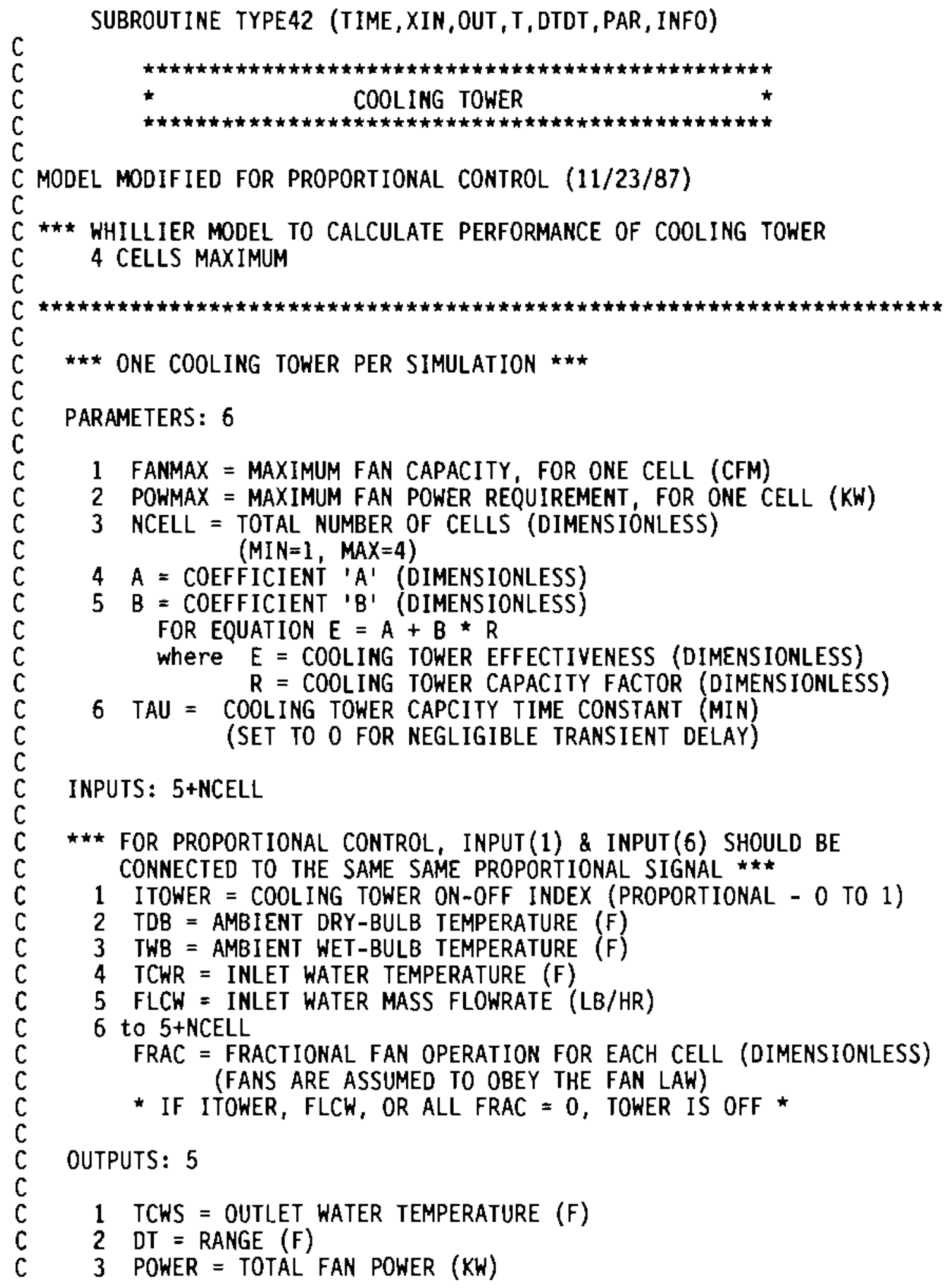




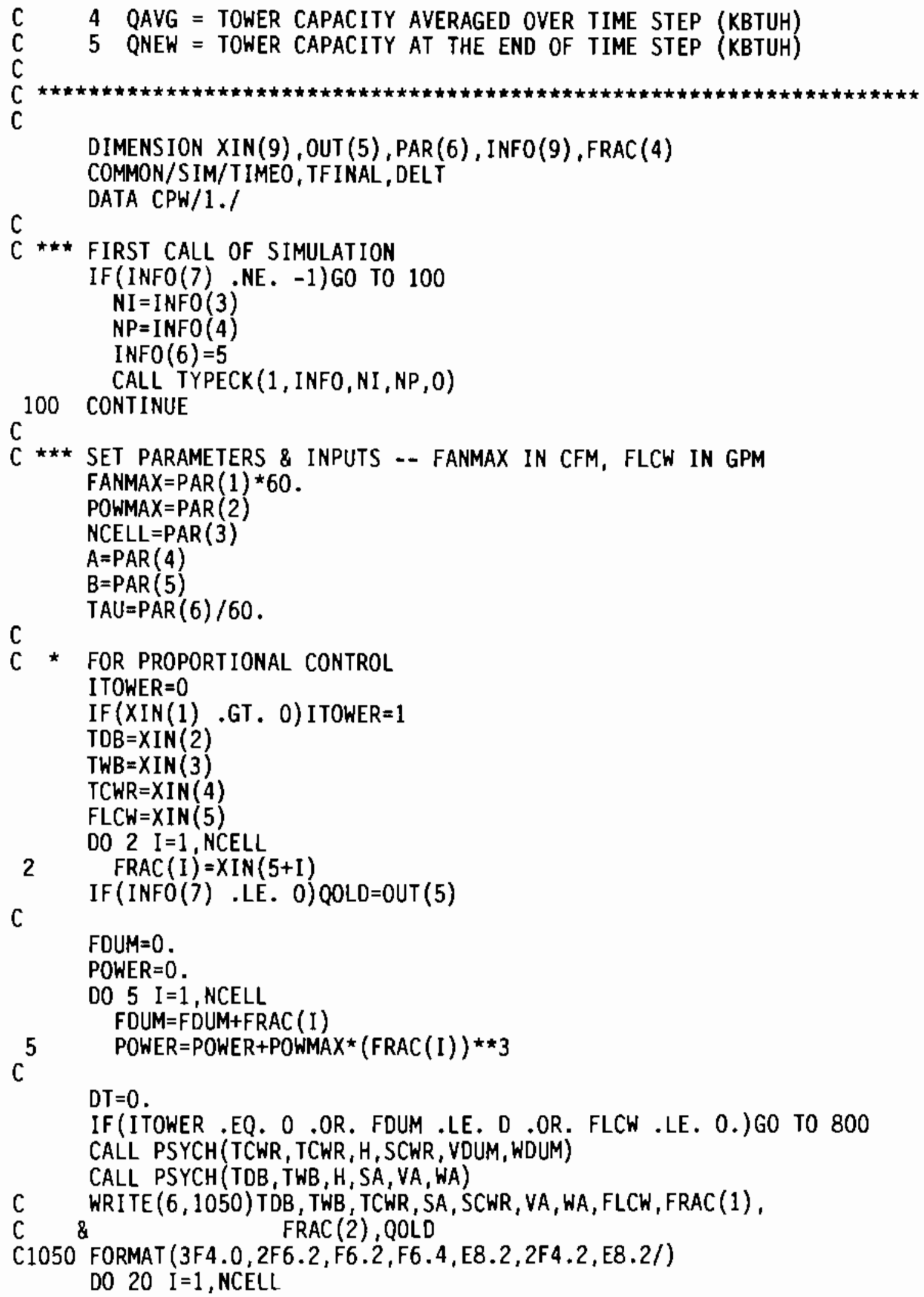




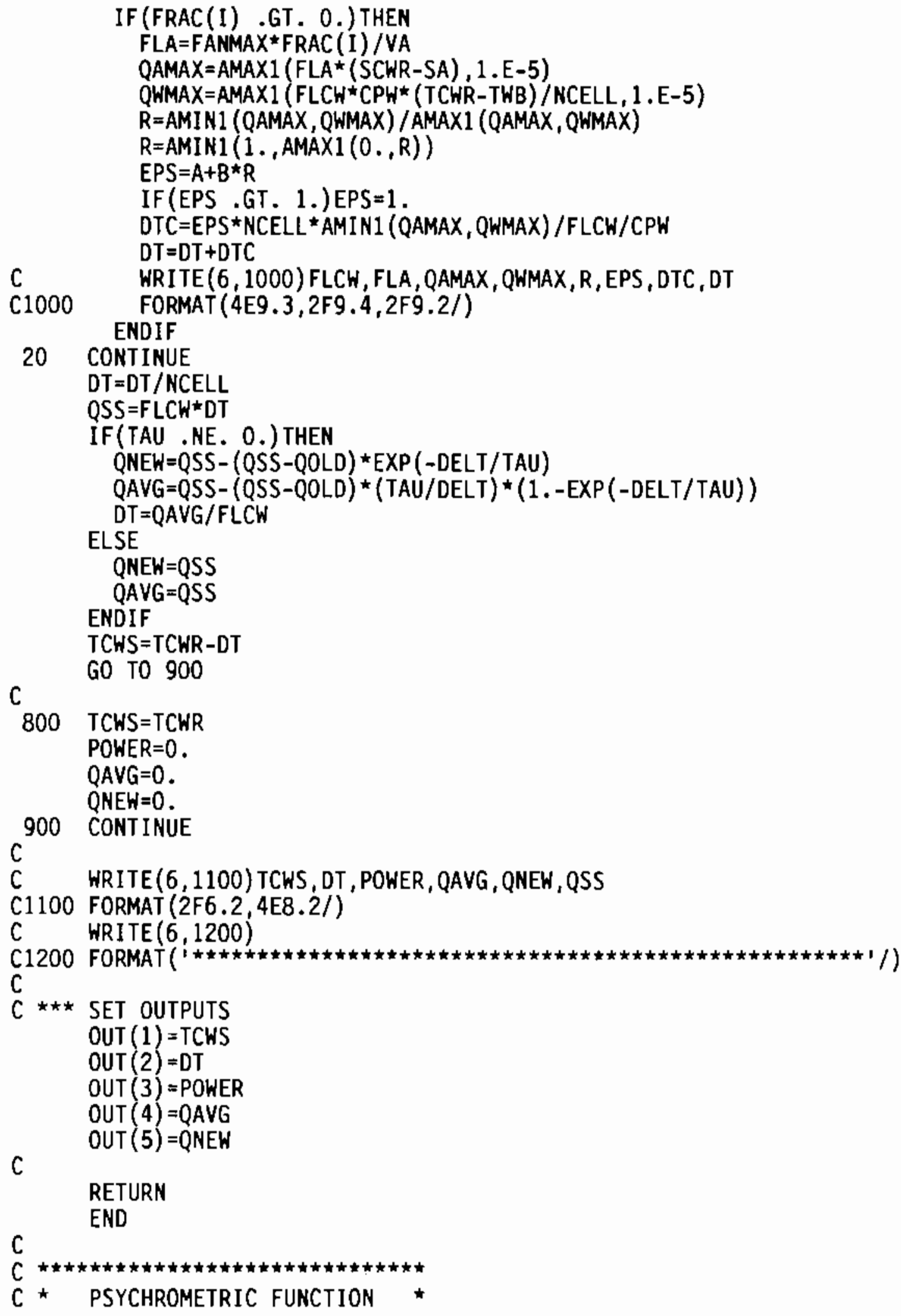




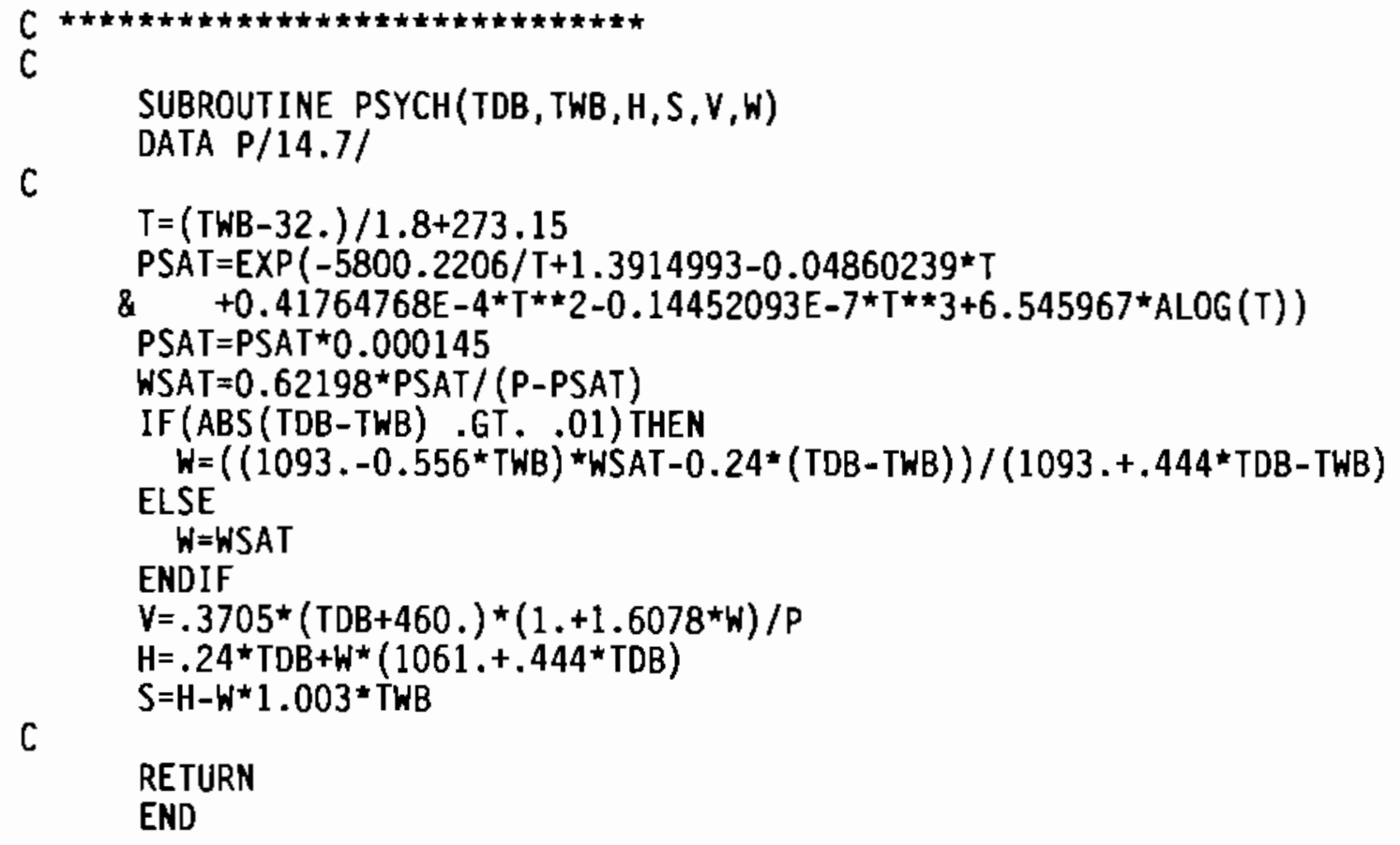

END 
PROPORTIONAL CONTROL THERMOSTAT

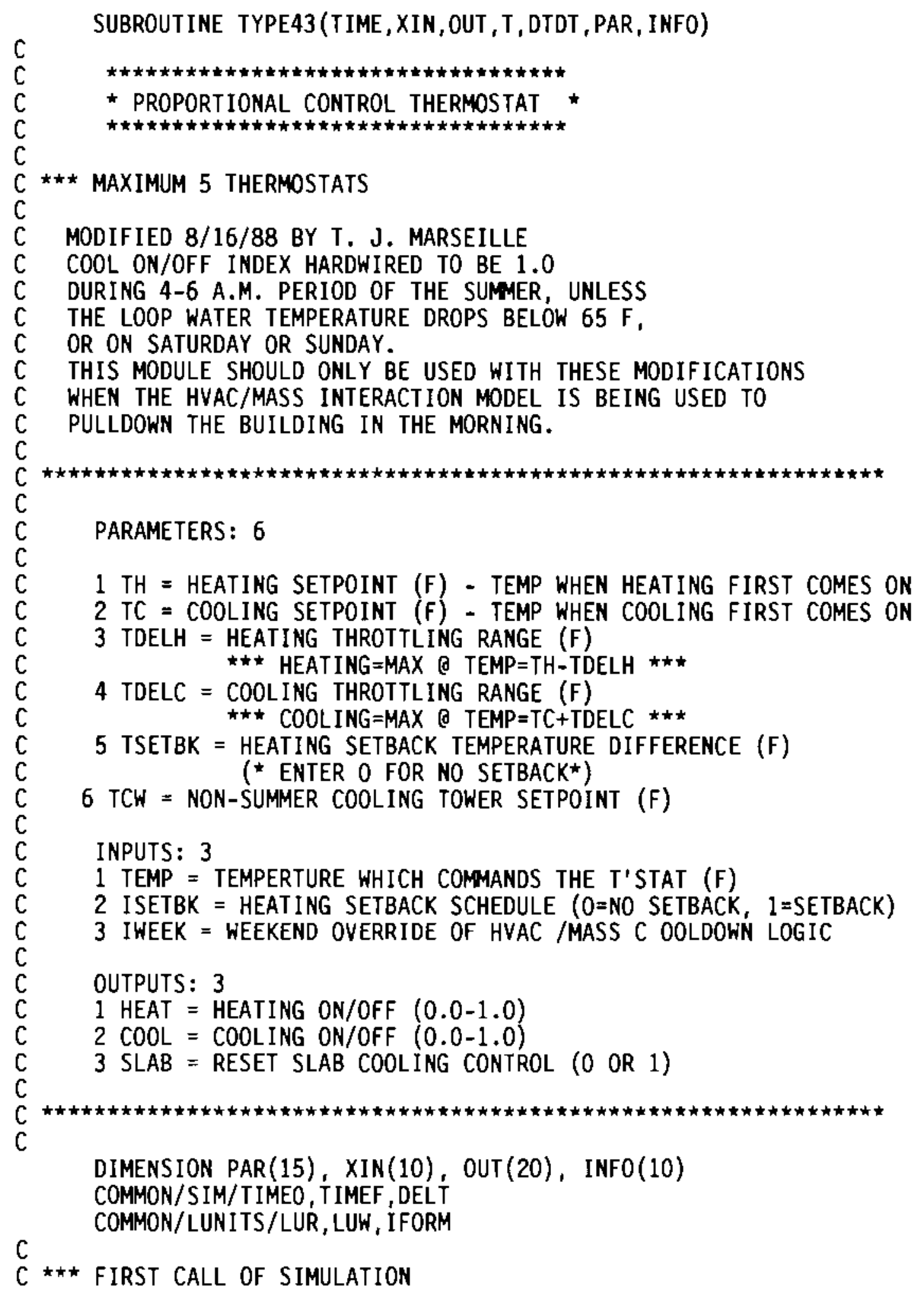




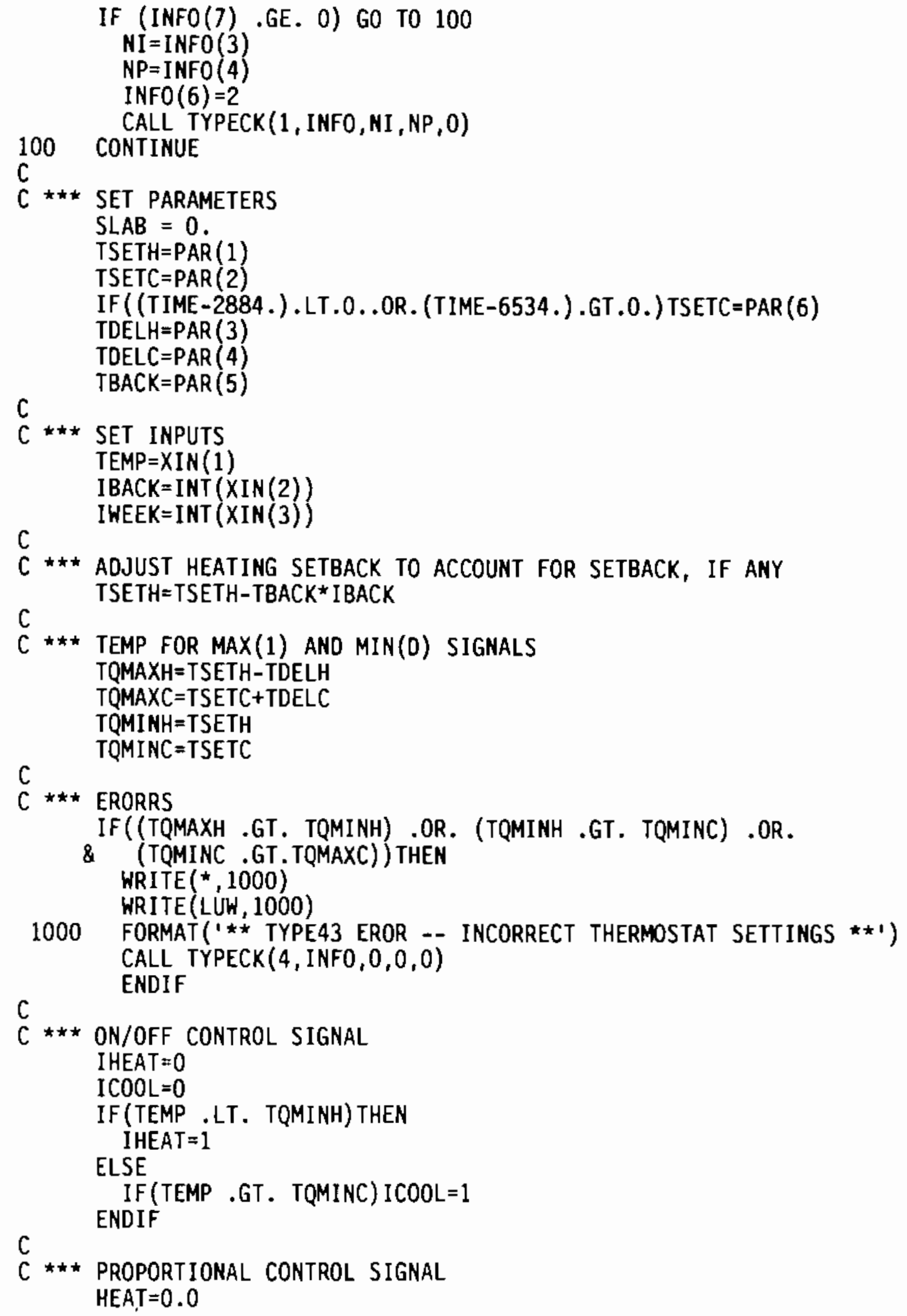




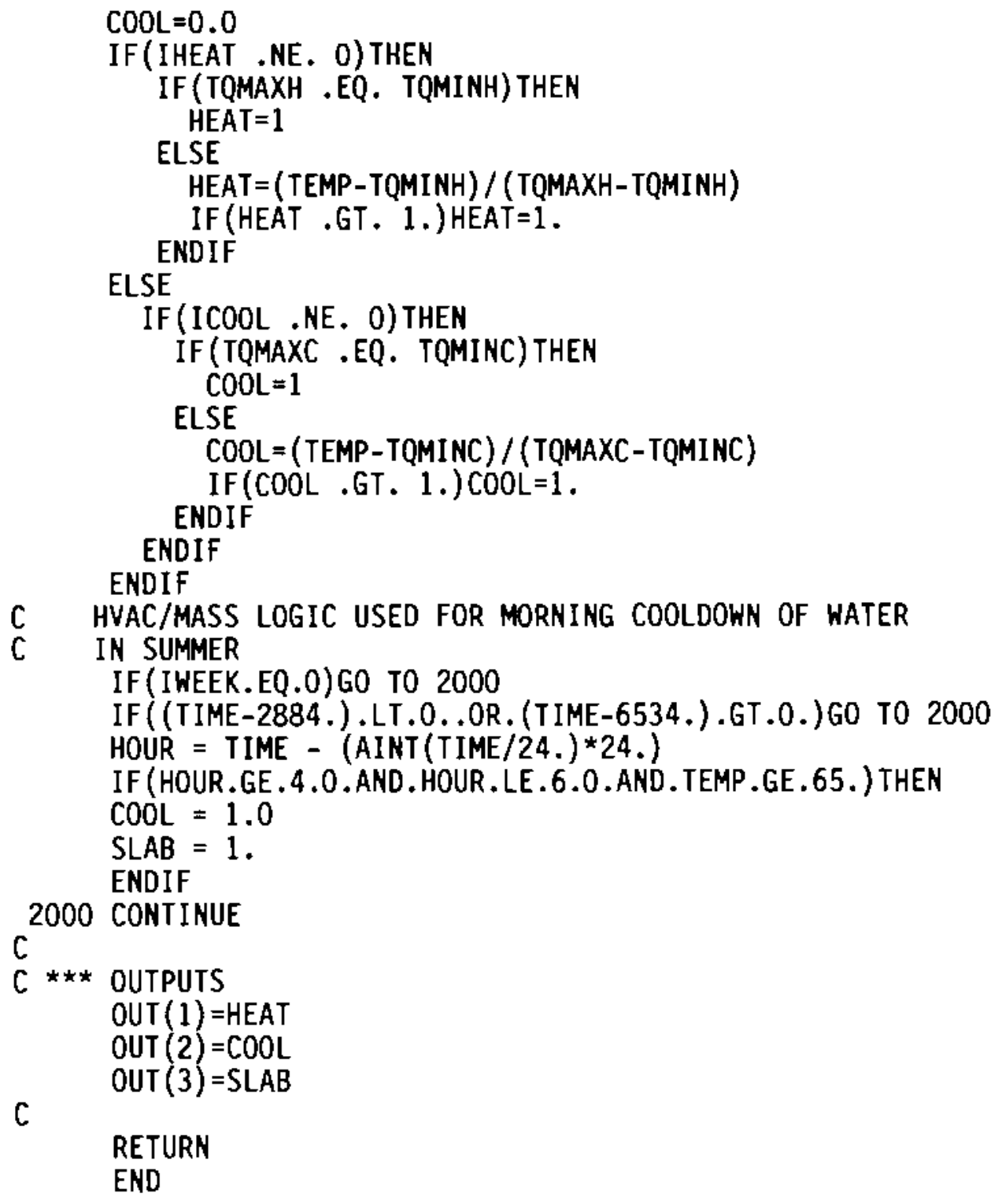


THERMAL ENERGY STORAGE IN SLAB

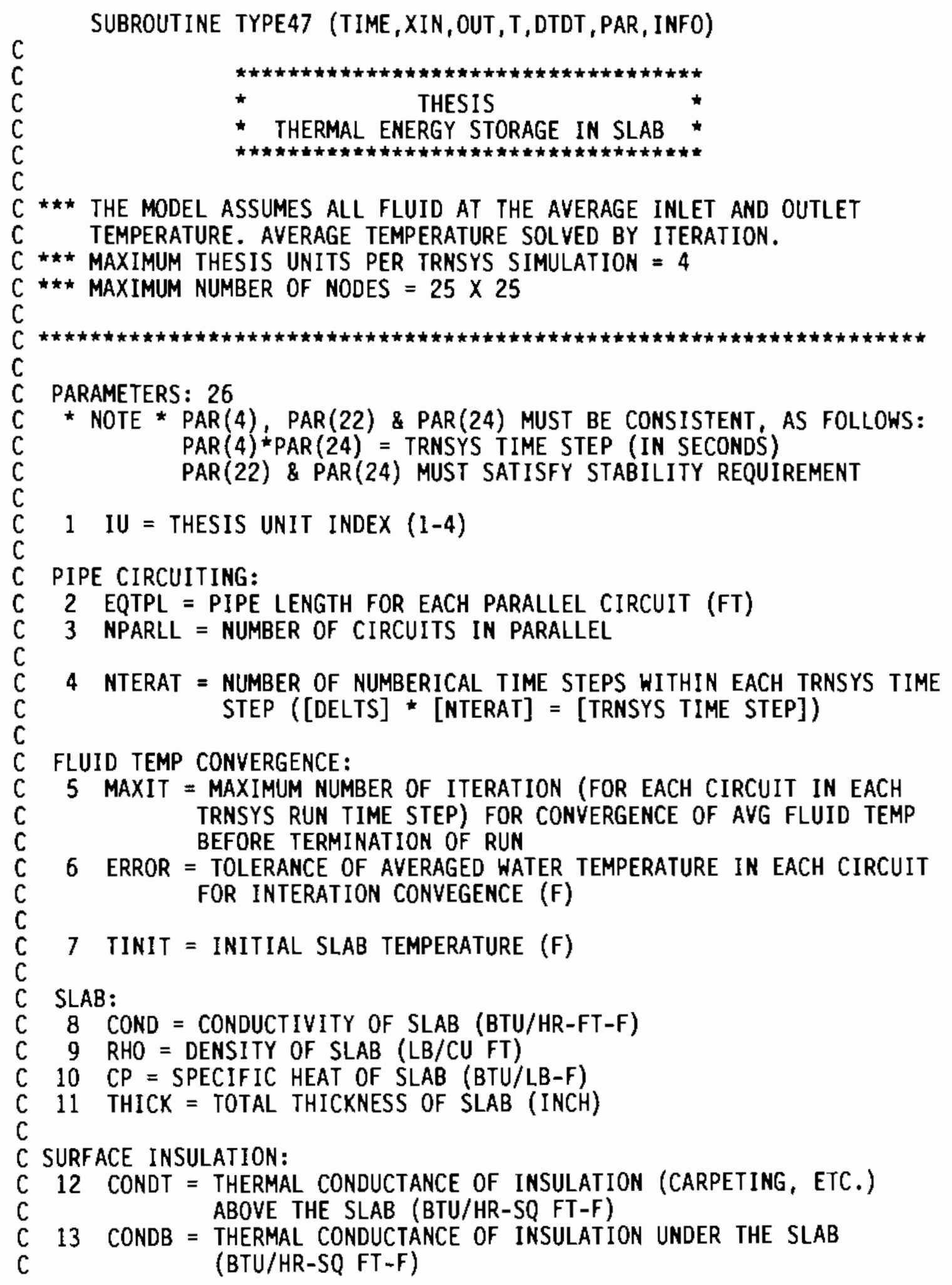




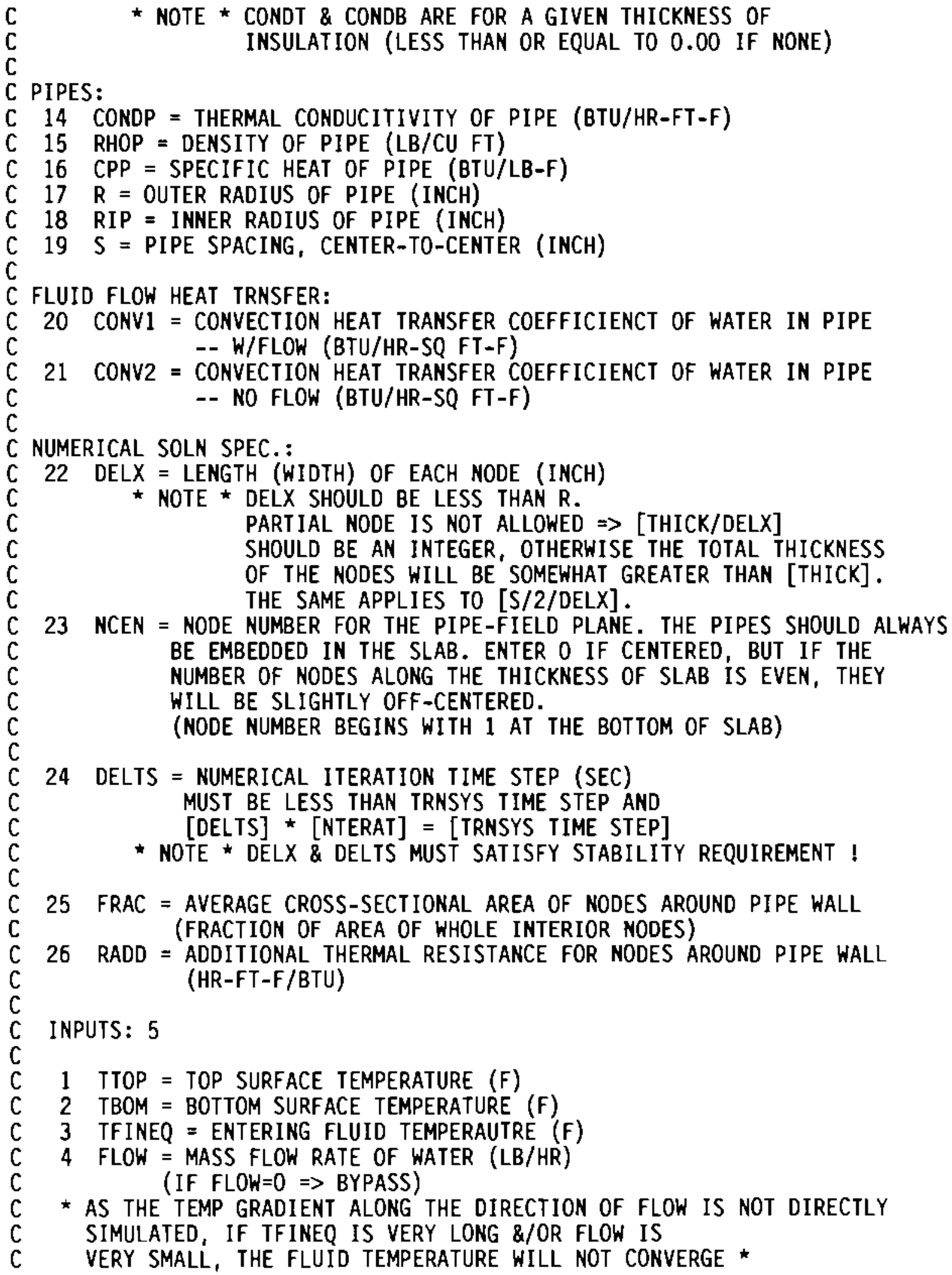




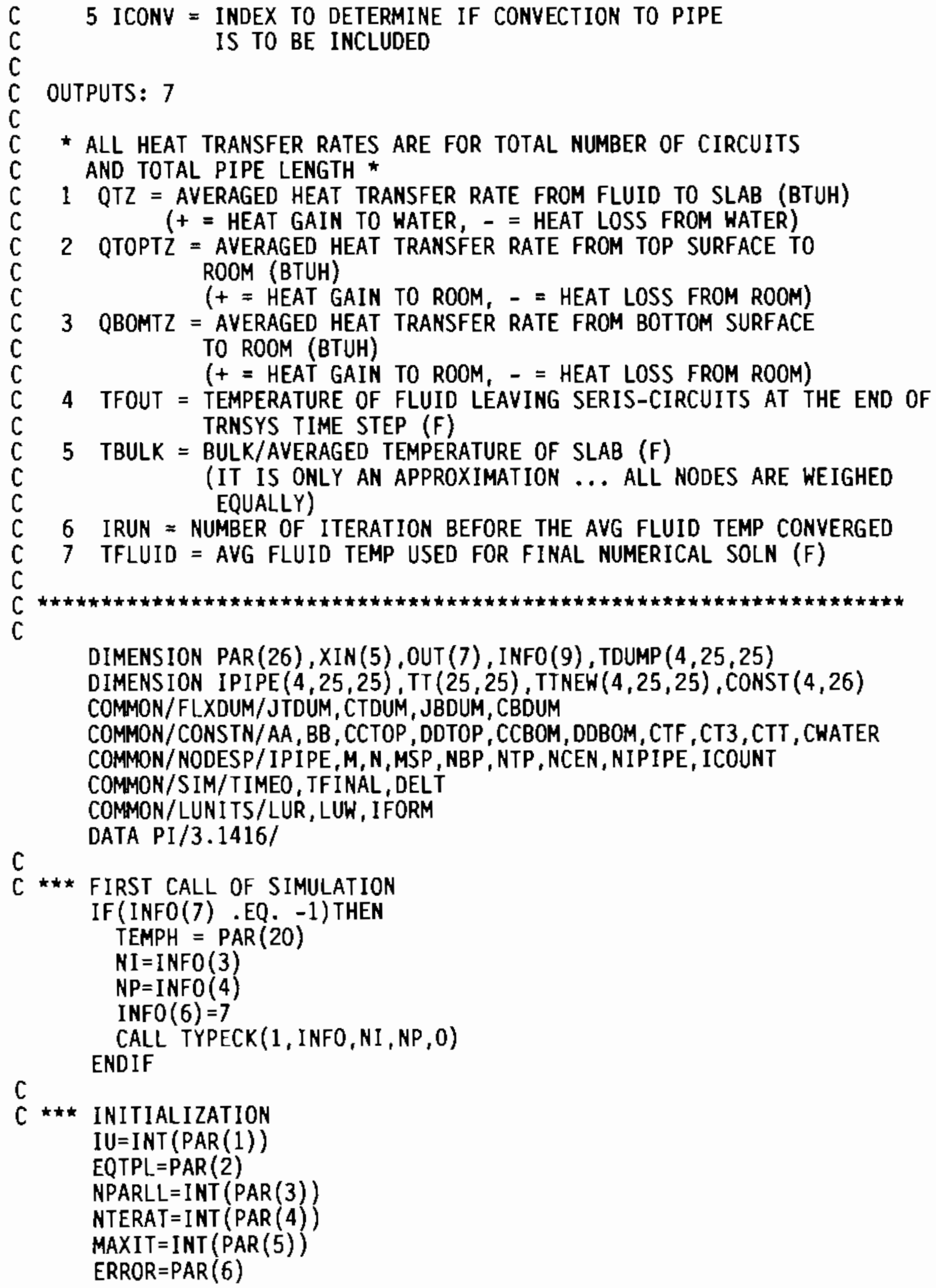




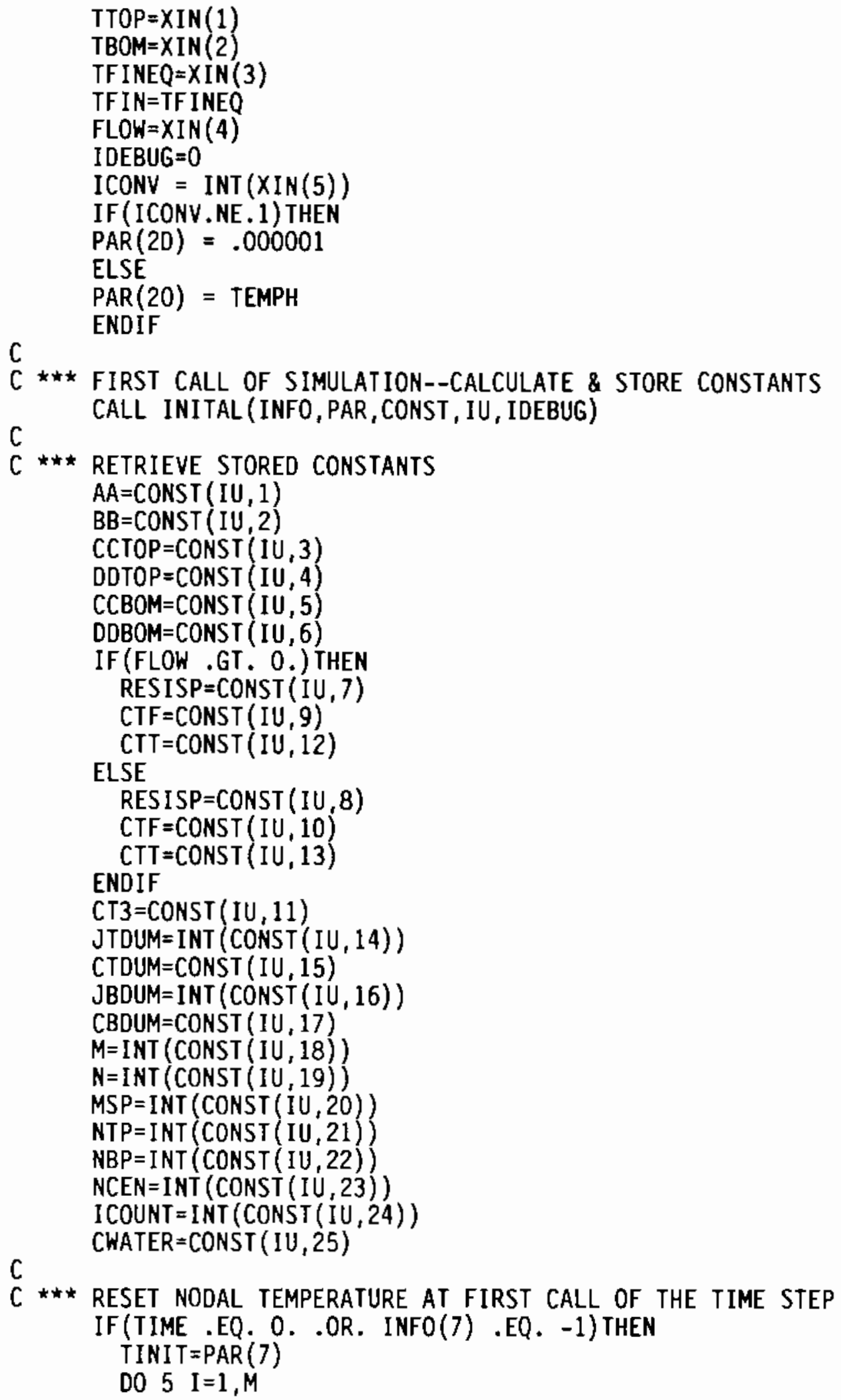




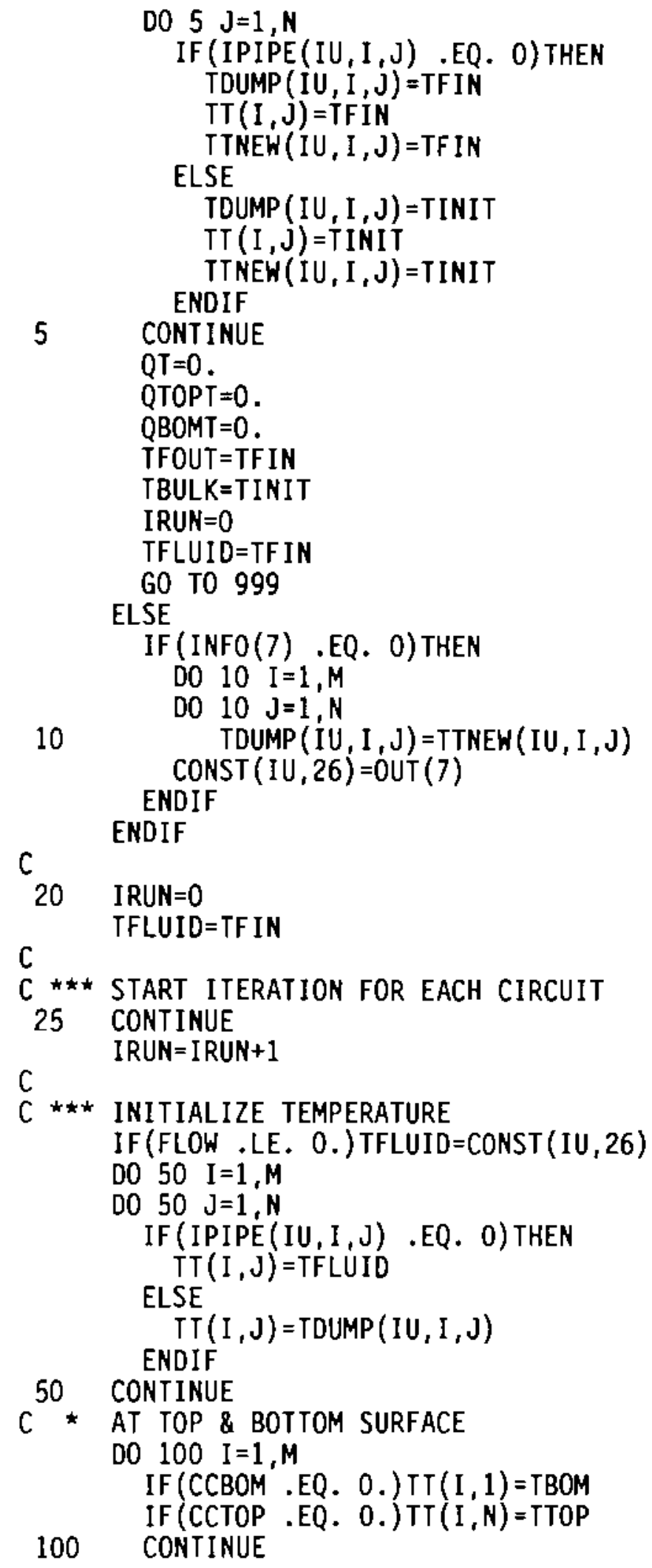




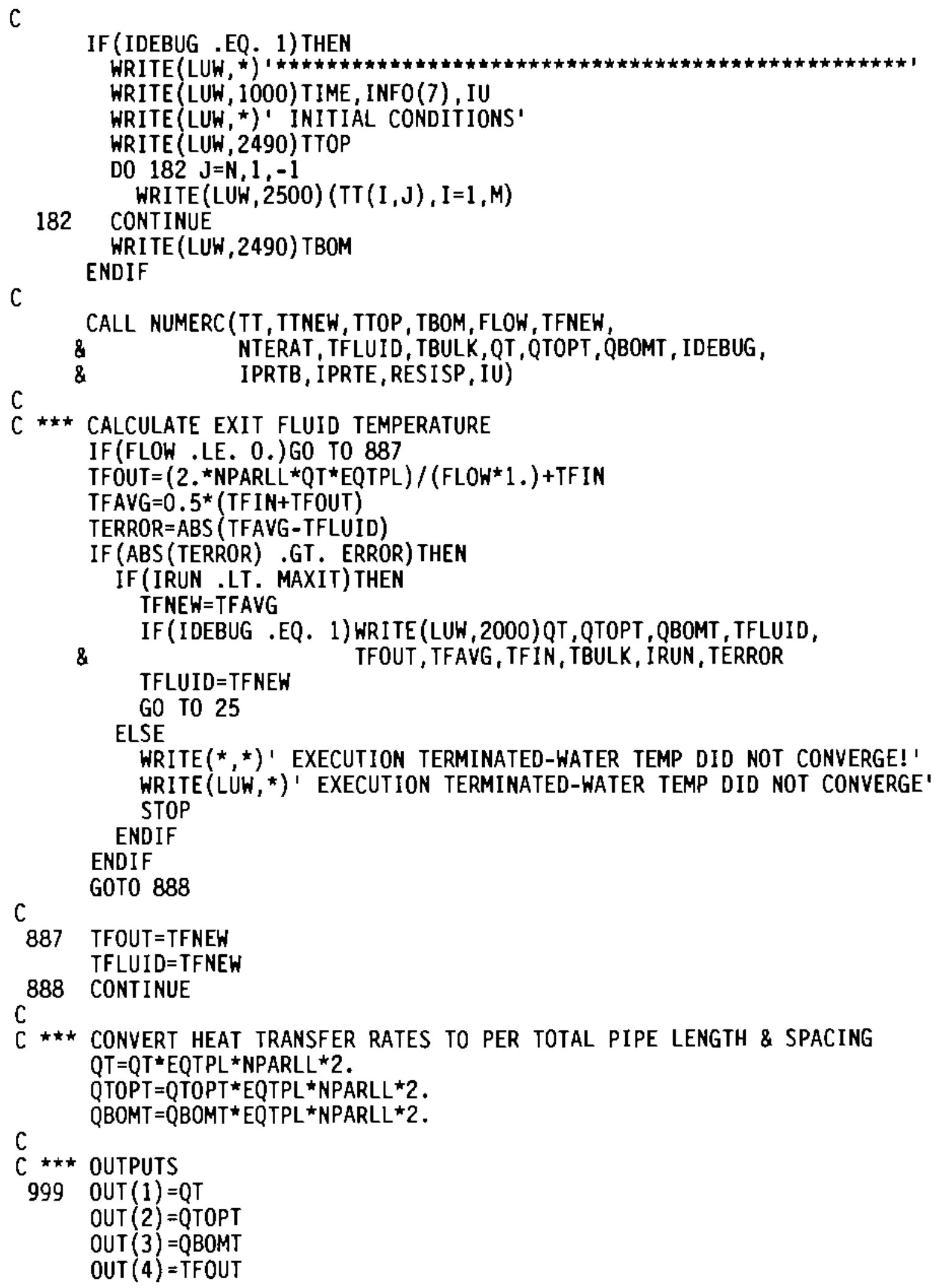




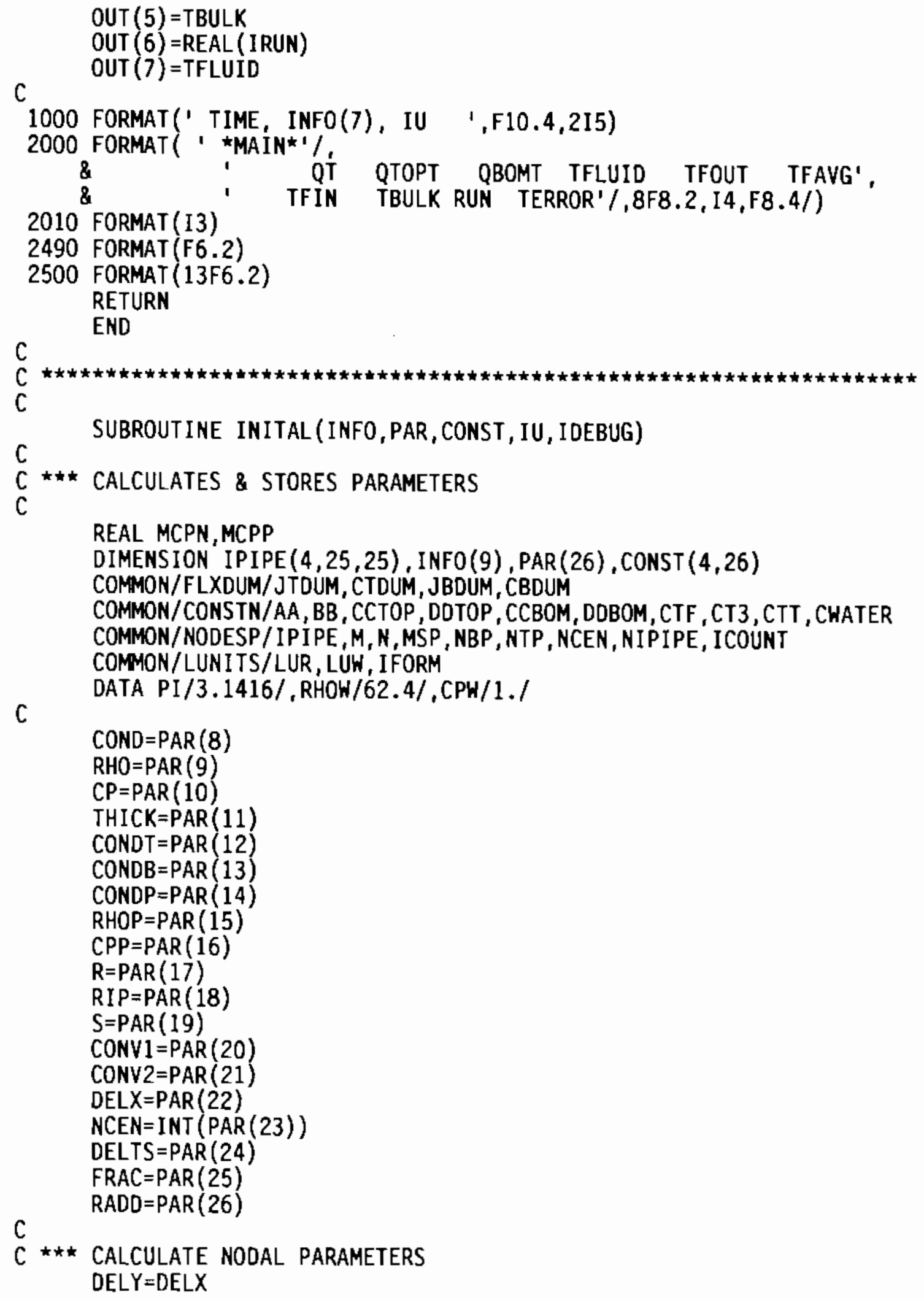




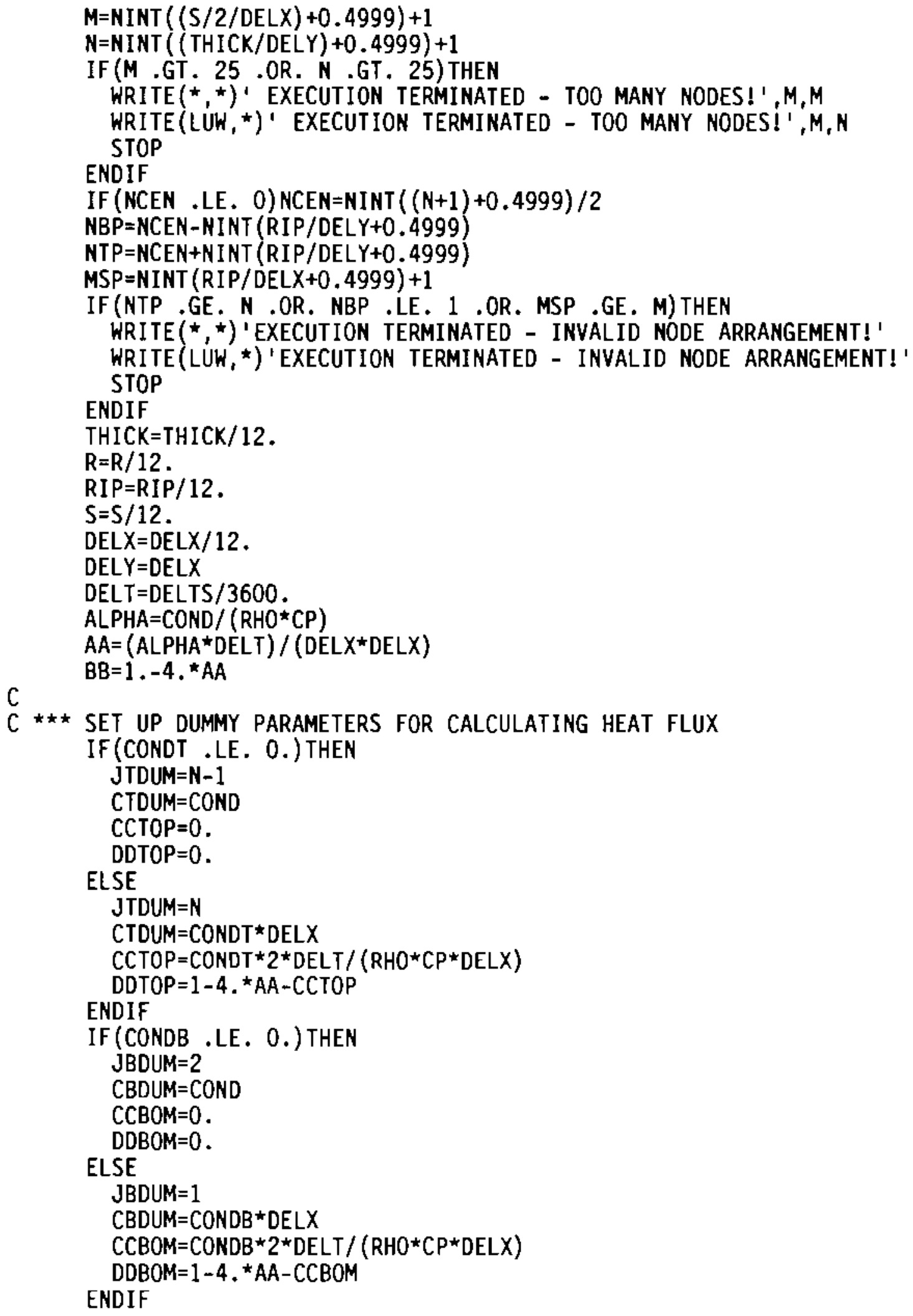




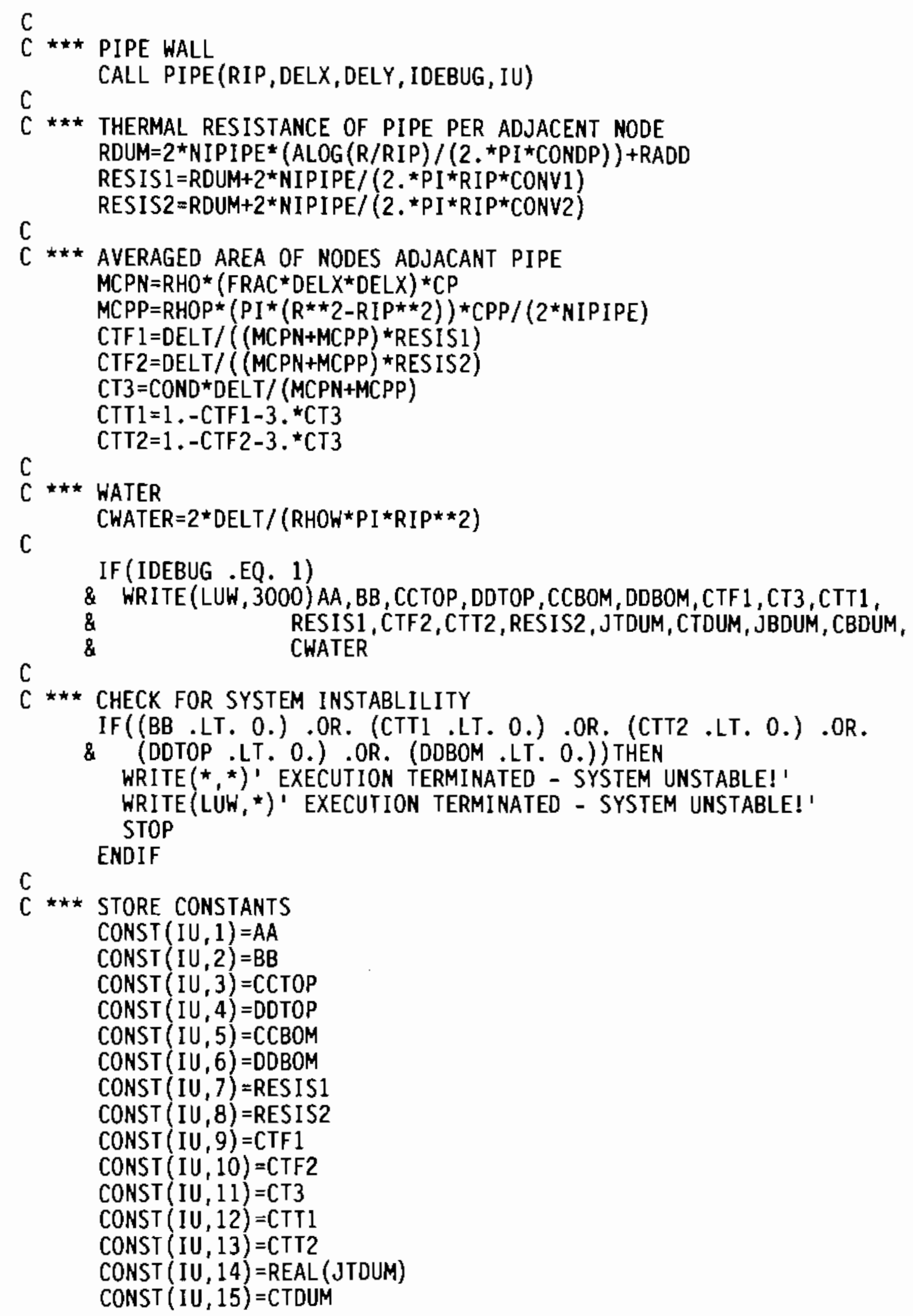




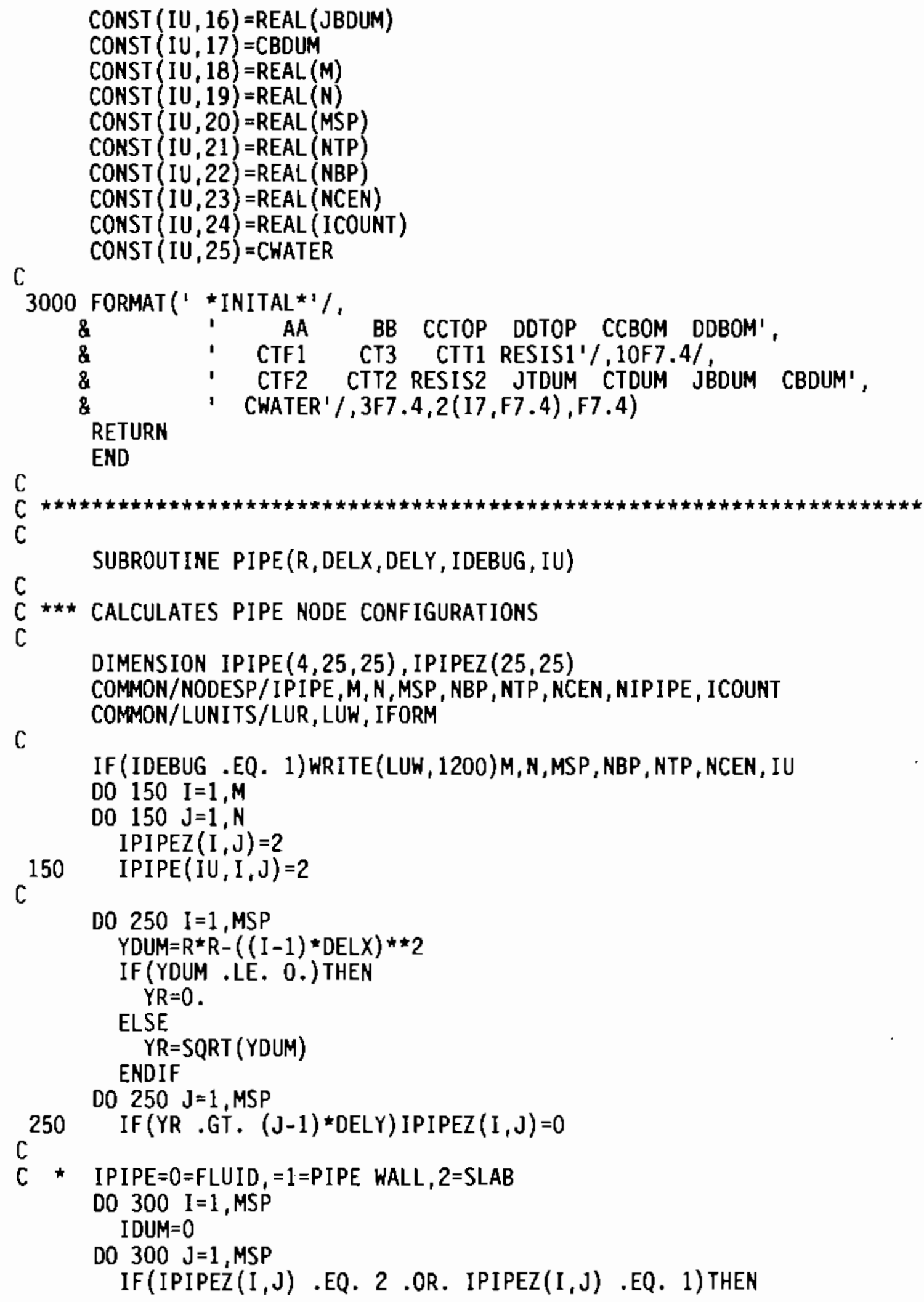




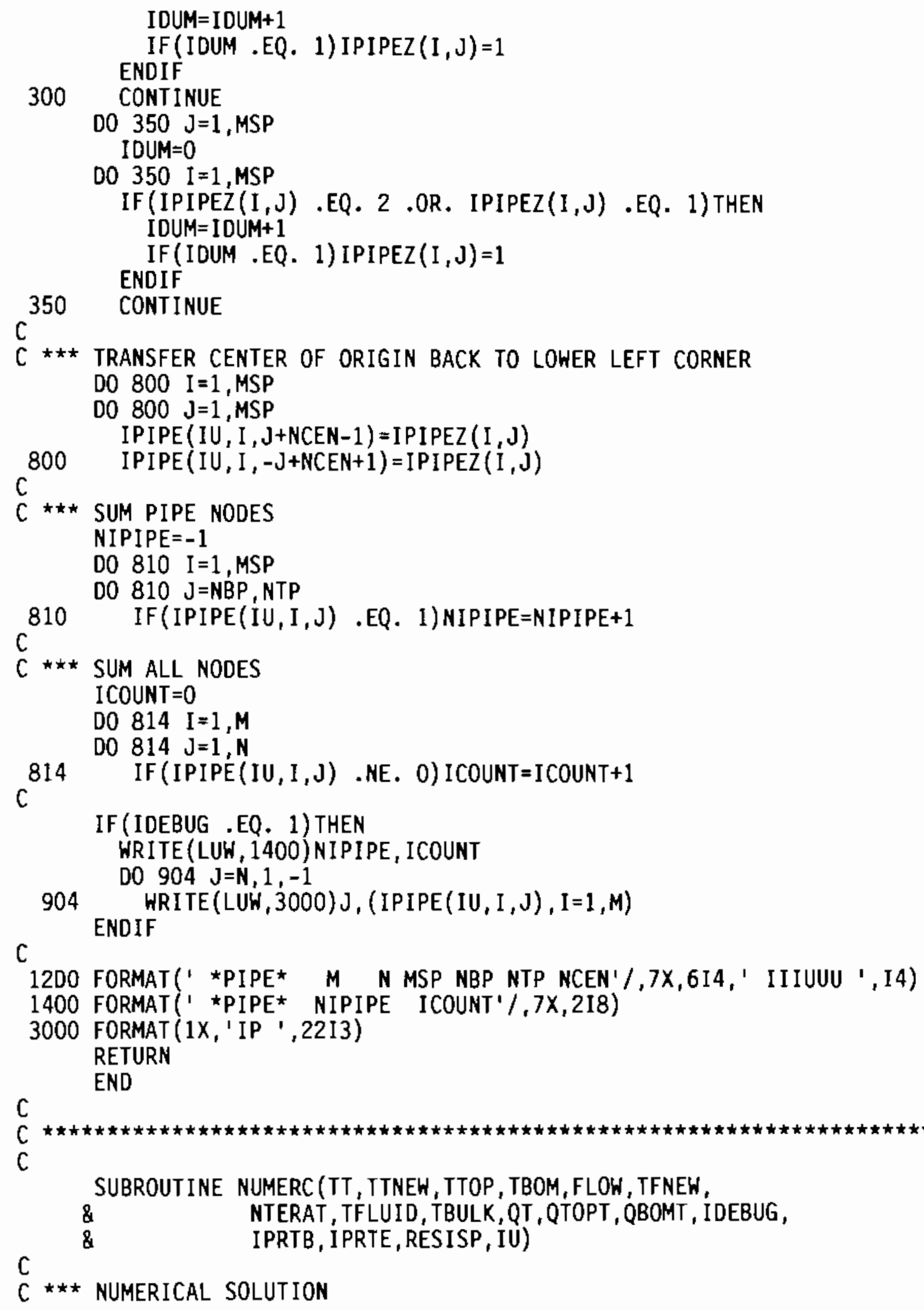




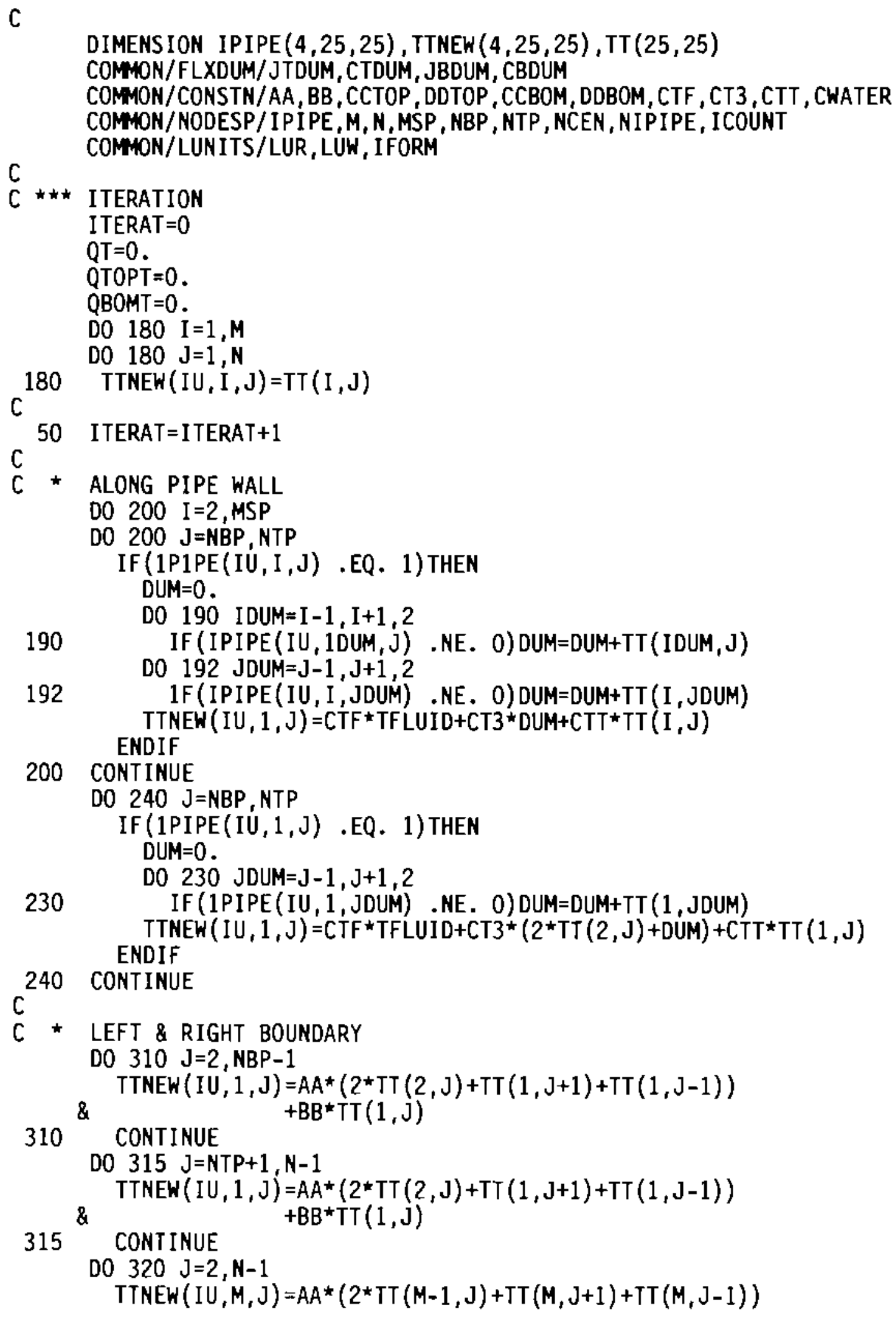




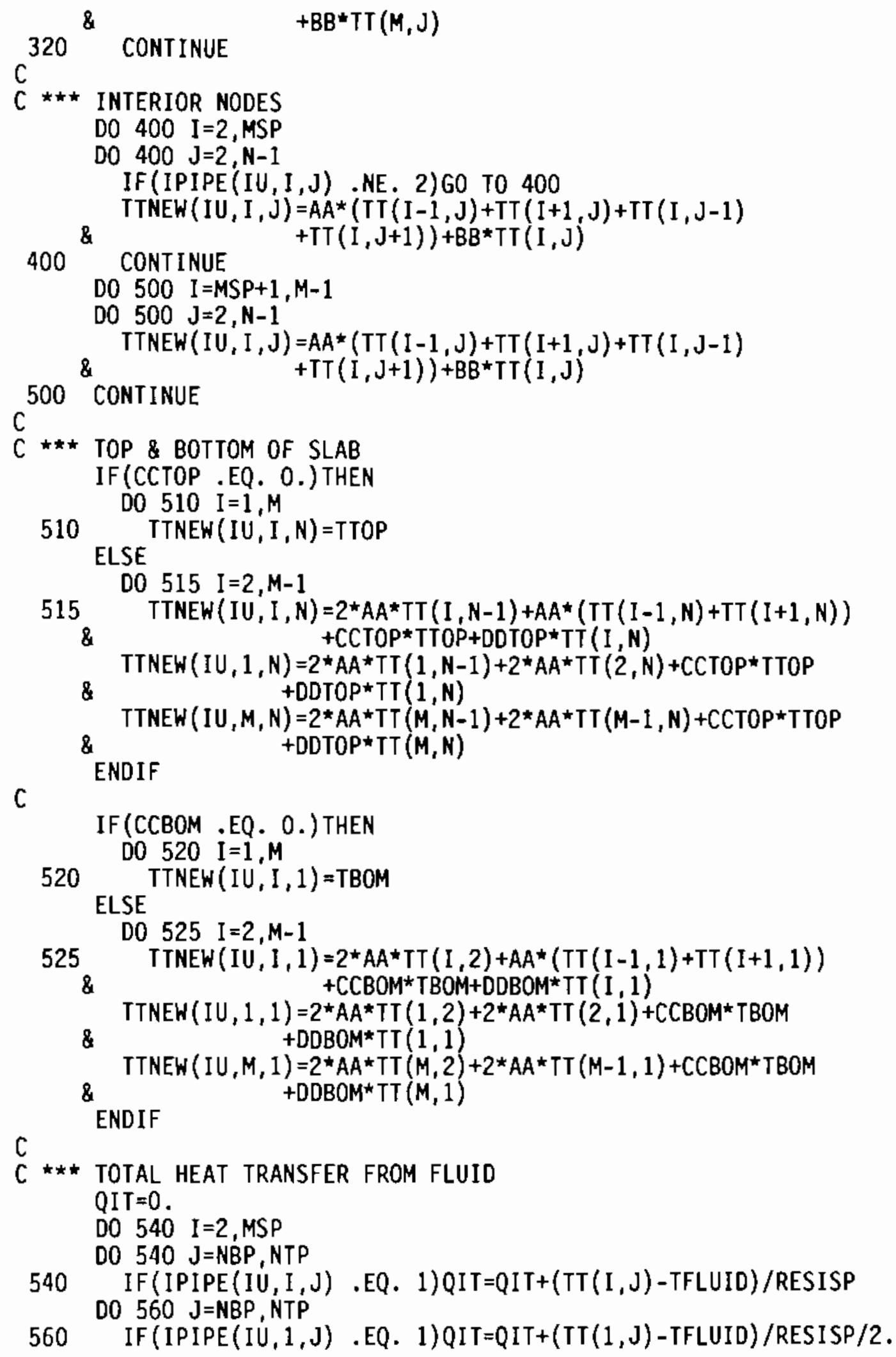




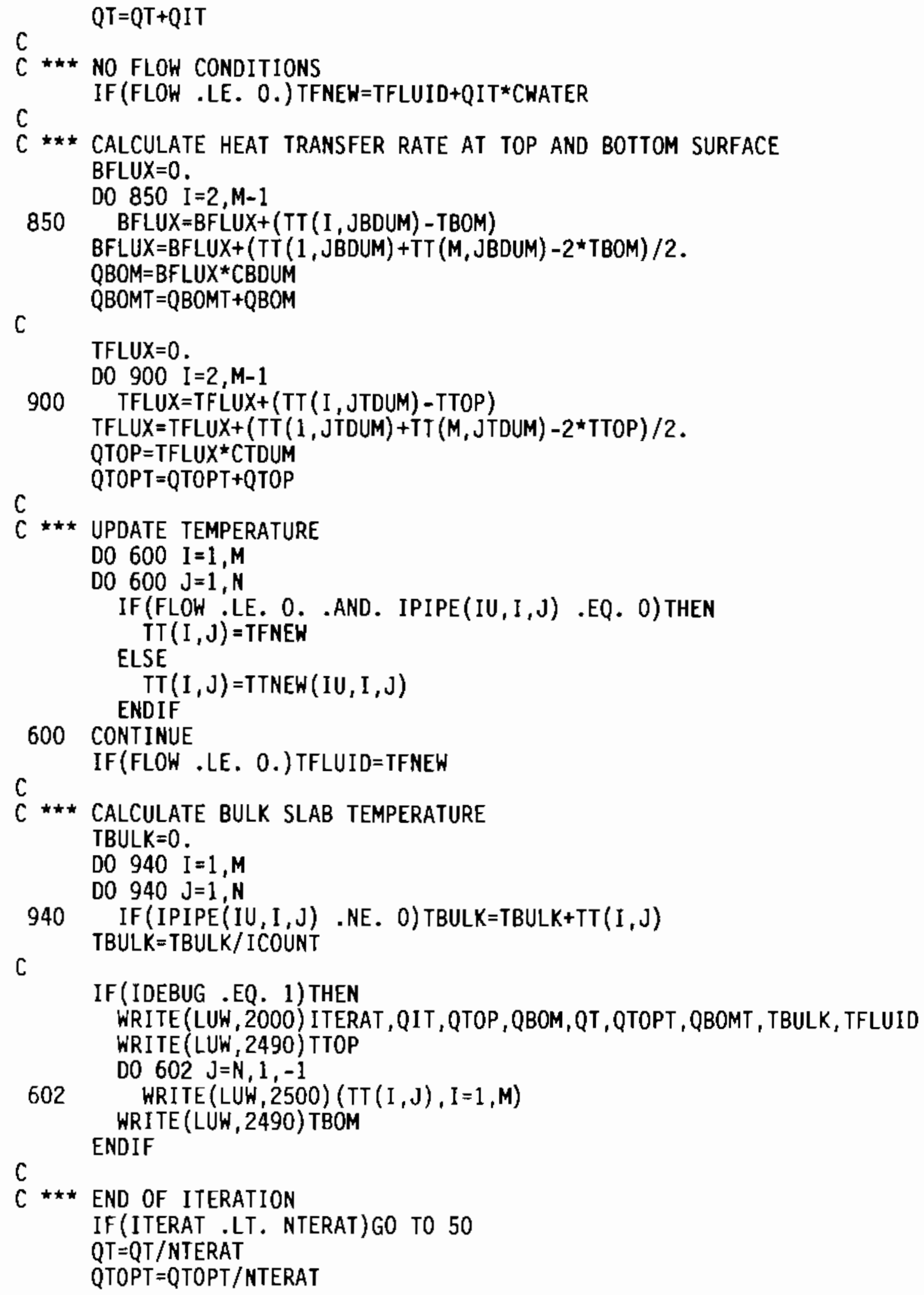




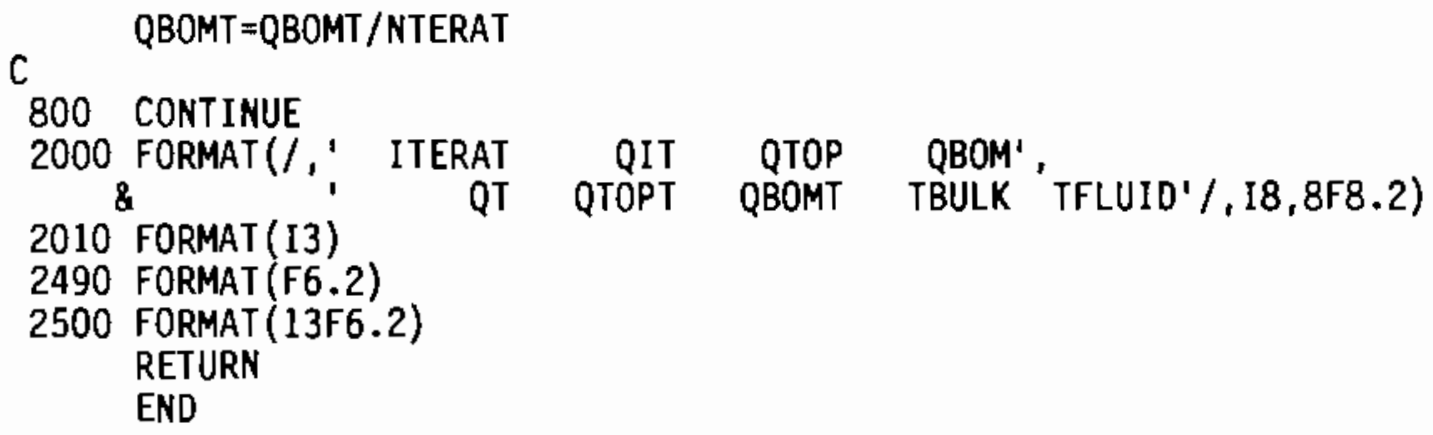




\section{HEAT PUMPS}

SUBROUTINE TYPE50 (TIME, XIN, OUT, T, DTDT, PAR, INF0)

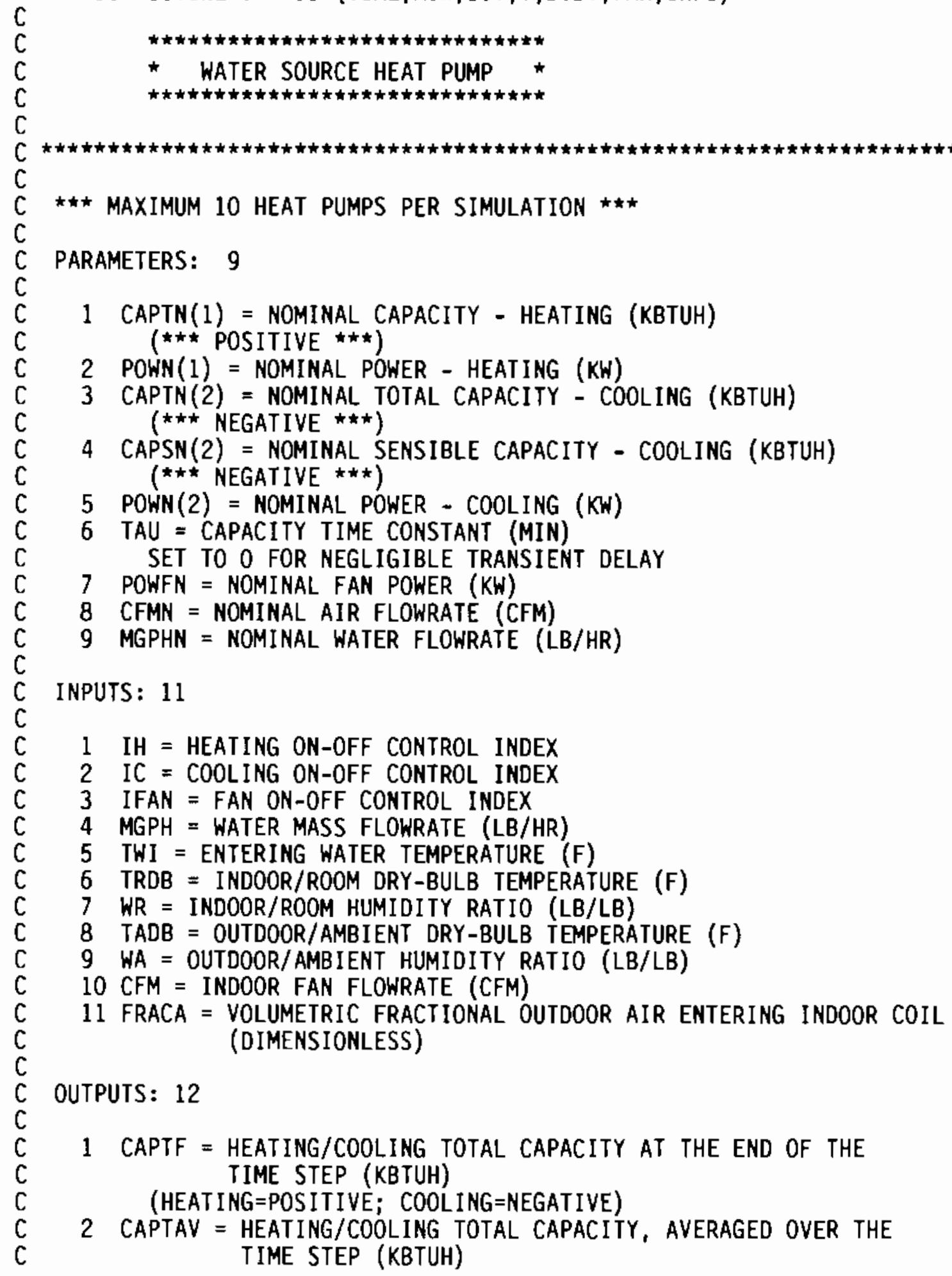




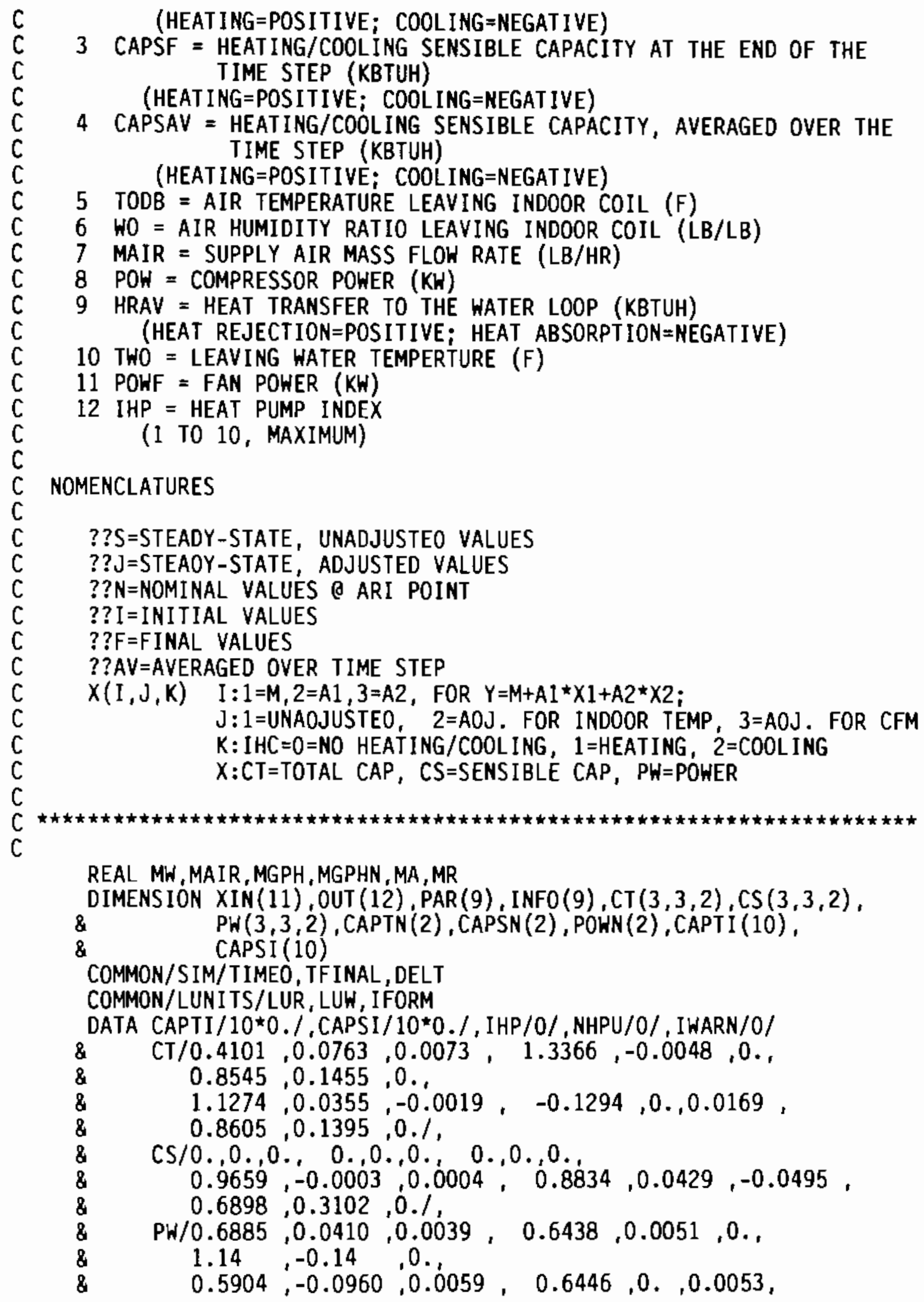




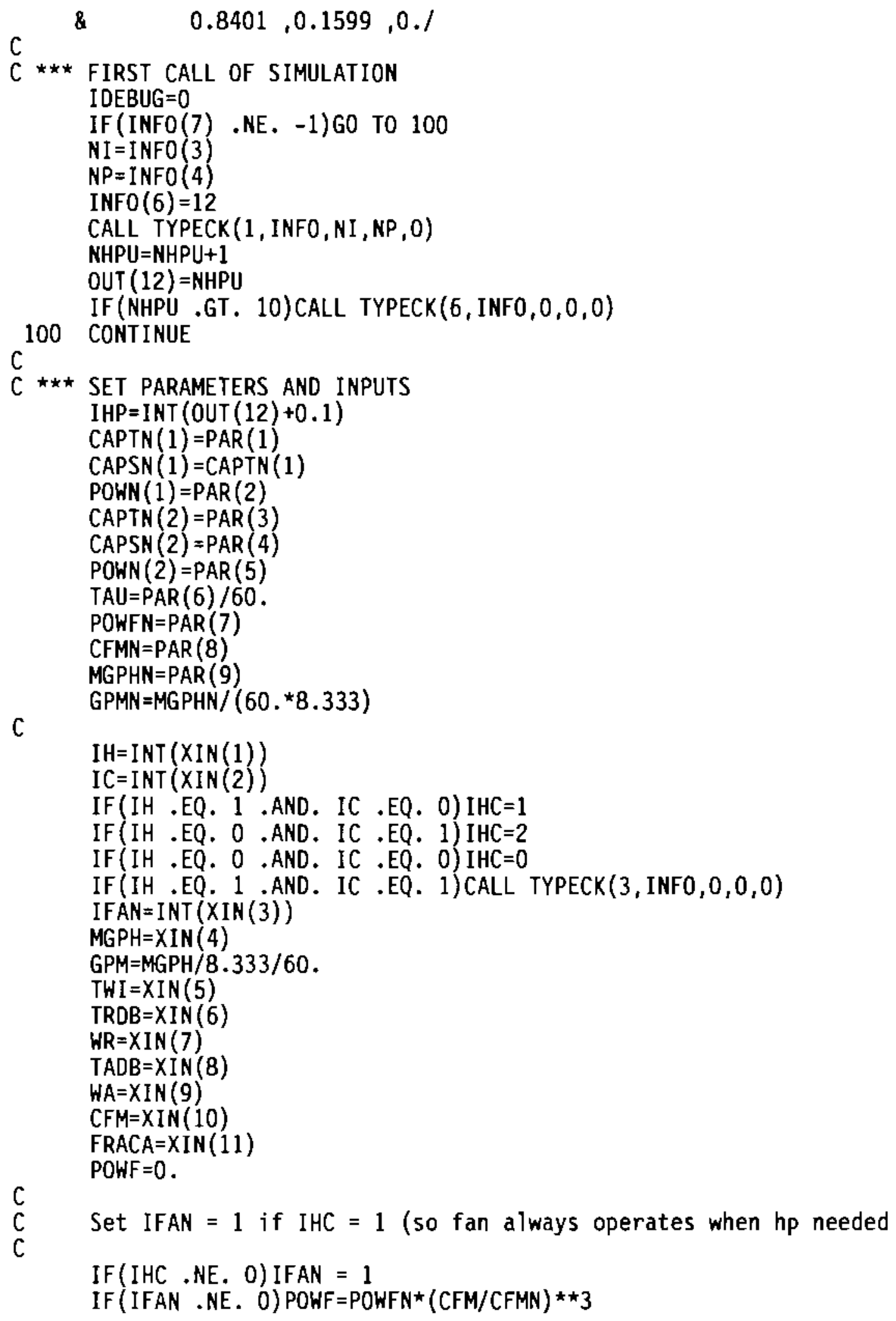




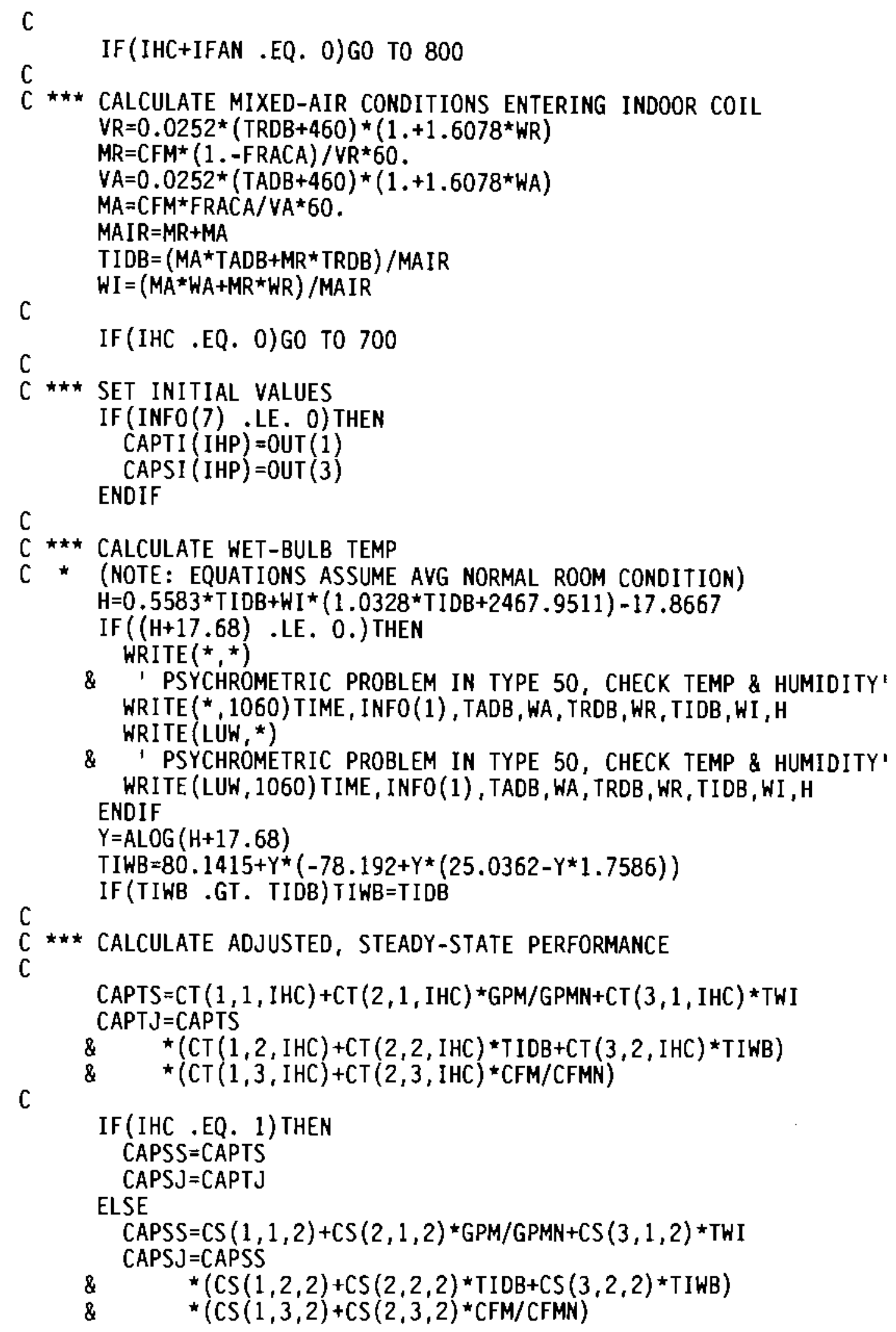


C

ENDIF

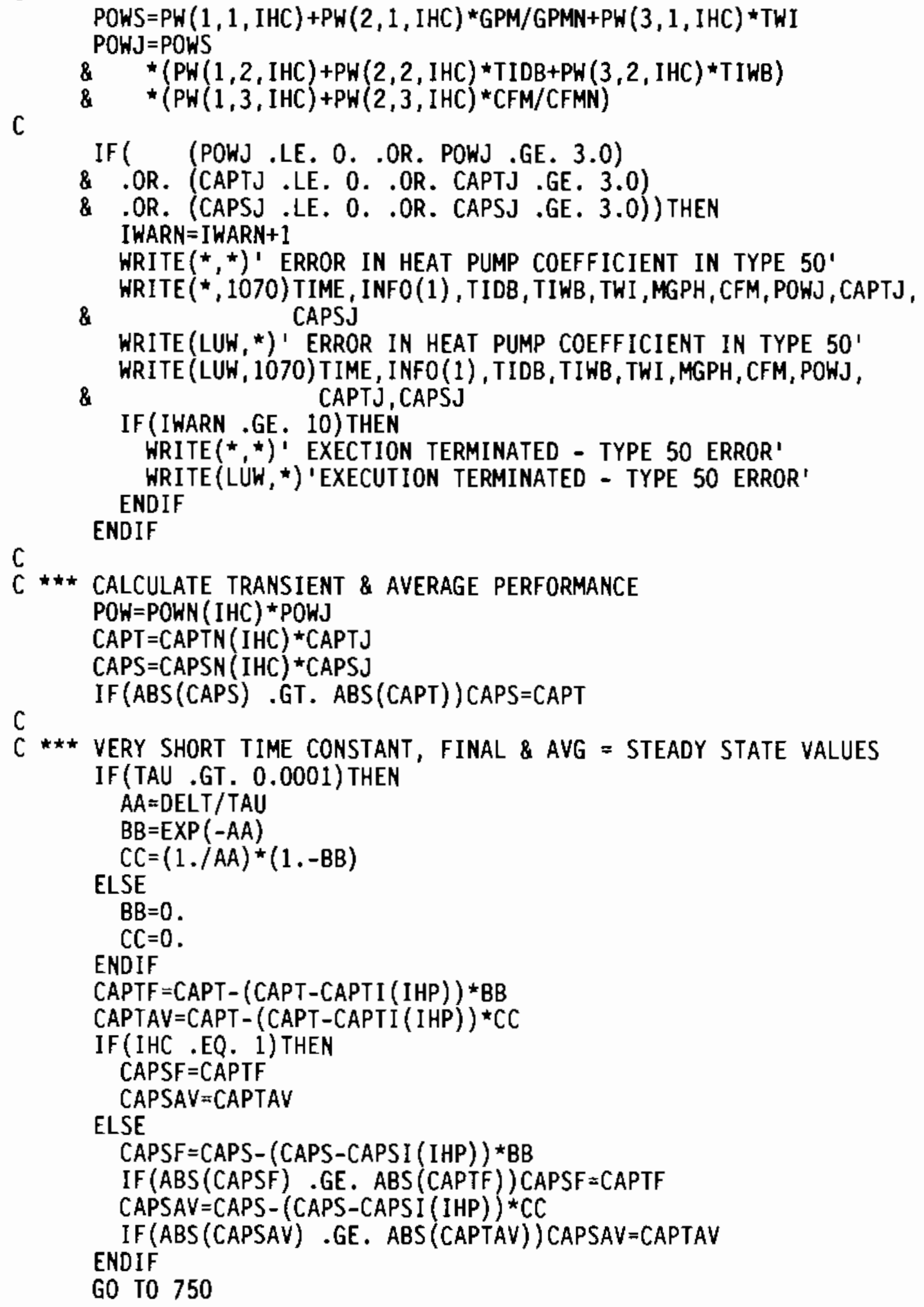




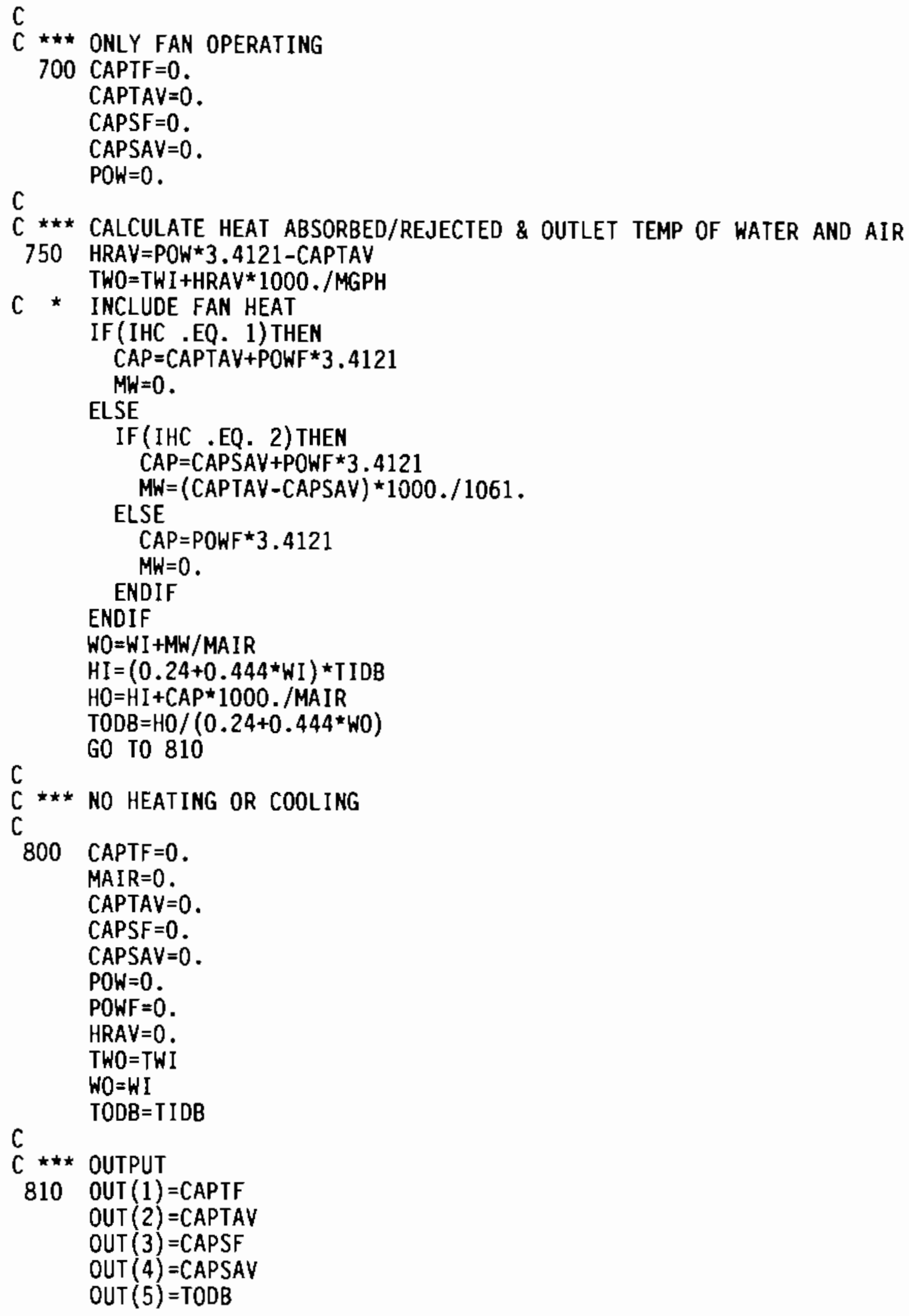




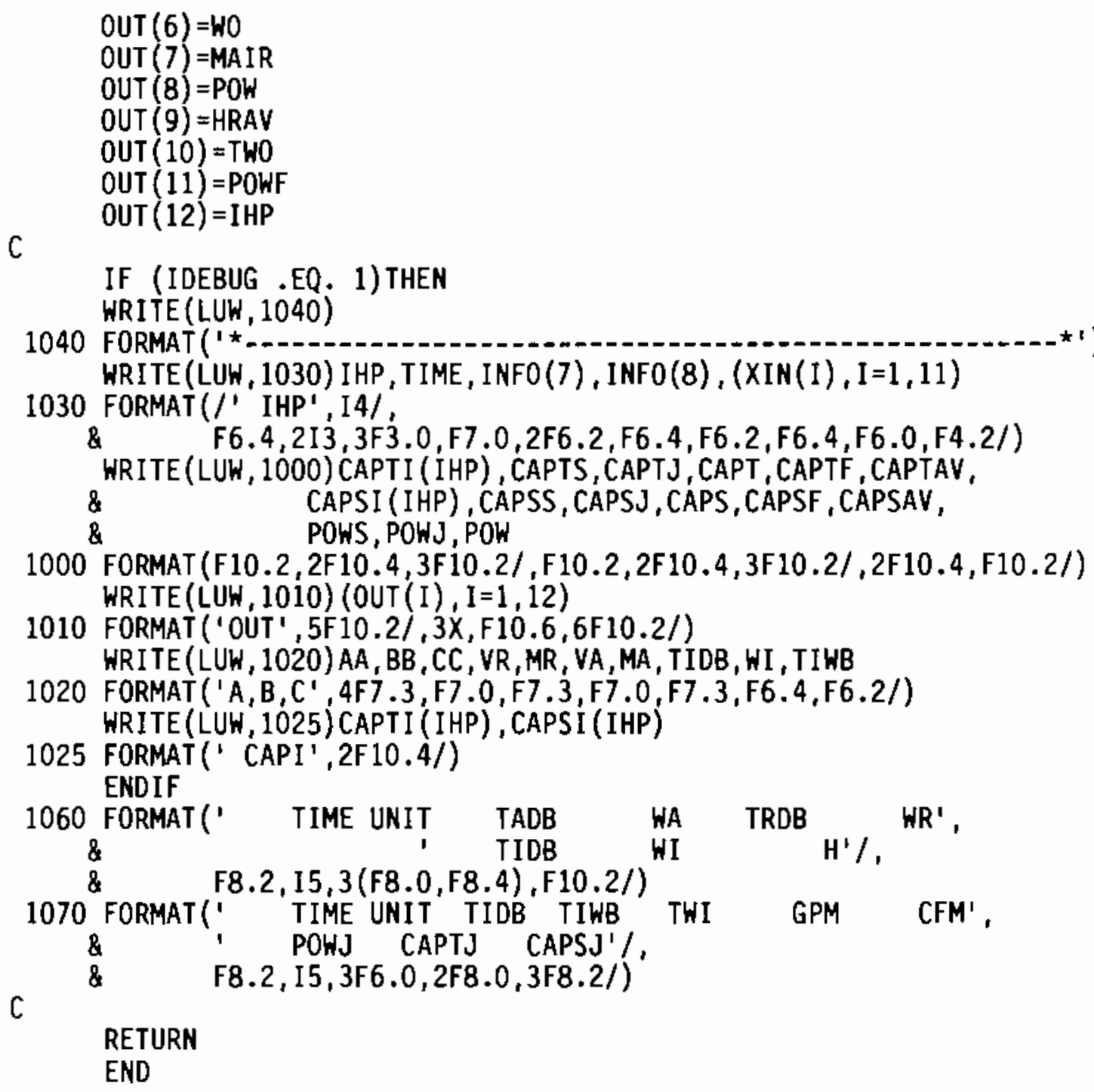


IRNSYS SIMULATION DECK

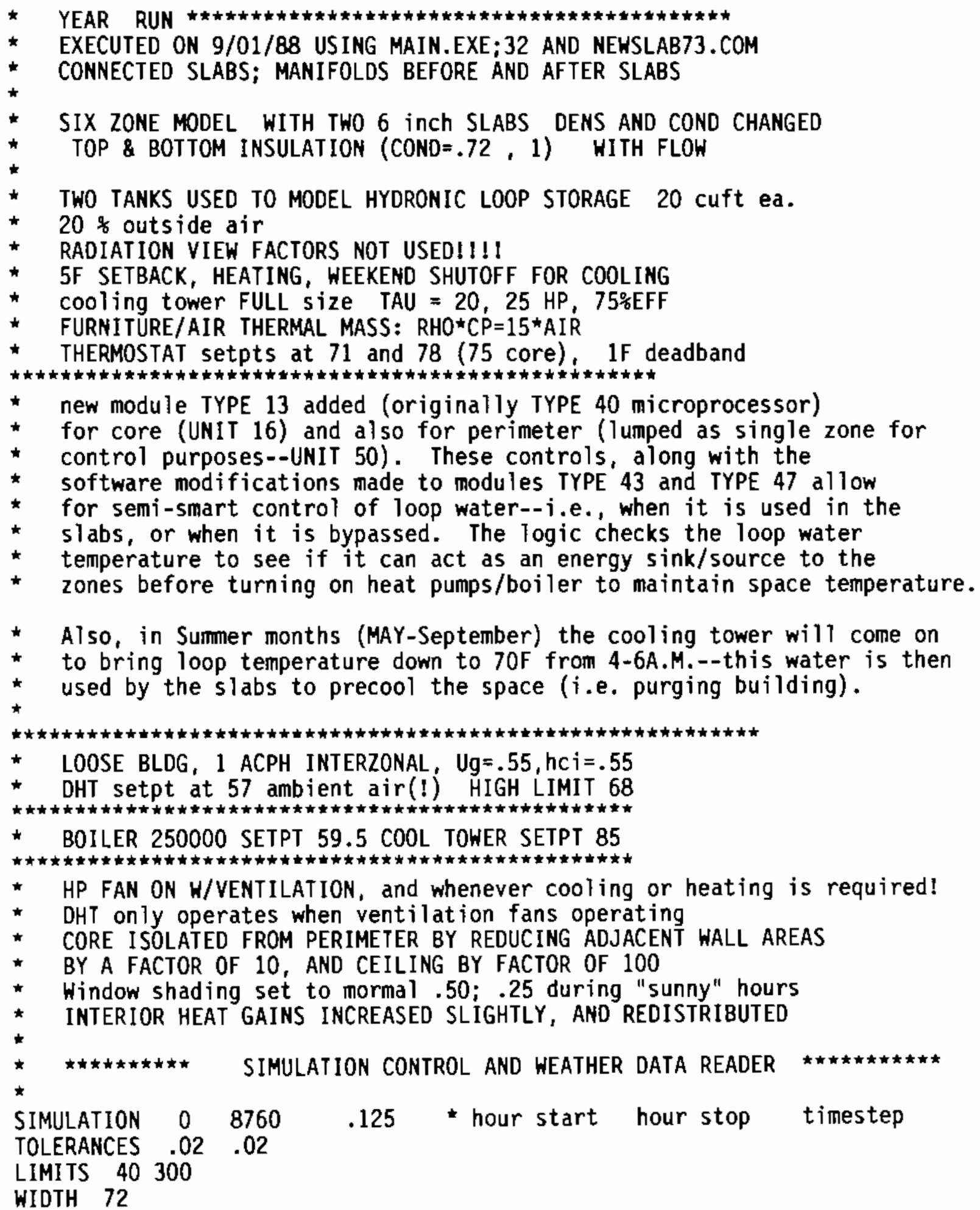




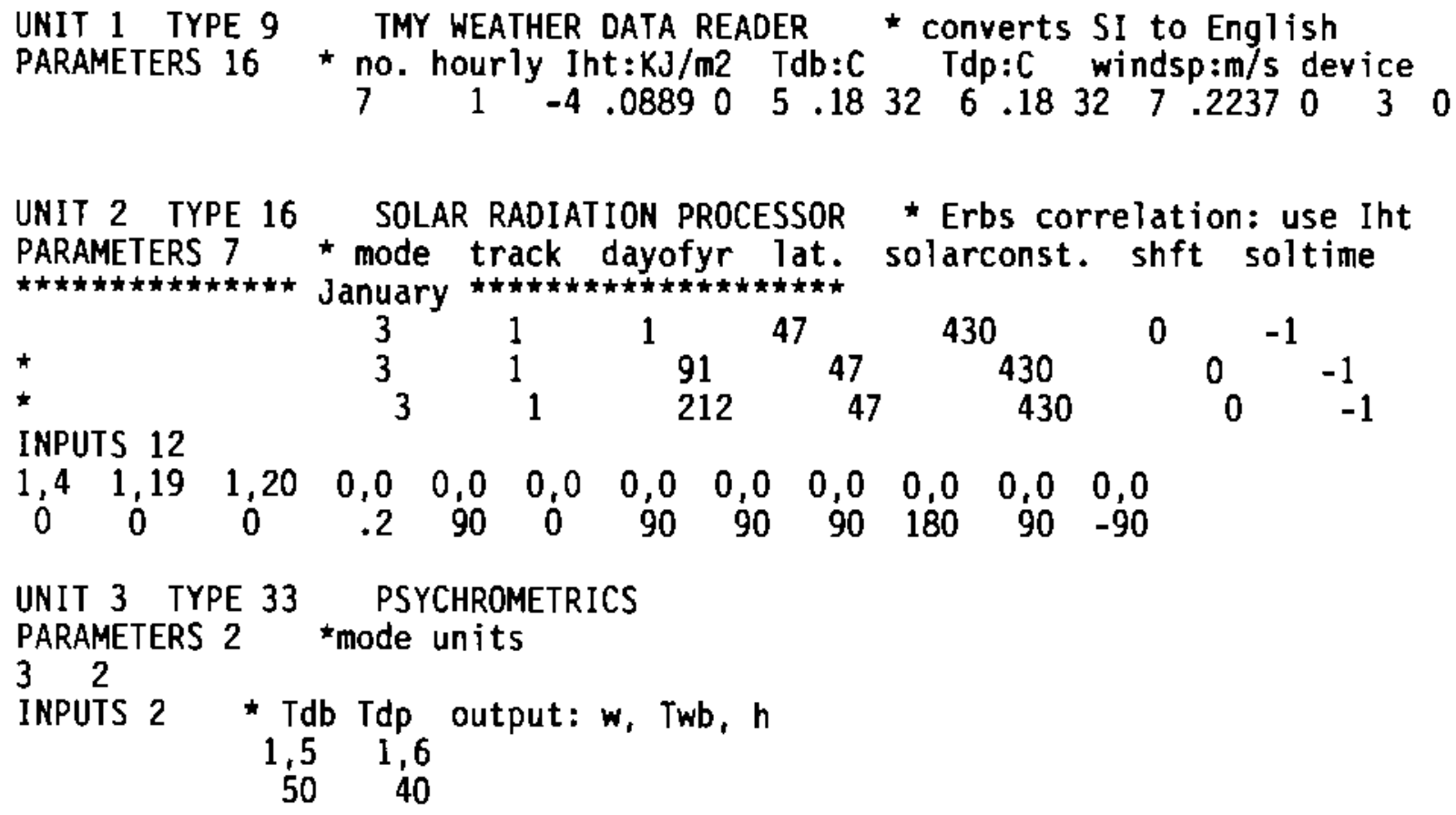


$\begin{array}{lllllll}0 & 1000 & 0 & 400 & 0 & 240 & 1400\end{array}$

ZONE DESCRIPTIONS

UNIT 10 TYPE 19 CORE ZONE

PARAMETERS 10

*mode units vol ac/h k2 k3 furn.cap \#surf Tinit winit (40\%)

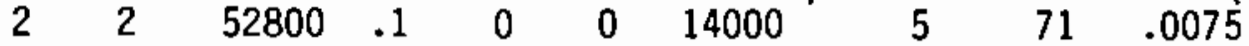

INPUTS 11 *Tamb wamb Tvin mdot wvin wint Nocc actv Qrad Qint wind $\begin{array}{lllllllllll}17,1 & 17,2 & 41,5 & 41,7 & 41,6 & 0,0 & 8,1 & 0,0 & 8,2 & 8,2 & 1,7 \\ 50 & 0 & 71 & 0 & 0 & 0 & 0 & 4 & 0 & 0 & 0\end{array}$

PARAMETERS 5 * CORE ZONE FLOOR

*no. type area refl hc

$\begin{array}{lllll}1 & 4 & 6600 & 0 & 1.08\end{array}$

INPUTS 1

40,2

0

PARAMETERS $17 \star$ CORE ZONE CEILING (LOW MASS SUSPENDED)

*no. type area refl abs icoef hc $\mathrm{Nb} N \mathrm{Nc} N \mathrm{Nd}$

$\begin{array}{llllllllll}2 & 3 & 66 & 0 & 0 & 4 & 1.63 & 3 & 3 & 1\end{array}$

$\begin{array}{lllllll}.23317 & .08172 & .00004 & .41976 & -.1049 & .00006 & -.00493\end{array}$

INPUTS 3 *Tsurf,eq Tplenum UAadd' 1

$\begin{array}{ccc}19,11 & 19,1 & 0,0 \\ 71 & 71 & 0\end{array}$

PARAMETERS 20 * NORTH INTERIOR WALL

*no. type area refl abs icoef hci $\mathrm{Nb} N \mathrm{Nc} N d$

$\begin{array}{lllllllllll}3 & 3 & 88 & 0 & 0 & 4 & 1.46 & 4 & 4 & 2\end{array}$

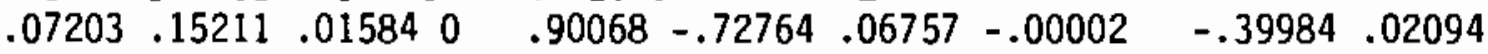

INPUTS 3 *Tsurf,eq Tnorth UAadd' 1

$\begin{array}{rrr}12,13 & 12,1 & 0,0\end{array}$

PARAMETERS 20 * SOUTH INTERIOR WALL

*no. type area refl abs icoef hci Nb Nc Nd

$\begin{array}{llllllllll}4 & 3 & 88 & 0 & 0 & 4 & 1.46 & 4 & 4 & 2\end{array}$

$\begin{array}{llllllllllll}.07203 & .025211 & .01584 & 0 & .90068 & -.72764 & .06757 & -.00002 & -.39984 & .02094\end{array}$

INPUTS 3 *Tsurf, eq Tsouth UAadd' I

$\begin{array}{ccc}17,13 & 17,1 & 0,0 \\ 71 & 71 & 0\end{array}$

PARAMETERS 20 * WEST INTERIOR WALL

*no. type area refl abs icoef hci Nb Nc Nd

$\begin{array}{lllllllllll}5 & 3 & 48 & 0 & 0 & 4 & 1.46 & 4 & 4 & 2\end{array}$

$\begin{array}{llllllllll}.07203 & .020911 & .01584 & 0 & .90068 & -.72764 & .06757 & -.00002 & -.39984 & .02094\end{array}$ 
$\begin{array}{cccc}\text { INPUTS } 3 & \text { *Tsurf,eq } & \text { Tsouth } & \text { UAadd' } 1 \\ & 14,13 & 14,1 & 0,0 \\ 71 & 71 & 0\end{array}$

*PARAMETERS 20 * EAST INTERIOR WALL

*no. type area refl abs icoef hci $\mathrm{Nb} \mathrm{Nc} \mathrm{Nd}$

$\begin{array}{llllllllll}* & 3 & 48 & 0 & 0 & 4 & 1.46 & 4 & 4 & 2\end{array}$

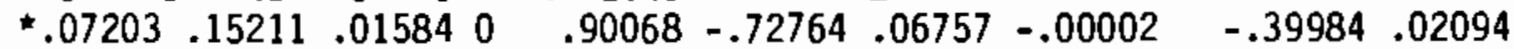

$\star$

${ }^{*}$ INPUTS $3 \quad$ *Tsurf, eq Tsouth UAadd' 1

* 71 71 710

PARAMETERS 1 * VIEW FACTORS--NOT USED

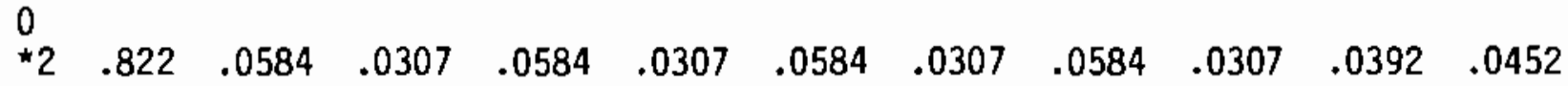

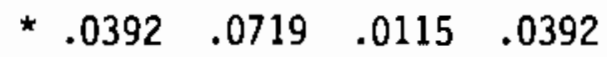

PARAMETERS 11 * OPTIONAL OUTPUTS--EQUIVALENT ROOM TEMP. OF ADJ. ZONE

$\begin{array}{lllllllllll}5 & 1 & 1 & 2 & 2 & 2 & 3 & 2 & 4 & 2 & 5\end{array}$

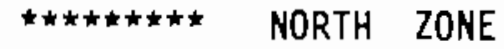

UNIT 11 TYPE 14 WINDOW SHADING ALL ZONES (TRANSMITTANCE MODIFIER)

PARAMETERS 45 * timel taul time2 tau2...

$\begin{array}{llllllllllllll}4 & 6 & 0 & .50 & 6 & .50 & 6 & .25 & 18 & .25 & 18 & .50 & 24 & .50\end{array}$

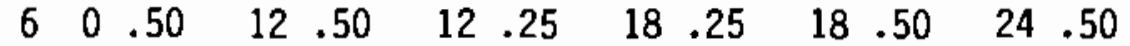

$\begin{array}{lllll}2 & 0 & .50 & 24.50\end{array}$

$\begin{array}{lllllllllllll}6 & 0 & .50 & 6 & .50 & 6 & .25 & 12 & .25 & 12 & .50 & 24 & .50\end{array}$

UNIT 12 TYPE 19 NORTH PERIMETER ZONE

PARAMETERS 10

*mode units vol ac/h k2 k3 cap \#surf Tinit winit $\begin{array}{llllllllll}2 & 2 & 20800 & .1 & .0128 & .031 & 5550 & 5 & 71 & .0075\end{array}$ INPUTS 11

* Tamb wamb Tvin mdot wrin wint Nocc actv Qrad Qint wind

$$
\begin{array}{ccccccccccc}
1,5 & 3,1 & 43,5 & 43,7 & 43,6 & 0,0 & 8,3 & 0,0 & 8,4 & 8,4 & 1,7 \\
50 & 0 & 71 & 0 & 0 & 0 & 0 & 4 & 0 & 0 & 0
\end{array}
$$

PARAMETERS 29 * EXTERIOR WALL NORTH ZONE

*no. type area refl abs icoef hc Nb Nc Nd $\begin{array}{llllllllll}1 & 1 & 300 & .5 & .7 & 4 & 1.2 & 7 & 7 & 5\end{array}$

$\begin{array}{lllllll}0.00078 & .00387 & .00267 & .00032 & .00001 & 0\end{array}$

$\begin{array}{lllllll}.79537 & -1.65181 & 1.09955 & -.24727 & .01184 & -.00005 & 0\end{array}$

$\begin{array}{lllll}-1.46336 & .63577 & -.09710 & .00401 & .00002\end{array}$

INPUTS 1 * total incident solar radiation 2,14
} 
0

PARAMETERS $5 \quad * \quad$ NORTH ZONE FLOOR

*no. type area refl hc

$\begin{array}{lllll}2 & 4 & 2600 & 0 & 1.08\end{array}$

INPUTS 1

42,2

0

PARAMETERS 17 * NORTH ZONE CEILING

*no. type area refl abs icoef hc $\mathrm{Nb} N \mathrm{NC} N$

$\begin{array}{llllllllll}3 & 3 & 2600 & 0 & 0 & 4 & 1.63 & 3 & 3 & 1\end{array}$

$\begin{array}{lllllll}.23317 & .08172 & .00004 & .41976 & -.1049 & .00006 & -.00493\end{array}$

INPUTS 3 *Tsurf, eq Tplenum UAadd' 1

$$
\begin{array}{ccc}
19,12 & 19,1 & 0,0
\end{array}
$$

PARAMETERS 20 * INTERIOR WALL SEPARATING CORE FROM NORTH ZONE

*no. type area refl abs icoef he Nb Nc Nd

$\begin{array}{lllllllllll}4 & 3 & 88 & .5 & .7 & 4 & 1 & 4 & 4 & 2\end{array}$

$\begin{array}{llllllllllll}.07203 & .15211 & .01584 & 0 & .90068 & -.72764 & .06757 & -.00002 & -.39984 & .02094\end{array}$

INPUTS 3 *Tsurf, eq Tcore UAadd' 1 $\begin{array}{crr}10,13 & 10,1 & 0,0 \\ 71 & 71 & 0\end{array}$

PARAMETERS 8 * NORTH W1NDOW

*no. type area mode taud hci NI s1

$\begin{array}{llllllll}5 & 5 & 900 & 1 & .8 & .55 & 1 & 2\end{array}$

INPUTS $5{ }^{*} \mathrm{IT}$ IbT Tau $\mathrm{Ug} \mathrm{fkl}$

$\begin{array}{ccccc}2,14 & 2,15 & 11,3 & 0,0 & 0,0 \\ 0 & 0 & .86 & .55\end{array}$

PARAMETERS 1 * VIEW FACTORS--NOT IN PROBLEM!

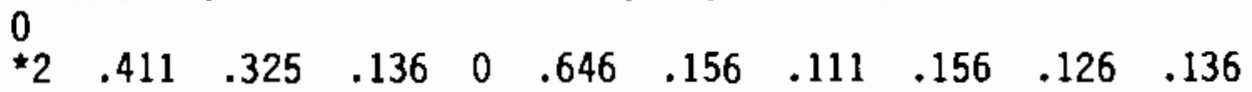

PARAMETERS 7 * OPTIONAL OUTPUTS--EQUIVALENT ROOM TEMP. OF ADJ. ZONE

$\begin{array}{lllllll}3 & 1 & 2 & 2 & 3 & 2 & 4\end{array}$

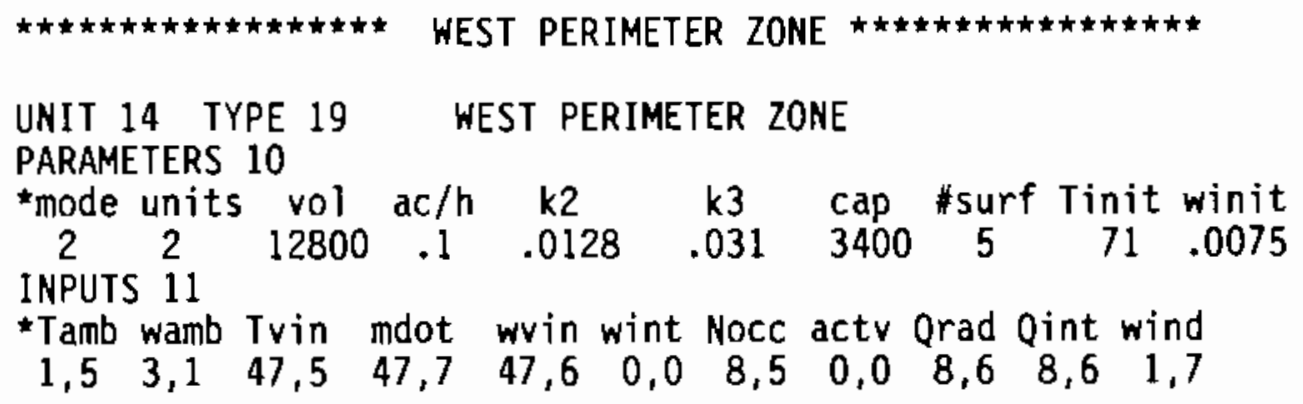




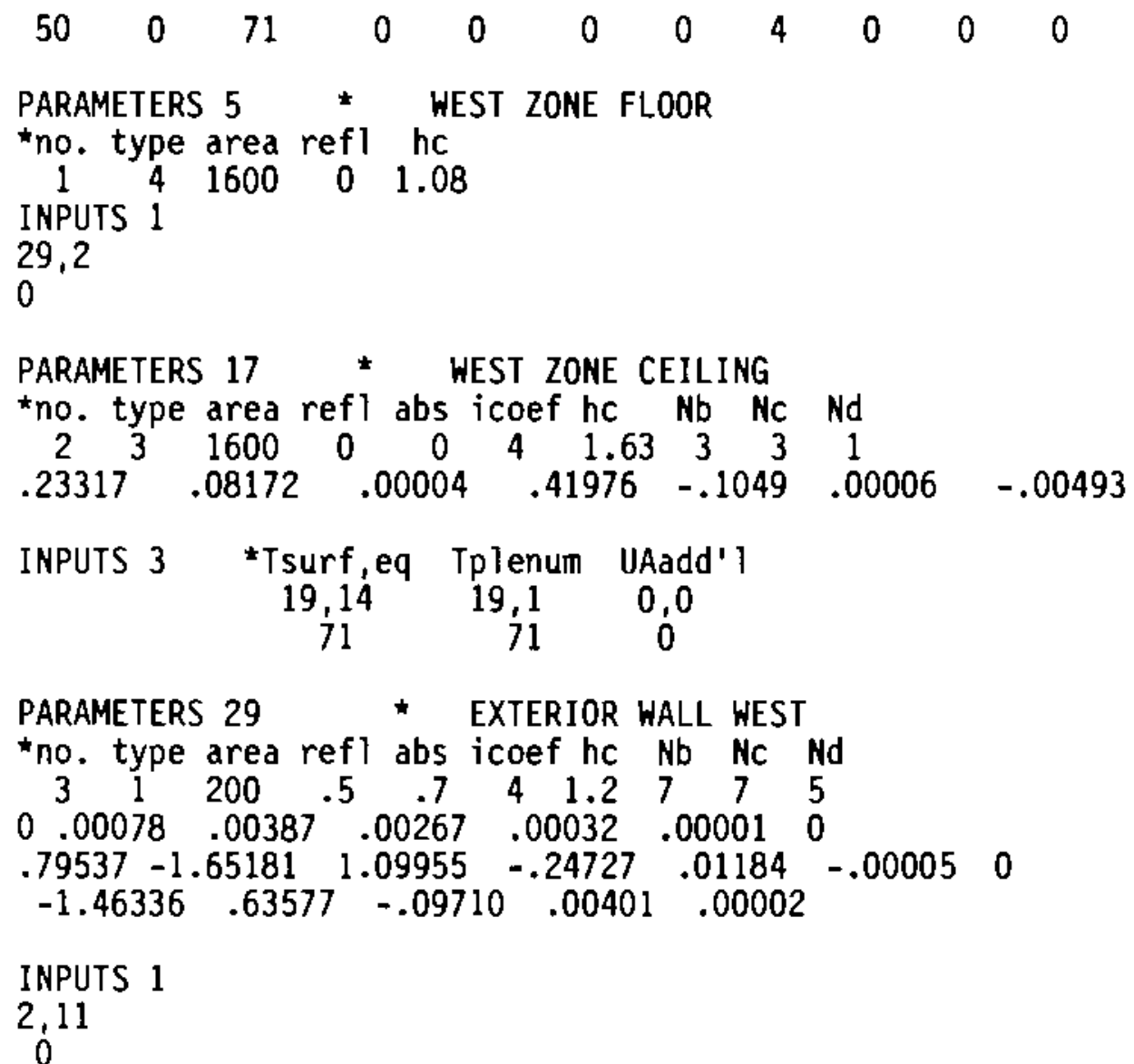

PARAMETERS 20 INTERIOR WALL SEPARATING CORE FROM WEST ZONE

*no. type area refl abs icoef hc $\mathrm{Nb} \mathrm{Nc} N \mathrm{Nd}$

$$
\begin{array}{cccccccccccc}
4 & 3 & 48 & .5 & .7 & 4 & 1.63 & 4 & 4 & 2 & & \\
.07203 & .15211 & .01584 & 0 & .90068 & -.72764 & .06757 & -.00002 & -.39984 & .02094
\end{array}
$$

INPUTS 3 *Tsurf,eq Tcore UAadd' 1

$$
\begin{array}{crr}
10,15 & 10,1 & 0,0 \\
71 & 71 & 0
\end{array}
$$

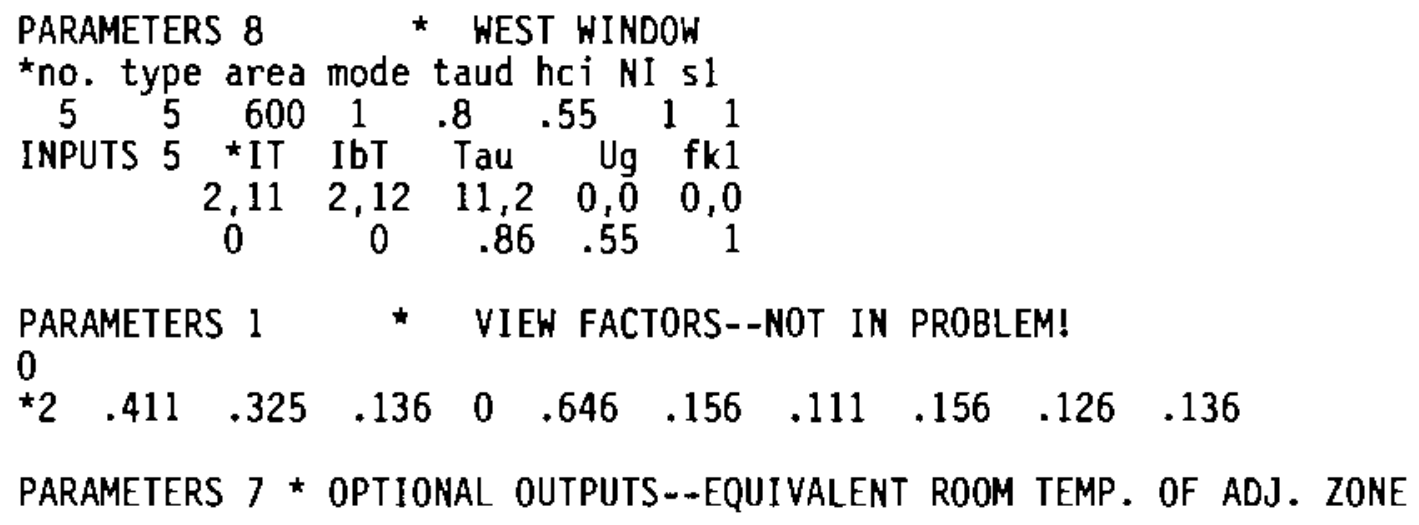




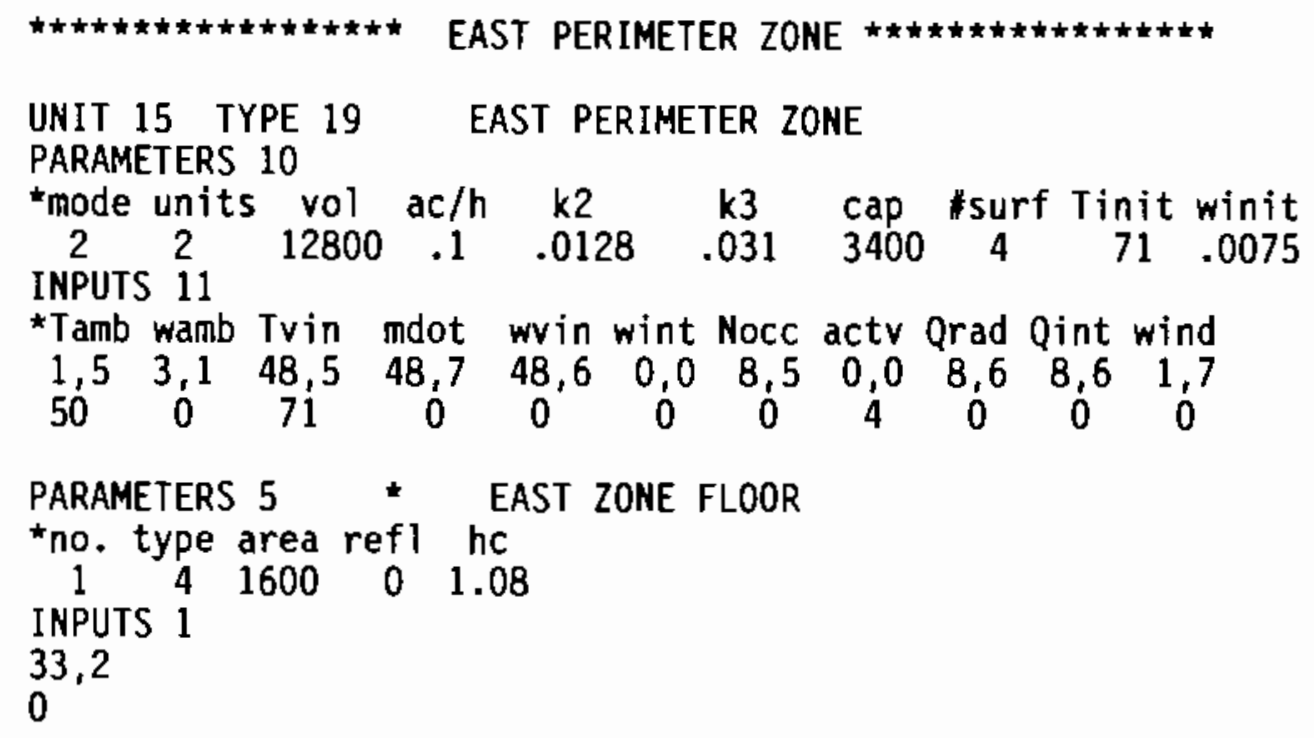

0

PARAMETERS $17 \quad$ EAST ZONE CEILING

*no. type area refl abs icoef hc Nb Nc Nd

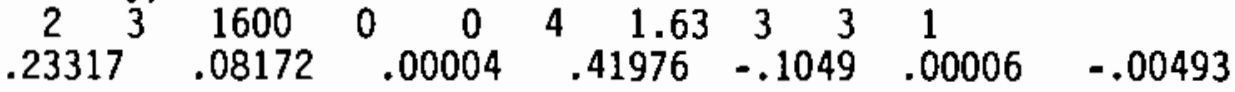

INPUTS 3 *Tsurf,eq Tplenum UAadd' 1

$$
\begin{array}{ccc}
19,15 & 19,1 & 0,0 \\
71 & 71 & 0
\end{array}
$$

PARAMETERS 29 EXTERIOR WALL EAST

*no. type area refl abs icoef hc $\mathrm{Nb} N \mathrm{NC} N$

$\begin{array}{llllllllll}3 & 1 & 200 & .5 & .7 & 4 & 1.2 & 7 & 7 & 5\end{array}$

$\begin{array}{lllllll}0.00078 & .00387 & .00267 & .00032 & .00001 & 0\end{array}$

$\begin{array}{lllllll}.79537 & -1.65181 & 1.09955 & -.24727 & .01184 & -.00005 & 0\end{array}$

$\begin{array}{llllll}-1.46336 & .63577 & -.09710 & .00401 & .00002\end{array}$

INPUTS 1 * total incident solar radiation

2,17

0

*PARAMETERS 20 * INTERIOR WALl SEPARATING CORE FROH EAST ZONE

*no. type area refl abs icoef hc Nb Nc Nd

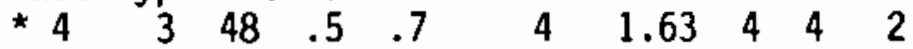

$\begin{array}{llllllllllll}\star & \star 07203.02094\end{array}$

*INPUTS 3 *Tsurf,eq Tcore UAadd' 1

$\begin{array}{cccc}* & 10,16 & 10,1 & 0,0 \\ * & 71 & 71 & 0\end{array}$

PARAMETERS 8 * EAST WINDOW 


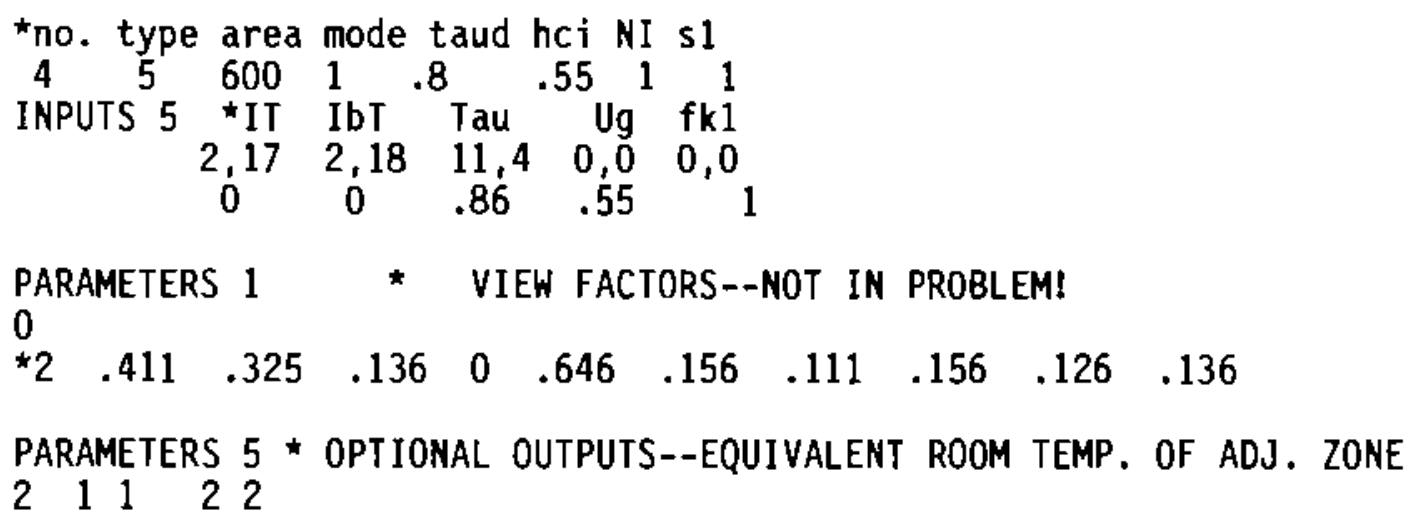

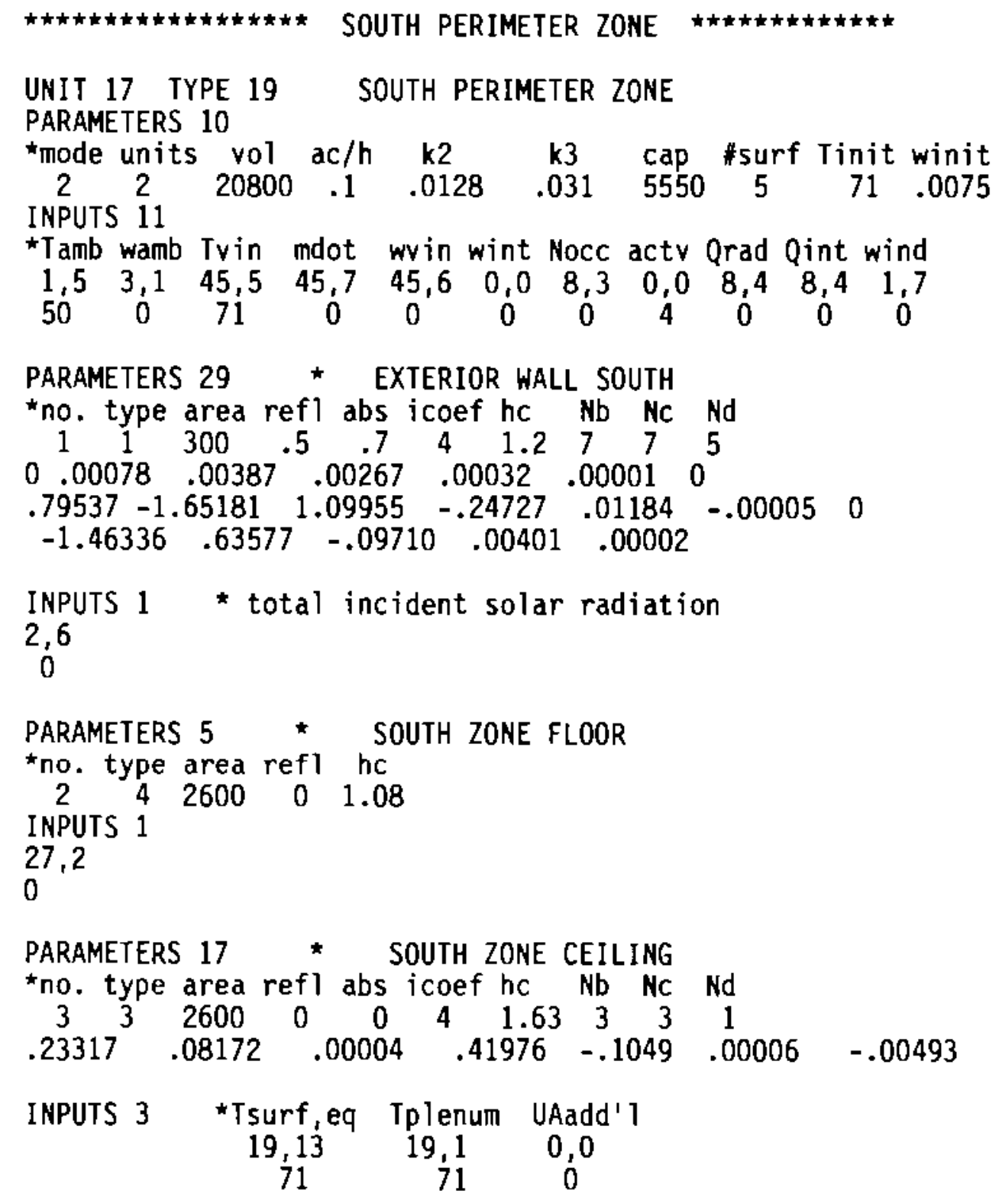


PARAMETERS 20 * INTERIOR WALL SEPARATING CORE FROM S ZONE

*no. type area reft abs icoef hc Nb Nc Nd

$\begin{array}{llllllllll}4 & 3 & 88 & .5 & .7 & 4 & 1.2 & 4 & 4 & 2\end{array}$

$\begin{array}{llllllllll}.07203 & .025211 & .01584 & 0 & .90068 & -.72764 & .06757 & -.00002 & -.39984 & .02094\end{array}$

INPUTS 3 ॠTsurf, eq Tcore UAadd'1

$$
\begin{array}{ccc}
10,14 & 10,1 & 0,0 \\
71 & 71 & 0
\end{array}
$$

PARAMETERS 8 * SOUTH WINDOW

*no. type area mode taud hci NI sl

$\begin{array}{llllllll}5 & 5 & 900 & 1 & .8 & .55 & 1 & 2\end{array}$

INPUTS 5 *IT IbT Tau Ug fkI

$2,6 \quad 2,7 \quad 11,1 \quad 0,0 \quad 0,0$

PARAMETERS 1 * VIEW FACTORS--NOT IN PROBLEM!

$\begin{array}{llllllllllll}0 & \star 2 & .411 & .325 & .136 & 0 & .646 & .156 & .111 & .156 & .126 & .136\end{array}$

PARAMETERS 7 * OPTIONAL OUTPUTS--EQUIVALENT ROOM TEMP. OF ADJ. ZONE $\begin{array}{lllllll}3 & 1 & 2 & 2 & 3 & 2 & 4\end{array}$

UNIT 19 TYPE 19 COMMON PLENUM ZONE

PARAMETERS $10 \star 1500 \mathrm{s.f.} \times 3.5 \mathrm{ft}$.

*mode units vol ac/h k2 k3 cap \#surf Tinit winit

$\begin{array}{llllllllll}2 & 2 & 52500 & 0.1 & 0.0128 & .031 & 26300 & 15 & 71 & .0075\end{array}$

INPUTS 11

* Tamb wamb Trin mdot win wint Nocc actv Qrad Qint wind $\begin{array}{ccccccccccc}1,5 & 3,1 & 32,1 & 32,2 & 3,1 & 0,0 & 0,0 & 0,0 & 8,7 & 8,7 & 1,7 \\ 50 & 0 & 71 & 0 & 0 & 0 & 0 & 4 & 0 & 0 & 0\end{array}$

PARAMETERS 29 * SOUTH EXTERIOR WALL PLENUM ZONE

*no. type area refl abs icoef hc $\mathrm{Nb} N \mathrm{Nc} N d$ $\begin{array}{llllllllll}1 & 1 & 600 & .5 & .7 & 4 & 1.2 & 7 & 7 & 5\end{array}$

$\begin{array}{lllllll}0.00078 & .00387 & .00267 & .00032 & .00001 & 0\end{array}$

$\begin{array}{lllllll}.79537 & -1.65181 & 1.09955 & -.24727 & .01184 & -.00005 & 0\end{array}$

$\begin{array}{lllll}-1.46336 & .63577 & -.09710 & .00401 & .00002\end{array}$

INPUTS 1 * total incident solar radiation

2,6

PARAMETERS 29 * PLENUM ZONE WEST EXIERIOR WALL

\#no. type area refl abs icoef hc $\mathrm{Nb}$ Nc $\mathrm{Nd}$

$\begin{array}{llllllllll}2 & 1 & 400 & .5 & .7 & 4 & 1.2 & 7 & 7 & 5\end{array}$

$\begin{array}{lllllll}0 & .00078 & .00387 & .00267 & .00032 & .00001 & 0\end{array}$ 


$$
\begin{aligned}
& \begin{array}{lllllll}
.79537 & -1.65181 & 1.09955 & -.24727 & .01184 & -.00005 & 0
\end{array} \\
& \begin{array}{llllll}
-1.46336 & .63577 & -.09710 & .00401 & .00002
\end{array} \\
& \text { INPUTS } 1 \text { * total incident solar radiation } \\
& 2,11 \\
& 0
\end{aligned}
$$

PARAMETERS 29 * PLENUM ZONE NORTH EXTERIOR WALL

*no. type area refl abs icoef hc Nb Nc Nd

$\begin{array}{llllllllll}3 & 1 & 600 & .5 & .7 & 4 & 1.2 & 7 & 7 & 5\end{array}$

$\begin{array}{lllllll}0.00078 & .00387 & .00267 & .00032 & .00001 & 0\end{array}$

$\begin{array}{llllllll}.79537 & -1.65181 & 1.09955 & -.24727 & .01184 & -.00005 & 0\end{array}$

$\begin{array}{llllll}-1.46336 & .63577 & -.09710 & .00401 & .00002\end{array}$

INPUTS 1 * total incident solar radiation

2,14

0

PARAMETERS 29 * PLENUM ZONE EAST EXTER10R WALL

*no. type area refl abs icoef hc Nb Nc Nd

$\begin{array}{llllllllll}4 & 1 & 400 & .5 & .7 & 4 & 1.2 & 7 & 7 & 5\end{array}$

$\begin{array}{lllllll}0.00078 & .00387 & .00267 & .00032 & .00001 & 0\end{array}$

$\begin{array}{llllllll}.79537 & -1.65181 & 1.09955 & -.24727 & .01184 & -.00005 & 0\end{array}$

$\begin{array}{llllll}-1.46336 & .63577 & -.09710 & .00401 & .00002\end{array}$

INPUTS 1 * total incident solar radiation

2,17

PARAMETERS 17 * ZONE CEILING: ADJ. TO CORE

*no. type area refl abs icoef hc Nb Nc Nd

$\begin{array}{llllllllll}5 & 3 & 66 & 0 & 0 & 4 & 1.63 & 3 & 3 & 1\end{array}$

$\begin{array}{llllllll}.23317 & .08172 & .00004 & .41976 & -.1049 & .00006 & -.00493\end{array}$

INPUTS 3 *Tsurf, eq Tcore UAadd' 1

$$
\begin{array}{ccc}
10,12 & 10,1 & 0,0 \\
71 & 71 & 0
\end{array}
$$

PARAMETERS 17 * ZONE CEILING: ADJ. TO NORTH PERIMETER ZONE

*no. type area refl abs icoef hc $\mathrm{Nb} \mathrm{Nc} N \mathrm{Nd}$

$\begin{array}{llllllllll}6 & 3 & 2600 & 0 & 0 & 4 & 1.63 & 3 & 3 & 1\end{array}$

$\begin{array}{llllllll}.23317 & .08172 & .00004 & .41976 & -.1049 & .00006 & -.00493\end{array}$

INPUTS 3 *Tsurf, eq Tsouth UAadd' 1

$$
\begin{array}{ccc}
12,12 & 12,1 & 0,0 \\
71 & 71 & 0
\end{array}
$$

PARAMETERS 17 * ZONE CEILING: AOJ. TO SOUTH PERIMETER ZONE

*no. type area refl abs icoef hc $\mathrm{Nb} \mathrm{Nc} N \mathrm{Nd}$ 


$$
\begin{array}{ccccccc}
.23317 & .08172 & .00004 & .41976 & -.1049 & .00006 & -.00493 \\
\text { INPUTS } 3 & \text { *Tsurf,eq } & \text { Tsouth } & \text { UAadd' 1 } & & \\
& 17,12 & 17,1 & 0.0 & & \\
& 71 & 71 & 0 & & &
\end{array}
$$

PARAMETERS 17 * ZONE CEILING: ADJ. TO WEST PERIMETER ZONE

*no. type area refl abs icoef hc $\mathrm{Nb} N \mathrm{Nc} N \mathrm{Nd}$

$\begin{array}{lllllllllll}8 & 3 & 1600 & 0 & 0 & 4 & 1.63 & 3 & 3 & 1\end{array}$

$\begin{array}{lllllll}.23317 & .08172 & .00004 & .41976 & -.1049 & .00006 & -.00493\end{array}$

$\begin{array}{cccc}\text { INPUTS } 3 & \text { *Tsurf, eq } & \text { Tsouth } & \text { Uadd' ' } \\ & 14,12 & 14,1 & 0,0 \\ & 71 & 71 & 0\end{array}$

PARAMETERS 17 * ZONE CEILING: ADJ. TO EAST PERIMETER ZONE

*no. type area refl abs icoef hc Nb Nc Nd

$\begin{array}{llllllllll}9 & 3 & 1600 & 0 & 0 & 4 & 1.63 & 3 & 3 & 1\end{array}$

$\begin{array}{lllllll}.23317 & .08172 & .00004 & .41976 & -.1049 & .00006 & -.00493\end{array}$

INPUTS 3 "Tsurf, eq Tsouth UAadd' 1

$\begin{array}{ccc}15,12 & 15,1 & 0,0 \\ 71 & 71 & 0\end{array}$

PARAMETERS 5 * CORE ZONE FLOOR

*no. type area refl hc

$\begin{array}{lllll}10 & 4 & 6600 & 0 & 1.08\end{array}$

INPUTS 1

40,3

0

PARAMETERS 5 * NORTH PERIMETER ZONE FLOOR

*no. type area refl hc

$\begin{array}{lllll}11 & 4 & 2600 & 0 & 1.08\end{array}$

INPUTS 1

42,3

0

PARAMETERS 5 * SOUTH PERIMETER ZONE FLOOR

*no. type area refl hc

$12 \quad 42600 \quad 0 \quad 1.08$

INPUTS 1

27,3

0

PARAMETERS 5 * WEST PERIMETER ZONE FLOOR

*no. type area refl hc

$\begin{array}{lllll}13 & 4 & 1600 & 0 & 1.08\end{array}$

INPUTS 1

29,3 


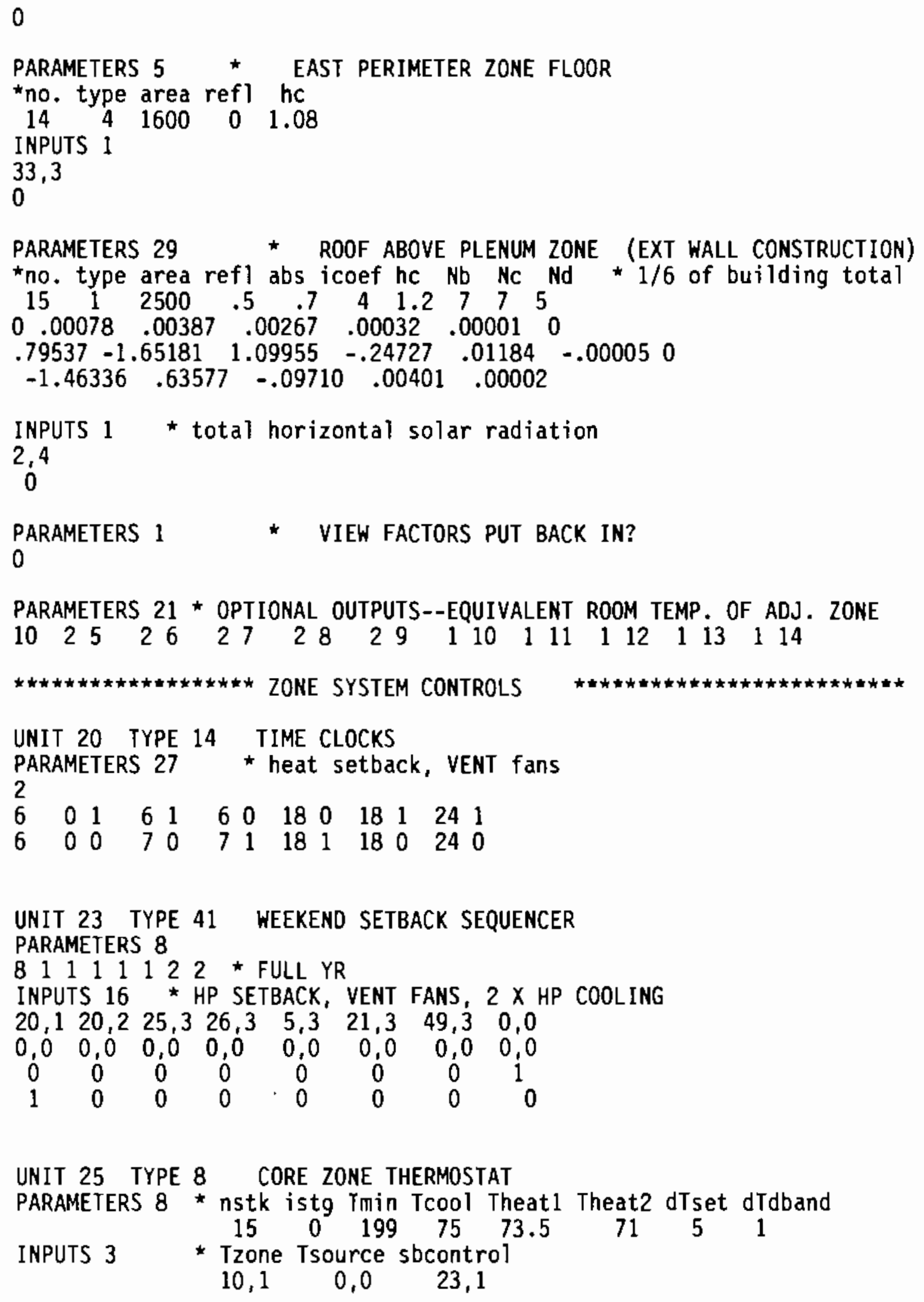


UNIT 5 TYPE 8 SOUTH PERIMETER ZONE THERMOSTAT

PARAMETERS 8 * nstk ist9 Tmin Tcool Theat1 Theat2 diset dTdband INPUTS 3

$$
\begin{array}{cccc}
15 & 0 & 199 & 78 \\
\text { Tzone } & \text { Tsource } & \text { sbcontrol } \\
17,1 & 0,0 & 23,1 \\
71 & 99 & 0
\end{array}
$$

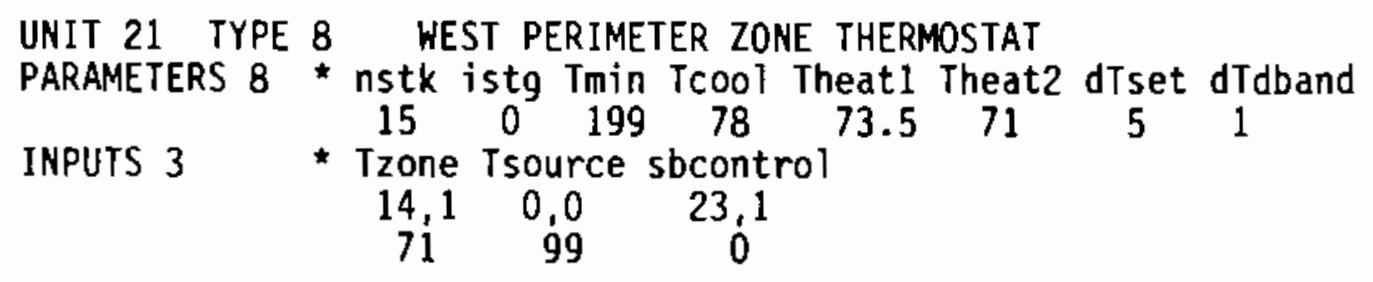

UNIT 49 TYPE 8 EAST PERIMETER ZONE THERMOSTAT

PARAMETERS 8 * nstk istg Tmin Tcool Theat1 Theat2 dTset dTdband INPUTS 3

$$
\begin{array}{cccc}
15 & 0 & 199 & 78 \\
* & \text { Tzone } & \text { Tsource } & \text { sbcontrol } \\
15,1 & 0,0 & 23,1 \\
71 & 99 & 0
\end{array}
$$

UNIT 26 TYPE 8 NORTH PERIMETER ZONE THERMOSTAT

PARAMETERS 8 * nstk istg Tmin Tcool Theat1 Theat2 dTset dTdband

INPUTS 3 * Tzone Tsource sbcontrol

$\begin{array}{llllllll}15 & 0 & 199 & 78 & 73.5 & 71 & 5 & 1\end{array}$

$$
\begin{array}{ccc}
12,1 & 0,0 & 23,1 \\
71 & 99 & 0
\end{array}
$$

\footnotetext{
UNIT 30 TYPE 3 SUPPLY/EXHAUST FAN

PARAMETERS 2 *maxflow maxKW

7350.932

INPUTS 3 * Tin $1 \mathrm{~b} / \mathrm{hr}$ contrl

$\begin{array}{ccc}1,5 & 0,0 & 23,2\end{array}$
}

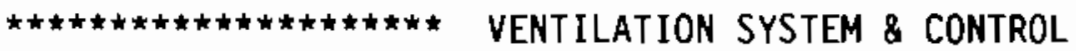

UNIT 31 TYPE 17 OUTSIDE AIR PREHEATER (WASTE HEAT RECOVERY)

PARAMETERS 15 ty glyol runaround loop overall eff $=.64$ const.

* \#xx mdot Cp stick tol mode Eff1 Cpc ctrl dTmin mode Eff2 Cp2 ctrl dTmin2

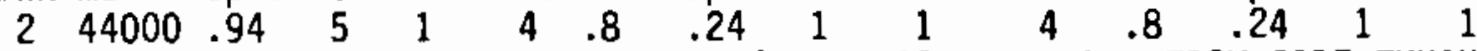
INPUTS 4 *Tin1 Min1 Tin2 Min2 (ALL RECOVERED HEAT FrOM CORE EXHAUST) 


$$
\begin{array}{cccc}
30,1 & 30,2 & 10,1 & 30,2 \\
50 & 0 & 71 & 0
\end{array}
$$

* Change duct heater so it only works when ventilation fan is on;

* also change the air it senses to be the air leaving the preheater.

$$
\begin{aligned}
& \text { UNIT } 22 \text { TYPE } 8 \text { DUCT HEATER THERMOSTAT } \\
& \text { PARAMETERS } 6 \text { * nstk istg Tmin Tcool Theat1 Theat2 } \\
& \text { INPUTS } 2 \text { * Tair Tsource ctrl } \\
& \begin{array}{rrr}
1,5 & 0,0 & 23,2 \\
50 & 99 & 1
\end{array}
\end{aligned}
$$

UNIT 32 TYPE 6 DUCT (OUTSIDE AIR) HEATER (123 KW/6)

$$
\text { PARAMETERS } 3 \quad \text { *BTU/H Tmax } \quad \text { CP }
$$

INPUTS $3 *$ Tin mdot on/off

$$
\begin{array}{ccc}
31,1 & 31,2 & 22,2 \\
71 & 0 & 0
\end{array}
$$

HEAT PUMPS \& THERMAL STORAGE SLABS

UNIT 41 TYPE 50 HEAT PUMP CORE ZONE * sizing basis: $370 \mathrm{sf} / \mathrm{ton}, 3 \mathrm{gpm} /$ ton

PARAMETERS 9 *hcap hpwr ccaptot csens cpwr Tauh fKWn cfmn Mwatn

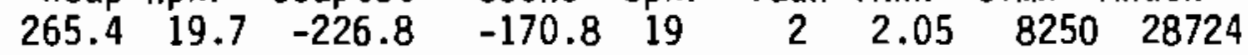

INPUTS 11

*heat cool fanON Mwat Twat Tdbra wra Tplen wplen cfm OAfrac $\begin{array}{lllllllllll}25,2 & 23,3 & 23,2 & 0,0 & 37,1 & 10,1 & 10,2 & 19,1 & 19,2 & 0,0 & 0,0\end{array}$

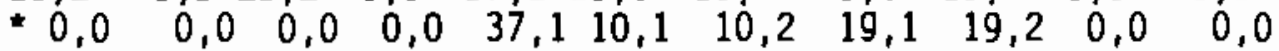
$\begin{array}{llllllllllll}0 & 0 & 0 & 28724 & 71 & 71 & 0 & 71 & 0 & 8250 & .2\end{array}$ *out: tcap avcap scap avscap Tsupp wsupp Msupp CompKW Qloop Tloop fanKW index

UNIT 43 TYPE 50 HEAT PUMP NORTH PERIM ZONE * sizing basis: $370 \mathrm{sf} / \mathrm{ton}, 3$ $\mathrm{gPm} / \mathrm{ton}$

PARAMETERS 9 *hcap hpwr ccaptot csens cpwr Tauh fKWn cfmn Mwatn

INPUTS 11

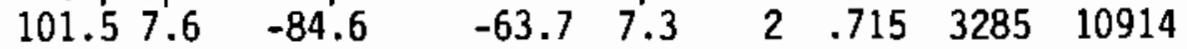

*heat cool fanON Mwat Twat Tdbra wra Tplen wplen cfm OAfrac $\begin{array}{lllllllllll}26,2 & 23,4 & 23,2 & 0,0 & 37,1 & 12,1 & 12,2 & 19,1 & 19,2 & 0,0 & 0,0\end{array}$ $\begin{array}{lllllllllllll}0,0 & 0,0 & 0,0 & 0,0 & 37,1 & 12,1 & 12,2 & 19,1 & 19,2 & 0,0 & 0,0\end{array}$ $\begin{array}{lllllllllll}0 & 0 & 0 & 10914 & 71 & 71 & 0 & 71 & 0 & 3285 & .2\end{array}$ 
*out: tcap avcap scap avscap Tsupp wsupp Msupp CompKW Qloop Tloop fanKW index

UNIT 45 TYPE 50 HEAT PUMP SOUTH PERIM ZONE * sizing basis: $370 \mathrm{sf} / \mathrm{ton}, 3$ gpm/ton

PARAMETERS 9 thcap hpwr ccaptot csens cpwr Tauh fKHn cfmn Mwatn

INPUTS 11

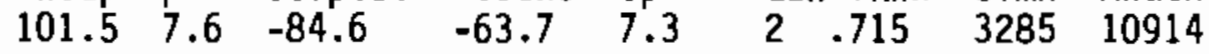

*heat cool fanON Mwat Twat Tdbra wra Tplen wplen cfm OAfrac $\begin{array}{lllllllllll}5,2 & 23,5 & 23,2 & 0,0 & 37,1 & 17,1 & 17,2 & 19,1 & 19,2 & 0,0 & 0,0\end{array}$

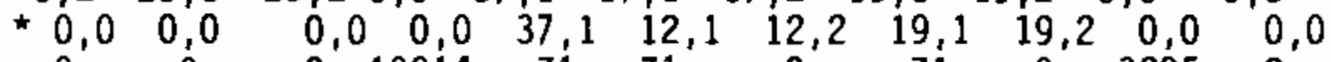
$\begin{array}{llllllllllll}0 & 0 & 0 & 10914 & 71 & 71 & 0 & 71 & 0 & 3285 & .2\end{array}$

*out: tcap avcap scap avscap Tsupp wsupp Msupp CompKW Qloop Tloop fankW index

UNIT 47 TYPE 50 HEAT PUMP HEST PERIM ZONE * sizing basis: $370 \mathrm{sf} /$ ton, 3 $\mathrm{gpm} /$ ton

PARAMETERS 9 "hcap hpwr ccaptot csens cpwr Tauh fKWn cfmn Mwatn

INPUTS 11

*heat cool fanON Mwat Twat Tdbra wra Tplen wplen cfm OAfrac $\begin{array}{lllllllllll}21,2 & 23,6 & 23,2 & 0,0 & 37,1 & 14,1 & 14,2 & 19,1 & 19,2 & 0,0 & 0,0\end{array}$ $\begin{array}{llllllllllll}0,0,0 & 0,0 & 0,0 & 37,1 & 12,1 & 12,2 & 19,1 & 19,2 & 0,0 & 0,0\end{array}$ $\begin{array}{llllllllllll}0 & 0 & 0 & 6716.2 & 71 & 71 & 0 & 71 & 0 & 2021.7 & .2\end{array}$

*out: tcap avcap scap avscap Tsupp wsupp Msupp CompKW Qloop Tloop fanKW index

UNIT 48 TYPE 50 HEAT PUMP EAST PERIM ZONE * sizing basis: 370 sf/ton, 3 gpm/ton

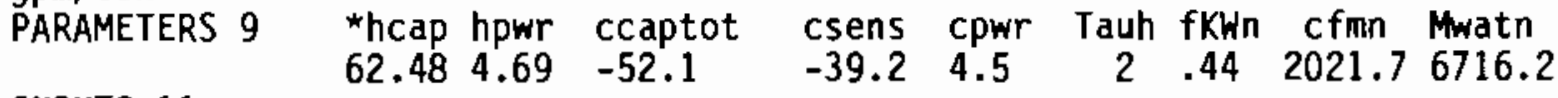

INPUTS 11

*heat cool fanON Mwat Twat Tdbra wra Tplen wplen cfm OAfrac $\begin{array}{lllllllllll}49,2 & 23,7 & 23,2 & 0,0 & 37,1 & 15,1 & 15,2 & 19,1 & 19,2 & 0,0 & 0,0\end{array}$

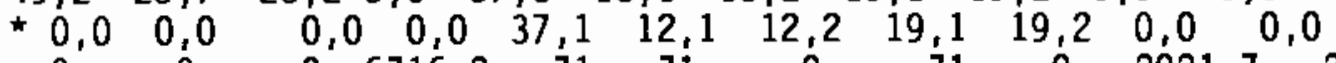
$\begin{array}{lllllllllll}0 & 0 & 0 & 6716.2 & 71 & 71 & 0 & 71 & 0 & 2021.7 & .2\end{array}$ *out: tcap arcap scap avscap Tsupp wsupp Msupp CompKW Qloop Tloop fanKW index

UNIT 28 TYPE 15 NOT-SO-SIMPLE MANIFOLD PARAMETERS 32

$\begin{array}{llllllllll}0 & -11 & 3 & -12 & 3 & -12 & 3 & -13 & 3 & -3\end{array}$ 
$\begin{array}{llllllllllllllllllllll}-11 & -14 & 1 & -11 & -15 & 1 & 3 & -12 & -16 & 1 & 3 & -12 & -17 & 1 & 3 & -13 & -18 & 1 & 3 & -7 & 2 & -4\end{array}$ INPUTS 8

$0,0 \quad 0,0 \quad 0,043,1045,1047,1048,1041,10$ *DISCONNECTED SLAB N S W E CORE 109146716.2287240000000 *out: total flow, mixed temp

UNIT 18 TYPE 15 SLAB ALGEBRAIC OPERATOR

PARAMETERS 43

$\begin{array}{lllllllll}0 & -17 & -17 & 3 & -18 & 3 & -18 & 3\end{array}$

$\begin{array}{lllllllllllllll}-11 & -17 & 1 & -12 & -17 & 1 & 3 & -13 & -18 & 1 & 3 & -14 & -18 & 1 & 3\end{array}$

$\begin{array}{llll}-7 & 2 & -4\end{array}$

$\begin{array}{lllllllll}-1 & 77 & -15 & -1 & 3 & 1 & 4 & -4\end{array}$

$\begin{array}{llllllllll}-1 & 72 & -16 & -1 & 4 & 1 & 4 & -4 & -4\end{array}$

INPUTS 8

*PERIMETER ZONE TEMPS: N S E W, CLG TOWER INDEX, HEATING STBACK INDEX

$\begin{array}{cccccccc}12,1 & 17,1 & 15,1 & 14,1 & 24,3 & 23,1 & 0,0 & 0,0 \\ 71 & 71 & 71 & 7 i & 0 & 0 & 20800 & 12800\end{array}$

UNIT 16 TYPE 13 CORE SLAB FLOW PROCESSOR

PARAMETERS 67

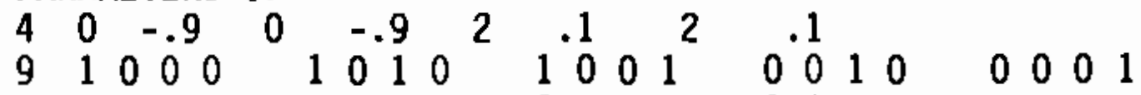

$\begin{array}{llllllllllllllllllllll}0 & 0 & 0 & 0 & 0 & 1 & 0 & 0 & 0 & 1 & 1 & 0 & 0 & 1 & 0 & 1\end{array}$

$\begin{array}{llllllllllll}1 & 0 & 0 & 1 & 0 & 0 & 0 & 0 & 1 & 0 \\ 4 & 0 & 0 & 0 & 0 & 0 & 0 & 0 & 0 & 0 & 2\end{array}$

INPUTS 8

* core temp compared to cooling setpoint, heating setpoint, and loop wtr temp $\begin{array}{rrrrrrrr}10,1 & 0,0 & 18,3 & 10,1 & 28,2 & 10,1 & 10,1 & 28,2\end{array}$

UNIT 50 TYPE 13 PERIMETER SLAB FLOW PROCESSOR

PARAMETERS 67

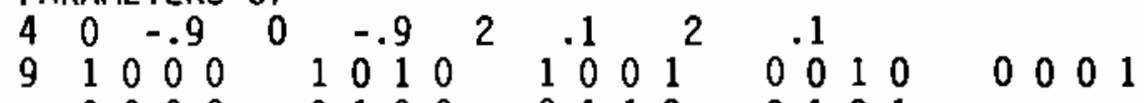

$\begin{array}{llllllllllllllllll}0 & 0 & 0 & 0 & 0 & 1 & 0 & 0 & 0 & 1 & 1 & 0 & 0 & 1 & 0 & 1\end{array}$

$\begin{array}{lllllllllll}1 & 0 & 0 & 1 & 0 & 0 & 0 & 0 & 1 & 0 & \\ 4 & 0 & 0 & 0 & 0 & 0 & 0 & 0 & 0 & 0 & 2\end{array}$

INPUTS 8

* core temp compared to cooling setpoint, heating setpoint, and loop wtr temp

$\begin{array}{ccccccccc}18,1 & 18,2 & 18,3 & 18,1 & 28,2 & 18,1 & 18,1 & 28,2\end{array}$

* REDUCE RHO tO dECREASE IMPACt OF MASS--MAKing LIKE STANOARD fLOOR 
UNIT 40 TYPE 47 CORE ZONE THERMAL ENERGY STORAGE SLAB

PARAMETERS 26

* no eqpit nparl nterat maxit ertol tinit cond rho $c P$ thk contop conbot

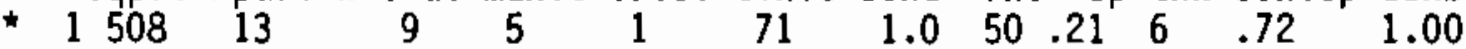

$\begin{array}{lllllllllllll}1 & 507.7 & 13 & 9 & 5 & 1 & 71 & 1.0 & 50 & .21 & 6 & .72 & 1.00\end{array}$

* cndpipe rhop cpp radout radin space fconv nconv delx ncen delts frac radd $\begin{array}{lllllllllllll}.125 & 75 & .48 & .57 & .50 & 12 & 400.000 & 10 & 1 & 0 & 50 & .75 & 0\end{array}$

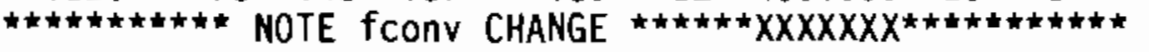

INPUTS 5 *Ttop Tbot Tfin flow iconv $10,11 \quad 19,16 \quad 28,2 \quad 0,0 \quad 16,1$

$\begin{array}{lllll}71 & 71 & 50 & 28724 & 1\end{array}$

*out: Qtrans Qtop Qbot Tfout Tbulk Irun Tfavg

TRACE 43964416

UNIT 42 TYPE 47 NORTH PERIMETER ZONE THERMAL ENERGY STORAGE SLAB

PARAMETERS 26

* no eqpft nparl nterat maxit ertol tinit cond rho cp thk contop conbot

$\begin{array}{llllllllllll}* & 2520 & 5 & 9 & 5 & 1 & 71 & 1.0 & 50.21 & 6 & .72 & 1.00\end{array}$

$\begin{array}{lllllllllllll}2 & 520 & 5 & 9 & 5 & 1 & 71 & 1.0 & 50 & .21 & 6 & .72 & 1.00\end{array}$

* cndpipe rhop cpp radout radin space fconv nconv delx ncen delts frac radd

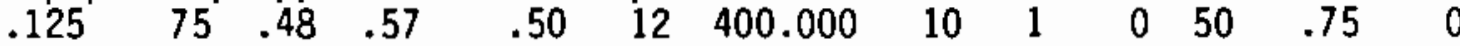

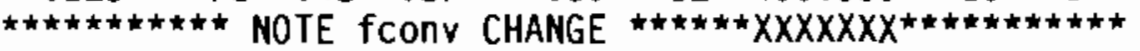

INPUTS 5 * Ttop Tbot Tfin flow iconv

$$
12,11 \quad 19,17 \quad 28,2 \quad 0,0 \quad 50,1
$$

*out: Qtrans Qtop Qbot Tfout Tbulk Irun Tfavg

TRACE 43964416

UNIT 27 TYPE 47 SOUTH PERIMETER ZONE THERMAL ENERGY STORAGE SLAB

PARAMETERS 26

*no eqpft nparl nterat maxit ertol tinit cond rho cp thk contop conbot

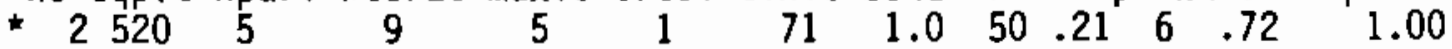

$\begin{array}{lllllllllllll}3 & 520 & 5 & 9 & 5 & 1 & 71 & 1.0 & 50.21 & 6 & .72 & 1.00\end{array}$

* cndpipe rhop cpp radout radin space fconv nconv delx ncen delts frac radd $\begin{array}{lllllllllllll}.125 & 75 & .48 & .57 & .50 & 12 & 400.000 & 10 & 1 & 0 & 50 & .75 & 0\end{array}$

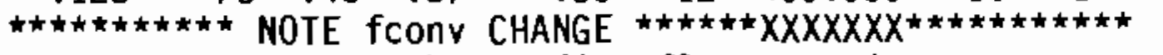

INPUTS 5 * Ttop Tbot Tfin flow iconv

$17,11 \quad 19,18 \quad 28,2 \quad 0,0 \quad 50,1$

$\begin{array}{lllll}71 & 71 & 50 & 10914 & 1\end{array}$

*out: Qtrans Qtop Qbot Tfout Tbulk Irun Tfavg

UNIT 29 TYPE 47 WEST PERIMETER ZONE THERMAL ENERGY STORAGE SLAB

PARAMETERS 26

* no eqpft nparl nterat maxit ertol tinit cond rho $\mathrm{cp}$ thk contop conbot

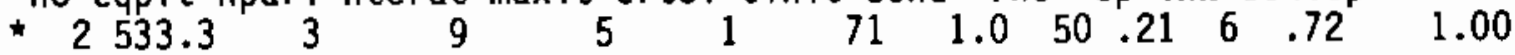


$\begin{array}{llllllllllllll}4 & 533.3 & 3 & 9 & 5 & 1 & 71 & 1.0 & 50 & .21 & 6 & .72 & 1.00\end{array}$

*cndpipe rhop cpp radout radin space fconv nconv delx ncen delts frac radd

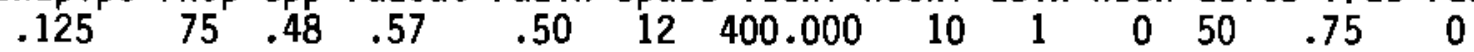

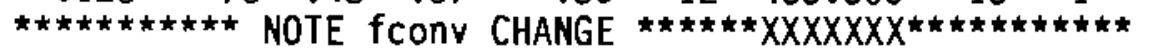

INPUTS 5 * Ttop Tbot Tfin flow iconv $14,11 \quad 19,1928,2 \quad 0,0 \quad 50,1$ $\begin{array}{lllll}71 & 71 & 50 & 6716 & 1\end{array}$

*out: Qtrans Qtop Qbot Tfout Tbulk 1run Tfavg

UN1T 33 TYPE 47 EAST PER1METER ZONE THERMAL ENERGY STORAGE SLAB PARAMETERS 26

*no eqpft nparl nterat maxit ertol tinit cond rho cp thk contop conbot

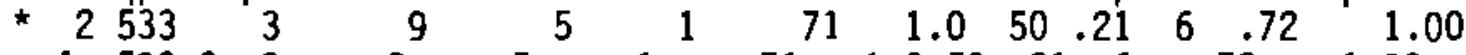

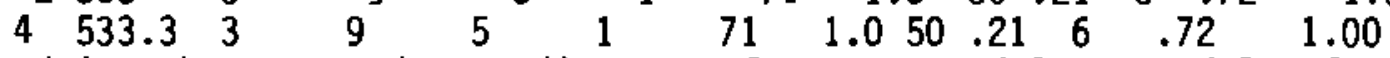

* cndpipe rhop cpp radout radin space fconv nconv delx ncen delts frac radd $\begin{array}{lllllllllllll}.125 & 75 & .48 & .57 & .50 & 12 & 400.000 & 10 & 1 & 0 & 50 & .75 & 0\end{array}$

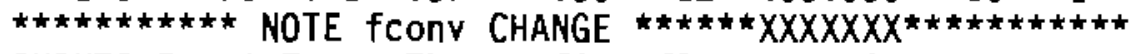

INPUTS 5 * Ttop Tbot Tfin flow iconv $\begin{array}{lllll}15,11 & 19,20 & 28,2 & 0,0 & 50,1\end{array}$

*out: Qtrans Qtop Qbot Tfout Tbulk Irun Tfavg

UNIT 44 TYPE 15 NOT-SO-SIMPLE MANIFOLD

PARAMETERS 32

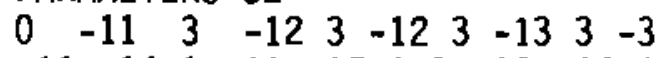

$\begin{array}{llllllllllllllllllllll}-11 & -14 & 1 & -11 & -15 & 1 & 3 & -12 & -16 & 1 & 3 & -12 & -17 & 1 & 3 & -13 & -18 & 1 & 3 & -7 & 2 & -4\end{array}$

INPUTS 8

$0,00,00,042,427,429,433,440,4$ "CONNECTED SLAB N S W E CORE

109146716.228724000000 "out: total flow, mixed temp

AUXILIARY WATER SYSTEM \& CONTROLS

UNIT 34 TYPE 4 STRATIFIED THERMAL STORAGE TANK 1(400 gal. water/floor)

PARAMETERS 6 "mode cuft $C p$ dens Ut height

INPUTS $5 \quad$ *Thot Mhot Tret Mret Tenv

$44,2 \quad 44,1 \quad 34,144,1 \quad 1,5$

DERIVATIVES 1 *Tinit

$\begin{array}{llllll}71 & 0 & 71 & 0 & 71\end{array}$ *out: Tsource Msource Tload Mload 71 


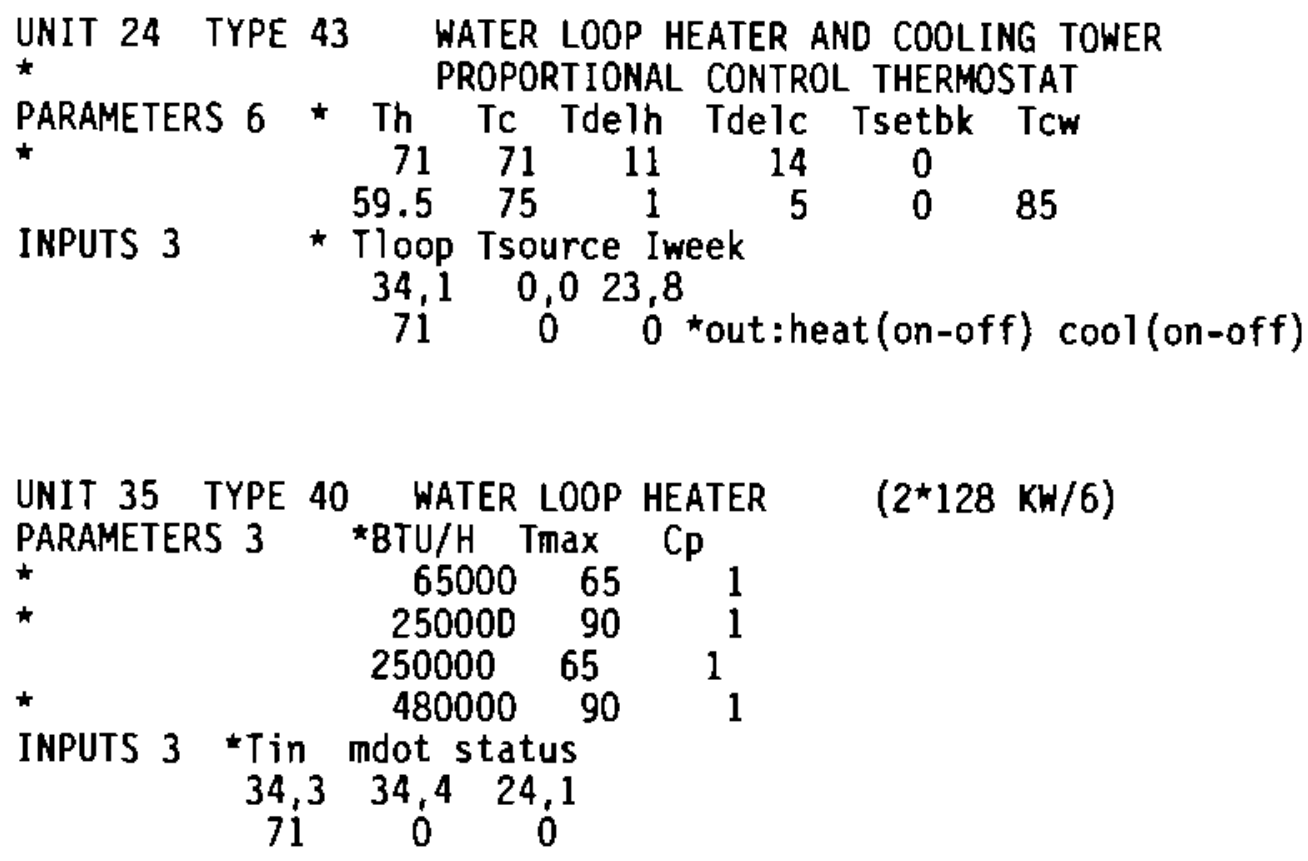

UNIT 36 TYPE 42 COOLING TOWER (BAC Mode1 VXT 150) $/ 6$ PARAMETERS 6 * fanmax powmax ncell a b tau

\begin{tabular}{ccccccccc} 
* & \multicolumn{2}{c}{2800} & 1.24 & 1 & 1.0899 & -.44565 & 20 \\
INPUTSS 6 & *status Tdb & Twb Twat mdot & frac & -.44565 & 20 \\
& 24,2 & 1,5 & 3,2 & 35,1 & 35,2 & 0,0 & & \\
& 0 & 50 & 50 & 71 & 0 & 1 & &
\end{tabular}

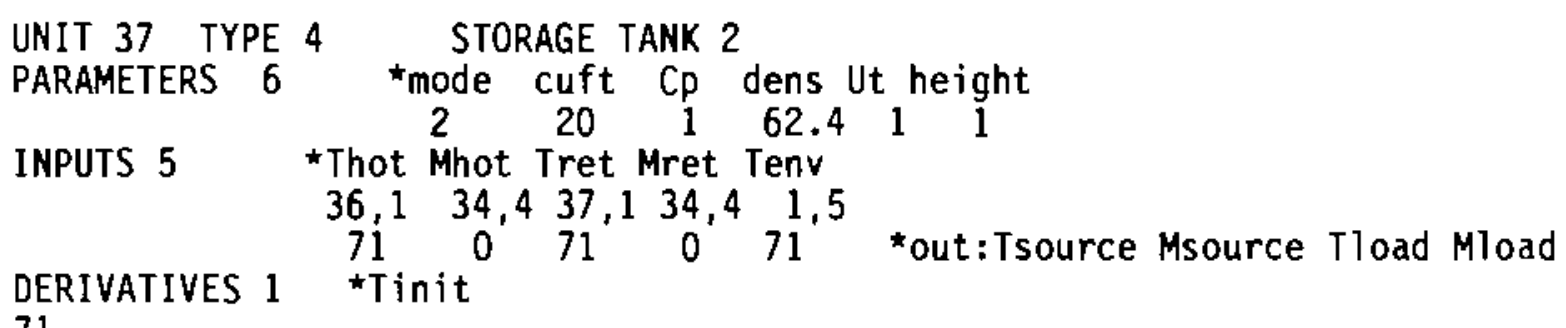
71

UNIT 4 TYPE 46 CAPACITY \& ENERGY SUMMER PARAMETERS 1 * FLOOR

6 INPUTS 36 * $5 X$ IH, 5X 1C,5X IF0,5X Q, 5X COMP, 5X FAN, B, DHT, CT FAN * CORE-NORTH-EAST-WEST-SW-SE 


$\begin{array}{llllllllllll}25,2 & 26,2 & 49,2 & 21,2 & 5,2 & 23,3 & 23,4 & 23,7 & 23,6 & 23,5 & & \\ 23,2 & 23,2 & 23,2 & 23,2 & 23,2 & 41,2 & 43,2 & 48,2 & 47,2 & 45,2 & \\ 41,8 & 43,8 & 48,8 & 47,8 & 45,8 & 41,11 & 43,11 & 48,11 & 47,11 & 45,11 & \\ 35,3 & 32,3 & 36,3 & 30,3 & 16,1 & 50,1 & & & & & & \\ 0 & 0 & 0 & 0 & 0 & 0 & 0 & 0 & 0 & 0 & 0 & 0 \\ 0 & 0 & 0 & 0 & 0 & 0 & 0 & 0 & 0 & 0 & 0 & 0 \\ 0 & 0 & 0 & 0 & 0 & 0 & 0 & 0 & 0 & 0 & 0 & 0\end{array}$

UNIT 6 TYPE 24 QUANTITY INTEGRATOR

PARAMETERS 1

-1 * resets each month .- leave alone for all runs

INPUTS 10

$\begin{array}{cccccccccc}4,2 & 4,3 & 4,4 & 4,5 & 4,6 & 4,7 & 4,8 & 4,9 & 4,10 & 4,11\end{array}$

${ }^{\star} C L$ CAP, HT_HP, CL_HP, FN_HP, TOT_HP, BOIL, DHT, TOWER, FAN, PUMP

*UNIT 13 TYPE 24 QUANTITY INTEGRATOR

\# PARAMETERS 1

*1 * integrates each hour -- leave alone for all runs

*INPUTS 11

$\begin{array}{lllllllllll}\star_{4}, 1 & 4,2 & 4,3 & 4,4 & 4,5 & 4,6 & 4,7 & 4,8 & 4,9 & 4,10 & 4,11 \\ \star_{0} & 0 & 0 & 0 & 0 & 0 & 0 & 0 & 0 & 0 & 0\end{array}$

**HT CAP, CL CAP, HT_HP, CL_HP, FN_HP, TOT_HP, BOIL, DHT, TOWER, FAN, PUMP

\title{
PRINTERS
}

\author{
UNIT 13 TYPE 25 P1 INTEGRATED ENERGY QUANTITY PRINTER \\ PARAMETERS 4 \\ $\begin{array}{llll}* & 0 & 8760 & 50\end{array}$ \\ $\begin{array}{llll}* 120 & 0 & 720 & 50\end{array}$ \\ $\begin{array}{llll}24 & 0 & 8760 & 13\end{array}$ \\ INPUTS 9 \\ $\begin{array}{lllllllll}6,6 & 6,7 & 6,8 & 6,2 & 6,3 & 6,4 & 6,5 & 6,9 & 6,10 \\ 0 & 0 & 0 & 0 & 0 & 0 & 0 & 0 & 0\end{array}$ \\ * interval start stop lu \\ * FULl year or month \\ * JanUARY \\ * daily totals \\ *BOIL, DHT, TOWER, HP HEAT, HP COOL, HP VENT, TOT_hP, FAN, PUMP \\ UNIT 39 TYPE 25 P2 WATER LOOP TEMP \\ PARAMETERS 4 \\ $\begin{array}{llll}1 & 0 & 8670 & 39\end{array}$ \\ INPUTS 7 \\ $37,1 \quad 40,4 \quad 42,4 \quad 27,4 \quad 29,4 \quad 33,4 \quad 44,2 \quad 34,1$ \\ HP IN OUT_C OUT_N OUT_S OUT_W OUT_E OUT_MAN TANK1
}


UNIT 38 TYPE 25 P3 ZONE TEMPS

PARAMETERS 4

$\begin{array}{llll}1 & 0 & 8670 & 38\end{array}$

INPUTS 6

$\begin{array}{cccccc}* 12,16 & 19,16 & 12,1 & 42,2 & 42,3 & 43,2 \\ \star 0 & 0 & 0 & 0 & 0 & 0\end{array}$

* TTOP TBOM TZONE QTOP QBOM QHP

$12,1 \quad 10,1 \quad 19,1 \quad 14,1 \quad 15,1 \quad 17,1$

TZONE_N TZONE_C TZONE_PL TZONE_W TZONE_E TZONE_S

*UNIT 46 TYPE 25 P4 SLAB TEMPS

* PARAMETERS 4

$\begin{array}{lllll}* 1 & 0 & 8670 & 46\end{array}$

*INPUTS 5

$\begin{array}{lccccc}\star \star 12,16 & 19,16 & 12,1 & 42,2 & 42,3 & 43,2\end{array}$

**TTOP TBOM TZONE QTOP QBOM QHP

$\begin{array}{lllll}* 40,5 & 42,5 & 27,5 & 29,5 & 33,5\end{array}$

*SLAB_C SLAB_N SLAB_S SLAB_W SLAB_E

END 
PNL-6751

UC-95d

\section{DISTRIBUTION}

No. of

Copies

10 DOE/Office of Scientific and Technical Information

10 M. Bailey, CE-131

U.S. Department of Energy 1000 Independence Ave., SW Washington, DC 20585

J. Boulin, CE-131

U.S. Department of Energy 1000 Independence Ave., SW Washington, DC 20585

T. Kurkowski, CE-131

U.S. Department of Energy 1000 Independence Ave., SW Washington, DC 20585

H. Lane, CE-231

U.S. Department of Energy 1000 Independence Ave., SW Washington, DC 20585

J. Millhone, CE-13

U.S. Department of Energy 1000 Independence Ave., SW Washington, DC 20585

J. Smith, CE-131

U.S. Department of Energy

1000 Independence Ave., SW

Washington, DC 20585

W. Beckman

Solar Energy Laboratory

1303 Engineering Research Bldg. University of Wisconsin - Madison 1500 Johnson Drive

Madison, WI 53706
No. of

Copies

J. Brodrick

Gas Research Institute

8600 West Bryn Mawr Ave.

Chicago, IL 60631

F. Bueh1

Lawrence Berkeley Laboratory

1 Cyclotron Road, Bldg. 90

Berkeley, CA 94720

3 A. Chiu

NASA - Ames

M/S 234-1

Moffet Field, CA 94035

C. Cleary

Seattle City Light

1015 Third Avenue

Seattle, WA 98104

J. Duffie

Solar Energy Laboratory

1303 Engineering Research B1dg.

University of Wisconsin - Madison

1500 Johnson Drive

Madison, WI 53706

C. Gardner

Puget Energy Systems

1750 112th NE, Suite E175

Bellevue, WA 98004

K. Johnson

Electric Power Research Institute 3412 Hillview Avenue

P 0. Box 10412

Palo Alto, CA 94303 
S. Treado

National Institute of Standards and Technology

BLG 226

Gaithersburg, MD 20899

R. Urban

Solar Energy Laboratory

1303 Engineering Research Bldg.

University of Wisconsin - Madison

1500 Johnson Drive

Madison, WI 53706

3 R. Wallin

920 NW Front Avenue \$J5

Portland, OR 97209

F. Winkelman

Lawrence Berkeley Laboratory

Building 90, Room 2111

Berkeley, CA 94720

M. Witte

University of Illinois

144 MEB, $1206 \mathrm{~W}$. Green St.

Urbana, IL 61801

\section{FOREIGN}

\section{J. Clarke \\ University of Strathclyde \\ 131 Rottenrow \\ Glasgow, G4 ONG}

A. Cordier

Laboratoier D'Energie Solaire et Thermique de l'Habitat

Universite Paul Sabatier

118 route de Narbonne

361062 Toulouse

FRANCE

D. van Hattem

Centre of the European

Communities-Joint Research Centre

Heat Transfer Division

21020 Ispra (Varese)

ITALY
FOREIGN Cont'd.

M. Strengnart

Laboratory of Thermodynamics

University of Liege

Rue E. Solvay, 21 - Bat. C3

B 4000 LIEGE

BELGIUM

ONSITE

3 DOE Richland 0perations office

R. F. Christensen, A5-90

D. R. Segna, A5-90

J. J. Sutey, A5-90

2 Kaiser Engineers Hanford

D. W. Dean

M. S. Rees

29 Pacific Northwest Laboratory

M. R. Brambley, $K 5-20$

R. S. Briggs, K5-20

C. C. Conner, K5-20

D. B. Crawley (5), K5-20

B. K. Johnson (5), K5-20

B. M. Johnson, K5-12

T. J. Marseille (5), K5-20

R. G. Pratt, $\mathrm{k} 5-20$

J. S. Schliesing, $K 5-20$

T. J. Secrest, K5-20

G. M. Stokes, K5-51

Publishing Coordination

Technical Report Files 